\title{
Four Passages to Information Use Related Phenomena in Bachelor Theses at the Finnish Universities of Applied Sciences
}

\author{
Kämäräinen, Juha \\ Oulun yliopisto \\ 2019
}

Kämäräinen , J , Mönkkönen , I \& Saarti , J 2019 , Four Passages to Information Use Related Phenomena in Bachelor Theses at the Finnish Universities of Applied Sciences . in pÿS `piranec, S Kurbanoglu, M-L Huotari, E Grassian, D Mizrachi , L Roy \& D Kos (eds), The Sixth European Conference on Information Literacy (ECIL) September 24th - 27th, 2018 , Oulu, Finland, Abstracts . Oulun yliopisto, Oulu , pp. 475-482, European Conference on Information Literacy (ECIL208), Oulu , 24/09/2018 . https://doi.org/10.1007/978-3-030-13472-3_45

http://hdl.handle.net/10138/300381

https://doi.org/10.1007/978-3-030-13472-3_45

publishedVersion

Downloaded from Helda, University of Helsinki institutional repository.

This is an electronic reprint of the original article.

This reprint may differ from the original in pagination and typographic detail.

Please cite the original version. 


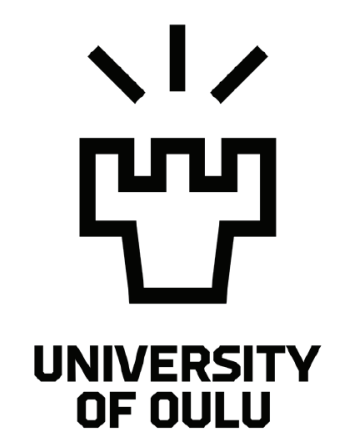

Department of Information and Communication Studies

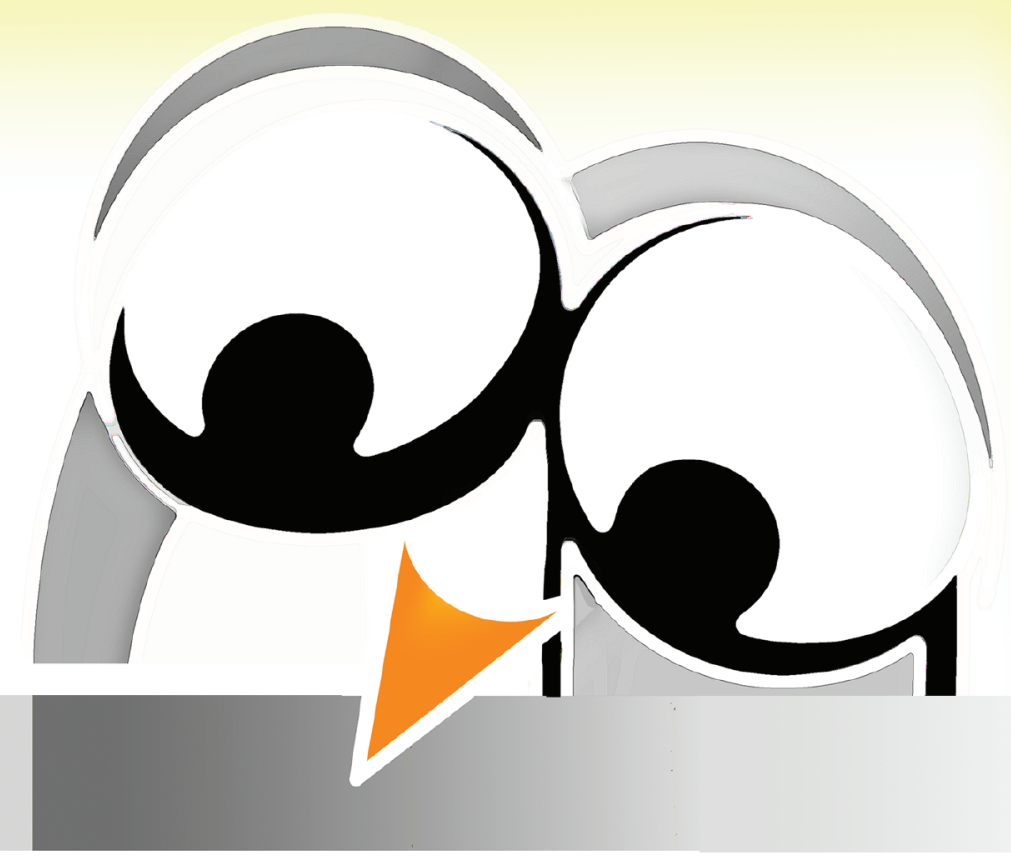

\section{European Conference on Information Literacy (ECIL) Oulu, Finland 24-27 September 2018}

Editors: S. Špiranec, S. Kurbanoğlu, M-L. Huotari, E. Grassian, D. Mizrachi, L. Roy, D. Kos 


\section{The Sixth European Conference on Information Literacy (ECIL)}

September $24^{\text {th }}-27^{\text {th }}, 2018$, Oulu, Finland

Abstracts

Oulu, 2018 



\title{
The Sixth European Conference on Information Literacy (ECIL)
}

\author{
September $24^{\text {th }}-27^{\text {th }}, 2018$, Oulu, Finland
}

\begin{abstract}
s
Editors:

Sonja Špiranec, Serap Kurbanoğlu, Maija-Leena Huotari, Esther Grassian, Diane Mizrachi, Loriene Roy, Denis Kos
\end{abstract}

University of Oulu

Department of Information and Communication Studies

Oulu, 2018 
The Sixth European Conference on Information Literacy, September $24^{\text {th }}-27^{\text {th }}, 2018$, Oulu, Finland: Abstracts

http://ecil2018.ilconf.org

Publisher: University of Oulu, Department of Information and Communication Studies http://www.oulu.fi

ISBN 978-952-62-2013-0

Copyright $@ 2018$ by University of Oulu, Department of Information and Communication Studies and authors

All rights reserved

European Conference on Information Literacy $(6: 2018:$ Oulu)

The Sixth European Conference on Information Literacy, September $24^{\text {th }}-27^{\text {th }}, 2018$, Oulu, Finland : (ECIL) : abstracts / editors Sonja Špiranec, Serap Kurbanoğlu, Maija-Leena Huotari, Esther Grassian, Diane Mizrachi, Loriene Roy, Denis Kos. Oulu : University of Oulu, Department of Information and Communication Studies, 2018.

xxv, $196 \mathrm{p}$.

Includes index and references.

ISBN 978-952-62-2013-0 


\section{Organization}

The Sixth European Conference on Information Literacy (ECIL) was co-organized by the Department of Information Management of Hacettepe University, the Department of Information and Communication Sciences of the University of Zagreb, the Information Literacy Association (InLitAs), France and the Department of Information and Communication Studies at the University of Oulu.

\section{Standing Committee}

1. Paul G. Zurkowski, USA (Honorary Chair)

2. Serap Kurbanoğlu, Hacettepe University, Turkey (General Co-chair)

3. Sonja Špiranec, University of Zagreb, Croatia (General Co-chair)

4. Joumana Boustany, Paris-Est Marne-la-Vallée University, France (General Co-chair)

5. $\quad$ Maija-Leena Huotari, University of Oulu, Finland (Co-chair for ECIL 2018)

6. Szarina Abdullah, MARA Technology University, Malaysia

7. Buket Akkoyunlu, Hacettepe University, Turkey

8. Aharon Aviram, Ben-Gurion University, Israel

9. George Awad, UNESCO Regional Office, Lebanon

10. Tomaz Bartol, University of Ljubljana, Slovenia

11. Athina Basha, Albanian Library Association, Albania

12. David Bawden, City University, UK

13. Dilara Begum, East West University, Bangladesh

14. Albert K. Boekhorst, University of Pretoria, South Africa

15. Alexander Botte, German Inst. for International Educational Research, Germany

16. Christine Bruce, Queensland University of Technology, Australia

17. Mersini Moreleli-Cacouris, Alexander Technological Education Inst. of Thessaloniki, Greece

18. Maria Carme Torras Calvo, Bergen University, Norway

19. Toni Carbo, Drexel University, USA

20. Paola De Castro, National Institute of Health, Italy

21. Ralph Catts, University of Stirling, UK

22. Jerald Cavanagh, Limerick Institute of Technology, Ireland

23. Kunjilika Chaima, University of Montreal, Canada

24. Samuel Kai Wah Chu, University of Hong Kong, China

25. Ioannis Clapsopoulos, University of Thessaly, Greece

26. John Crawford, Independent Information Professional, UK

27. Gülçin Cribb, Singapore Management University, Singapore

28. Lenka Danevska, Central Medical Library, Republic of Macedonia

29. Lourense H. Das, ENSIL Foundation, The Netherlands

30. Senada Dizdar, University of Sarajevo, Bosnia and Herzegovina

31. Noraida Dominguez, University of Puerto Rico, Puerto Rico

32. Elisabeth Adriana Dudziak, University of Sao Paulo, Brasil

33. Michael B. Eisenberg, University of Washington, USA

34. Susana Finquelievich, University of Buenos Aires, Argentine

35. Almuth Gastinger, University of Science and Technology Trondheim, Norway 
36. Natalia Gendina, Kemerovo State University of Culture and Arts, Russia

37. Nieves González, University of Seville, Spain

38. Esther Grassian, University of California, Los Angeles, USA

39. Eystein Gullbekk, Oslo University, Norway

40. Thomas Hapke, Hamburg University of Technology, Germany

41. Päivi Helminen, Helsinki University, Finland

42. Jos van Helvoort, The Hague University, The Netherlands

43. Forest Woody Horton, International Library and Information Consultant, USA

44. Bill Johnston, University of Strathclyde, UK

45. László Z. Karvalics, University of Szeged, Hungary

46. Irmgarda Kasinskaite-Buddeberg, Knowledge Societies Division, UNESCO

47. Anthi Katsirikou, University of Piraeus, Greece

48. Padraig Kirby, Limerick Institute of Technology, Ireland

49. Tibor Koltay, Szent István University, Hungary

50. Rumyana Koycheva, Global Libraries, Bulgaria

51. Carol C. Kuhlthau, Rutgers University, USA

52. Claudio Laferlac, University of Malta, Malta

53. Hana Landová, Association of Libraries of Czech Universities, Czech Republic

54. Ane Landøy, University of Bergen, Norway

55. Jesús Lau, Veracruzana University, Mexico

56. Anne Lehmans, University of Bordeaux, France

57. Louise Limberg, University of Borås, Sweden

58. Vincent Liquete, University of Bordeaux, France

59. Annemaree Lloyd, Charles Sturt University, Australia

60. Szu-chia Scarlett Lo, National Chung-hsing University, Taiwan

61. Latifa Mammadova, Ministry of Culture and Tourism, Republic of Azerbaijan

62. Luisa Marquardt, Roma Tre University, Italy

63. Vanessa Middleton, Petroleum Institute, United Arab Emirates

64. Muhammad Sajid Mirza, International Islamic University, Pakistan

65. Theophilus E. Mlaki, Consultant ICT for Development, Tanzania

66. María Pinto Molina, Granada University, Spain

67. Camilla Moring, Royal School of Library and Information Science, Denmark

68. Rajen Munoo, National Library Board NLB Academy, Singapore

69. Mitsuhiro Oda, Aoyama Gakuin University, Japan

70. Anna Onkovich, National Academy of Pedagogical Sciences, Ukraine

71. Chido Onumah, African Centre for Media Literacy, Nigeria

72. Heike vom Orde, Int. Central Inst. for Youth and Educational Television, Germany

73. Judith Peacock, Queensland University of Technology, Australia

74. Zdravka Pejova, Library and Information Consultant, Republic of Macedonia

75. Manuel Pinto, University of Minho, Portugal

76. Gloria Ponjuan, University of Havana, Cuba

77. Maria Próchnicka, Jagiellonian University, Poland

78. Angela Repanovici, Transilvania University of Brasov, Romania

79. Laurie Ortiz Rivera, University of Puerto Rico, Puerto Rico

80. Manuela Rohrmoser, Vienna University, Austria

81. Jurgita Rudzioniene, Vilnius University, Lithuania

82. Philip Russell, Institute of Technology Tallaght, Ireland

83. Ramza Jaber Saad, Lebanese National Commision of UNESCO, Lebanon 
84. Jarmo Saarti, University of Eastern Finland, Finland

85. Chutima Sacchanand, Sukhothai Thammathirat Open University, Thailand

86. Armando Malheiro da Silva, University of Porto, Portugal

87. Diljit Singh, University of Malaya, Malaysia

88. Jagtar Singh, Punjabi University, India

89. Kaisa Sinikara, Helsinki University Library, Finland

90. Eero Sormunen, University of Tampere, Finland

91. Philipp Stalder, University of Zurich, Switzerland

92. Jela Steinerova, Comenius University, Slovakia

93. Gordana Stokić Simončić, Belgrade University, Serbia

94. Paul Sturges, University of Pretoria, South Africa

95. Olof Sundin, Lund University, Sweden

96. Samy Tayie, Cairo University, Egypt

97. Ellen R. Tise, Stellenbosch University, South Africa

98. Ross J. Todd, The State University of New Jersey, USA

99. Ramon R. Tuazon, Asian Institute of Journalism and Communication, Phillippines

100. Anne Sissel Vedvik Tonning, University of Bergen, Norway

101. José Manuel Pérez Tornero, University of Barcelona, Spain

102. Jordi Torrent, United Nations Department of Education, USA

103. Alejandro Uribe Tirado, University of Antioquia, Colombia

104. Egbert John Sanchez Vanderkast, National Autonomous University of Mexico, Mexico

105. Tapio Varis, UNESCO Chair, University of Tampere, Finland

106. Aurora de la Vega, Catholic University of Peru, Peru

107. Jose de Jesus Cortes Vera, Autonomous University of Ciudad Juárez, Mexico

108. Henri A. Verhaaren, Ghent University, Belgium

109. Sirje Virkus, Tallin University, Estonia

110. Li Wang, University of Auckland, New Zealand

111. Sheila Webber, University of Sheffield, UK

112. Sharon A. Weiner, National Forum of Information Literacy, USA

113. Barbro Wigell-Ryynanen, Ministry of Education and Culture, Finland

114. Pradeepa Wijetunge, University of Colombo, Sri Lanka

115. Carolyn Wilson, University of Toronto, Canada

116. Tom Wilson, University of Sheffield, UK

117. Andrew Whitworth, University of Manchester, UK

118. Michaela Zemanek, Vienna University, Austria

119. Julia Zhang Xiaojuan, Wuhan University

\section{Programme Committee}

1. Tuulikki Alamettälä, University of Tampere, Finland

2. Ines Amaral, Instituto Superior Miguel Torga, Portugal

3. Kanwal Ameen, University of the Punjab, Lahore, Pakistan

4. Tatjana Aparac-Jelusic, University of Zadar, Croatia

5. Fatima Baji, Ahvaz Jundi Shapur University of Medical Sciences, Iran

6. Laura Ballestra, Biblioteca Mario Rostoni, Italy

7. Mihaela Banek Zorica, University of Zagreb, Croatia

8. Tomaz Bartol, University of Ljubljana, Slovenia

9. Glória Maria Lourenço Bastos, Universidade Aberta, Portugal 
10. Bojana Boh Podgornik, University of Ljubljana, Slovenia

11. Bourret Christian, DICEN-IdF, University of Paris-Est Marne-la-Vallée, France

12. Joumana Boustany, DICEN-IdF, University of Paris-Est Marne-la-Vallée, France

13. Saskia Brand-Gruwel, Open University of the Netherlands, The Netherlands

14. Leslin Charles, Rutgers The State University of New Jersey, USA

15. Sabina Cisek, Jagiellonian University, Poland

16. Ioannis Clapsopoulos, University of Thessaly, Greece

17. John Crawford, Independent Information Professional, UK

18. Patricia Dawson, Rider University, USA

19. Mary Jean Tecce DeCarlo, Drexel University, USA

20. Anneke Dirkx, Leiden University Library, The Netherlands

21. Güleda Doğan, Hacettepe University, Turkey

22. Heidi Enwald, Oulu University, Finland

23. Kristiina Eriksson-Backa, Åbo Akademi, Finland

24. Viviana Fernández Marcial, University of La Coruña, Spain

25. Rosaura Fernández Pascual, University of Granada, Spain

26. Fabian Franke, University of Bamberg, Germany

27. Emmanouel Garoufallou, Alexander Tech. Educational Inst. of Thessaloniki, Greece

28. Almuth Gastinger, University of Science and Technology Trondheim, Norway

29. José Antonio Gómez-Hernández, University of Murcia, Spain

30. Allen Grant, Drexel University, USA

31. Stacey Greenwell, University of Kentucky, USA

32. Vincas Grigas, Vilnius University, Lithuania

33. Eystein Gullbekk, Oslo University, Norway

34. Gaby Haddow, Curtin University, Australia

35. Lejla Hajdarpasic, University of Sarajevo, Bosnia \& Herzegovina

36. Jannica Heinström, Åbo Akademi, Finland

37. Jos van Helvoort, The Hague University, The Netherlands

38. Merinda Kaye Hensley, University of Illinois at Urbana-Champaign, USA

39. Lisa Janicke Hinchliffe, University of Illinois, USA

40. Noora Hirvonen, University of Oulu, Finland

41. Baiba Holma, University of Latvia, Latvia

42. Kim Holmberg, University of Turku, Finland

43. Ma Lei Hsieh, Rider University, USA

44. Hilary Hughes, Queensland University of Technology, Australia

45. Maija-Leena Huotari, University of Oulu, Finland

46. Frank Huysmans, University of Amsterdam, the Netherlands

47. Zhang Jiuzhen, Peking University, China

48. Veronica Johansson, Univerity of Borås, Sweden

49. Nicole Johnston, Edith Cowan University, Australia

50. Christina Kanaki, Panteion University of Social and Economic Sciences, Greece

51. László Z. Karvalics, University of Szeged, Hungary

52. Paulette Kerr, University of the West Indies, Jamaica

53. Tibor Koltay, Eszterházy Károly University, Hungary

54. Terttu Kortelainen, University of Oulu, Finland

55. Denis Kos, University of Zagreb, Croatia

56. Pavla Kovarova, Masaryk University, Czech Republic

57. Liga Krumina, Liepaja University Library, Latvia 
58. Sanna Kumpulainen, University of Tampere, Finland

59. Serap Kurbanoğlu, Hacettepe University, Turkey

60. Hana Landova, Czech University of Life Sciences, Czech Republic

61. Elina Late, University of Tampere, Finland

62. Jesús Lau, Veracruzana University, Mexico

63. Vera J. Lee, Drexel University, USA

64. Krista Lepik, University of Tartu, Estonia

65. Louise Limberg, University of Borås, Sweden

66. Mandy Lupton, Queensland University of Technology, Australia

67. Juan D. Machin-Mastromatteo, Universidad Autonoma de Chihuahua, Mexico

68. Afrodite Malliari, DataScouting, Greece

69. Konstantina Martzoukou, The Robert Gordon University, UK

70. Yolande Maury, Artois University, France

71. Andrea Miljko, University of Mostar, Bosnia and Herzegovina

72. Camilla Moring, University of Copenhagen, Denmark

73. Danuta A. Nitecki, Drexel University, USA

74. Inci Onal, Hacettepe University, Turkey

75. Ágústa Pálsdóttir, University of Iceland, Iceland

76. Helen Partridge, University of Southern Queensland, Australia

77. Kornelija Petr Balog, University of Osijek, Croatia

78. Ola Pilerot, University of Borås, Sweden

79. Ewa Rozkosz, University of Lower Silesia, Poland

80. Jurgita Rudzioniene, Vilnius University, Lithuania

81. Jarmo Saarti, University of Eastern Finland, Finland

82. Dragana Sabovljev, Zarko Zrenjanin Public Library, Serbia

83. Chutima Sacchanand, Sukhothai Thammathirat Open University, Thailand

84. Dora Sales, Jaume University, Spain

85. Tatiana Sanches, Universidade de Lisboa, Portugal

86. Egbert John Sanchez Vanderkast, National Autonomous University of Mexico, Mexico

87. Laura Saunders, Simmons College, USA

88. Elham Sayyad Abdi, Queensland University of Technology, Australia

89. Jane Secker, London School of Economics, UK

90. İpek Şencan, Hacettepe University, Turkey

91. Gordana Stokić Simončić, University of Belgrade, Serbia

92. Eero Sormunen, University of Tampere, Finland

93. Irem Soydal, Hacettepe University, Turkey

94. Sonja Špiranec, University of Zagreb, Croatia

95. Jela Steinerova, Comenius University, Slovakia

96. Kristine Steward, Zayed University, UAE

97. Karmen Stopar, University of Ljubljana, Slovenia

98. Ivanka Stricevic, University of Zadar, Croatia

99. Paul Sturges, University of Pretoria, South Africa

100. Anna Suorsa, University of Oulu, Finland

101. Ana Lúcia Terra, Oporto Polytechnic Institute, Portugal

102. Tania Todorova, University of Library Studies and Information Technologies, Bulgaria

103. Tereza Trencheva, SULSIT, Bulgaria

104. Kimmo Tuominen, Helsinki University, Finland

105. Yurdagül Ünal, Hacettepe University, Turkey 
106. Zehra Taşkın, Hacettepe University, Turkey

107. Sirje Virkus, University of Tallinn, Estonia

108. Andrew Whitworth, University of Manchester, UK

109. Gunilla Widen, Åbo Akademi University, Finland

110. Zuza Wiorogorska, University of Warsaw, Poland

111. Iwan Wopereis, Open University of the Netherlands, the Netherlands

112. Mei-Mei Wu, National Taiwan University, Taiwan

113. Sharon Q. Yang, Rider University, USA

114. Pan Yantao, Sun Yat-Sen University, China

115. Manuel Zacklad, DICEN-IdF, CNAM

116. Sandy Zinn, University of the Western Cape, South Africa

\section{Local Organizing Committee}

1. Maija-Leena Huotari, University of Oulu, Finland (Chair)

2. Terttu Kortelainen, University of Oulu, Finland

3. Heidi Enwald, University of Oulu, Finland

4. Anna-Maija Huhta, University of Oulu, Finland

5. Iira Rautiainen, University of Oulu, Finland

6. Merja Kummala-Mustonen, Ministry of Education and Culture, Finland 


\section{Patronage}

UNESCO

INFLA

\section{Sponsors}

Federation of Finnish Learned Societies

City of Oulu

Department of Information and Communication Studies

AMKIT Universities of

Applied Sciences

Finnish Library Association

The Finnish Research Library Association
Suomen UNESCO-toimikunta

Finlands UNESCO-kommission

Finnish National Commission for UNESCO

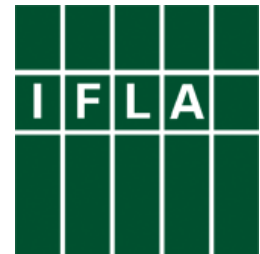

FEDERATION OF FINNISH LEARNED SOCIETIES
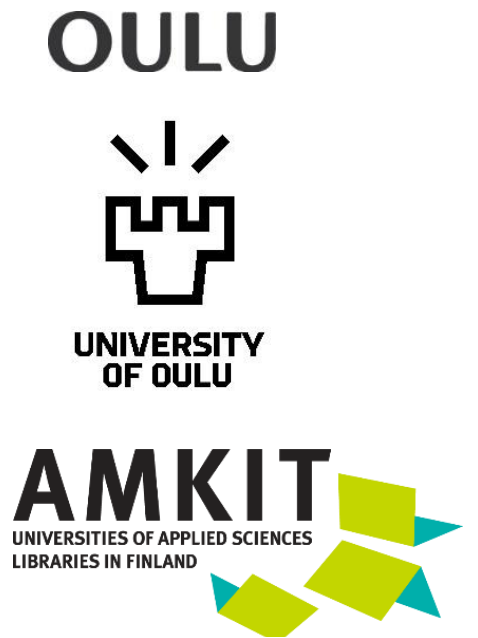

SUOMEN KIRJASTOSEURA

FINLANDS BIBLIOTEKSFÖRENING

FINNISH LIBRARY ASSOCIATION

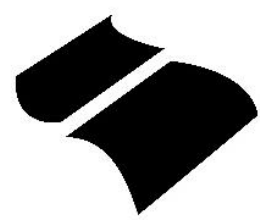

Hyvässä

seurassa 



\section{Foreword}

Dear participants of ECIL 2018, dear colleagues and friends,

It is time to get together again, now for the 6th European Conference of Information Literacy. ECIL 2018 is coorganized by the Department of Information Management of Hacettepe University, Turkey, the Department of Information and Communication Sciences of Zagreb University, Croatia, and Information Literacy Association (InLitAs), France. Our Department of Information and Communication Studies of the University of Oulu is the privileged local organizer of ECIL 2018. Therefore, it is our great joy to welcome you all to this conference in Oulu, Finland.

This year the theme is information literacy and related phenomena in different arenas of people's everyday life. This is a research area whose body of studies is still quite limited. The presentations will increase our understanding of information literacy in terms of conceptual and methodological development and application in professional practice that aims to enhance learning, coaching, and teaching. They may inspire us towards novel approaches for getting hold of the phenomena in different everyday life environments and contexts.

This year we had the total of 234 original initially submitted proposals, of which 180 were finally accepted for presentation and are thus included in this Book of Abstracts. The major part of the presentations is formed by papers, 98 in total. We have 38 presentations of best practices, seven workshops, 19 posters, 11 PechaKucha presentations, and three doctoral students' papers. We have three distinguished Keynote Speakers from the broad field of information sciences. Frans Mäyrä has investigated games and digital cultures for more than 20 years, Karen Fisher's research interests are in refugees' information behaviour and people's experiences of information in their everyday life, and Peter Bath is an expert of health informatics and sharing of information in online environments. Our Invited Speaker, Kristiina Kumpulainen from educational sciences, has studied young children's learning, development and wellbeing in formal education and beyond, as well as multiliteracies, dialogic learning, agency and identity, and teachers' professional development. All these 180 presentations of ECIL 2018 will provide us an opportunity to deepen our professional competence and widen our views of information literacy and related issues when the context is familiar to all of us, but the studies of these phenomena are rather rare.

It is delightful to tell you that this year Finnish National Commission for UNESCO is a patron of ECIL along with IFLA's permanent patronage. ECIL's sponsors are the City of Oulu, the Finnish Library Association FLA, the Finnish Research Library Association, the AMKIT Universities of Applied Sciences Libraries in Finland, the Librarians' Foundation, and the Federation of Finnish Learned Societies. Furthermore, the Finnish Association for Information Studies is in charge of the Doctoral Forum that is organized with the support from the Finnish Association of Scholarly Publishing. Moreover, besides providing working hours, our Department of Information and Communication Studies has financially contributed in organizing ECIL 2018. We would like to thank all these bodies for their valuable support.

Most of all, we are grateful to the initiators and pioneers of ECIL, Serap Kurbanoglu and Sonja Špiranec, for providing us this possibility to organize ECIL in Oulu. We also thank Joumana Boustany for her expertise with the finances and the conference management system, and Denis Kos for his support. In addition, ECIL would not take place without the Standing and Programme Committees' hard work. Moreover, as the local organizers, we have had a team of colleagues who have been active since ECIL in St. Malo. Of this labor, we would like to acknowledge Iira Rautiainen, our Coordination Assistant, for her proactive and persistent work. Without Iira, we could not stay as calm as we are now, three weeks before opening this excellent annual event for you, the participants of ECIL 2018, who have arrived from 44 countries to learn, network, enjoy, and have fun under the Northern sky of Oulu, Finland. Our warmest thanks to all of you.

On behalf of the Local Organizing Committee,

\section{Maija-Leena Huotari, Chair}

Professor of Information Studies, Faculty of Humanities, University of Oulu, Finland 



\section{In memoriam}

\section{Forest Windham "Woody" Horton Jr. (1930-2017)}

Forest Windham "Woody" Horton Jr died on December $7^{\text {th }}, 2017$, in the age of 87 years ${ }^{1}$. When I was working as an assistant professor at the University of Amsterdam, one of the subjects I was teaching, was 'Information in the Organisation'. One of the inputs that I used for this module was Woody's book: 'Information resources management'. He was the guru in the field. In 1991 I attended a conference in this field in Budapest. It was one of my first international conferences and there he was: the man himself alive. I was thrilled. It took me a day before I dared to speak to him. He was sitting somewhere at a small table... and I took my chance. He was most amiable and open to conversation. That was the start of what proved to become a long period of collaboration and even friendship. A few years later we met again and found that both our interest has moved to 'Information Literacy'. So, we went on collaborating and meeting on this new subject together. The 'main' thing we managed together was the UNESCO project of a series of 11 'Training-the-trainers in information literacy (TTT) workshops'.

\begin{tabular}{|ll|}
\hline - Montego Bay, Jamaica & \\
(30 May-1 June 2008) & (31 on-campus) \\
- Quebec City, Canada (8-9 August) & (35 on-campus) \\
- Port Dickson, Malaysia & (78 on-campus) \\
(11-14 August) & \\
- Tallinn, Estonia (21-23 August) & (47 on-campus) \\
- Ankara, Turkey (3-5 September & (50 on-campus) \\
- Cape Town, South Africa & (27 on-campus) \\
(4-6 October) & (104 on-campus) \\
- Wuhan, China (21-23 October) & (50 on-campus, \\
- Granada, Spain (27-30 October) & 134 online) \\
- Alexandria, Egypt & (94 on-campus) \\
(4-6 November) & \\
- Latiala, India (5-7 November) & (66 on-campus) \\
(22-24 January 2009) & (45 on-campus) \\
\hline
\end{tabular}

Boekhorst, Albert K. \& Horton, Forest Woody. 2009. Training-thetrainers in information literacy (TTT) Workshops Project, Final Report to UNESCO.

The International Information \& Library Review, Volume 41, Issue 4, December 2009, Pages 224-230.

http://www.sciencedirect.com/science/journal/10572317

A second project was the 'List of Information Resources in Different Languages'. To emphasize the importance of the context of information resources. It contains resources from around the world in 42 language lists and includes selected resources - from websites, books, journals and other kinds of publications.

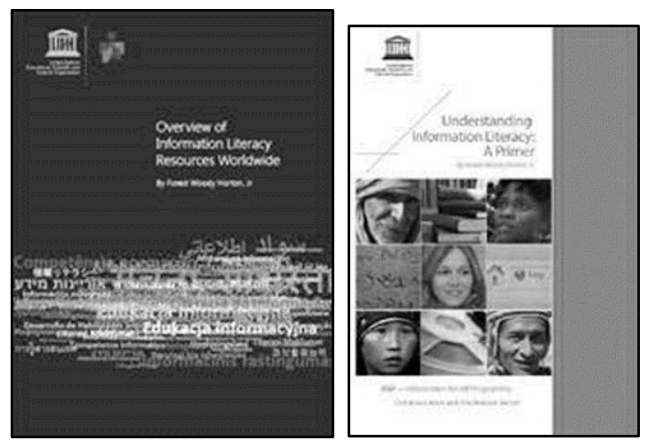

But next to that, his UNESCO publication 'Understanding information literacy: a primer' was an important contribution to the field.

Privately: when I managed to get him to the University of Amsterdam on a Fullbright Grant, he stayed at our house on a canal I the centre of Amsterdam. He enjoyed every day of it. During the 'classes' he was sitting, talking relaxed about his ideas and experiences on the subject. As for 'Information Recourses': being at his home, you could talk for 'days', inspired by all the 'souvenirs' he had collected. Fortunately, his 'mind' and 'typing' qualities were not affected after his TIA, only his speaking suffered a little. So we went on, on-line, nearly every day: useful sites, interesting activities, persons to be contacted and so on. 'Information Literacy' owes a lot to him. Personally, I do miss his daily comments and his suggestions, but we all have to learn to live with it.

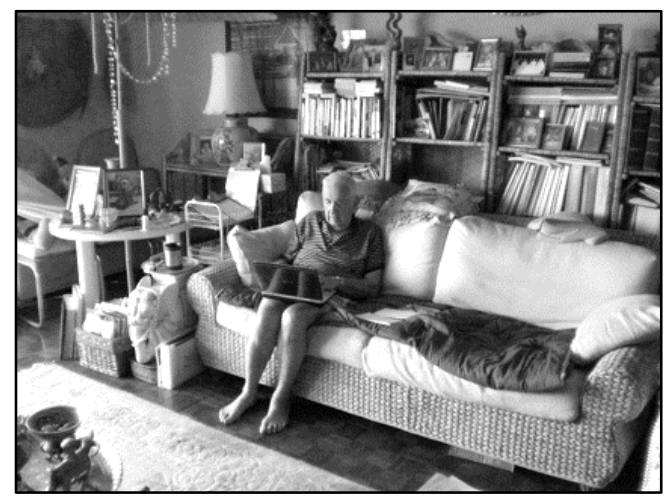

Albert K. Boekhorst

\footnotetext{
${ }^{1}$ Official obituary is to be found at https://www.adventfuneral.com/archives/forest-woody-horton-jr.htm
} 



\section{Contents}

\section{KEYNOTES}

Information Behaviour in Online Health Forums: The Importance of Trust and Empathy in Sharing Information,

Experiences and Emotions

Peter Bath

Information Literacy in Refugee Camps: Cultural Effects of Gender, Place and Time 3

Karen Fisher

Reading Pervasive Games in a Ludic Society.

Frans Mäyrä

\section{INVITED PAPERS}

Learning Multiliteracies from Early Years Onwards: An Educational Reform Initiative in Finland 6

Kristiina Kumpulainen

\section{PAPERS}

Information Literacy in Multilingual Workplaces

Farhan Ahmad

How Does Information Literacy Instruction in Secondary Education Affect Students' Self-efficacy Beliefs, Attitudes, and Information Practices?

Tuulikki Alamettälä, Eero Sormunen and Arman Hossain

Do We Need (Digital) Archeology Literacy?

Mihaela Banek Zorica, Rajna Sosic Klindzic and Sanja Potkonjak

Gender Differences in Information Literacy among Brazilian Youngsters

Nadia Bernuci, Gilda Olinto and Sonoe Sugahara

Research Data Management in France: Are French Researchers Ready to Face this Issue?

\section{Joumana Boustany}

Developing Health Information Literacy in Disadvantaged and Dependent Circumstances: The Everyday Role of Family Nurses

Steven Buchanan and Emma Nicol

A Phenomenological Imperative for Information Literacy.

John M. Budd and Anna Suorsa

Disciplinary Contexts in Research Data Management: A Case-Study of Three Disciplines

Maryam Bugaje and Gobinda Chowdhury

An Invitation to Globalize the Information Literacy Agenda: Expanding Discourse 16

Sergio Chaparro and Zachary Newell

The Politicisation of Information Literacy

John Crawford

Gaming for Multiliteracies: Video Games in a Case Study with Primary School Students to Enhance Information, Visual and Media Literacies

Eduardo Cruz-Palacios and Miguel Ángel Marzal García-Quismondo 
Developing Food and Nutrition Literacy with the Croatian Facebook Group, "Homemade Food for Babies"

Drahomira Cupar and Mate Juric

Relationship between Media Literacy and Civic Participation among Young Adults in Latvia Agnese Davidsone and Vineta Silkane

Information Literacy Self-Efficacy of Medical Students: A Longitudinal Study

Ann De Meulemeester and Jan De Maeseneer, Sven De Maeyer and Renaat Peleman and Heidi Buysse

Impact of Purposefully Designed Learning Activities in the Case of Information Literacy Self-Efficacy .....

Ann De Meulemeester, Renaat Peleman and Heidi Buysse

An Exploration of Information Literacy as a Form of Deweyan Inquiry

Brendan Devlin

Information Literacy of University Freshmen, and Differences in ICT Use, Internet Confidence, and Motivation ...24 Danica Dolničar and Bojana Boh Podgornik

Examining Subject-specific Information Literacy Elements on Economics and Business Administration for Use in a MOOC.

Stefan Dreisiebner

Effects of New Public Management (NPM) and Austerity in European Public and Academic Libraries

Petra Düren, Stéphane Goldstein, Ane Land $\phi y$, Angela Repanovici and Jarmo Saarti

Information Behavior of Humanities Students in Bulgaria, Italy and Sweden: Planning a Game-based Learning Approach for Avoiding Fake Content

Marina Encheva and Plamena Zlatkova, Anna Maria Tammaro and Mats Brenner

Teaching Yourself to Learn: A Case for Incorporating Self-Directed Learning Concepts into Information Literacy

Education.

Allison Nowicki Estell

Workplace Information Literacy of Croatian Fitness and Conditioning Personal Trainers

Kristina Feldvari, Kornelija Petr Balog and Sanjica Faletar Tanacković

Digital Literacy and Social Inclusion in Public Libraries: A Review of Research

Helena Francke, Noah Lenstra, Andreas Vårheim and Roswitha Skare

Genealogy and Learning: Acquiring Information and Digital Literacy Skills through a Hobby .....

Crystal Fulton

Print or Electronic Course Readings: Implications for Library Space and Information Literacy Programmes

Almuth Gastinger and Ane Land $\phi y$

Copyright Literacy Skills of LIS Students in Norway.

Almuth Gastinger and Ane Land $\phi y$

Epistemic vs Non-epistemic Criteria to Assess Wikipedia Articles: Evolution of Young People's Perceptions

Sahut Gilles and Josiane Mothe

Cultural Implications of the ACRL Framework .

Samantha Godbey and Xan Goodman

Secondary School Teachers' Attitudes to Information Literacy: A Pilot Study of a Multinational Survey

Vincas Grigas, Anna Mierzecka, Tímea Tomori and Tibor Koltay 
Research Orientation and Collaboration in Information Literacy in Post-socialist European Countries

Andrea Grkinić, Sonja Špiranec and Maja Jokić

Serendipity in High School Students' Information Acquisition

Jannica Heinström, Eero Sormunen and Teemu Mikkonen

Four Spaces of Civic Literacy Education: A Literature Review

Jos van Helvoort

Setting the Scene: An Set of Initial Premises for Everyday Information Literacy Alison Hicks

Finnish School Health Education Viewed through an Information Literacy Lens

Noora Hirvonen, Laura Palmgren-Neuvonen, Tuula Nygård, Anna-Maija Huhta and Maija-Leena Huotari

Information Overload: A Comparison of Disciplines in Australia

Katherine Howard and James Nicholson

Health Information Literacy Practices of Young Bloggers: A Nexus Analytical Study

Anna-Maija Huhta, Noora Hirvonen and Maija-Leena Huotari

Differences in Health Information Literacy Competencies among Older Adults, Elderly and Younger Citizens.

Isto Huvila, Heidi Enwald, Noora Hirvonen and Rose-Mharie Åhlfeldt

Personal Information Management and Organisation Competences: A Review of Information Literacy Conceptual

Frameworks and Standards.

Jerry Jacques

Data Sharing in Social Sciences: A Case Study at Charles University .

Adela Jarolimkova and Barbora Drobikova

Biometric Tools in Information Science. The Example of an Information Literacy Study - A Holiday Planning

Experiment

Justyna Jasiewicz, Małgorzata Kisilowska and Anna Jupowicz-Ginalska

Researching Information in Everyday Life: The Contribution of Autoethnography and Information Grounds Theory.

Bill Johnston and Sheila Webber

Four Passages to Information Use related Phenomena in Bachelor Theses at the Finnish Universities of Applied

Sciences

Juha Kämäräinen, Ilkka Mönkkönen and Jarmo Saarti

Gender Literacy: Fanfiction and Self-expression.....

Brittany Kelley and Kristen Schuster

How to Measure Energy Information Literacy? An Explorative Study

Teija Keränen, Noora Hirvonen, Anna-Maija Huhta and Maija-Leena Huotari

The Social Dynamics of Innovation in French Public Libraries: Communities of Practice and Knowledge Production

Susan Kovacs

Copyright Literacy of LIS Students in the Czech Republic

Pavla Kovářová 
Information Literacy of Masaryk University Students and Evaluation of Campus-wide Course

Pavla Kovářová

Data Literacy and Research Data Management Practices of Academics and Research Students in Australian Universities

P. Thomas Lacey and Katherine Howard

Academic Writing Centers as Tools for Information Literate Students

Ane Landøy, Natalia Cheradi, Angela Repanovici and Silvia Ghinkulov

Artificial Intelligence and Labor: Media and Information Competencies Opportunities for Higher Education

Jesus Lau, José Luis Bonilla and Alberto Gárate

Information Overload of Academic Staff in Higher Education Institutions in Estonia

Liia Lauri and Sirje Virkus

Students on a Social Media 'Detox': Disrupting the Everyday Practices of Social Media Use.....

Krista Lepik and Maria Murumaa-Mengel

Usability of Social Network Analysis in Assessing Libraries' Community Roles. Proof of Concept

Helena Lipkova, Tomáš Diviak, Adéla Jarolímková, Barbora Drobikova and Hana Landova

The Everyday Information Experiences of Breastfeeding Mothers: A Literature Review.

Hayley Lockerbie and Konstantina Martzoukou

Information Literacy and Open Science: Before and After the New ACRL Framework

Carlos Lopes, Maria da Luz Antunes and Tatiana Sanches

Digital Competence for Digital Citizenship: an Emerging Agenda for Students, Academics and Libraries in Partnership

Konstantina Martzoukou and Crystal Fulton

Unique or Ubiquitous? Information Literacy Instruction Outside Higher Education.

Miriam Matteson and Beate Gersch

Thinking Youth Popular University as a Participative Space: Focus on a Speakers' Corner Experience, between

Participatory Culture, Citizen Commitment and Political Empowerment

Yolande Maury and Asmaa Azizi

The Data and Information Literacy of Runners: Quantifying Diet and Activity

Pamela McKinney, Andrew Cox and Laura Sbaffi

Character Building in Children's Online Information Behaviours: Applying a Virtue Epistemology Perspective to Information Literacy

David McMenemy and Steven Buchanan

Young People's Digital Safety and Wellbeing: Findings from the Philippines and Qatar

Virgilio G Medina Jr and Ross J. Todd

Information Literacy as a Material Culture? Ordinary Practices of Knowledge in Academic Libraries

Béatrice Micheau

Foundations of Information Literacy Trends: A Textual Data Based Analysis on International Frameworks ...... . .70

Florent Michelot and Bruno Poellhuber 
Migration of Clusters from Pre-session to Post-session: An Analysis of Elderly Students' Perceived Digital

Literacy

Makiko Miwa, Emi Nishina, Hideaki Takahashi, Yoshitomo Yaginuma, Yoko Hirose and Toshio Akimitsu

A Critical Praxis in the LIS Education Classroom Using the ACRL Framework for Information Literacy for Higher

Education

Shehaamah Mohamed

Teacher's Resistances to Mobile Learning in Turkey and Spain: What Similarities? What Differences?

Tugba Mutlu and Cristina Aliagas

Collaboration Building between Teaching Faculty and Librarians: Based on a Case Study on Field Librarians at the

University of Michigan

Tayo Nagasawa

Information Literacy in Portuguese School Libraries: A Longitudinal Study of Master Degree Dissertations

Ana Novo and Glória Bastos

Collaborative Knowledge Building to Enhance Information Literacy in Health Education

Tuula Nygård, Laura Palmgren-Neuvonen, Noora Hirvonen, Anna-Maija Huhta and Maija-Leena Huotari

Advocacy in Everyday Life: The Role of Information Literacy Skills

Peggy Nzomo and Paul Fehrmann

Biographical Space, Digital Death and Information Literacy Skills: Current Issues .....

Paula Ochôa and Leonor Gaspar Pinto

Conceptions of Information Literacy and Multiliteracies from the Perspectives of Teachers and Librarians in the

Context of the Finnish National Core Curriculum. .79

Anu Ojaranta, Siinamari Tikkinen and Riitta-Liisa Korkeamäki

Which Approaches and Methods are Most Appropriate for Exploring Health Information Behavior?

Marianne Paimre

Copyright Literacy among Students of Information Science at the University of Iceland

Ágústa Pálsdóttir

Privacy Literacy and the Everyday Use of Social Technologies

Zablon Pingo and Bhuva Narayan

The Attitudes of teachers-in-training towards Information Literacy Skills and the Inclusion of Mobile Devices in the

Process of Teacher Education

María Pinto, David Caballero-Mariscal, Rosaura Fernández-Pascual, Dora Sales and David Guerrero-Quesada

The Health of a Musician: Identifying Musicians' Unrecognized Health Information Needs. .... .84

Loriene Roy and Yan Zhang

Drop Out Factors in Data Literacy and Research Data Management Survey: The Vilnius University Experience....85

Jurgita Rudžionienè and Vincas Grigas

Influence of Leadership Behaviour on Information Culture Typology within Higher Education Institutions: A

Multiple Case Study .86

Anmar Salman and Sirje Virkus

Changing Roles for Research and Information Skills Development: Librarians as Teachers, Researchers as Learners

Tatiana Sanches 
Multi-literacies and Social Sustainability

Egbert John Sanchez Vanderkast

Critical Information Literacy Teaching in Canadian Academic Libraries .

Debbie Schachter

Using Constructive Alignment to Support Metaliteracy in International Classrooms.....

Kristen Schuster and Kristine N. Stewart

Impact of Intrinsic Motivators on Knowledge Sharing in Virtual Environments: Implications for Workplace Information Literacy and Collaborative Practices

Rajesh Singh

Adapting the New ACRL Framework to IL Teaching at Tampere University of Technology.

Miikka Sipilä, Mervi Miettinen and Johanna Tevaniemi

Data Literacy Perception and Practices in the Information Environment

Jela Steinerová and Miriam Ondrišová

\#MuslimTravelBan: A Semantic and Social Network Analyses of Executive Order 13769 on Twitter

Kristine N. Stewart

Understanding Health Literacy through the Lens of Phronesis: The Case of Coronary Artery Disease Patients

Venkata Ratnadeep Suri, Shaheen Majid, Schubert Foo, Hannah Trinity Dumaual-Sibal and Yun-Ke Chang

Investigating Knowledge Management Practices at OpenStack

José Apolinário Teixeira, Helena Karsten and Gunilla Widén

Research Data Management Findings at ULSIT

Tania Todorova, Rositza Krasteva and Elisaveta Tsvetkova

Information Seeking Behavior of Primary Teachers in Estonia: An Exploratory Study

Sirje Virkus and Marit Mathiesen

Information Culture at the Statistics Estonia: An Exploratory Study

Sirje Virkus and Olga Albrecht

Using Open Badges to Foster Information Literacy: An Action Research Approach

Sirje Virkus

Scientific Literacy Education Outside the Classroom: A Study in Acquisition of Knowledge and Skills about Science in Public Libraries in Croatia

Radovan Vrana

Measuring the Psychophysiology of Information Literacy

Geoff Walton, Andy Wilkinson, Martin Turner, Matt Pointon and Jamie Barker

Exploring the Information World of Non-Resident Informal Carers

Sheila Webber and Pamela McKinney

"Who Wants the Power?": A Foucaultian View of Authority in Developing Information Literacy

Andrew Whitworth

Information Problems Encountered by Asian Students at the European Universities. A Case of Poland .105

Zuzanna Wiorogórska 


\section{DOCTORAL PAPERS}

The Role of Intuition in the Development of MIL as a Cultural Practice.

Maryna Gallardo-Romagnoli, Jesus Lau and Carlos Arturo Torres Gastelú

Why Information Literacy Integration Doesn't Work: Exploring the Experience of Academic Staff.

\section{Hiroyuki Ida}

Information Literacy Education as a Lens to Understand Inquiry-based Learning amongst Universities in East Asia

Qianxiu Liu and Hiroshi Itsumura

\section{BEST PRACTICE}

Use of Open (Research) Data in Teaching (UDIT): An Open Online Resource

Helene N. Andreassen, Torstein Låg, Harrie van der Meer, Mijke Jetten and Monique Schoutsen

It's Universal: Librarians, Student Digital Devices, and Universal Design Create a Winning Combination for a New

Era.....

Catherine Baldwin

Playing for Knowledge

Anna Callejón Mateu

Using Metacognition to Address the 'Illusion of Knowing' among First Year Students in How to Determine Credible Sources of Information Received via Social Media.

Leslin H. Charles

School-Work Alternation: Work the Information to Turn it into Knowledge

Elena Collina and Rita Patregnani

Coinfo-Inclusion Model - Cards for Teacher Training to Work with Inclusive Education

Célia Revilândia Costa Seabra

Five Years of Plagiarism School: Lessons \& Impact.

Vanessa J. Earp

Copyright Law and Copyright Literacy in Germany

Fabian Franke

Going Local: Designing a Homegrown Information Literacy Test for Your Own Institutional Context

Susan Gardner Archambault

Upsizing and Upskilling Library Student Assistants: Experiences from SMU Libraries

Sumita Govindan, Siew Khim Lim and Vincent Ong

Flipped Classroom Teaching Method in Information Skills Courses .

Riitta Holopainen

Teaching Critical Information and Media Literacy through the Black Power Movement and Documentary Film .. 123

Viola Huang

Using Authentic Passions to Inspire Curiosity

Daniel Ireton and Ellen Urton

Building Bridges: Using Information Literacy to Support High School to University Transitions 125

Zoe Jarocki 


\section{Marion Kelt}

Decision Based and Learner Driven: The EconBiz Online Tutorial Guided Walk

Nicole Krüger

Reflective Practice as a Pathway towards Information Literacy for Future English Teachers

Karin Lach

Starting Off on The Right Foot: A Common Curriculum for an Introductory Program.

M. Sara Lowe and Sean M. Stone

Maximizing the Learning Value of e-Textbooks: Practice Recommendations Based on a Quasi-Experiment

Teresa MacGregor and A. M. Salaz

Navigating the Maze: Collaborating with Teachers to Meet Information Literacy Challenges.....

Olga Martinová and Pavlína Tassanyi

The Postgraduate Information Literacy Survey and Instructional Design: A Case Study in University Chinese

Academy of Science

Wu Ming

The Hague Fact Checking Factory; Towards Civic Literacy

Fenneke Mink and Jos van Helvoort

Evidence Based Practice: Accessing and Assessing Evidence: Course Development Proposal at Implementation Phase

Mbachi Ruth Msomphora

Information Literacy Concepts in Swedish Legislation, Methods of Teaching and Their Impact on the Design of

Library Instruction Sessions at Linköping University .....

Magdalena Öström

Information Literacy as an Integrative Part of Academic Projects: Partnership with Stakeholders of the

University

Kristyna Paulova and Jana Rimanova

From Information Literacy to the Learner Journey: Using What Academics Really Think to Develop the Teaching Offer at the University of Worcester.

Sarah Pittaway

Murder in the Library - Using Escape Rooms for Information Literacy Teaching

Essi Prykäri and Riikka Sinisalo

Towards Digital Literacy: The Case of Adult Users at Lithuanian Public Libraries.

Jurgita Rudžioniené

Best Practices: Librarians, Journalists, and Allied Professionals Working to Challenge Fake News

Laura Saunders and Lisa Janicke Hinchliffe

Information Literacy MOOC: An Experience and Learners' Perspective

Vilve Seiler and Lilian Neerut

On Campus and Beyond: A Multipronged Approach to Information Literacy .....

Priyanka Sharma 
Text, Lies, and Video Tutorials: Examining Format Preference and Effectiveness in Blended IL Instruction ........

Tara Stieglitz and Lindsey Whitson

Developing Best Practices for International Student Information Literacy Instruction Sean Stone and M. Sara Lowe

Collaboration in Teaching Open Science Skills

Katin Syvälahti and Taina Kettunen

Online Reading Lists: Encouraging Staff Engagement to Improve Student Information Literacy..... Allie Taylor

An Educational Program on Research Competence Offered by a Faculty Library Anne-Lise Van der Meulen and Paul Buschmann

The Delphi Model: Transforming Flemish Libraries into User-oriented Points of Information

Patrick Vanden Berghe

Voluntary or Mandatory? Assessing Two Ways to Disseminate Information Skills Using a MOOC

Lieselot Verryckt and Steven Laporte

\section{PECHA KUCHA}

Digital Literacy vs. Computer Learning: Social Representations of Information and Communication Technologies (ICT) among Middle School Students ....

Laure Bolka-Tabary and Florence Thiault

IL for Bachelor's Students at University of Oulu: Best Practices

Kaisu Clarot, Ursula Heinikoski and Pertti Martinmäki

How to Integrate Visual Literacy in Adult Second Language Training?

Noémi Cobolet

Content Curation for Every-day Life Citizen Journalism and Beyond

Gilbert C. Faure

Incorporating Information Literacy Threshold Concepts into Disciplinary Instructional Contexts

Samantha Godbey

Visual Resources and Social Media: Leveraging Everyday Practices to Teach Information Literacy

Chelsea Heinbach and Krystyna K. Matusiak

Access to Information as Prerequisite for Information Literacy Skills: Case Eritrea-Finland Cooperation Project in Higher Education

Päivi Helminen

Trust, Engagement, and the $21^{\text {st }}$ Century Learner

Martha J. Hoff

The Algorithmic Intersection of Scholarly Communication, [Un]informed Citizenship, and Information Literacy:

The Preprint as a Case Study

Christopher Hollister and Robert Schroeder

The Survey of Information Literacy among Pupils and Teachers in Junior High School 161

Kazuyuki Sunaga

A Literature Review on the Linkages between Digital Inclusion and Information Literacy

Sharon Wagg, Louise Cooke and Boyka Simeonova 


\section{POSTERS}

Digital Literacy Competencies of English Teachers in Kuwait Schools

Reham AlHuraiti

Media Education Technologies in Developing Students' Professional Competence.

Volodymyr Biletsky, Anna Onkovych and Olha Yanyshyn

The Role of Academic Libraries in Teaching Information Literacy: From the Students' and Professors'

Perspective

Mojca Brenko-Puzak and Lahorka Crnković

An Academic Library as a Partner in LIS Students' Education

Hana Holoubková

Developing Data Literacy and Research Data Management in University of Eastern Finland Library.....

Anne Karhapää, Katja Hyvärinen and Kaisa Hartikainen

Let Them Bloom! The Library Cultivating New Ground for Learning in Third Space.

Riitta-Liisa Karjalainen, Eerika Kiuru, Arja Kunnela, Elina Laineenoja, Mari Mäkynen and Sanna Savolainen

Making it Together: Information Specialist and Toxicologist Developing Students' Professional Information

Skills

Heikki Laitinen, Risto O. Juvonen and Jarmo Saarti

Analysis of Teaching Design and Teaching Effect in Patent Application and Utilization Skills Course

Ling Li and Dongrong Zhang

The Role of International Partnerships in Supporting Library-Based Instruction

Mark Mattson, Mirta Matošić and Florent Michelot

Digital Literacy Beyond Social Media: Undergraduates' Self-Perceived Competence of Academic Digital Skills..174

Olivia-Dumitrina Nechita, Yolanda Capdevila Tomàs and Montserrat Casanovas Català

Co-creating an Engaging Tool for Source Criticism

Daniel Prasius and Martin Gundtoft

The Teaching of the Discipline User Studies and User Formation in a Brazilian University through the Use of Comics: An Experience Report

Fernando Bittencourt dos Santos, Janaina F. Fialho and Marta Leandro da Mata

Characterization of the Academic Research on Informational Behavior in the Field of Meteorology: Conceptual and

Methodological Approaches

Fernando Bittencourt dos Santos and Fernanda Martins

Information Literacy as a Tool for Lifelong Learning: Case Study about Systematic Co-Operation between School and Public Library

Leena Toivonen, Outi Vaskin, Jorma Riikonen and Minna Edgren

Mapping Mechanical Engineering Students' Information Literacy Needs ....

Evanthia Tramantza, Sheila Webber and Panayiotis Ketikidis

Information Preferences when Facing a Health Threat - The Role of Subjective Versus Objective Health Information Literacy 180

Oliver Wedderhoff, Anita Chasiotis and Anne-Kathrin Mayer

A Domain-Specific e-Learning Course to Support Teaching of Information Literacy for Psychology Students at the University of Vienna. 


\section{Michaela Zemanek}

Opportunities and Challenges for Information Literacy Education under the Core Competencies and Values for

Chinese Students' Development

Jing Zhang,Naiyi Yang and Yang Zhang

\section{WORKSHOPS}

Evaluating and Constructing Tools for the Assessment of Information Literacy .....

Anita Chasiotis, Oliver Wedderhoff and Anne-Kathrin Mayer

Using Social Media to Teach Students How to Create a Research Query and Find Effective Keywords

Kiersten Cox and Vicki Gregory

Assessment and the ACRL Framework

Samantha Godbey

Problem Setting Information Literacy: Reconsidering Techniques for Instructional Design

Merinda Kaye Hensley

The Power of Primary Sources: Integrating Archives into the Critical Information Literacy Classroom

Julie M. Porterfield and Rebecca K. Miller

Brainstorming on Data Literacy: Bringing out the Best Practices by Mind Mapping

Marco Schirone and Kaisa Hartikainen

What's My Approach? Deciding on the Approach to Use for Your Research

Sheila Webber, Bill Johnston and Pamela McKinney 



\section{KEYNOTES}




\title{
Information Behaviour in Online Health Forums: The Importance of Trust and Empathy in Sharing Information, Experiences and Emotions
}

\author{
Peter Bath \\ University of Sheffield, UK, p.a.bath@sheffield.ac.uk
}

This keynote talk will present recent research examining how online health forums support information seeking and information behaviours among patients and family members. An increasing number of online health forums are available for patients, informal carers and family members for a range of medical conditions including long-term illnesses, acute health problems, and life-threatening and terminal illnesses. An emerging body of research has examined the role of online health forums in providing emotional and informational support among people affected by these conditions. Relatively little research has examined specifically how people use and share information in online health forums and the importance trust and empathy in these acts of sharing (Hargreaves et al., 2018; Lovatt et al., 2017). The project, A Shared Space and a Space for Sharing (http://www.space4sharingstudy.org/), investigated how people in extreme circumstances share information in different online spaces and the role of trust and empathy. In Sheffield, we explored how sharing takes place in online health forums. The study adopted a qualitative approach which involved a thematic analysis (Braun and Clarke, 2006) of the content of posts on two online health forums, provided by Breast Cancer Care and the Motor Neurone Disease (MND) Association, and semi-structured interviews with users of these forums. The talk will discuss the ways people develop trust in others while using the forums and how this affects the information they share and use. It will consider how information sharing among users supports the development of empathic connections and the development of friendships. The talk will conclude with consideration of how we are using the results to promote online health forums as a way for people with serious illnesses to share information and meet their information needs.

\section{References}

Braun, V., \& Clarke, V. (2006). Using thematic analysis in psychology. Qualitative Research in Psychology, 3(2), $77-101$.

Hargreaves, S., Bath, P. A., Duffin, S., \& Ellis, J. (2018). Sharing and empathy in digital spaces: Qualitative study of online health forums for breast cancer and motor neuron disease (Amyotrophic Lateral Sclerosis). Journal of Medical Internet Research, 20(6), e222.

Lovatt, M., Bath, P. A., \& Ellis, J. (2017). Development of trust in an online breast cancer forum: A qualitative study. Journal of Medical Internet Research,19(5), e175.

Keywords: online health forums, sharing, trust, empathy, information behaviour, information seeking, health 


\title{
Information Literacy in Refugee Camps: Cultural Effects of Gender, Place and Time
}

\author{
Karen Fisher \\ University of Washington, USA, fisher@uw.edu
}

What is information literacy for the millions of people forcibly displaced by war and persecution? In 2018 almost 70 million people are displaced, half of whom are children, with a majority residing in low to middle-income countries close to situations of conflict. In this keynote, Dr. Fisher draws upon years of embedded fieldwork at UNHCR Za'atari Camp, by the Jordan-Syria border, to discuss the nature of everyday information literacy for survival and resilience by Syrian refugees.

Using co-design and information science techniques, Dr. Fisher addresses the high constraint, low affordance environment of refugee camps and how cultural factors such as gender, place, and time affect information behavior and can guide the design of libraries and information systems.

Keywords: information literacy, refugee camps, gender, place, time 


\title{
Reading Pervasive Games in a Ludic Society
}

\author{
Frans Mäyrä \\ University of Tampere, Finland, frans.mayra@uta.fi
}

Information, and interacting with it, is becoming a crucial element in late modern societies and lifestyles. Information and communication technologies (ICT) are increasingly not limited to narrowly defined utilitarian or instrumental roles. Rather, ICT is distributed to our everyday lives and plays important roles in how we interact with each other and construct our realities. The focus on Professor Frans Mäyrä's keynote is on construction of realities in pervasive games and play, and on the opportunities and challenges that mixed reality technologies present for our information literacies. Discussing what he calls "Ludic Society" - a version of late modern culture and society where games and play hold a central role-Professor Mäyrä will promote a multidimensional view of reality, where the ability to construct meaning, act, and decode messages within multiple overlapping layers of reality simultaneously is an important civic skill. Pokémon $G O$ is a recent, commercial example of an entertainment game that relies on overlaying of digital, fictional and playful information on top of everyday, physical and urban environments. The foreseeable future can be expected to serve us more, and qualitatively increasingly sophisticated experiences and services where such "mixed reality" will be the new standard. In such realities, it is not enough to be able to technically operate new technology, but rather it becomes important to be able to cultivate critical literacies and creative competencies that foster growth of ludic, social agency. Otherwise, the technological inequalities will radically aggravate the societal fragmentation: splintered into non-compatible information environments, the consumers of such dystopian mixed realities are separated by politics and economics alike. In contrast, people who play together, stay together. The boundary crossing potential of pervasive games and play should thus be highlighted as an important area where the key skills of future information societies come together - including the ludic, media literacy and civic skills alike.

Keywords: reading, pervasive games, ludic society 


\section{INVITED PAPERS}




\title{
Learning Multiliteracies from Early Years Onwards: An Educational Reform Initiative in Finland
}

\author{
Kristiina Kumpulainen \\ Playful Learning Center / University of Helsinki, Finland, kristiina.kumpulainen@ @elsinki.fi
}

Finland has recently introduced multiliteracies as a foundational competency in its new national core curricula for the education of children up to the age of 16. In my presentation, I will be discussing the impetus and rationale for the introduction of multiliteracies in the Finnish curriculum reform. Whilst linking my discussion to the international research literature on multiliteracies, I will be pointing out some challenges in defining and promoting multiliteracies in education.

The second part of my presentation concentrates on The Joy of Learning Multiliteracies (MOI), an ongoing national research and development programme funded by the Finnish Ministry of Education and Culture ${ }^{1}$. The programme responds to the need to conceptualise and promote young children's (0-8 years) engagement with multiliteracies in formal education and beyond through research and co-design of learning environments and pedagogies. Drawing on Green's 3D (1988) model, MOI holds that learning multiliteracies entails at least three dimensions: the operational, the cultural and the critical. In addition, MOI relates multiliteracy to human agency and transformation-that is, understanding the affordances of different modes and media for participation and influence and supporting young children's meaning-making and participation in an increasingly diverse world. Ten communities situated in the metropolitan area of Helsinki are participating in the MOI programme, each includes an early years center, a primary school, a local library and other cultural providers within the community. The participating children and their families represent diverse social and cultural backgrounds. Altogether, about 1500 children and their guardians are participating in the MOI programme, along with 500 teachers. The research and development work involves close collaboration between the academics, teachers and community members in the field in co-designing learning activities and materials for the enhancement of young children's multiliteracies learning.

The pedagogical principles promoted by MOI involve multisensory, playful and story-like learning environments that encourage children to use their imaginative, creative and collaborative capacities. The development work aims for rich textual environments in which the culture produced by children themselves comes into dialogue with the culture produced for them. Rich and multimodal textual environments are aimed at inviting children to investigate, interpret, use and produce texts for multiple purposes and audiences. MOI learning environments are designed to form flexible, pedagogically coherent and continuous entities across the curriculum, drawing on children's social ecologies, including their home cultures and literacies. The learning environments can be situated outdoors and indoors, in nearby nature areas, parks and cities, in cultural institutions and in digital and virtual spaces. Observation, video documentation and analysis, children's productions and artefacts, interviews and surveys of teachers, parents and the children themselves all contribute to building the MOI data corpus. The MOI programme's multilevel approach is designed to enhance understanding and promotion of children's multiliteracies through (a) designed learning activities; (b) communities of practice; (c) knowledge construction and creation and (d) agency and identity formation. It is further hoped that the programme will contribute to global discussion on the meaning and purpose of multiliteracies in contemporary education and in societies at large.

Keywords: multiliteracies, early childhood education, learning across contexts, pedagogy, professional learning

\footnotetext{
${ }^{1}$ http://www.monilukutaito.com
} 


\section{PAPERS}




\title{
Information Literacy in Multilingual Workplaces
}

\author{
Farhan Ahmad \\ Åbo Akademi University, Finland, fahmad@abo.fi
}

\section{Introduction and Objective}

Information literacy is a crucial skill in the pursuit of knowledge. The dynamics of workplace information environment, which is characterized by globalization, competition, and constant change, are different from traditional educational environments (Gilbert, 2017). Consequently, individuals learn to define information needs, sources, and applications at the workplace according to the job demands and information environment of the organization. One of the important characteristic of today's workplace is language diversity. International recruitment and immigration have rendered many workplaces multilingual (Ahmad, 2017). Language diversity introduces complexity in information landscape of the workplace. Translation, interlingual interaction, communication in non-native language, and variation in common language competency mean that information needs to be produced, accessed, and interpreted in different languages. Previous research has rarely discussed information literacy from the language diversity perspective. This paper aims to fulfil this research gap. The main aim of this paper is to understand how language diversity in workplace can influence the realization of information literacy.

\section{Methodology}

A qualitative study involving 21 in-depth interviews were conducted in a Finnish multinational organization. All the interviewees were from middle and lower management in different common functional areas. Interviews were transcribed verbatim and analyzed following the two stage inductive coding method (Lofland \& Lofland, 2006).

\section{Findings}

The data analysis showed that language diversity in organizations influences information literacy in two ways. First, it influences information comprehension and evaluation capability of employees. Our analysis showed that employees had trouble understanding and comprehending information while interacting with colleagues in non-native language. As knowledge intensive work requires extensive information sharing between employees, making sense of information in context of work-related problems is extremely important. Nevertheless, language differences characterized by language competency and linguistic contextual variations create problems for employees in their information comprehension process. Another impact of language diversity was on information access. Due to language differences, employees were not able to access information produced in other languages. Although English was the corporate language, emails and local documents were often produced in other languages. Consequently, employees' capacity to access such documents were limited.

\section{Conclusion and Implications}

This paper shows that workplace characteristics, such as language diversity, can render traditional information literacy skills insufficient. It shows that information literacy skills developed and practiced in monolingual environments are not enough to navigate in information landscape of the linguistically diverse workplace. Even information literate individuals may find their capability to access, share, and evaluate information constrained due to multilingual nature of the information environment. It has implications for educational context. The information literacy programs should expose and train students to multilingual information communication. In organizational context, information professionals and managers must account for the language differences in the development of positive information culture in the organization.

\section{References}

Ahmad, F. (2017). Knowledge sharing in a non-native language context: Challenges and strategies. Journal of Information Science, 44(2), 248-264.

Gilbert, S. (2017). Information literacy skills in the workplace: Examining early career advertising professionals. Journal of Business \& Finance Librarianship, 22(2), 111-134.

Lofland, J., \& Lofland, L. H. (2006). Analyzing social settings. Belmont, CA: Wadsworth Publishing Company.

Keywords: information literacy, workplace information literacy, language diversity, information management 


\title{
How Does Information Literacy Instruction in Secondary Education Affect Students' Self-efficacy Beliefs, Attitudes, and Information Practices?
}

\author{
Tuulikki Alamettälä, Eero Sormunen and Arman Hossain \\ University of Tampere, Finland, \{tuulikki.alamettala, eero.sormunen\} @uta.fi, armanhossain.isl@gmail.com
}

Information literacy instruction typically aims to improve students' information literacy skills and learning outcomes are assessed accordingly (Oakleaf, 2009). However, the instruction may affect students beyond procedural knowledge and cognition. The aim of this study is to show how a long-term, inquiry-based, curriculum-embedded information literacy instruction changes students' self-efficacy beliefs, attitudes, and information practices.

The study was conducted as a pre-post intervention study in a Finnish lower secondary school. A Finnish language teacher and two history teachers designed and implemented three information literacy modules during a two-year teaching period. In the beginning, Guided Inquiry (Kuhlthau, Maniotes \& Caspari, 2015) was introduced to the teachers but they were free to embed it into their pedagogical practices as extensively as they saw appropriate. For the details of the interventions, see Alamettälä \& Sormunen (2018).

The data were collected by a questionnaire from five parallel classes. The test group consisted of three classes and 58 students; the control group comprises two classes and 36 students. The questionnaire was administrated both before and after the interventions. The questionnaire was designed by using the validated SORAB instrument by Putman (2014) as a framework. The questionnaire consisted of multiple-choice questions or declarative sentences exploring the students' self-efficacy in information literacy (22 items), inquiry related attitudes ( 24 items), and information practices (33 items).

Statistical analyses were performed using SPSS. By means of exploratory factor analysis, the instrument was reduced to seven factors to be used as the measures of progress. Preliminary results indicated that the teaching interventions developed students' self-reported information practices regarding the evaluation of search results. No effect was observed in other factors: self-efficacy beliefs, attitudes, or information practices in searching and writing.

\section{References}

Alamettälä, T., \& Sormunen, E. (2018). Lower secondary school teachers' experiences of developing inquiry-based approaches in information literacy instruction. In S. Kurbanoğlu et al. (Eds.), Information Literacy in the Workplace, The Fifth European Conference on Information Literacy, ECIL 2017, Saint Malo, France, September 18-21, 2017: Revised Selected Papers (pp. 683692). Cham: Springer International Publishing.

Kuhlthau, C. C., Maniotes, L. K., \& Caspari, A. K. (2015). Guided inquiry: Learning in the 21st century (2nd ed.). Santa Barbara: Libraries Unlimited.

Oakleaf, M. (2009). Using rubrics to assess information literacy: An examination of methodology and interrater reliability. Journal of the American Society for Information Science and Technology, 60, 969-983.

Putman, S. M. (2014). Exploring dispositions toward online reading: Analyzing the survey of online reading attitudes and behaviors. Reading Psychology, 35(1), 1-31.

Keywords: information literacy, information literacy instruction, intervention, lower secondary school, students 


\title{
Do We Need (Digital) Archeology Literacy?
}

\author{
Mihaela Banek Zorica, Rajna Sosic Klindzic and Sanja Potkonjak \\ University of Zagreb, Croatia, \{mbanek, rsosic, spotkonj\}@ffzg.hr
}

It is undisputable that information communication technology (ICT) has influenced many new fields and forced interdisciplinarity. One of the examples is the digital humanities domain which has started from two streams computational linguistics and digitization of heritage. Through its development digital humanities has brought a whole new array of questions and research challenges. As Berry citing Presner (2010) states "Digital Humanities 2.0 introduces entirely new disciplinary paradigms, convergent fields, hybrid methodologies, and even new publication models that are often not derived from or limited to print culture." [1] Transformation of this field is also seen through the convergence of various disciplines both on social science and humanities specter. One of such is seen in entering of information literacy field in the digital archeology. Huvila (2006) emphasizes that "The basic principles of information literacy are seen through every step that archaeologist make during the research but there is no help in making their life easier i.e. educating and training them in information literacy." There are two sides of archaeological field that have been transformed due to the technology management that are closely related to the question of how we handle information: the information practice of archaeologists and the archeological documentation. Authors of this paper agree and, in their paper, support the idea that information literacy has become one of the pillars of archeology practice and education. Therefore, the objective of the research is to identify concepts emerging in the field of the digital archaeology and connect them with information literacy concepts. Such findings will present a platform for integrating information literacy in both formal and informal education of archaeologists.

\section{Methodology}

Focus groups with field archaeologists to identifying skills and competences necessary in their practical work.

\section{Outcomes}

Mapping of digital archeology concepts with information literacy framework presents a first step towards connecting these two fields thus creating bridges for an interdisciplinary approach to digital archeology and its curriculum.

\section{References}

Berry, D. M. (2011). The computational turn: Thinking about the digital humanities. Culture machine, 12. Retrieved from http://www.culturemachine.net/index.php/cm/article/viewarticle/440

Uotila, K., \& Huvila, I. (2006). The education of little archeologist? Reflections on the digital education and training of archeological professionals. In Proceedings of the International Congress Kulturelles Erbe und Neue Technologien Workshop 10 Archäologie und Computer, Magistrat der Stadt Wien, MA 7 - Referat Kulturelles Erbe - Stadtarchäologie.

Keywords: digital archeology, information practice, curriculum, formal education, informal education 


\title{
Gender Differences in Information Literacy among Brazilian Youngsters
}

\author{
Nadia Bernuci \\ IBGE, Rio de Janeiro, Brazil, nadiabernuci@yahoo.com.br \\ Gilda Olinto \\ IBICT, Rio de Janeiro, Brazil, gildaolinto@gmail.com \\ Sonoe Sugahara \\ IBGE, Rio de Janeiro, Brazil, sonoes@gmail.com
}

\section{Theme and Motivation}

This work considers media and information literacy (MIL) indicators focusing on gender differences among Brazilians youngsters.

The importance of gender equality in knowledge society is being considered in the social and information science literature. Gender differences in science and technology, as well as in information technology, is unjust and has serious impact on overall societal development. It is well known that development in some societies has been accompanied by significant increase in gender equality in society.

Several authors, as well as international institutions, emphasize the importance of promoting information literacy aiming at the reduction of gender barriers limiting women's liberty and autonomy. As a possible development of the information literacy concept, UNESCO proposes the concept of MIL, an approach that emphasizes the communication aspect of information literacy as well as other principles, such as human's rights, attention to cultural diversity, and to the rights of societal segments, as it is the case of women's rights (Moeler, 2011, Web Foundation, 2016). Focusing on the gender issue, we point out here that communication abilities are especially relevant for the empowerment of women. The social networks and social media sites are, according to Paris Declaration on Media and Information Literacy in the Digital Age (2014), referenced as new forms of social interaction as well as new rights and participation models such as global citizenship in a digital age.

\section{Methodology}

In this study we focused on aspects of information and communication technology (ICT) use by a representative sample of the Brazilian student population. We considered how the social situation of these youngsters also weighed on their ICT use and how these social factors interacted with gender.

We analysed data from the 2016 survey of the Federal Bureau of Census (IBGE, 2016) that measured aspects of internet use of the Brazilian population. From this survey, which was recently made available to researchers, we selected students enrolled in high school, youngsters with the approximate age of 14 to 18 years. The main focuses of our analyses were measures about types of internet use, considered as indicators of aspects of information literacy.

We present the quantitative analyses, providing new indicators of gender differences in ICT access and use. We will follow this analysis with a qualitative study that will search for factors that can influence girls' information literacy, notably their autonomy and liberty through ICT use.

\section{References}

European Media and Information Literacy (MIL) Forum. (2014). Paris declaration on media and information literacy in the digital age. Paris: Unesco.

IBGE. (2016). Pesquisa nacional por amostra de domicílios. Rio de Janeiro: IBGE.

Moeller, S. et al. (2011). Towards media and information literacy indicators. Paris: Unesco.

Web Foundation. (2016). Women's rights online: Translatins access into empowerment. Stockholm: Sida.

Keywords: information literacy, gender, ICT use 


\title{
Research Data Management in France: Are French Researchers Ready to Face this Issue?
}

\author{
Joumana Boustany \\ DICEN IDF EA 7339, Université Paris-Est Marne-la-Vallée, Paris, France, jboustany@ gmail.com
}

\begin{abstract}
Nowadays research data management is a requirement for any financed project. For the European Commission (2016), Research data has to be findable, accessible, interoperable and reusable (FAIR), and "good research data management is not a goal in itself, but rather the key conduit leading to knowledge discovery and innovation, and to subsequent data and knowledge integration and reuse." The issue of research data is not recent; it started in the year's 2000 with some key actions: In 2004, Ministers of science and technology of OECD countries adopted in Paris the Declaration on Access to Research Data from Public Funding (2004), and as a result, guidelines were published (2007). In this document, OECD defines research data "as factual records (numerical scores, textual records, images and sounds) used as primary sources for scientific research, and that are commonly accepted in the scientific community as necessary to validate research findings."
\end{abstract}

This paper intends to address the issue of research data management in France. Although France is a member of OECD, interest in research data became public only in 2011 when the Ministry of Higher Education and Research implemented a platform for monitoring and providing information about research data ${ }^{1}$. The aim of this platform is to "develop knowledge about research data; raise awareness concerning their importance; to encourage a debate around issues related to research data." Two years later, still under the aegis of the same Ministry, a research infrastructure Huma$\mathrm{Num}^{2}$ has been created "which aims to facilitate the digital turn in humanities and social sciences... It also provides research teams in the Human and Social sciences with a range of utilities to facilitate the processing, access, storage and interoperability of various types of digital data." In addition, it offers a platform, NAKALA, to archive and share research data. But, today, where are French researchers regarding this issue?

This study is part of the broader international project regarding research data management (ReDaM). It uses the survey developed by researchers from Hacetteppe University (Turkey), University Paris-Est Marne-la-Vallée (France) and Northumbria (UK). The questionnaire covers 25 issues under two groups: six demographic questions such as primary role, age, discipline, gender, experience, and institution, and 18 questions concerning data like the type of data, the volume of data used and produced, the source of data, etc. The survey was mailed to more than 50000 nominative accounts of researchers from all universities in France in all disciplines. Due to technical limits of the maximum number of pieces of mail that can be sent per day, the survey was distributed from January $20^{\text {th }}$ to April 20, 2017.

Results will be analyzed using SPSS software, which will allow us to know how things stand for France, and to produce comprehensive knowledge regarding Research Data Management in this country. Are French researchers ready to face issues related to the management of research data? This paper will also address the relationship, if any, between discipline, experience, age and gender, and the way data is managed.

\section{References}

European Commission. Directorate-General for Research \& Innovation. (2016). H2020 Programme: Guidelines on FAIR data management in Horizon 2020. Retrieved May $2, \quad 2018$ from http://ec.europa.eu/research/participants/data/ref/h2020/grants_manual/hi/oa_pilot/h2020-hi-oa-data-mgt_en.pdf

OECD. (2004). Declaration on access to research data from public funding. Retrieved May 2, 2018 from https://legalinstruments.oecd.org/en/instruments/157

OECD. (2007). Principles and Guidelines for Access to Research Data from Public Funding. Retrieved May 2, 2018 from https://www.oecd.org/sti/sci-tech/38500813.pdf

Keywords: research data management, France, open science

\footnotetext{
${ }^{1}$ http://www.donneesdelarecherche.fr/

2 http://www.huma-num.fr/about-us
} 


\title{
Developing Health Information Literacy in Disadvantaged and Dependent Circumstances: The Everyday Role of Family Nurses
}

\author{
Steven Buchanan and Emma Nicol \\ University of Strathclyde, Glasgow, UK, steven.buchanan@strath.ac.uk
}

\section{Objectives}

The purpose of this paper is to advance our understanding of the theoretical and practical challenges of developing health information literacy (understood as information literacy in the health context) amongst disadvantaged (socioeconomic) and dependent (support) populations, and from the perspective of professional's outside of information professions occupying community-based support roles (e.g. health and social care). Such a perspective is important as two recent information behavior studies by Buchanan with at-risk (health and wellbeing) groups in areas of multiple deprivations (e.g., employment, education, health, crime) evidence general disengagement with information professions (e.g., librarians, educators) and associated structured learning programmes, and a localised dependence upon support workers when seeking everyday information (Buchanan \& Tuckerman, 2016; Buchanan et al, 2018). Buchanan, et al. (2018) define an important information intermediary role amongst support workers outwith information professions, variously pivotal to information needs recognition, information sourcing, and information comprehension in situations of problematic needs, insular existence, and poor comprehension. Both studies highlight low information literacy (IL) as a significant barrier to the meeting of health information needs, and in consideration of dependence upon intermediaries, raise questions regarding IL education in disadvantaged and disengaged populations, and the role of non-information professionals engaged in everyday support roles.

\section{Methodology}

We explore IL education at the intersection of workplace IL and everyday life IL, and interplays between. Our approach was exploratory and qualitative in nature. Our primary data collection methods were observation, semistructured interviews, and focus group, conducted over six months, and designed to explore support worker understanding of IL, approaches to (or not) the development of IL in their clients, and influencing factors. Data analysis incorporated deductive and inductive elements, with data disaggregated into meaningful categories via identification of patterns and regularities through iterative pattern coding and thematic analysis. Our participants were a team of UK National Health Service Family Nurse Partnership nurses providing intensive one-to-one outreach (home visit) parenting support to vulnerable first-time young mothers from areas of multiple deprivations.

\section{Outcomes}

Our family nurse participants, as information intermediaries, play a key role in recognising, understanding, and meeting the health information needs of young mothers. An important support role is evident, but with limited evidence of transitions to independent information seeking or underpinning pedagogical IL practices to achieve such goals. Our participants all believe that they have an important role in developing self-efficacy in young mothers, but are the majority are unfamiliar with IL concepts, have not received any IL training, and are not familiar with any IL frameworks. Consequently, their confidence in their own ability to develop IL skills in young mothers is limited. Further challenges include how to incorporate IL skills development into primary care responsibilities and prioritised parental learning outcomes, and enduring issues of digital access. Our findings evidence an important IL role outside of traditional information professions and call for further research into appropriate pedagogical approaches to IL education that are adaptable to semi-structured everyday situations and implementable by non-information professionals. We raise important questions regarding approaches to developing health information literacy in at-risk populations.

\section{References}

Buchanan, S., \& Tuckerman, L. (2016). The information behaviours of disadvantaged and disengaged adolescents. Journal of Documentation, 72(3), 527-548.

Buchanan, S., Jardine, C., \& Ruthven, I. (2018). Information behaviours in disadvantaged and dependent circumstances and the role of information intermediaries. [In submission].

Keywords: information literacy, health information literacy, information behaviour, information intermediary 


\title{
A Phenomenological Imperative for Information Literacy
}

\author{
John M. Budd \\ University of Missouri, MO, USA, buddj@missouri.edu
}

\author{
Anna Suorsa \\ University of Oulu, Finland
}

The Framework for Information Literacy in Higher Education expresses a new way of envisioning what information literacy is and what it aims to accomplish. The definition states, "Information literacy is the set of integrated abilities encompassing the reflective discovery of information, the understanding of how information is produced and valued, and the use of information in creating new knowledge and participating ethically in communities of learning" (ACRL, 2016, p. 2). A particular means of achieving results is presented. It is readily admitted that a set of skills must be a component of information literacy instruction, but it is also proposed that a way of thinking about information, informing, an individual's relation to information and to the sources of information (speakers) is needed.

What is required here in this proposal is a rationale for incorporating phenomenology into information literacy. According to Sokolowski (2000), "Phenomenology is the study of human experience and of the ways things present themselves to us in and through such experiences" (p. 2). That is a simplistic definition; particulars will clarify how phenomenology relates closely to information literacy instruction. For example, Smith (1999) advocates for a naturalized intentionality. There are some essential elements of phenomenology that illustrate the connection: intentionality, ontology, and, especially, the phenomenological attitude, which students should be instructed to adopt. The phenomenological attitude is not so simple; among other things, it necessitates apprehending the natural world in a particular manner: "The manner in which we accept the things in the world, and the world itself, is one of belief. As we experience other people. . . we experience them as being there, as true, as real" (Sokolowki, 2000, p. 45). The experience of the "true" refers to experience of people and what is presented as it is.

Why phenomenology, and what can it promise? As Husserl (1973) notes, "this new philosophy seeks nothing less than to encompass, in the unity of a theoretical system, all meaningful questions in a rigorous scientific manner" (pp. 8-9). As Merleau-Ponty (1962) asserts, phenomenology relies on rationality to perceive the world as it is presented to us. Husserl (1973) (and Merleau-Ponty) also calls upon reason as the means by which we are able to apprehend what is. What all this means for instruction is that students are trained to employ reason to see things as they are. This includes the truth of an assertion or a proposition. Students thus trained are able to assess truth as what is; truth is not opinion, but is the foundation of knowledge and the antithesis of psychologism. The assessment is key in applying phenomenology in order to become conscious of what is said or written. The presentation will make clear that the essentials of phenomenology give students the wherewithal to evaluate information as it is given, and to perceive what is true. Students will engage in the exercise "what it is like" to explore different assessments of topics. The phenomenological exercise will enable students to explore the reasons and rationale for holding certain beliefs and building their actions around those beliefs. Evaluation of propositions is a major element of the project.

\section{References}

ACRL. (2016). Framework for information literacy in higher education. Chicago: ACRL.

Husserl, E. (1973). The crisis of European sciences and transcendental phenomenology. Evanston: Northwestern University Press. Merleau-Ponty, M. (1962). Phenomenology of perception. London: Routledge.

Smith, D. W. (1999). Intentionality naturalized?. In J. Petitot et al. (Eds.), Naturalizing Phenomenology: Issues in Contemporary Phenomenology and Cognitive Science (pp. 83-110). Stanford: Stanford University Press.

Sokolowski, R. (2000). Introduction to phenomenology. Cambridge: Cambridge University Press.

Keywords: phenomenology, truth, rationality, Husserl, Merleau-Ponty 


\title{
Disciplinary Contexts in Research Data Management: A Case-Study of Three Disciplines
}

\author{
Maryam Bugaje and Gobinda Chowdhury \\ Northumbria University, Newcastle, UK, \{maryam.bugaje; gobinda.chowdhury\}@ northumbria.ac.uk
}

\section{Introduction \& Aims of Study}

It is generally established that fundamental differences exist between disciplines with respect to norms, research methodologies, research processes, and communication patterns. (Borgman, 2015). The same with respect to research data management (RDM), however, is less established, although recent studies demonstrate that significant gaps exist amongst researchers' awareness of, and preparedness for, RDM (http://ecil2017.ilconf.org/wpcontent/uploads/sites/6/2017/09/ECIL-2017-Book-of-abstracts.pdf; Chowdhury et al, 2017). This paper reports on a study that aims to obtain an in-depth, descriptive, and discipline-specific appreciation of researchers' experiences, attitudes, and habits concerning research data products in the day-to-day course of their work with a view to discovering any inter or intra-disciplinary similarities dissimilarities and similarities. More specifically, we aim to: a) Ascertain as to the existence of shared values, norms, and data attributes within disciplines, as well as inter-disciplinary differences that bear special importance to RDM; b) Understand how researchers approach the task of sourcing, using, disseminating, and/or disposing of their research datasets, with particular focus on points that bear on research data repositories; c) Discover the opinions and perceptions of researchers as regards the ethics, perceived sensitivity, and sharing of their research datasets.

\section{Methodology and Findings}

The study was conducted in the form of semi-structured, face-to-face, interviews with 18 researchers, 6 each from the departments of History, Solar Physics, and Information Science at a University in UK. The selection of these three disciplines was guided by the motive to ensure diversity by studying representatives from two opposite ends of the disciplinary spectrum, as exemplified in the sharp contrasts between the History and Solar Physics disciplines on several points including method of data collection/generation, types and size of data, and conformity to metadata standards. Information Science, possessing a mix of attributes and characteristics from both extremes, was included as a middle-ground. To ensure a fuller representation within each discipline, interviewees were chosen from academic staff, postdoctoral fellows, and doctoral students. A thematic analysis of transcripts was undertaken.

Our findings confirm a priori observations obtained by preliminary studies on the subject, revealing marked dissimilarities between the disciplines sampled. The principal similarity that cuts across all three disciplines is the reluctance of researchers to do manual operations, such as tagging and annotation of datasets, unless these prove absolutely necessary and even then, to follow intuitive and spontaneous personal methods rather than standard schemas and/or conventions. Key findings of our study are summarized under the following thematic headings: a) Resource requirements: This refers to the need for extensive and/or advanced computing resources for data processing and storage, which showed itself particularly prevalent among our Solar Physics subjects; b) Data attributes: Includes such details as data size (in MB, GB, and TB), type (file extensions) and format (digital vs physical data, such as manuscripts; qualitative/narrative data vs quantitative/numeric data), depending on the discipline; c) Norms and community dynamics: This pertains to, amongst others, the presence or absence of a data-sharing culture, which seemed weakest among our History subjects; team-orientation which seemed strongest in Solar Physics; and d) Data sourcing \& dissemination: This relates to the origin of the data (e.g. computer simulation), the method(s) of collection (e.g. manually or by the use of machine), and the channels through which data is shared. Our Solar Physics subjects, for instance, mostly use FTP while others create their own data or download from known sources.

\section{References}

Borgman, C. (2015). Big data, little data, no data: Scholarship in the networked world. Cambridge: The MIT Press.

Chowdhury, G. et al. (2017). Preparedness for research data sharing: A study of university researchers in three European countries. In S. Choemprayong et al. (Eds.), Digital Libraries: Data, Information, and Knowledge for Digital Lives: 19th International Conference on Asia-Pacific Digital Libraries, ICADL 2017, Bangkok, Thailand, November 13-15, 2017: Proceedings (pp. 104116). Cham: Springer.

Keywords: research data management, user behaviour, metadata 


\title{
An Invitation to Globalize the Information Literacy Agenda: Expanding Discourse
}

\author{
Sergio Chaparro and Zachary Newell \\ Salem State University, MA, USA, schaparrouniva@salemstate.edu, zlnewell@gmail.com
}

This paper attempts to investigate and discuss concepts of information literacy in light of global challenges to information access, the pervasiveness of educational inequalities, and the culture of informality that affects information consumers across spectrums around the world. We explore the possibility that these factors suggest a need to refine IL as a way of increasing its impact for the everyday citizen and expanding its mostly inside-the-classroom effect. We also propose the need to investigate the role of social media in normalizing misinformation and disinformation for everyday citizens in developing nations - what the authors see as dysfunctional information scenarios (DIS), where the majority of news is retrieved through contaminated channels. In turn, these problems erode the basic principles of both democracy and Information Literacy and point to a need for IL educators to do more to expand the reach of information literacies across socioeconomic, cultural and political divides.

The authors apply lessons from varied professional and cultural contexts to argue that we need to move beyond the exclusive standards and frameworks that have traditionally been used in formal contexts of IL to consider a more widespread application for information literacy in more varied and flexible contexts and spheres. As the fake news crisis has made clear, dictates of IL are not necessarily universally applicable to the way information consumption/mediation takes place in everyday contexts. An examination of the literature suggests that most of the information literacy we teach inside the classroom is situational and pertains only to the subjects as it relates to specific coursework.

The authors propose a reconsideration of information literacy that takes into account the realities of access and consumption in scenarios and contexts where information access is limited. The authors will consider opportunities for IL as a Human Right within a rich media/digital context, re-examine democratic principles at work around the globe in outlining opportunities in considering educational opportunities and authentic dialogue in the public sphere the way the "street pedestrian" or otherwise dubbed "information poor" accesses and understands information - and provide a re-application and expansion of what it means for IL to be socially enacted and in what expanding contexts it is possible. The authors argue that practitioners and educators must further enact information literacy to better promote social, intellectual and personal agency - as a proper mental shelter, addressed at all stages of life, to address discrepancies between those more and less privileged.

Keywords: public sphere, human rights, socially enacted information literacy, information poor 


\section{The Politicisation of Information Literacy}

\section{John Crawford}

The Right Information: Information literacy skills for a $21^{\text {st }}$ century, Glasgow, Scotland. johncrawford705@yahoo.co.uk

\section{Need and Objectives}

Politics and information literacy is a relatively unstudied area but has come to prominence relatively recently as indicated by presentations at the 2017 ECIL conference, although the issue itself is hardly new. The proposal reviews the issues and offers suggestions as to how to take the matter forward.

\section{Methodology}

Definitions, terminology and keywords are a problem. The Alexandria Proclamation (Garner 2005) discusses a wide range of issues beyond education but focuses primarily on governance and citizenship and the discussion is primarily a range of reported expert views. Political literacy is not a used term. In an extremely helpful review of the literature of Everyday Life Information Seeking (ELIS) Martzoukou and Abdi (2017) situate civic participation as part of ELIS but note that the broad area of 'citizenship' issues has not attracted much interest although citizenship is an important issue. Behind this lies a historic 'underinvestment 'in IL research outside education. A study by Whitworth (2014) revealed that $60 \%$ of the IL literature is found within the context of higher education. It is worth noting in this context that $6.5 \%$ of the world's population is university graduates while the world's population is over 7.6 billion. Battista et al (2017) found unambiguous connections between social justice, human rights, and information literacy. At the first ECIL conference in Istanbul, Paul Zurkowski delivered a notable keynote which discussed political issues but seemed to have little long-term impact. There were however, several presentations on the subject of 'fake news' at the 2017 conference, this being apparently a preferred term to political literacy. Situating political literacy therefore seems to be a somewhat imprecise activity. There is no precise definition of political literacy although Smith and McMenemy (2017) discuss the nature of 'political information'.

\section{Outcomes}

In achieving progress in the development of political literacy scope and definitions need to be better understood. Several strategies are possible. Appropriate strategies will be discussed including working with secondary education, raising awareness among politicians and harnessing the ethical values of the information professionals, especially among public librarians.

\section{References}

Battista, A. et al. (2015). Seeking social justice in the ACRL framework. Communications in Information Literacy, 9(2), 111-125.

Garner, S. D. (2005). High-level colloquium on information literacy and lifelong learning. Retrieved January 19, 2018 from http://www.ifla.org/publications/high-level-colloquium-on-information-literacy-and-lifelong-learning

Martzoukou, K., \& Abdi, E. S. (2017). Towards an everyday information literacy mindset: A review of literature. Journal of Documentation, 73(4), 634-665.

Smith, L. N., \& McMenemy, D. (2017). Young people's conceptions of political information: Insights into information experiences and implications for intervention. Journal of Documentation, 73(5), 877-902.

Whitworth, A. (2014). Radical information literacy: Reclaiming the political heart of the IL movement. Oxford: Chandos Publishing.

Keywords: information literacy, fake news, political literacy, citizenship 


\title{
Gaming for Multiliteracies: Video Games in a Case Study with Primary School Students to Enhance Information, Visual and Media Literacies
}

\author{
Eduardo Cruz-Palacios and Miguel Ángel Marzal García-Quismondo \\ Universidad Carlos III de Madrid, Getafe, Spain, eduardocruzpalacios@gmail.com, mmarzal@bib.uc3m.es
}

\section{Objectives}

The aims are to:

- Evaluate the effectiveness of video games when learning information, visual and media literacies competences;

- $\quad$ study how to use video games on educational contexts;

- $\quad$ carry through a program with primary school students; and

- draw recommendations to design similar projects.

\section{Methodology}

The competence-based 21st Century Education and pedagogical potential of video games are analyzed from a Multiliteracies perspective. A program aimed at primary school students for the learning of information, media and visual literacies competences is designed. The European Union Digital Competence Framework for Citizens (2017), the curricula reform of Wales (2018), and the American College and Research Libraries Visual Literacy Framework (ACRL, 2011) have been used to design the program. Video games are used as digital objects, context, environment and media to make students of Miguel Hernández school (Fuenlabrada, Spain) do projects library catalogs, museum collections, blogs and social networking sites. Learning outcomes are measured by analysing the activities undertaken as well as direct observation.

\section{Outcomes}

Video games are utmost effective didactic materials to increase student motivation to learn, understand complex ideas, and engage in projects. Although this program has considerably helped students develop their information, media and visual literacies, it lacks the scalable, global and integrated dimension to achieve literate students for the 21 st century, so it is necessary to integrate these competences transversally into curricula. Taking into consideration the educational perspective when using video games on learning processes improved the design and development of the program. Recommendations to design and develop similar projects are given in terms of organizing pedagogical activities, considering learners' habits of playing video games and the consoles they owe, suggesting the use of blogs and wikis as didactic materials, and managing digital repositories destined to learning objects that comprise video games.

\section{References}

ACRL (2011). ACRL Visual Literacy Competency Standards for Higher Education. Retrieved June 27, 2018 from http://www.ala.org/acrl/standards/visualliteracy

European Union. (2017). Digital competence framework for citizens. Retrieved March 25, 2018 from https://ec.europa.eu/jrc/en/digcomp/digital-competence-framework

Wales (2018). Digital Competence Framework. Retrieved June 27, 2018 from http://learning.gov.wales/resources/browseall/digital-competence-framework/?lang=en

Keywords: multiliteracies, competence education, information literacy, visual literacy, media literacy, gaming, video games 


\title{
Developing Food and Nutrition Literacy with the Croatian Facebook Group, "Homemade Food for Babies"
}

\author{
Drahomira Cupar and Mate Juric \\ University of Zadar, Croatia, \{dcupar, mjuric $\} @$ unizd.hr
}

Food literacy and nutrition literacy might look like new buzz words in the already long list of literacies. However, food choices are important in the context of healthy living. There is a large amount of information about preparing meals at home as many professional and amateur chefs, fitness trainers, and doctors have joined efforts in informing people how to prepare healthy meals. Parents play a crucial role in supporting healthy eating habits of their children, and the possible influence of the Facebook groups on their food choices is worth investigating.

The concepts of food literacy and nutrition literacy are specific forms of health literacy (Krause et al., 2016; Gibbs et al. 2016). Nutrition literacy focuses on the understanding of nutrition information. Krause et al. (2016) concluded that food literacy additionally includes applying information on food choices and critically reflecting on the effect of food choices on personal health. In the context of participatory digital environments, it is important to take into account the additional concepts of collaborative producing and sharing activities from the metaliteracy framework (Mackey and Jacobson, 2011). The core ideas of information literacy are present in all of the mentioned literacies.

This research is analyzing a specialized Croatian Facebook group with more than 108.000 members named "Homemade food for babies." Some of the administrators are educated in the field of nutrition, and the group follows the World Health Organization's recommendations how to introduce food to babies. Members contribute with their recipes but also ask for advice and collaboratively discuss nutrition and related topics. The aim of this research is to analyze possible benefits for the group members in changing their attitudes and perceived behavior related to food and nutrition literacy. The research questions are: 1) which topics are represented in the group documents? 2) What challenges the users and administrators are facing when seeking and sharing verified information? 3) How do users perceive the benefits from the group, specifically their behavioral changes towards healthier food choices? A multimethod approach is applied with content analysis of 131 group documents, a survey with 1081 members of the group, and an interview with the main administrator. The results imply that the group is highly valued by the majority of the surveyed group members and has a profound perceived impact on their everyday food choices. The group documents contain descriptions of nutritive values and ways of preparing meals, specific nutrition diet for health problems, and related topics. The main administrator uses credible sources to give informed advices. The challenges that the users and the main administrator are facing when seeking and sharing information include sometimes-false information from unverified sources, especially regarding food allergies, and opposite advices from various experts. Based on the results of factor analyses of the survey data, perceived food literacy is operationalised as a combination of nutritive literacy and healthy cooking behavior. The parents that are often using the group content (recipes, guidelines, advice) are enhancing their perceived food literacy. Visibly active participation and membership duration are less beneficial. Reading the group documents is crucial for nutrition literacy, and using the recipes is important for healthy cooking behavior. Additionally, motivation and using expert advice are predictors of both of those components of food literacy. In conclusion, the users that are engaged in using the group contents are enhancing their perceived food literacy, by improving nutrition literacy aspects of seeking and choosing the credible information, and by refining their healthy cooking behavior.

\section{References}

Gibbs, H. D. et al. (2016). Assessing the nutrition literacy of parents and its relationship with child diet quality. Journal of Nutrition Education and Behavior, 48(7), 505-509.

Krause, C. et al. (2016). Just a subtle difference?: Findings from a systematic review on definitions of nutrition literacy and food literacy. Health Promotion International. Retrieved from https://academic.oup.com/heapro/advancearticle/doi/10.1093/heapro/daw084/2572039

Mackey, T. P., \& Jacobson, T. E. (2011). Reframing information literacy as a metaliteracy. College \& Research Libraries, 72(1), $62-78$

Keywords: food literacy, nutritional literacy, information literacy, metaliteracy, health literacy, Facebook group, parents 


\title{
Relationship between Media Literacy and Civic Participation among Young Adults in Latvia
}

\author{
Agnese Davidsone and Vineta Silkane \\ Vidzeme University of Applied Sciences, Valmiera, Latvia, agnese.davidsone@va.lv
}

Scholars often assume that nowadays media and information literacy is an increasingly necessary life-skill in order to be successfully engaged and active in civic and political processes, both offline and online. As Mihailidis (2014) has argued, media literacy is a crucial aspect of the development of participatory democracy. The most popular notions of media and information literacy for active civic participation include the abilities of individuals to access, to gather, and to analyze information in various formats and platforms, to create informed opinions, and to share their perspectives with others, again, by using a variety of platforms and formats. In short, it is understood as a multidimensional concept, simultaneously containing the abilities for information consumption and production (prosumption).

Studies examining the relationships between different aspects of media literacy and active citizenship remain limited. Thus, we seek to address these gaps in our understanding by asking the following question: What are the relationships between practices of civic participation and the different dimensions of media literacy?

In our empirical work, we rely on the framework developed by Koc and Barut (2016) on four sub-segments of media literacy:

1. functional consumption

2. critical consumption

3. functional prosumption, and

4. critical prosumption.

The study is based on an online survey of 406 respondents ( $36 \%$ male respondents and $64 \%$ female respondents) in the age group of $18-30(\mathrm{M}=22.22, \mathrm{SD}=3.35)$. We measure respondents' media literacy and civic activity, as well as sociodemographic data such as age and education. The survey combines a New Media Literacy Scale (Koc \& Barut, 2016) and an original Civic Participation Scale which was developed during the study. Results show civic activity (F $(7,398)=14.60, \mathrm{p}<.001)$ being predicted only by the level of education $(\beta=.22, \mathrm{p}<.001)$, and the two sub-segments of presumption in media literacy scale: functional presumption $(\beta=.15, \mathrm{p}<.05)$, and critical presumption $(\beta=.20$, p $<.001)$.

Based on our results, we argue for media literacy promotion in school and university curricula, with an increased emphasis on various practices of information production and sharing as forms of self-expression, and prosumption being a vital part of active citizenship and citizen engagement. Furthermore, media literacy provides opportunities to be more informed and more able to form an opinion (to be a skilled media consumer), but it does not automatically guarantee increase in civic participation. Consequently, more research and empirical evidence is needed to examine the relationships between active citizenship and the various dimensions of media literacy, especially those related to media prosumption.

\section{References}

Koc, M., \& Barut, E. (2016). Development and validation of New Media Literacy Scale (NMLS) for university students. Computers in Human Behavior, 63, 834-843.

Mihailidis, P. (2014). Media literacy and the emerging citizen: Youth, engagement and participation in digital culture. New York: Peter Lang Publishing.

Keywords: media literacy, media consumption, media prosumption, civic participation, participatory democracy 


\title{
Information Literacy Self-Efficacy of Medical Students: A Longitudinal Study
}

\author{
Ann De Meulemeester and Jan De Maeseneer \\ Ghent University, Ghent, Belgium, \{ann2.demeulemeester, jan.demaeseneer\}@ugent.be \\ Sven De Maeyer \\ University of Antwerp, Antwerp, Belgium, sven.demaeyer@uantwerpen.be \\ Renaat Peleman and Heidi Buysse \\ Ghent University, Ghent, Belgium, \{renaat.peleman, heidi.buysse \} @ugent.be
}

\section{Objectives}

Medical curricula are investing more and more in educating students as lifelong reflective learners, so they can confidently find, select and use qualitative information within the context of clinical decision-making. The research analyses the development of medical students' information literacy self-efficacy and measures the differences between study years.

\section{Methods}

Data has been collected within a 6-year curriculum (mean n/academic year: 1192 students), for four continuous academic years (2011-2015). Students evaluated their information literacy self-efficacy on a validated information literacy self-efficacy scale for medicine (De Meulemeester, Peleman, \& Buysse, 2018; In press). In 2016, the research was finalised with a qualitative part to contextualise the quantitative results. Statistical analyses were performed, and a validated 5-factor model was used as subscales (S): 'Evaluating and Processing Information' (S1); 'Medical Information Literacy Skills' (S2); 'Searching and Finding Information' (S3); 'Using the Library' (S4); and 'Bibliography' (S5).

\section{Outcomes}

The results confirm the impact of training and practice on the students' information literacy self-efficacy, especially for the subscales S2, S4 and S5. The development towards more specialised information literacy skills seems to influence students' awareness and thus self-efficacy. Furthermore, the information literacy self-efficacy increases overall in more recent academic years. This research proposes the need to integrate information literacy skills in the curriculum at the right time, at different key moments and adjusted by level. It could be hypothesised that continuous, integrated education with practice and feedback from peers is needed to develop and retain medical student's information literacy self-efficacy.

\section{References}

De Meulemeester, A., Peleman, R., \& Buysse, H. (2018). Development and validation of an Information Literacy Self-Efficacy Scale for Medical Students. Journal of Information Literacy, 12(1), 27-47.

Keywords: information literacy self-efficacy, higher education, medical curriculum, longitudinal study, information literacy scale for medicine 


\title{
Impact of Purposefully Designed Learning Activities in the Case of Information Literacy Self-Efficacy
}

\author{
Ann De Meulemeester, Renaat Peleman and Heidi Buysse \\ Ghent University, Ghent, Belgium, \{ann2.demeulemeester, renaat.peleman, heidi.buysse\}@ugent.be
}

\section{Objective}

Developing the information literacy skills of medical students is one of the basic skills to become lifelong learners. Furthermore, integrating practice enhances students' learning. The information literacy course at the medical faculty at Ghent University has been adapted throughout the years from a more theoretical-oriented course to a theoreticalpractical integrated course. Because of the huge amount of information literacy skills that have to be taught, it was difficult to reach the learning goals. To design an effective course, it was needed to analyse which topics could be an added value to the integrated course and would enhance students' information literacy self-efficacy.

\section{Method}

The study focuses on the development of a first-year integrated information literacy course for medical students during three consecutive academic years. The course is given by an expert information literacy teacher. Each year, new topics (e.g. personal searching-report, peer review) were systematically added to the course, and students were invited to find out about their own information literacy skills. Students filled in a validated information literacy self-efficacy scale for medicine, encompassing five subscales (De Meulemeester, Peleman, \& Buysse, In Press 2018), at the beginning of the course (pre-intervention) and at the end of it (post-intervention).

\section{Results}

For all subscales and for the total scale, a statistically significant effect is found for "academic year" on postintervention score. Post-hoc testing showed that integrating a search-report has a significant positive effect for all subscales. For the subscale 'Medical information literacy skills', a significant positive difference is found for the academic year in which a peer review was introduced. Integrating personal experience has an undeniable impact on medical students' information literacy self-efficacy and should be further stimulated in the educational design. Integrating information literacy, within the context relevant for the student, enhances students' learning. Performing a peer review impacts the information literacy self-efficacy related to the specific medical information literacy skills and should therefore be further integrated in the course. Teachers need to evaluate the impact of course development continuously, as not all adaptations always have the expected impact.

\section{References}

De Meulemeester, A., Peleman, R., \& Buysse, H. (2018). Development and validation of an Information Literacy Self-Efficacy Scale for Medical Students. Journal of Information Literacy, 12(1), 27-47.

Keywords: information literacy self-efficacy, medical education, higher education, pre- and post-implementation, information literacy self-efficacy scale for medicine 


\title{
An Exploration of Information Literacy as a Form of Deweyan Inquiry
}

\author{
Brendan Devlin \\ Dublin Institute of Technology, Ireland, brendan.devlin@dit.ie
}

\section{Objectives}

The objective of this paper is to consider information literacy as a form of inquiry as described by John Dewey (1938). Dewey considers inquiry as a form of educative experience that parallels the manner in which an organism engages or more accurately transacts in its environment. Inquiry in these terms acknowledges the impact of the biological, social and cultural engagement of the subject in their environment. The subject in these terms shapes and is shaped by their environment. Biological and cultural elements are implicated in all inquiry. Inquiry does not concern the apprehension of a fixed universe. It concerns instead, an enactive realisation of the world based on our transactions with it. These ideas will inform a reconsideration of the nature of the process of information literacy.

\section{Methodology}

The paper will consider how these ideas provide an alternative perspective of ontology and epistemology underpinning information literacy. It thus provides a different understanding of the construct. The author will approach this task by examining the ideas registered in Dewey (1938) and other texts including, Dewey (1933) and commentaries on these texts. The author will also examine selective texts pertaining to information literacy including Secker (2013). The intent is to contrast the ideas in this paper with those of other commentators on information literacy.

\section{Outcomes}

What will emerge from this investigation is a recalibration of the underlying ontology and epistemology pertaining to information literacy. Ontology is described by Johnson and Christensen (2012 p.590) as "... the branch of philosophy dealing with the nature of reality and truth." The implication of Dewey's (1938) philosophy is that our understanding of the world is only possible through our transactions with it. Epistemology is described by Sikes (2004 p.21) as "...what constitutes knowledge and what it is possible to know and understand" and what we can know depends on our enactive engagement with the world. The continuity between the biological and intellectual aspects of Deweyan inquiry acknowledges the situated and embodied aspects of inquiry. Reconsidering information literacy as a form of Deweyan inquiry provides a different view of information use. The methods for finding and manipulating information are considered as tools of inquiry as is information per se. To be information literate involves the capacity to persistently develop a more expansive view of our world.

\section{References}

Dewey, J. (1933). How we think: A restatement of the relation of reflective thinking to the educative process. Lexington, MA: D.C. Heath and Company.

Dewey, J. (1938). Logic: The theory of inquiry. New York: Holt, Rinehart and Winston.

Johnson, B., \& Christensen, L. (2012). Educational research: Quantitative, qualitative and mixed approaches (4th ed.). Los Angeles: Sage.

Secker, J. (2013). Rethinking information literacy: A practical framework for supporting learners. London: Facet.

Sikes, P. (2004). Methodology, procedures and ethical concerns. In C. Opie (Ed.), Doing Educational Research (pp. 15-33). London: Sage Publications Inc.

Keywords: deweyan inquiry, information literacy, restructuring, enaction, embodiment, philosophy 


\title{
Information Literacy of University Freshmen, and Differences in ICT Use, Internet Confidence, and Motivation
}

\author{
Danica Dolničar and Bojana Boh Podgornik \\ University of Ljubljana, Slovenia, \{danica.dolnicar, bojana.boh\}@ntf.uni-lj.si
}

Students enroll in university from diverse educational backgrounds, potentially possessing differing levels of information literacy (IL) and related skills. IL education aims to prepare all students for academic work, so it i's important to assess their initial knowledge and investigate the differences as well as personal factors, such as motivation, in order to better address the gaps. Our study examined variations in IL of the first-year university students with regard to their IL scores, use of information and communication technologies (ICT), Internet confidence, and motivation. One hundred and twenty-six freshmen majoring in chemical education took a verified information literacy test (ILT) (Boh et al., 2016), a motivation questionnaire (Juriševič et al., 2016), and an ICT use and Internet confidence questionnaire (Šorgo et al., 2016). Based on ILT results, the students were divided into two groups - a weaker (lower half) and a stronger (upper half), with 65 and 61 students respectively. Results of ICT use, Internet confidence, and motivation questionnaires were compared to identify and better understand the differences between the weaker and stronger group, as well as differences in students' IL according to individual ILT items, five ACRL standards, and cognitive levels. T-tests on the scale/subscale level and chi-square tests on the item level were used to compare the two groups.

Results show that the stronger and the weaker group differed significantly in total IL level (respective means of $77.46 \%$ and 57.38\%). The differences were most evident in the database search (ACRL standard 2, mean difference 26.44\%) and in the IL legal/ethical issues (ACRL standard 5, 23.11\%). Students from the stronger group were significantly more successful in half of the test items: with a quarter of items the difference in correctness was larger than $30 \%$, particularly in the areas of referencing, understanding the role of abstracts in the structure of scientific articles, evaluating literature sources, using scientific search engines, and preparing effective search queries. The same group was significantly more confident using the Internet, especially using discussion forums for problem solving and sharing their knowledge on the Internet. The overall differences in ICT use were small between the two groups (significant only in the use of office tools and skype/email), suggesting that the use of ICT per se did not contribute to a higher level of IL. The motivation levels of the two groups were similar. However, the IL stronger group had a higher self-concept for problem solving and, at the same time, a lower level of controlled external motivation, suggesting that their motivation did not primarily depend on external factors. In turn, the students who relied on motivation from teachers were less successful. These results may contribute towards a better understanding of factors affecting students' IL. The findings may be applied by higher education specialists in preparing IL courses, their content and teaching styles and particularly in helping weaker students to achieve higher levels of IL.

\section{Acknowledgements}

The study was financially supported by the Slovenian Research Agency, projects J5-5535 and J5-8230.

\section{References}

Boh Podgornik, B. et al. (2016). Development, testing, and validation of an information literacy test (ILT) for higher education. Journal of the Association for Information Science and Technology, 67(10), 2420-2436.

Juriševič, M. et al. (2016). Motivational aspects of information literacy in higher education. Presented at The International Conference on Excellence \& Innovation in Basic-Higher Education \& Psychology, Rijeka, Croatia, May 18-21, 2016.

Šorgo, A. et al. (2016). Attributes of digital natives as predictors of information literacy in higher education. British Journal of Educational Technology, 48(3), 749-767.

Keywords: information literacy, higher education, freshmen, ICT use, internet confidence, motivation 


\title{
Examining Subject-specific Information Literacy Elements on Economics and Business Administration for Use in a MOOC
}

\author{
Stefan Dreisiebner \\ University of Graz, Austria, stefan.dreisiebner@uni-graz.at
}

\section{Objectives}

Recent literature on developing Information Literacy (IL) of students suggests that curricula should not only involve generic skills, but also knowledge about subject-specific content and research practices (Grafstein, 2002). While there are already several studies, which examine the IL skills of business students (Maurer, Schlögl, \& Dreisiebner, 2016), workplace requirements (Klusek \& Bornstein, 2006) or discuss various teaching approaches (Atwong \& Taylor, 2008), no thorough analysis has been performed so far identifying the main knowledge areas that are addressed in various IL teaching materials for economics and business administration. Therefore, the aim of this study is to answer the following research question: What are the most common knowledge areas emphasized in subject-specific teaching materials on IL for economics and business administration?

MOOCs (Massive Open Online Courses) are freely available online courses with no entry barriers aiming at unlimited participation that are increasingly gaining popular for providing IL courses (Gore, 2014). Nevertheless, these IL MOOCs usually provide generic learning materials and do not emphasize subject-specific contents (Dreisiebner \& Mandl, 2017). Therefore, in a next step, the results of the analysis are used to suggest the content of a subject-specific extension on economics and business administration for a generic MOOC.

\section{Methodology and Outcomes}

Several subject-specific teaching materials on IL for economics and business administration, available either as a book or publicly available online resource, are observed through a qualitative content analysis. The results show that most subject-specific IL teaching materials for economics and business administration focus on databases, web platforms and specialized library catalogues. In addition, citation indexes, rankings, citation styles and conference directories are mentioned.

The results build the basis for the content framework of a MOOC extension that will be proposed in the full paper. This extension represents an additional chapter for an existing MOOC on generic IL skills for higher education students that is currently developed within an Erasmus+ Strategic Partnership project (Dreisiebner \& Mandl, 2017).

\section{References}

Atwong, C., \& Taylor, L. (2008). Integrating information literacy into business education: A successful case of faculty-librarian collaboration. Journal of Business and Finance Librarianship, 13(4), 433-448.

Dreisiebner, S., \& Mandl, T. (2017). Development and evaluation of a platform teaching information competence: Presentation of 'Information Literacy Online', a project promoted by the European Union. Bibliotheksdienst, 51(9), 763-770.

Gore, H. (2014). Massive Open Online Courses (MOOCs) and their impact on academic library services: Exploring the issues and challenges. New Review of Academic Librarianship, 20(1), 4-28.

Grafstein, A. (2002). A discipline-based approach to information literacy. The Journal of Academic Librarianship, 28(4), $197-204$.

Klusek, L., \& Bornstein, J. (2006). Information literacy skills for business careers. Journal of Business \& Finance Librarianship, 11(4), 3-21.

Maurer, A., Schlögl, C., \& Dreisiebner, S. (2016). Comparing information literacy of student beginners among different branches of study. Libellarium, 9(2), 309-319.

Keywords: information literacy, subject-specific skills, economics and business, content analysis 


\title{
Effects of New Public Management (NPM) and Austerity in European Public and Academic Libraries
}

\author{
Petra Düren \\ Hamburg University of Applied Sciences, Germany, petra.dueren@haw-hamburg.de \\ Stéphane Goldstein \\ InformAll, UK, sg@informall.org.uk
}

Ane Landøy

University of Bergen Library, Norway, ane.landoy@uib.no

\section{Angela Repanovici}

Transilvania University of Brasov, Romania, arepanovici@unitbv.ro

\section{Jarmo Saarti}

University of Eastern Finland Library, Kuopio, Finland, jarmo.saarti@uef.fi

Libraries as guardians of the quality of information for everyday life have become even more important in a time of rapidly expanding information possibilities. Nowadays, however, information literate citizens must be enabled to reach views on the reliability of information. Information literacy in the public sphere is therefore an important task for libraries. At the same time, new public management (NPM) is changing the way libraries, both public and academic, are expected to act in their local communities (Pors \& Johannsen, 2003). The effects of economic austerity with libraries being closed owing to budgetary constraints must also be taken into account (Düren, Landøy \& Saarti, 2017), as must the neoliberal agenda surrounding libraries.

The changing circumstances call for new leadership, new competences and new approaches to the running of library services. In this paper, the authors will present data from interviews with library leaders from five European countries, about their experiences of changes in libraries as a result of implementing NPM. In the interviews, the leaders were asked if they found ways of training citizens in information literacy. They were also asked how this could be achieved when libraries are squeezed between demands for better service and less funding. The library leaders' experiences in each country are expected to be different, reflecting varying levels of economic austerity, and how closely each country adheres to NPM-theory and practice. The authors will also use national library statistics and data from the libraries where the leaders work, to compare user experiences and usage of the libraries.

While it is evident that the environment and the libraries are changing, it is not clear how the changes will actually impact the drive to make citizens more information literate. We see, for instance, that NPM and reduced budgets can lead to greater cooperation. In itself, this sometimes results in more or even better IL in libraries through bringing in external expertise and even financing.

\section{References}

Düren, P., Landøy, A., \& Saarti, J. (2017). New public management and libraries: A success story or just an excuse for cost reduction. Library Management, 38(8/9), 477-487.

Pors, N. O., \& Johannsen, C. G. (2003). Library directors under cross-pressure between new public management and value-based management. Library Management, 24(1/2), 51-60.

Keywords: new public management, library leadership, Germany, Romania, Finland, UK, Norway 


\title{
Information Behavior of Humanities Students in Bulgaria, Italy and Sweden: Planning a Game-based Learning Approach for Avoiding Fake Content
}

\author{
Marina Encheva and Plamena Zlatkova \\ University of Library Studies and Information Technologies, Sofia, Bulgaria, \{m.encheva, p.zlatkova $\} @$ unibit.bg
}

\author{
Anna Maria Tammaro
}

University of Parma, Italy, annamaria.tammaro@unipr.it

Mats Brenner

University of Gävle, Sweden, mats.brenner@hig.se

\section{Focus of the NAVIGATE Project}

This study presents the Erasmus+ project NAVIGATE - Information Literacy: A Game-based Learning Approach for Avoiding Fake Content, coordinated by the University of Library Studies and Information Technologies in Bulgaria. By applying a game-based approach to information literacy (IL) training of Bachelor's students in humanities in 3 European countries innovation can be brought into this field (Erasmus+ Project Results, 2017). If the new generation of learners does not have markers to navigate within the "staged reality", they will be lost in both the transitive and the literal sense (American Library Association, 2017). This project's use of digital games in IL training in a university environment will stimulate students' active involvement through research, experimentation, competition and cooperation. The traditional understanding of IL will be extended, as the training based on games adds the ability to collaborate in digital environments (Encheva, 2016). The serious games are directly aimed at the changing competencies necessary for the information era which the new generation of students must possess: self-regulation, information skills, network cooperation, strategies for problem solving and critical thinking. As the concepts of Fake News and Fake Content can no longer be regarded as homogeneous phenomena, their in-depth dissection is necessary in order to classify them in terms of their intended purpose, functions, genre typology and initiators. This will help educate students to more easily identify content of unproven and dubious nature. (Encheva et.al., 2018). The results of an empirical sociological survey conducted in the partners' institutions in Bulgaria, Italy and Sweden on the students' understanding of the concepts of IL and their attitude to the inclusion of educational games in the training process are presented. The level of information and digital literacy of the humanities students based on the survey's results is also analysed. One of the working hypotheses of the project team is that implementing a gaming approach in education, including the development of applications and platforms, is a form appropriate to the public dynamics to promote the interest in learning and to reinforce the knowledge gained. Emphasis is placed on the role of the library as a partner in the learning and as a centre for educational innovations. For the analysis of the results of the comparative survey the questions were divided in the following main groups: understanding the combined notions information literacy and mobile literacy; the library in the everyday life of students; approaches to searching for information and results assessment criteria, etc.

\section{References}

American Library Association. (2017). Resolution on access to accurate information. Retrieved February 10, 2018 from http://www.ala.org/advocacy/intfreedom/statementspols/ifresolutions/accurateinformation

Encheva, M. (2016). Teaching information literacy courses in the context of library and information science education in Bulgaria: Challenges and innovative approaches. Journal of Library Administration, 56(5), 592-605.

Encheva, M. et al. (2018). Changing information literacy training of undergraduate students in Europe through the game-based learning approach. In L. Gómez Chova, A. López Martínez, \& I. Candel Torres (Eds.), 12th International Technology, Education and Development Conference, Valencia, 5-7 March 2018 (pp. 587-592). Valencia: IATED Academy.

European Commission. (2017). Erasmus+ projects results platform. Retrieved February 10, 2018 from http://ec.europa.eu/programmes/erasmus-plus/projects/\#search/keyword=game-

based \%20learning\%20approach \&matchAllCountries=false

Keywords: information literacy of students, fake information, game-based learning, comparative survey, Bulgaria, Italy, Sweden 


\title{
Teaching Yourself to Learn: A Case for Incorporating Self-Directed Learning Concepts into Information Literacy Education
}

\author{
Allison Nowicki Estell \\ Wentworth Institute of Technology, Boston, MA, USA, estella@wit.edu
}

The Association of College \& Research Libraries (ACRL) has defined information literacy as "the set of integrated abilities encompassing the reflective discovery of information, the understanding of how information is produced and valued, and the use of information in creating new knowledge and participating ethically in communities of learning" (ACRL, 2015, Introduction). The ACRL's Framework for Information Literacy for Higher Education is designed to help librarians teach students to learn more effectively within the structured environment of higher education, in which arguably most information needs have been determined by the curriculum. But how well does it prepare students to learn once the curriculum is no longer determined by an external teacher? What can information literacy educators do to ensure that students learn to become their own teachers? As students enter their chosen professions and live their lives after the period of their formal education, they will need to set their own learning priorities, not only determining whether they have identified the information they need, but also recognizing when they need to seek information in the first place.

Self-directed learning is a form of learning "in which individuals take the initiative...in diagnosing their learning needs, formulating learning goals, identifying human and material resources for learning, choosing and implementing appropriate learning strategies, and evaluating learning outcomes" (Knowles, 1975, p. 18). Guglielmino discussed selfdirected learning in several contexts, such as formal learning settings, the workplace, and personal life (2008), and other literature has championed self-direction as an element of success in lifelong learning (Candy, 1991). Without a predetermined curriculum or rubric for assessment, self-directed learners become their own teachers, focusing on not just the content they are trying to learn, but also the process by which they learn. Self-directed learners strive to identify the moment and circumstances of their information need, and to evaluate the efficacy of their efforts. This paper examines the ACRL Framework for Information Literacy through the lens of self-directed learning theory and argues for the incorporation of self-directed learning concepts into information literacy education to support lifelong learning.

\section{References}

Association of College and Research Libraries. (2015). Framework for information literacy for higher education. Retrieved February 6, 2018 from http://www.ala.org/acrl/standards/ilframework

Candy, P. C. (1991). Self-direction for lifelong learning: A comprehensive guide to theory and practice. San-Francisco: JosseyBass.

Guglielmino, L. M. (2008). Why self-directed learning?. International Journal of Self-Directed Learning, 5(1), 1-14.

Knowles, M. (1975). Self-directed learning: A guide for learners and teachers. New York: Cambridge Adult Education.

Keywords: self-directed learning, lifelong learning, information literacy education 


\title{
Workplace Information Literacy of Croatian Fitness and Conditioning Personal Trainers
}

\author{
Kristina Feldvari, Kornelija Petr Balog and Sanjica Faletar Tanacković \\ University of Osijek, Croatia, \{kfeldvari, kpetr, sfaletar\}@ffos.hr
}

\section{Purpose}

This paper presents the findings of a pilot-study on workplace information literacy (IL) of Croatian fitness and conditioning personal trainers. Workplace IL generates experience that contributes to better understanding of designed roles and tasks (Forster, 2015). It also deepens the awareness of the information required in each workplace context, and the sources, processes and 'co-participatory practices' (Lloyd 2010) needed to develop knowledge as the context varies.

For fitness and conditioning personal trainers, regardless of whether their clients are doing sports for recreational purposes or are professional athletes, familiarization with information and information sources related to training practice processes, and their effects on the human body are of utmost importance. In Croatia, fitness and conditioning personal trainers can gain formal university education and informal training through various courses which are offered by non-accredited fitness academies, or workshops and training seminars given by various bodies, (some of which are even recognized at the formal level and entered into the trainer's official employment booklet). However, there are a few personal trainers that have neither the formal, nor the informal type of professional education; they learned everything on their own from literature and through talking to other experienced athletes/trainers.

The purpose of this study is to determine and compare the level of IL and information behavior of fitness and conditioning personal trainers with formal professional education to those with either informal education or without it. This includes looking into the type of information and information sources used by them in order to perform their work, as well as how they find the required information, how they evaluate it, and finally, how they utilize it in their work.

\section{Design / Methodology / Approach}

A paper and online survey will be used to gather the data.

The sample will consist of two groups of personal trainers - those with formal professional education, and those with informal or without any education. All personal trainers in our sample will have been working as trainers for at least one year. In our study, we are guided by the following research questions:

1. What are the information needs of personal trainers with formal education and those with informal or without any education?

2. What type of information sources do they use, and for what purposes do those two groups use them?

3. Is there a difference in the manner in which those two respondent groups retrieve, evaluate, and utilize information in their work practice?

\section{Originality / Value}

This is the first paper that looks into the workplace IL of fitness and conditioning personal trainers in Croatia. This paper is especially significant today when the number of people working with personal trainers is on the rise and the trainer has a direct influence on the health and general well-being of an individual.

\section{References}

Forster, M. (2015). 6 ways of experiencing information literacy in nursing: The findings of a phenomenographic study. Nurse Education Today, 35(1), 195-200

Lloyd, A. (2010). Information literacy landscapes: Information literacy in education, workplace and everyday contexts. Cambridge: Chandos Publishing.

Keywords: conditioning trainers, Croatia, fitness trainers, information behaviour, workplace information literacy 


\title{
Digital Literacy and Social Inclusion in Public Libraries: A Review of Research
}

\author{
Helena Francke \\ UiT The Arctic University of Norway, Troms $\varnothing$, Norway, helena.francke@hb.se
}

\author{
Noah Lenstra \\ University of North Carolina - Greensboro, Greensboro, NC; USA, njlenstr@uncg.edu

\section{Andreas Vårheim and Roswitha Skare} \\ UiT The Arctic University of Norway, Troms $\varnothing$, Norway, \{andreas.varheim, roswitha.skare $\} @$ uit.no
}

The practices through which people manage and enrich their everyday lives rely increasingly on their ability to make use of digital and informational resources. In policy texts, physical and intellectual access to digital information has been framed as a problem of social inclusion to which the public library may be part of the solution (Thompson et al., 2014). In library research, there is some evidence that public libraries contribute positively in strengthening social capital and participation in society among its patrons (Johnson, 2010; Vårheim, 2014; Vårheim, Steinmo \& Ide, 2008).

The present study investigates how the work done by public libraries to support digital and information literacy and, thus, potentially digital and social inclusion, is portrayed in the literature.

The literature review was based on publications from 2010-2017 collected through structured searches in the databases Web of Science, Scopus, and LISA. The publications were coded through qualitative content analysis (Altheide $\&$ Schneider, 2013) starting in the following analytical questions:

- which public library services or activities are described;

- which groups of patrons are intended beneficiaries;

- $\quad$ which methods and theoretical approaches were used;

- what were the main findings of the study;

- which aspects of digital and information literacies are emphasized; which kinds of knowledge, perceptions and attitudes are these literacies intended to support?

Many of the publications describe community projects in which public libraries play a leading role. Several studies address concepts such as digital inclusion and social capital, although few studies actually engage with them theoretically. The types of activities, outcomes, literacies, and beneficiaries vary greatly, but much work is focused on supporting literacies for active citizenship and employability.

This literature review is a building block in constructing a theoretical framework and a research design for empirical studies of the development of digital and information literacy activities in public libraries and the possible implications for physical and digital community participation.

\section{References}

Altheide, D. L., \& Schneider, C. J. (2013). Qualitative media analysis (2nd ed.). Los Angeles, CA: SAGE.

Johnson, C. A. (2010). Do public libraries contribute to social capital? A preliminary investigation into the relationship. Library \& Information Science Research, 32(2), 147-155.

Thompson, K. M. et al. (2014). Digital literacy and digital inclusion: Information policy and the public library. Lanham: Rowman $\&$ Littlefield.

Vårheim, A., Steinmo, S., \& Ide, E. (2008). Do libraries matter? Public libraries and the creation of social capital. Journal of Documentation, 64(6), 877-892.

Vårheim, A. (2014). Trust in libraries and trust in most people: Social capital creation in the public library. The Library Quarterly, 84(3), 258-277.

Keywords: public libraries, social participation, social capital, digital literacy, digital resources 


\title{
Genealogy and Learning: Acquiring Information and Digital Literacy Skills through a Hobby
}

\author{
Crystal Fulton \\ University College Dublin, Ireland, crystal.fulton@ucd.ie
}

Genealogy is a form of serious leisure (Stebbins, 1996), characterised by the extraction of information from sources and information systems to build understanding of family relationships and individual meaning around heritage and history. Retired adults frequently become involved in the hobby. However, researchers who have examined the digital divide for older adults and critical information skills have often pointed to lower levels of technological use and literacy among older adults in comparison with other groups (e.g., Anderson \& Perrin, 2017), which puts them at risk of missing out on critical information in their lives. Genealogy offers a particular context in which hobbyists must have significant literacy skills to locate and use detailed information spread widely across sources and information systems. How then do older adults engaged in genealogy learn the skills needed to become proficient in their hobby? Understanding how genealogists learn the information skills that support their hobby participation may help other older adults adopt lifelong learning approaches, which can promote community wellbeing (Merriam \& Kee, 2014).

Genealogists seeking their Irish ancestry from countries around the world were interviewed about their discovery, navigation, and use of information sources and systems, including technologically-mediated information. The project had multiple phases: in Phase 1, 24 genealogists were interviewed by telephone; in Phase 2, a deeper exploration of the impact of hobbyist activities on hobby outcomes was sought through more in-depth face-to-face interviews with 49 genealogists in Canada, Ireland, and the UK.

The outcomes of hobby activities included specific sharing and information creation behaviours (Fulton, 2009, 2016). Genealogists' approach to learning supported their hobby activities, as well as these hobby outcomes. Genealogists were self-taught, self-paced learners, who adopted a range of technologies and information sources and systems in support of their hobby over time as needed for their hobby, from microfilm machines to surfing the Internet, and from paper-based historical sources to DNA test results. Study participants demonstrated that they learned to navigate complex information and technologies with ease. They used peer learning to hone their skills and to take advantage of opportunities to demonstrate their new knowledge by sharing with others.

\section{References}

Anderson, M., \& Perrin, A. (2017). Tech adoption climbs among older adults. Retrieved May 21 , 2018 from http://www.pewinternet.org/2017/05/17/technology-use-among-seniors

Fulton, C. (2009). Quid pro quo: Information sharing in amateur genealogy. Library Trends, 57(4), 753-768.

Fulton, C. (2016). The genealogist's information world: Creating information in the pursuit of a hobby. The Journal of Multidisciplinary Research, 8(1), 85-100.

Merriam, S. B., \& Kee, Y. (2014). Promoting community wellbeing: The case for lifelong learning for older adults. Adult Education Quarterly, 64(2), 128-144.

Stebbins, R. A. (1996). Casual and serious leisure and post-traditional thought in the information age. World Leisure and Recreation, $38(3), 4-11$.

Keywords: digital literacy, genealogy, information literacy, lifelong learning, older adults, peer learning, selftaught learning 


\title{
Print or Electronic Course Readings: Implications for Library Space and Information Literacy Programmes
}

\author{
Almuth Gastinger \\ Norwegian University of Science and Technology, Trondheim, Norway, almuth.gastinger@ntnu.no \\ Ane Landøy \\ University of Bergen Library, Norway, ane.landoy@uib.no
}

For several years, there has been a debate about digital vs print format for study materials. The Academic Reading Format International Study (ARFIS) has investigated students' course reading preferences, which are clearly in favour of paper, both in Norway and many other countries. (Mizrachi D., 2015a; 2015b). These preferences have various implications for collection development decisions and reading recommendations, but also for the availability of space in academic libraries.

Study literature offered by academic libraries in digital format has huge advantages. It is not only more available (shorter loan periods; 24/7 availability), but it makes it possible to free up much needed floor and shelving space in physical libraries. It also reduces the time and work spent on handling physical books, from acquisition to reshelving. So how can these advantages be balanced with students' reading preferences?

The authors will discuss these challenges and explore the results of the ARFIS project conducted in Norway three years ago in more detail. They will look at student cohorts to see if there are differences between older and younger students, students in different cycles or differences that can be explained by the subject they are studying; and they will also examine what the library can do to support a change in student preferences across print to electronic course readings.

One suggestion (Landøy, Repanovici, Gastinger, 2015) is to develop training sessions in "how to use digital study literature?" with a special focus on practical issues like "how to highlight", "how to save the text." Some Norwegian universities have done this, and we will report on their results.

\section{References}

Landøy, A., Repanovici, A., \& Gastinger, A. (2015). The more they tried it the less they liked it: Norwegian and Romanian student's response to electronic course material. In S. Kurbanoğlu et al. (Eds.), Information Literacy: Moving Toward Sustainability, Third European Conference on Information Literacy, ECIL 2015, Tallinn, Estonia, October 19-22, 2015: Revised Selected Papers (pp. 455-463). Cham: Springer International Publishing.

Mizrachi, D. (2015a). Online or print: Which do students prefer?. In S. Kurbanoğlu et al. (Eds.), Information Literacy, Lifelong Learning and Digital Citizenship in the 21st Century, Second European Conference on Information Literacy, ECIL 2014, Dubrovnik, Croatia, October 20-23, 2014: Proceedings (pp. 733-742). Cham: Springer International Publishing.

Mizrachi, D. (2015b). Undergraduates' academic reading format preferences and behaviors. The Journal of Academic Librarianship, 41(3), 301-311.

Keywords: students' preferences, Norway, electronic study literature 


\title{
Copyright Literacy Skills of LIS Students in Norway
}

\author{
Almuth Gastinger \\ Norwegian University of Science and Technology, Trondheim, Norway, almuth.gastinger@ntnu.no
}

\section{Ane Landøy}

University of Bergen Library, Norway, ane.landoy@uib.no

The information society and constantly changing digital technologies make high demands for adequate knowledge and skills to meet these changes. Among others, students and staff of higher education institutions are required to have excellent competencies for dealing with copyright issues.

A few years ago, colleagues in Bulgaria initiated the multinational project/survey «Copyright Policies of Libraries and Other Cultural Institutions» (Todorova \& Peteva, 2013). Norway was among the many countries which conducted this survey, and professionals in archives, museums and libraries identified serious gaps in their knowledge and awareness of copyright laws and issues (Gastinger \& Landøy, 2015).

The study mentioned above is now followed by another multinational study, this time on copyright literacy skills among Library and Information Science (LIS) students, called Copyright Literacy of LIS Students (CoLIS).

In Norway, the authors will conduct this survey among the about 350 LIS students of the Oslo Metropolitan University in April 2018. All students at Bachelor, Master and $\mathrm{PhD}$ level will be asked at this university only, because there are no other higher education institutions in Norway that offer complete Library and Information Science studies.

The data analysis will be undertaken in May and June 2018, using SPSS.

The questionnaire was originally developed in English, but in order to maximize the understanding of the questions the authors translated it into the two official forms of written Norwegian: Bokmål and Nynorsk.

This paper will present a summary of the key findings of this web-based survey that includes questions about the familiarity, knowledge, awareness, and opinions on copyright related issues, but also seeks demographic information on respondents.

The findings are intended to be a starting point for the LIS education community to take actions to fill possible gaps in copyright competencies of library and information science students.

The results of the study will also allow further cross-country comparisons.

\section{References}

Gastinger, A., \& Landøy, A. (2015). Norske bibliotekarers kjennskap til copyright. Retrieved May 27, 2018 from http://docplayer.me/9862050-Norske-bibliotekarers-kjennskap-til-copyright.html

Todorova, T., \& Peteva, I. (2013). Information literacy competency of LIS students in SULSIT with a special focus on intellectual property. In S. Kurbanoğlu et al. (Eds.), Worldwide Commonalities and Challenges in Information Literacy Research and Practice, European Conference on Information Literacy, ECIL 2013, Istanbul, Turkey, October 22-25, 2013: Proceedings (pp. 610-616). Cham: Springer International Publishing.

Keywords: copyright literacy, Norway, LIS students 


\title{
Epistemic vs Non-epistemic Criteria to Assess Wikipedia Articles: Evolution of Young People's Perceptions
}

\author{
Sahut Gilles and Josiane Mothe \\ Université de Toulouse, France, gsahut@univ-tlse2.fr, josiane.mothe@irit.fr
}

This study aims at identifying and comparing the credibility criteria young students mention when asked how they assess Wikipedia articles. In the current informational context, credibility assessment of online information is a complex task, specifically for young people. Credibility can be assessed thanks to epistemic cues which directly refer to the truth value of the information (e.g. authors' expertise) but also according to other more non-epistemic criteria such as the web site graphic design (Watson, 2014) or the information quantity (Shenton, Dixon, 2004). Some studies mentioned that the ability for people to formulate credibility judgment evolve according to age or education (Metzger et al., 2015).

On the other hand, young people's intensive use of Wikipedia makes Wikipedia a relevant source to study young people's credibility judgement, specifically because Wikipedia articles are of unequal quality and the quality criteria Wikipedia highlights are quite specific (e.g. cited sources). Recent studies on criteria people use are not completely consistent. For example the importance of the various criteria varies according to the studies (Yaari et al., 2011; Rowley, Johnson, 2013). Moreover, past studies focus on university students only. As opposed to this, our goal is to conduct a broader study on the criteria young people use and how criteria evolve according to the education level.

\section{Methodology}

While most of the other studies rely on a limited number of participants, we analysed the answers that 841 young people from secondary school to master's degree programs responded to a questionnaire. We use descriptive statistics and ANOVA to compare the results between different levels of education.

\section{Outcomes}

We found that the frequency of credibility criteria that young people mention varies according to their education level. Criteria associated with formal characteristics and information quantity are mentioned less as education levels increase. Conversely, young people reported they pay increasing attention to source citation as they progress through their academic curriculum. In other words, we found that epistemic criteria increase with age. These results are also interpreted in the light of other explanatory variables such as Wikipedia usage and reputation, and consideration of information literacy (objectives, teaching means).

\section{References}

Metzger, M. et al. (2015). Believing the unbelievable: Understanding young people's information literacy beliefs and practices in the United States. Journal of Children and Media, 9(3), 325-348.

Rowley, J., \& Johnson, F. (2013). Understanding trust formation in digital information sources: The case of Wikipedia. Journal of Information Science, 39(4), 494-508.

Shenton, A. K., \& Dixon, P. (2004). Issues arising from youngsters' information-seeking behaviour. Library and Information Science Research, 26(2), 177-200.

Watson, C. (2014). An exploratory study of secondary students' judgments of the relevance and reliability of information. Journal of the Association for Information Science and Technology, 65(7), 1385-1408.

Yaari, E., Baruchson-Arbib, S., \& Bar-Ilan, J. (2011). Information quality assessment of community generated content: A user study of Wikipedia. Journal of Information Science, 37(5), 487-498.

Keywords: Wikipedia, credibility judgment, education level, student, teaching information literacy 


\title{
Cultural Implications of the ACRL Framework
}

\author{
Samantha Godbey and Xan Goodman \\ University of Nevada, Las Vegas, NV, USA, samantha.godbey@unlv.edu, xan.goodman@unlv.edu
}

The Framework for Information Literacy for Higher Education (Framework) is a document created by the Association of College and Research Libraries (ACRL, 2015) for academic librarians to use as a guiding document in their information literacy instruction practice. Because ACRL positions itself as a leader in the field of information literacy, the Framework is likely to be used by librarians to guide instructional practice outside of the western culture in which it was created. Salaz \& MacGregor (2016) characterize the ACRL Framework as one document within a body of national frameworks "that are likely to reflect the perspective and priorities of the source nation" (p. 47). The six frames and the theories that undergird the Framework are culturally western; however, the utilization of this framework outside of western contexts will likely have cultural implications that merit consideration. Each frame poses potential challenges for librarians and disciplinary faculty members who try to apply the frames in different cultural contexts and with students from different cultural backgrounds. For example, embedded within the frames is the American idea of questioning and challenging authority, which might be antithetical to or problematic in the context of non-American cultural values.

This paper provides an in-depth literature review related to the cultural implications of the ACRL Framework as applied within and outside of North American contexts. The paper clarifies common language around cultural values, including the terms cultural sensitivity, cultural humility, and cultural competence in order to provide context for the discussion of literature on the ACRL Framework in a range of cultural contexts. The authors also discuss each of the six frames in the ACRL Framework, identifying cultural implications of each.

The purpose of this literature review is to expand awareness of the cultural implications of this document. The ACRL Framework was filed fairly recently, in 2015, and in the wake of rescinding the Information Literacy Competency Standards for Higher Education (2000) in 2016, use of this framework is increasing worldwide, thereby increasing the demand for critical discussions around the implications of its contents. This paper provides readers with a departure point for informed reflection on the ACRL Framework and their instructional practices as related to students' cultural experience.

\section{References}

Association of College and Research Libraries. (2000). Information literacy competency standards for higher education. Retrieved February 15, 2018 from https://alair.ala.org/handle/11213/7668

Association of College and Research Libraries. (2015). Framework for information literacy for higher education. Retrieved February 15, 2018 from http://www.ala.org/acrl/standards/ilframework

Salaz, A., \& MacGregor, T. (2016). Have frameworks, will travel: Extending the frameworks into transnational higher education. In R. McClure, \& J. P. Purdy (Eds.), The Future Scholar: Researching and Teaching the Frameworks for Writing and Information Literacy (pp. 45-62). Medford, NJ: Association for Information Science and Technology.

Keywords: ACRL Framework, information literacy, threshold concepts, cultural values 


\title{
Secondary School Teachers' Attitudes to Information Literacy: A Pilot Study of a Multinational Survey
}

\author{
Vincas Grigas \\ Vilnius University, Lithuania, vincas.grigas@gmail.com \\ Anna Mierzecka \\ University of Warsaw, Poland, anna.mierzecka@uw.edu.pl \\ Tímea Tomori and Tibor Koltay \\ Eszterházy Károly University, Hungary, \{tomori.timea, koltay.tibor\} @uni.eszterhazy.hu
}

Recent developments in media and information literacy have heightened the need for analysing secondary school teachers' preparedness to play a crucial role in providing students with sophisticated information literacy skills. A considerable amount of literature has been published on the topic of media and information literacy recently. These studies suggest that information literacy is being studied by a variety of different scholars using a variety of concepts (Koltay, 2017). These rapid changes are having enormous effect, obliging secondary school teachers to have present date knowledge about information literacy. The Association of College \& Research Libraries (ACRL) created a highly sophisticated Information Literacy Standards for Teacher Education in 2011, with the purpose of guiding teacher education faculty in developing information literacy instruction for teacher education students (Association of College \& Research Libraries, 2011). However, there are no related standards of any kind in Eastern and Central Europe and until recently, there has been no reliable evidence that there was any particular preparation for teachers to be sophisticated in information literacy in such countries as Hungary, Poland and Lithuania.

The primary purpose of this study is to develop an understanding of secondary school teachers' knowledge of information literacy and practices implemented with developing student's' information literacy skills in Hungary, Poland, and Lithuania. This research will support a research project that aims to harmonise various theories of information literacy with the proper application of information literacy to public (K12) education.

This paper describes the preliminary phase of the survey by presenting a pilot survey among Lithuanian teachers with a sample of 107 participants in the Spring of 2018. We gathered data for this study using a computer-assisted web interviewing (CAWI) technique. We administered an online survey using the 1KA.SI web survey tool. The paper presents the general background of the study, and the structure and content of the questionnaire. Besides collecting the demographic information of the participants (age, length of experience in teaching, the student level/class where they teach, main discipline), we asked them to rate their student's' ability in information literacy skills, and the teachers' readiness for teaching information literacy. We intended to find out if there is awareness of the existence and importance of information literacy and media literacy, how they acquired their information literacy skills, if they felt prepared to teach information literacy skills themselves, and what experience they had with information literacy teaching. The collected data was analysed by IBM SPSS Statistics ver. 19 using descriptive and inferential statistical tests. The data acquired in the pilot survey and their possible interpretations are presented. The questionnaire's usability for the multinational survey and possible adoption to surveying other countries' secondary school teachers' views on information and media literacy issues are discussed.

The researchers suppose that the present survey instrument can be fine-tuned to enable measuring secondary school teachers' attitudes towards information literacy and media literacy, despite the apparent differences between the school systems in the three countries and diverse levels of awareness regarding information literacy and media literacy.

\section{References}

Association of College \& Research Libraries. (2011). Information literacy standards for teacher education. Chicago: American Library Association.

Koltay, T. (2017). The media and the literacies: Half decade of selected developments. Kwartalnik Nauk o Mediach, 2. Retrieved from http://knm.uksw.edu.pl/982-2/

Keywords: information literacy, teachers, secondary school 


\title{
Research Orientation and Collaboration in Information Literacy in Post- socialist European Countries
}

\author{
Andrea Grkinić and Sonja Špiranec \\ University of Zagreb, Croatia, \{agrkinic, sspiran\}@ffzg.hr \\ Maja Jokić \\ Institute for Social Research in Zagreb, Croatia, maja@idi.hr
}

\section{Objectives}

The objective of this paper is to define the process of research development of the field of information literacy (IL), to identify and to compare its tendencies and trends in research orientation and collaboration, and to describe the thematic focus of IL in post-socialist European countries. All European post-socialist countries are an integral part of the European Research Area (ERA) as European Union (EU) member states or EU candidate countries. The aim of this research is to determine how is the concept of IL elaborated in the scientific literature of authors from post-socialist European countries.

\section{Methodology}

The sample was obtained within the RACOSS project (IDIZ, 2015), led by Institute for Social Research in Zagreb, from the Scopus database. It consists of scientific social science papers published in the period 1996-2013 with at least one of the authors having an address from one of the 15 European post-socialist countries, 11 EU member states: Estonia, Latvia, Lithuania, Poland, Czech Republic, Slovakia, Hungary, Romania, Bulgaria, Slovenia, Croatia and 4 EU candidate countries: Bosnia and Herzegovina, Macedonia, Montenegro and Serbia.

Analyzed papers $(\mathrm{N}=45)$ were limited to the field of Information and Communication Science and contain the term literacy in the papers' title, keywords, and/or abstracts. The higher-order term literacy was used in order to analyze conceptual patterns between IL and other related literacies. A content and bibliometric analysis of the papers will be conducted. The content analysis of the papers will be made using categories (strands) devised by Ola Pilerot (2016) for the field of IL: research, practice, and policy-making. The content analysis of the author's affiliation institutions will be conducted using Järvelin \& Vakkari's (1990) categories of institutions for the field of Library and Information Science (LIS). The paper will also present a statistical descriptive analysis of authorship patterns (geographical distribution, affiliation, and collaboration) and keywords.

\section{Outcomes}

The research will provide a deep and thorough insight into a research activity, orientation, and collaboration in the field of IL in post-socialist European countries. The research is also intended to shed a light on the differences between information literacy and other connected literacies (for example, media literacy, digital literacy, and computer literacy) as treated in the literature sample. The papers' results will serve as a reference point to future research and as a reference point for comparison with similar research conducted in other countries in the field of IL.

\section{References}

IDIZ: Institute for Social Research in Zagreb. (2015). Research activity, collaboration and orientation in social sciences in Croatia and other post-socialist European countries (RACOSS) - IP-09-2014-9351. Retrieved February 15, 2018 from http://racoss.idi.hr/index_en.html

Järvelin, K., \& Vakkari, P. (1990). Content of research articles in library and information science. Library \& Information Science Research, 12(4), 395-421.

Pilerot, O. (2016). Connections between research and practice in the information literacy narrative: A mapping of the literature and some propositions. Journal of Librarianship \& Information Science, 48(4), 313-321.

Keywords: information literacy, post-socialist European countries, content analysis, bibliometrics 


\title{
Serendipity in High School Students' Information Acquisition
}

\author{
Jannica Heinström \\ University of Tampere and Åbo Akademi University, Finland, jheinstr@abo.fi \\ Eero Sormunen and Teemu Mikkonen \\ University of Tampere, Finland, \{ eero.sormunen, teemu.mikkonen\} @ staff.uta.fi
}

\section{Objectives}

The aim of this paper is to investigate serendipity as part of everyday life information behaviour. Opportunistic discovery of information is increasingly enabled through social media and RSS-flows (Foster and Ellis, 2014; Erdelez et al., 2011). Research show that youth acquire more information passively than through active information seeking (Ito et al, 2008).

\section{Methodology}

Data was collected through interviews which served as a pilot study for a questionnaire on everyday life information behavior. The respondents were twenty high school students. The interviews were designed based on Savolainen's model of everyday life information seeking (1995), focusing on: 1) way of life (how things are when in order), and 2) mastery of life (keeping things in order). One question concerned whether the respondents had found useful information by chance at times when they had not been looking for it.

\section{Outcomes}

None of the respondents mentioned serendipity when they described their information acquisition for their way of life or mastery of life. When prompted, however, seventeen of the twenty respondents stated that they had retrieved information serendipitously. Six of them remembered a particular occasion while the others acknowledged that this frequently occurred. The respondents had run across useful information by chance on the Internet, in newspapers or on social media. They had found information for their everyday life, career-choices and school assignments. Opportunistically discovered information had helped the respondents to keep up to date with news, build stronger arguments and get ideas for school assignments. Only three of the twenty respondents said that they had not retrieved any useful information by chance.

\section{Conclusions}

We conclude that serendipity plays an important role in young people's everyday life information behaviour. Serendipity is, however, often not acknowledged as a part of information acquisition. Awareness of the role of opportunistic discovery of information would be important as a first step in utilizing its potential.

\section{References}

Erdelez, S., Basic, J., \& Levitov, D. D. (2011). Potential for inclusion of information encountering within information literacy models. Information Research, 16(3). Retrieved from http://InformationR.net/ir/16-3/paper489.html

Foster, A., \& Ellis, D. (2014). Serendipity and its study. Journal of Documentation, 70(6), 1015-1038.

Ito, M. et al. (2008). Living and learning with new media: Summary of findings from the digital youth project. Retrieved February 14, 2018 from http://digitalyouth.ischool.berkeley.edu/files/report/digitalyouth-WhitePaper.pdf

Savolainen, R. (1995). Everyday life information seeking: Approaching information seeking in the context of 'way of life'. Library \& Information Science Research, 17(3), 259-294.

Keywords: everyday life information behavior, information acquisition, serendipity, high school students 


\title{
Four Spaces of Civic Literacy Education: A Literature Review
}

\author{
Jos van Helvoort \\ The Hague University of Applied Sciences, Netherlands, a.a.j.vanhelvoort@hhs.nl
}

To be prepared for living and working in the 21 st century, the current generation of students must learn how to handle the tremendous amount of information, both solicited and unsolicited, they have to sort through. It is crucial for them to possess the ability to assess the reliability and usefulness of the information around them. Media and information literacy are therefore strongly linked to the concept of 21st century skills (www.p21.org).

Most research studies on information literacy are conducted within the context of educational institutions (Rader, 2002; Weiner, 2011). Those research papers study how students perform information tasks while carrying out their coursework. Studies that focus on the development of more 'civic' information tasks are much harder to find in the library and information science literature. Active information seeking and a critical evaluation of information and media are nonetheless essential components of democratic participation (Cats and Lau, 2008; Sturges and Gastinger, 2010). This is particularly true in this age of fake news (Yerbury and Henninger, 2017).

\section{Research Purpose and Methods}

The purpose of this literature study was to obtain an overview of previous civic literacy projects and their characteristics, as primarily described in the educational science literature. Eighteen academic articles about civic literacy projects in higher education were studied in detail and coded using the qualitative data analysis instrument Atlas.ti. The codes and quotations compiled were then divided in various categories and represented in a two-axis model.

\section{Findings}

The definitions of 'civic literacy' found in the literature varied from an interest in social issues and a critical attitude to a more activist attitude (axis number 1). An analysis of the literature showed that, especially in more recent years, students have benefited more from civic literacy projects than have citizens (axis number 2). The main benefits for students pertained to such learning goals as critical thinking and developing a social attitude. The best learning environments for developing such social skills have an interdisciplinary character that necessitates student collaboratation with others. The role of teaching professionals is primarily restricted to guidance and feedback.

\section{References}

Catts, R., \& Lau, J. (2008). Towards information literacy indicators. Paris: Unesco.

Rader, H. B. (2002). Information literacy 1973-2002: A selected literature review. Library Trends, 51(2), 242-259.

Sturges, P., \& Gastinger, A. (2010). Information literacy as a human right. Libri, 60(3), 195-202.

Weiner, S. (2011). Information literacy and the workforce: A review. Education Libraries, 34(2), 7-14.

Yerbury, H., \& Henninger, M. (2017). Civil commitment and the role of public librarians. In S. Špiranec et al. (Eds.), The Fifth European Conference on Information Literacy (ECIL): Abstracts, September 18-21, 2017, Saint-Malo, France (p. 152). SaintMalo: Information Literacy Association.

Keywords: civic literacy, higher education, literature review 


\title{
Setting the Scene: An Set of Initial Premises for Everyday Information Literacy
}

\author{
Alison Hicks \\ University College, London. UK, a.hicks@ucl.ac.uk
}

The purpose of this paper is to draw from a recent doctoral study to precipitate discussion and provide an initial guiding structure for the emerging shape of everyday information literacy. As Martzoukou and Sayyad Abdi (2017) point out in their scoping literature review, everyday situations have been relatively underexplored within information literacy research. To this end, they propose the need for an "information literacy mindset", which plays out as a set of transferable skills that enable individuals to meet the evolving challenges of any information environment in which they find themselves. Yet, in limiting our understanding of everyday information literacy to an exploration of how seemingly common information literacy skills can be shuttled between contexts, we ignore how the affordances (Gibson, 1977) or the sociocultural pressures of a setting enable and constrain both an individual's access to and means of constructing their information landscapes (Lloyd, 2006). In further shying away from critiquing widely accepted information literacy concepts such as transfer and lifelong learning, we also risk continuing to dwell on idealistic librarian-led ambitions rather than engaging with community-driven multimodal and vernacular ways of knowing (Barton \& Hamilton, 1998; Lloyd \& Wilkinson, 2016).

This paper will present several premises about the emerging shape of everyday information literacy. These propositions will be derived from a recent doctoral study that forms one of the first extended explorations of everyday information literacy. Taking a sociocultural approach (Tuominen, Talja \& Savolainen, 2005), this study employed constructivist grounded theory methodology as well as interviews and visual research methods to explore the information literacy practices of 26 English-speakers who were learning one of eight languages in 14 different countries for a period of between four and 12 months, overseas. Exploring how language learners mediate a variety of challenges and opportunities during their time overseas, including finding accommodation, mastering transportation systems and establishing new shopping and leisure activities, this study will be used as the basis for the presentation of various key implications for the emerging area of everyday information literacy as well as highlighting directions for future research.

\section{References}

Barton, D., \& Hamilton, M. (1998). Local literacies: Reading and writing in one community. London: Routledge.

Gibson, J. J. (1977). The theory of affordances. In: R. Shaw, \& J. Bransford (Eds.), Perceiving, Acting, and Knowing: Toward an Ecological Psychology (pp.67-82). Hillsdale, NJ: Lawrence Erlbaum.

Lloyd, A. (2006). Information literacy landscapes: An emerging picture. Journal of Documentation, 62(5), 570-583.

Lloyd, A., \& Wilkinson, J. (2016). Knowing and learning in everyday spaces: Mapping the information landscape of refugee youth learning in everyday spaces. Journal of Information Science, 42(3), 300-312.

Martzoukou, D., \& Sayyad Abdi, E. (2017). Towards an everyday life information literacy mind-set: A review of literature. Journal of Documentation, 73(4), 634-665.

Tuominen, K., Savolainen, R., \& Talja, S. (2005). Information literacy as a sociotechnical practice. Library Quarterly, 75(3), 329345.

Keywords: everyday information literacy, lifelong-learning, sociocultural 


\title{
Finnish School Health Education Viewed through an Information Literacy Lens
}

\author{
Noora Hirvonen \\ University of Oulu and Medical Research Center Oulu, Finland / Åbo Akademi University, Turku, Finland \\ \{noora.hirvonen\} @ oulu.fi
}

Laura Palmgren-Neuvonen and Tuula Nygård

University of Oulu, Finland, \{ laura.palmgren-neuvonen; tuula.nygard\} @ oulu.fi

Anna-Maija Huhta and Maija-Leena Huotari

University of Oulu and Medical Research Center Oulu, Finland, \{anna-maija.huhta; maija-leena huotari\}@oulu.fi

\section{Background and Objectives}

In Finland, health education is included in the core curriculum for basic education where it is suggested to promote learners' health literacy (FNBE 2016). In this study, we examine Finnish health education in schools from the viewpoint of information literacy, which is understood as competencies needed to access, evaluate, and use information. These competencies are particularly relevant in the context of health, since in this field of knowledge, information is received from various sources and changes dynamically. The study asks, in the context of Finnish secondary school education, (1) how are information literacy competencies addressed in documents guiding health education classroom practices, and (2) what trends can be identified in the documents with regard to these competencies?

\section{Material and Methods}

The main material of this qualitative study comprised of documents, namely, the most recent Finnish core curricula for basic education $(2004,2014)$ and health education text books $(n=4)$. The data were analyzed with qualitative content analysis guided by theoretical conceptions of information literacy. Moreover, we used ethnographic data (observation, video recordings, and interviews of teachers and students) collected in three health education classrooms in Finnish schools to reflect how the ideas presented in the documents were implemented in practice.

\section{Results}

Although the concept of information literacy is not explicitly used in the core curricula, there are closely related learning objectives especially in the curriculum launched in 2014. Already in the 2004 curriculum, seeking and critical evaluation of information were addressed as skills to be included in health education. In the 2014 curriculum, the notions of both individual and collaborative information seeking, construction, evaluation, and use were acknowledged as health education objectives. Moreover, the most recent curriculum includes transversal competency areas, such as 'multiliteracy' and 'thinking and learning to learn' that overlap with information literacy. Textbooks vary in the way information literacy themes are acknowledged. However, information evaluation topics seem to be more prevalent than those concerning information access. Based on the ethnographic data, collaborative assignments including information seeking were conducted in health education classrooms but the opportunities to promote information literacy competencies were often missed.

\section{Discussion and Conclusions}

The study increased our understanding of the ways school health education may help to promote the information literacy of young people in health contexts, that is, health information literacy. Health education classrooms have the potential to serve as effective arenas for information literacy education, and teachers may benefit from information literacy guidelines in developing pedagogical practices.

\section{References}

Finnish National Board of Education. (2016). National core curriculum for basic education 2014. Helsinki: FNBE.

Keywords: information literacy, health education, education, health 


\title{
Information Overload: A Comparison of Disciplines in Australia
}

\author{
Katherine Howard \\ Flinders University, Adelaide, Australia, katherine.howard@flinders.edu.au \\ James Nicholson \\ University of Queensland, Brisbane, Australia, j.nicholson@uq.edu.au
}

\section{Introduction}

As information professionals, we are acutely aware that the amount of information created and made available to people has not only increased significantly in the last decades, but that it continues to do so. This can lead people to experience what has been called 'information overload.' One of the earliest definitions of information overload comes from Rogers and Argarwala-Rogers, (1975), who define it as "the state of an individual or system in which excessive communication inputs cannot be processed and utilised, leading to breakdown." In other words, information overload occurs in humans because of our finite cognitive capacity to effectively process information (Jones, 2003).

Mandre, Virkus and Pals (2017) noted in a recent paper that although much research had taken place about information overload, (2,469 articles from 1990-2017), only 10.2\% (251 articles) originate from information science and library science. The highest contribution to information overload research comes from the computer science discipline (56\% or 1,382 articles). This research seeks to contribute to not only redressing this balance, but to go a step further in offering an empirically derived solution to the information overload phenomenon in humans.

\section{Methods}

This research replicates that of Mandre, Virkus and Pals (2017), thus allowing for a comparative study at a later stage. The study uses a mixed methods approach in a two-stage research design consisting of both qualitative and quantitative methodologies. Firstly, a quantitative questionnaire will be distributed to students in three disciplines: psychology, mathematics, and computer science. These will be followed up by qualitative, semi-structured interviews. The research questions to be answered are as follows:

- How do students perceive information overload?

- How do students cope with information overload?

- What are the disciplinary differences in perceiving and coping with information overload?

This paper will report on the initial results of the study that explore the perception of information overload in students in three disciplines: psychology, mathematics, and computer science.

\section{Conclusions}

The results of this study may be used to inform the design of discipline-specific training to facilitate greater coping mechanisms for students who may experience information overload. These recommendations and potential solutions will form the basis of another study using action research to evaluate the discipline specific training.

\section{References}

Jones, Q. (2003). Information overload. In K. Christiansen, \& D. Levinson (Eds.), Encyclopedia of Community: From the Village to the Virtual World (pp.660-662). Thousand Oaks, CA: SAGE Publications.

Mandre, S., Virkus, S., \& Pals, E. (2017). Information overload in a disciplinary context. In S. Špiranec et al. (Eds.), The Fifth European Conference on Information Literacy (ECIL): Abstracts, September 18-21, 2017, Saint-Malo, France (p. 92). SaintMalo: Information Literacy Association.

Rogers, E., \& Argarwala-Rogers, R. (1975). Organisational communication. In G. L. Hanneman, \& W. J. McEwan (Eds.), Communication Behaviour (pp. 218-236). Reading, MA: Addison-Wesley.

Keywords: information overload, information literacy, mixed-methods research, higher education, students, Australia 


\title{
Health Information Literacy Practices of Young Bloggers: A Nexus Analytical Study
}

\author{
Anna-Maija Huhta \\ University of Oulu and Medical Research Center Oulu, Finland, \{anna-maija.huhta\} @oulu.fi \\ Noora Hirvonen \\ University of Oulu and Medical Research Center Oulu, Finland / Åbo Akademi University, Turku, Finland
}

Maija-Leena Huotari

University of Oulu, Finland and Medical Research Center Oulu, Finland

Health literacy research in the context of online information environments is usually quantitative, conducted within the fields of medicine and public health. It aims to assess the functional skills of individuals in a variety of settings (Huhta, 2018). This study focuses on health information literacy (HIL) traditionally understood as information literacy (IL) in health settings but adopts a broader sociocultural view on literacies as social practices enacted in everyday life situations (Lloyd, 2010). The study draws on literacy research conducted in information studies and health sciences. The concept of cognitive authority (Wilson 1983) is applied to build understanding of HIL practices on social media. According to Wilson (1983), people gain information about the world through their own experience and second-hand from others. The credibility of the second-hand information is evaluated subjectively and in multiple ways, such as according to its competence and trustworthiness (Wilson, 1983). Cognitive authority relates to the concept of social epistemology, which presents knowledge as a socially constructed phenomenon (Doty, 2015).

This study aims to investigate the health information literacy practices of young bloggers with a focus on cognitive authority construction in content creation.

The methodological framework of this study is a form of ethnography known as nexus analysis. It enables focusing on social action. The nexus of practice is described as an intersection of three dimensions: (1) historical bodies of the actors at hand; (2) the interaction order produced by them; and, (3) the discourses used as mediational means to enable action (Scollon \& Scollon, 2004). Interviews, observational, and blog content data will be collected in spring and summer 2018. From eight to twelve young people (15-24 years) who actively produce health related content on social media platforms such as blogs, YouTube, Facebook, Instagram, and Snapchat will be recruited as informants. They will be contacted personally or via discussion forums.

Preliminary findings will be presented and discussed. The study increases understanding of health information literacy as a sociocultural phenomenon and the role of cognitive authorities among young people when evaluating and creating health related content online. This can benefit the development of health education and promotion targeted to and when interacting with younger age groups.

\section{References}

Doty, C. (2015). Social epistemology and cognitive authority in online comments about vaccine safety. Retrieved February 20, 2018 from http://hdl.handle.net/2142/73664

Huhta, A. M., Hirvonen, N., \& Huotari, M. L. (2018). Concepts related to health literacy in online information environments: A systematic review with an emphasis on approach to information. In S. Kurbanoğlu et al. (Eds.), Information literacy in the workplace, 5th European Conference on Information Literacy, ECIL 2017, Saint Malo, France, September 18-21, 2017: Revised Selected Papers (pp. 460-469). Cham: Springer International Publishing.

Lloyd, A., Bonner, A., \& Dawson-Rose, C. (2014). The health information practices of people living with chronic health conditions: Implications for health literacy. Journal of Librarianship and Information Science, 46(3), 207-216.

Scollon, R., \& Scollon, S. W. (2004). Nexus analysis: Discourse and the emerging internet. New York: Routledge.

Wilson, P. (1983). Second-hand knowledge: An inquiry into cognitive authority. Westport, Conn.: Greewood Press.

Keywords: health information literacy, social practices, cognitive authority, nexus analysis, online information environments, social media, young people 


\title{
Differences in Health Information Literacy Competencies among Older Adults, Elderly and Younger Citizens
}

\author{
Isto Huvila \\ Uppsala University, Sweden / Åbo Akademi University, Finland, isto.huvila@abm.uu.se \\ Heidi Enwald and Noora Hirvonen \\ University of Oulu and Medical Research Center, Oulu, Finland / Åbo Akademi University, Turku, Finland \\ Rose-Mharie Åhlfeldt \\ University of Skövde, Sweden
}

An adequate understanding of the health information literacy of older citizens is crucial for providing health information for this group in a manner that would encourage and help them to become better informed in health-related matters. In spite of the growing corpus of research on older citizens and their health information literacy (e.g., Yates et al., 2012; Eriksson-Backa, 2013; Eriksson-Backa \& Ek, 2015; Enwald et al., 2017), there are still relatively few studies that have investigated this topic regarding how elderly patients differ from other age groups (Huvila et al., 2016). To address this research gap, this presentation reports how older adults differ from other populations according to their self-perceived health information literacy competencies.

The analysis is based on the results of a national survey of patients who had consulted their medical records online using the national patient accessible electronic health record system (Journalen) in Sweden. Altogether 2587 users, of whom $67 \%$ were women, responded to the online survey. Aspects related to health information literacy were measured using 11 items focusing on information literacy, self-perceived competence, and ability to obtain and use health information and to influence one's own health. Group-wise differences between groups Elderly (born -1945), Older Adults (1946-1960) and Younger (1960-) were tested using one-way ANOVA in SPSS 24.0 with Tamhane T2 post hoc test.

The findings show differences among age groups in several HIL statements. Older adults and the elderly differed from younger respondents in their opinion that it is important to be informed of health issues. Older adults were, however, least likely to compare information from multiple sources, but most likely to think that health information can be difficult to understand. Elderly differed from the two other groups in that they considered that it was least easy to understand medicine package labels, and to determine when they needed health information. There were no significant differences in the level of education of the different age groups. In light of the findings, older adulthood appears to be a transitory period from younger adulthood to becoming an elderly citizen. An awareness of the importance of health issues is increasing in this phase of life. However, it seems that the health information literacy skills of the respondents are not necessarily improving but changing and adapting to new issues and challenges of advanced age.

\section{References}

Enwald, H. et al. (2017). Health information behaviour, attitudes towards health information and motivating factors for encouraging physical activity among older people: Differences by sex and age. Information Research, 22(1). Retrieved from http://www.informationr.net/ir/22-1/isic/isic1623.html

Eriksson-Backa, K. (2013). The role of online health information in the lives of Finns aged 65 to 79 years. International Journal of Networking and Virtual Organisations, 13(1), 5-23.

Eriksson-Backa, K., \& Ek, S. (2015). Health information literacy and communication in healthcare contexts: A study of older Finnish adults. In P. Bath, H. Spring, \& B. Sen (Eds.) Proceedings of the 17th International Symposium on Health Information Management Research (ISHIMR 2015), 24-26 June 2015 (pp. 77-91). York: York St. John University: University of Sheffield.

Huvila, I. et al. (2016). Taking health information behaviour into account in the design of e-health services. Finnish Journal of eHealth and eWelfare, 8(4), 153-163.

Yates, C. et al. (2012). Exploring health information use by older Australians within everyday life. Library Trends, 60(3), 460-478.

Keywords: health information literacy, older adults, elderly, young 


\title{
Personal Information Management and Organisation Competences: A Review of Information Literacy Conceptual Frameworks and Standards
}

\author{
Jerry Jacques \\ University of Namur, Belgium, jerry.jacques@unamur.be
}

The development of information and communication technologies pushes individuals to deal with complex and large collections of digital information. To make sense of these collections and to meet their life's objectives and fulfil their roles and responsibilities, either in personal or professional situations, people have to put great effort into the management and organisation of personal information (Jones, 2008; Bergman \& Whittaker, 2016). Personal information management and organisation practices call for specific competences and development of personal information literacy (Mioduser et al, 2008), an area that remains largely unexplored in the field of personal information management.

The aim of this paper is to identify, in information literacy conceptual frameworks and standards, contributions and definitions related to personal information management and organisation competences. We reviewed the scientific literature pertaining to information literacy and information behaviour (i.e Eisenberg \& Berkowitz, 1990; Kuhlthau, 1991) and information literacy standards proposed by educational institutions and information professional associations (i.e. SCONUL, 2011; ACRL, 2016). Our analysis consists in an inventory highlighting the need of (1) information literacy frameworks and standards dedicated specifically to these competences and (2) dedicated research on personal information management and organisation competences.

The conclusion of this paper introduces a framework of personal information organisation competences defined on the basis of guided-tour interviews with students of their personal information spaces (Jacques, 2016). It takes the form of a matrix of four core-activities (inclusion, exclusion, apprehension, and implementation), three dimensions of information (technical, informational, and social), and three types of relationships (adequacy, optimization, and virtualization) used to characterize the mediating role of competences between the individual's intentions and the opportunities and constraints of the situations where they are mobilized. This framework is a first attempt to define information organization competences as essential components of personal information management literacy, leading the way for its recognition as a key domain of information literacy.

\section{References}

Association of College and Research Libraries. (2016). Framework for information literacy for higher education. Retrieved May 5, 2018 from http://www.ala.org/acrl/sites/ala.org.acrl/files/content/issues/infolit/Framework_ILHE.pdf

Bergman, O., \& Whittaker, S. (2016). The science of managing our digital stuff. Cambridge: MIT Press.

Eisenberg, M. B., \& Berkowitz, R. E. (1990). Information problem solving: The big six skills approach to library \& information skills instruction. Norwood: Ablex Publishing Corporation.

Jacques, J. (2016). Définition des compétences propres à l'organisation des collections d'informations personnelles numériques (Thesis). Université catholique de Louvain, Louvain-la-Neuve.

Jones, W. (2008). Keeping found things found: The study and practice of personal information management. Burlington: Morgan Kaufmann.

Kuhlthau, C. C. (1991). Inside the search process: Information seeking from the user's perspective. Journal of the American Society for Information Science, 42(5), 361-371.

Mioduser, D., Nachmias, R., \& Forkosh-Baruch, A. (2008). New literacies for the knowledge society. In J. Voogt, \& G. Knezek (Éds.), International Handbook of Information Technology in Primary and Secondary Education (pp. 23-42). New York: Springer.

SCONUL Working Group on Information Literacy. (2011). The SCONUL seven pillars of information literacy: Core model for higher education. Retrieved May 5, 2018 from https://www.sconul.ac.uk/sites/default/files/documents/coremodel.pdf

Keywords: personal information management, information organisation, literacy, literature review 


\title{
Data Sharing in Social Sciences: A Case Study at Charles University
}

\author{
Adela Jarolimkova and Barbora Drobikova \\ Charles University, Prague, Czech Republic, \{adela.jarolimkova, barbora.drobikova\}@ff.cuni.cz
}

\section{Introduction}

Data sharing is an important building block of data-intensive science, but it is highly dependent on researchers' behavior (Koltay, 2017). As we have discovered in our recent research both academics and doctoral students of Charles University are willing to share data, but at the same time they expressed various concerns for data sharing. The most common method of sharing data is upon request, the least common is the open access to data. We have also identified some interdisciplinary differences between social sciences and medicine on one side and humanities and natural sciences on the other (Drobikova, 2017, Jarolimkova, 2018). The research was carried out using a Czech version of the Data Literacy Multinational Study questionnaire (Chowdhury, 2016), that allowed us to gain an overview of the situation but did not provide sufficient details of the data-sharing topic.

\section{Methods and Results}

In our present study we focus on a group of social sciences researchers of Charles University. We use the data (results partially published in Drobikova, 2017 and Jarolimkova, 2018) from the questionnaire as a foundation for a more indepth research into the questions of sharing one's own data and using data shared by others. We collected 1434 completed questionnaires, of which 279 fall into social sciences. By applying the Pearson chi-square test, we found some differences in the willingness to share data and current data sharing practices between the social sciences researchers and other groups. It seems that the social scientists are less willing to share their data, their data are more often unavailable and they are more concerned for potential ethical and legal problems. As for the usage of data shared by other researchers, there are no statistically significant differences apart from the fact that social scientists use data from other researchers within their own "scientific network" more often.

The analysis of the questionnaire results is followed by semi-structured interviews with selected social scientists. Its main focus is on the factors affecting data sharing within this field, including both external factors, such as availability of usable data repositories, infrastructure for data sharing and institutional support for data sharing, and internal factors, such as motivation for data sharing and trust in other researchers' ethics.

\section{References}

Chowdhury, G. et al. (2016). Information practices for sustainability: Information, data and environmental literacy. In S. Špiranec et al. (Eds.), The Fourth European Conference on Information Literacy (ECIL): Abstracts, October 10-13, 2016, Prague, Czech Republic (p. 22). Prague: Association of Libraries of Czech Universities.

Drobíková, B., Jarolímková, A., \& Souček, M. (2017). Data literacy of Charles University PhD students: Are they prepared for their research careers?. In S. Špiranec et al. (Eds.), The Fifth European Conference on Information Literacy (ECIL): Abstracts, September 18-21, 2017, Saint-Malo, France (p. 41). Saint-Malo: Information Literacy Association.

Jarolímková, A., Drobíková, B., \& Souček, M. (2018). Attitudes of Charles University academic staff to data sharing. The Grey Journal, 14(Special Winter Issue), 37-43.

Koltay, T. (2017). Data literacy for researchers and data librarians. Journal of Librarianship and Information Science, 49(1), 3-14.

Keywords: research data management, data sharing, data sharing behaviour, data literacy 


\title{
Biometric Tools in Information Science. The Example of an Information Literacy Study - A Holiday Planning Experiment
}

\author{
Justyna Jasiewicz, Małgorzata Kisilowska and Anna Jupowicz-Ginalska \\ University of Warsaw, Poland, \{justyna.jasiewicz, mdkisilo, a.ginalska\}@uw.edu.pl
}

Effective studies within interdisciplinary research fields, such as information literacy, require complex research methodologies and tools, coming from the social sciences, the humanities, and the sciences. Biometric tools, first introduced in psychological, neurological, marketing, and media studies (see for example: (Plassmann \& Yoon, 2011; Roderer \& Roebers, 2014; Uggeldahl, Jacobsen, Lundhede, \& Olsen, 2016), can be successfully applied in information science as well. They are mostly used along with surveys or interviews, enabling comparisons and deepening information gathered from different sources. Biometric tools in library and information science have been applied mostly in research concerning information behaviours (Lund, 2016), reading (Kang, 2014), or searching patterns (Wang, Xie, \& Lee, 2015).

This paper aims to present the possibilities of biometric tools and their potential use in the field of information science in triangulation with methods and techniques being used in the social sciences. Besides a literature review, this paper presents a project concerning the information skills of young respondents in everyday life tasks, such as planning a holiday trip. The project took place November 2017 - January 2018 with a group of 19 respondents (college and university students). The study was conducted utilizing triangulation of the following research methods: behavioral experiment, biometric measurements, and individual interviews. Skills analysed included those from the following levels of Jan van Dijk's model (van Dijk \& van Deursen, 2014).

Results of the research proved that young people are not as fluent in social media usage as it may seem. College students, even though they grew up in a time of unlimited access to information and communication technology, have limited communication and content creation skills. University students, however, present more advanced information skills. That might indicate the positive influence of university education and socialization on information literacy. It must be stressed that the analysis of eye movements clearly revealed insights such as the respondents' searching strategies, moments of decision. Emotions reflect such additional moments of deliberation as positive or negative feelings during information searching. Interviews reinforced those observations. All the outcomes are exploratory in their nature, both due to the use of biometric methods in information literacy research, and the limited number of participants, that do not enable generalizations. Therefore further research in the topic is needed.

During the project, biometric measures were proved to be effective tools in exploring psycho-physiological reactions while executing information tasks. Additionally, it was demonstrated that triangulation of methods from diverse fields allows for deeper exploration and better understanding of researched issues, and therefore they can and should be included in information literacy studies as the tools enabling collection of specific data.

\section{References}

Kang, H. (2014). Understanding online reading through the eyes of first and second language readers: An exploratory study. Computers and Education, 73, 1-8.

Lund, H. (2016). Eye tracking in library and information science: A literature review. Library Hi Tech, 34(4), 585-614.

Plassmann, H. et al. (2011). Consumer neuroscience. In J. N. Sheth, \& N. Malhotra (Eds.), Wiley International Encyclopedia of Marketing (pp. 115-122). Chichester, UK: Wiley-Blackwell.

Roderer, T., \& Roebers, C. M. (2014). Can you see me thinking (about my answers)?: Using eye-tracking to illuminate developmental differences in monitoring and control skills and their relation to performance. Metacognition and Learning, 9(1), $1-23$.

Uggeldahl, K. et al. (2016). Choice certainty in discrete choice experiments: Will eye tracking provide useful measures?. Journal of Choice Modelling, 20, 35-48.

Van Dijk, J. A. G. M., \& Van Deursen, A. J. J. A. M. (2014). Digital skills: Unlocking the information society. New York: Palgrave MacMillan.

Wang, Y., Xie, I., \& Lee, S. (2015). Explore eye movement patterns in search result evaluation and individual document evaluation. Proceedings of the Association for Information Science and Technology, 52(1), 1-4.

Keywords: information literacy, digital skills, biometric tools, experiment, methodology design 


\title{
Researching Information in Everyday Life: The Contribution of Autoethnography and Information Grounds Theory
}

\author{
Bill Johnston \\ University of Strathclyde, Glasgow, Scotland, b.johnston@strath.ac.uk

\section{Sheila Webber} \\ University of Sheffield, UK, s.webber@sheffield.ac.uk
}

The aim of this methods-focused paper is to propose a qualitative approach, autoethnography, as a way of researching information literacy in everyday contexts and in different cultures and settings. In addition we introduce Information Grounds Theory as a means of exploring particular sites of everyday information literacy. We will illustrate our proposals by examples from two ongoing autoethnographic studies: of the 2014 Scottish Independence Referendum, and of practice in the 3D virtual world, Second Life.

Autoethnography is defined by Ellis, Adams \& Bochner (2011, pp273) as: "an approach to research and writing that seeks to describe and systematically analyse (graphy) personal experience (auto) in order to understand cultural experience (ethno)." Autoethnographic researchers draw reflexively and analytically on their experience to uncover insights relevant to a wider cultural context, not just the individual researcher. Anderson \& Fourie (2015) note that research is enriched by a dual perspective (i.e. a person with a specific social/cultural role, who is also an expert information researcher).

Information grounds are environments created when people gather to do something not primarily about information, but information sharing occurs spontaneously and serendipitously (Pettigrew, 1999). Pettigrew's (1999) original study focused on a foot clinic. Other information grounds include places of worship, cafes, and bus stops (Fisher \& Naumer, 2006) and virtual environments (e.g. Talip \& Yin, 2017). Savolainen (2006) noted that Information Grounds is distinctive in surfacing both spatial and temporal issues: a characteristic of information grounds is that they can occur temporarily. Together, these approaches enable rich insights into everyday life. Autoethnography provides rich comprehension of personal experience, and Information Grounds provides an analytical framework, and sharpening awareness of the spatial and temporal dimensions of a given situation.

The first study, focusing on the Scottish Independence Referendum 2014 voting day (as experienced in the city of Glasgow), is part of an ongoing autoethnographic investigation into the first author's experience of the referendum on whether Scotland should become an independent nation. The second study is an exploration of the second author's professional practice in co-organising an international educator's discussion group in the 3D virtual world, Second Life. Drawing primarily on autoethnographic evidence, she is using Information Grounds Theory as one of the lenses to look at practice in a virtual environment. The authors will show how autoethnography and Information Grounds Theory are valuable in these two very different settings, and give examples of autoethnographic analysis.

\section{References}

Anderson, T. D., \& Fourie, I. (2015). Collaborative autoethnography as a way of seeing the experience of care giving as an information practice. Information Research, 20(1). Retrieved from http://InformationR.net/ir/20-1/isic2/isic33.html

Ellis, C., Adams, T. E., \& Bochner, A. P. (2011). Autoethnography: An overview. Historical Social Research, 36(4), $273-290$.

Fisher, K., \& Naumer, C. (2006). Information grounds: Theoretical basis and empirical findings on information flow in social settings. In A. Spink, \& C. Cole. (Eds.), New Directions in Human Information Behaviour (pp. 93-111). Berlin: Springer.

Pettigrew, K. (1999). Waiting for chiropody: Contextual results from an ethnographic study of the information behaviour among attendees at community clinics. Information Processing \& Management, 35(6), 801-817.

Savolainen, R. (2006). Time as a context of information seeking. Library \& Information Science Research, $28,110-127$.

Talip, B., \& Yin, D. B. M. (2017). A proposed model of online information grounds. In IMCOM '17: Proceedings of the 11th International Conference on Ubiquitous Information Management and Communication. New York: Association for Computing Machinery, Inc.

Keywords: autoethnography, citizenship, research methods, information grounds 


\title{
Four Passages to Information Use related Phenomena in Bachelor Theses at the Finnish Universities of Applied Sciences
}

\author{
Juha Kämäräinen \\ Independent researcher, Finland, juha.t.kamarainen@gmail.com \\ Ilkka Mönkkönen \\ University of Helsinki, Finland \\ Jarmo Saarti \\ University of Eastern Finland, Finland
}

Information seeking and use play an important role in completing theses at Finnish Universities of Applied Sciences (UASs). The theses carry values and aims based on those of the UASs, the external partners involved, and the studentauthors. It is discussed how Bachelor theses are built at Finnish UASs in terms of information use events and related processes. A qualitative multiple case study is reported. Our research task is to find out what are the basic assumptions that guide the student's' approaches in information use during the thesis project.

With "passage" we refer to approaches, that student-authors maintain to handle the complexities in information use during the thesis processes. The examples discussed are:

1. Student's' expectations of quantitative norms related to the number of references required.

2. Student's' feelings of aloneness and being unable to find relevant research for her viewpoint.

3. Student's' uneasy stance towards written sources.

4. Examples of replacing proper theories with general heuristics.

In qualitative research, researchers need theoretical sensitivity to gain valid access to data. A researcher would set a broader research task instead of a research question. Our research task is to conceptualize the information use phenomena present in the making of Bachelor theses. Views of information processes in theses can be based on different systemic assumptions. We suggest that these findings should be worked up as part of the efforts necessary in the Finnish Universities of Applied Sciences when students articulate their assumptions and values related to information use. They help in building more effective IL instruction. The systemic assumptions adopted in this study work as "formal categories" in grounded theory research as a link between substantive findings and relevant theoretical developments. The cases analyzed (total of 23) were selected from a database of accepted theses by theoretical sampling. They were selected to challenge and extend the current view of the spectrum of phenomena in information use already identified.

The research task is focused on three different sets of systemic assumptions and related dimensions of information use:

1. The thesis is carried out within quite a predetermined frame that the student is assumed to follow. Given structures and quantitative requirements are essential parts of the information use in this viewpoint. The students may ask about the minimum number of pages and sources cited.

2. The experiences of making theses appear as unique parts of students' life paths. The guidance should consider the subjective dimension of the process. Uncertainty belongs to information use in this point of view.

3. The thesis process appears as a series of events following or challenging information practices considered a part of the thesis as an object and the related processes. When researching and writing an accepted thesis the student connects her selected topic and viewpoint to traditions through information use. Reflection belongs to this view, that combines the predetermined and subjective dimensions of information use.

We suggest that these views, from objectivist to individualist and inter-subjectivist, should be noted in the guiding activities related to developing the students' capabilities under information literacy in higher education.

Keywords: universities of applied sciences, polytechnics, bachelor theses, references 


\title{
Gender Literacy: Fanfiction and Self-expression
}

\author{
Brittany Kelley and Kristen Schuster \\ King's College London, UK, \{brittany.kelley, kristen.schuster\}@kcl.ac.uk
}

Within a year of each other, Shirley Brice-Heath (1983) and Brian Street (1984) made the then ground-breaking argument that literacy is not a neutral, apolitical skill, but rather sets of practices that are shaped by and shape everyday life. Less than a decade later, Henry Jenkins (1992) demonstrated how fans use the tactics of their own readings of pop culture texts to create spaces for their identities, values, and ideas. As Jenkins (1992) argued then, fanfiction remains an important window into how people create and maintain (and even embed) literacy practices into their everyday lives. Online fanfiction is a literacy practice where fans take their favourite characters, settings, and plot points from popular books, movies, or TV shows and write their own, new stories. What at first might seem to some to be a practice of wish fulfilment, has been found by many scholars to be a highly transformative practice for writers, in terms of establishing their legitimacy (Jenkins 1992; Bacon-Smith, 1992; Bury 2005), in terms of becoming more comfortable writing in English (Black 2008), and certainly in terms of providing expanded space for reimaging gender (Scodari \& Felder 2000; Jenkins, Green, \& Jenkins, 2006; Ng 2017; Pande \& Moitra 2017). Two particularly transformative practices within online fanfiction communities include 'Mary Sue' stories, which often place the fanwriter at the centre of the action, and 'slash' stories, which pair two characters of the same sex (and sometimes gender) who are often not paired in the original source text. However, while both of these practices are often denigrated within fan communities, they also provide unique outlets for writers to engage with and rewrite norms related to gender and sexuality.

We suggest that their practices facilitate creative and critical engagement with texts, although their practices are not always connected to information literacy (IL) research and theory. To address this gap, we synthesize Chatman's (1999) theory of small worlds and Gee's (2000) theories of affinity spaces. Whilst Chatman's work provides an analytical framework for examining literacy and information practices in marginalized communities, Gee's research offers a means to examine how rhetorical and social practices shape networks within communities. Together their theories support a more nuanced evaluation of IL practices in fanfiction networks where gender and sex are challenged, but often only to a certain point. Overall, we discuss how literacy practices reflect wider social and cultural norms and offers insight into the tensions and potential points of transformation in rhetorical and social frameworks for understanding gender.

\section{References}

Bacon-Smith, C. (1992). Enterprising women: Television fandom and the creation of popular myth. Philadelphia: University of Pennsylvania Press.

Black, R. (2008). Adolescents and online fan fiction. New York: Peter Lang.

Bury, R. (2005). Cyberspaces of their own: Female fandoms online. New York: Peter Lang.

Chatman, E. (1999). A theory of life in the round. Journal of the American Society for Information Science, 50(3), $207-217$.

Gee, J. P. (2000). The new literacy studies: From 'socially situated' to the work of the social. In D. Barton, M. Hamilton, \& R. Ivanic (Eds.), Situated Literacies: Reading and Writing in Context (pp. 197-209). London: Routledge.

Green, S., Jenkins, C., \& Jenkins, H. (2006). 'Normal female interest in men bonking': Selections from the Terra Nostra Underground and Strange Bedfellows. In H. Jenkins (Ed.), Fans, Bloggers, and Gamers: Exploring Participatory Culture (pp. 61-88). New York: New York University Press.

Heath, S. B. (1983). Ways with words: Language, life, and work in communities and classrooms. Cambridge, UK: Cambridge University Press.

Jenkins, H. (1992). Textual poachers: Television fans and participatory culture. London; New York: Routledge.

$\mathrm{Ng}$, E. (2017). Between text, paratext, and context: Queerbaiting and the contemporary media landscape. Transformative Works and Cultures, 24. doi: 10.3983/twc.2017.0917

Pande, R., \& Moitra, S. (2017). 'Yes, the Evil Queen is Latina!': Racial dynamics of online femslash fandoms. Transformative Works and Cultures, 24. doi: 10.3983/twc.2017.0908

Scodari, C., \& Felder, J. L. (2000). Creating a pocket universe: 'Shippers', fan fiction, and the X-Files online. Communication Studies, 51(3), 238-257.

Street, B. V. (1984). Literacy in theory and practice. Cambridge, UK: Cambridge University Press.

Keywords: literacy frameworks, fanfiction, online 


\title{
How to Measure Energy Information Literacy? An Explorative Study
}

\author{
Teija Keränen
}

University of Oulu, Finland, teija.keranen@oulu.fi

\section{Noora Hirvonen}

University of Oulu and Medical Research Center, Oulu, Finland / Åbo Akademi University, Turku, Finland, noora.hirvonen@oulu.fi

\author{
Anna-Maija Huhta and Maija-Leena Huotari \\ University of Oulu and Medical Research Center, Oulu, Finland, \{anna-maija.huhta, maija-leena.huotari\}@oulu.fi
}

\section{Background and Aim}

This study has two aims: (1) to develop an energy information literacy (EIL) measure that contains both subjective and objective dimensions; and (2) to outline its empirical testing. EIL refers to information literacy (IL) in an energy context and contains the aspects of both energy literacy (EL) and IL. Measures of IL in everyday situations are rare. EL refers to people's understanding and competencies in energy-issues in households, traffic, and industry. In these studies, EL tend to be measured objectively, often by tests, and with subjective measures about attitudes or behavior (DeWaters \& Powers 2013; Blasch et al. 2017). In IL studies, in turn, subjective measures typically reflect self-efficacy (Kurbanoglu 2003). However, appropriate measures depend on the definition of the object that is being measured and its operationalization.

\section{Method and Plan for Empirical Testing}

Our method is argumentative reasoning focusing on strengths and weaknesses of both measurement types. Everyday EIL includes competences that cannot be measured objectively. Objective measures enable comparing screening results as they indicate understanding of current facts on the matter, for example. It is challenging to specify the most essential objective aspects, for example, topical areas of energy knowledge to be included in the measure to capture the competencies related to EIL. A wide range of topics may lead to massive questionnaire forms that may repel less informed respondents and favor experts and, therefore, bias results. We will outline a comparative empirical study among inhabitants of a pioneering municipality pursuing carbon neutrality and other Finns for testing the developed EIL measure. We will explore via questionnaire how the pioneer municipality's example is reflected in residents' everyday EIL. We will compare residents' subjectively and objectively evaluated EIL and their relationship in the similar vein as has been done in health context (Altin et al. 2014; Mayer 2017).

\section{Conclusion}

The contribution of combining subjective and objective measures is significant to the field of everyday EIL and EL. The results may be used to tailor communication, education, and counselling to increase their effectiveness in practice. The societal impact is to raise people's awareness on energy issues for preventing climate change in their everyday lives.

\section{References}

Altin, S. V. et al. (2014). The evolution of health literacy assessment tools: A systematic review. BMC Public Health, $14,1207$.

Blasch, J. et al. (2017). Explaining electricity demand and the role of energy and investment literacy on end-use efficiency of Swiss households. Energy Economics, 68(Supplement 1), 89-102.

DeWaters, J., \& Powers, S. (2013). Establishing measurement criteria for an energy literacy questionnaire. Journal of Environmental Education, 44(1), 38-55.

Kurbanoglu, S. (2003). Self-efficacy: A concept closely linked to information literacy and lifelong learning. Journal of Documentation, 59(6), 635-646.

Mayer, A. K. (2017). Subjective and objective measures of health information literacy: Do they provide complementary or redundant information. In S. Špiranec et al. (Eds.), The Fifth European Conference on Information Literacy (ECIL): Abstracts, September 18-21, 2017, Saint-Malo, France (p. 95). Saint-Malo: Information Literacy Association.

Keywords: energy information literacy, everyday life, self-efficacy, subjective measurement, objective measurement 


\title{
The Social Dynamics of Innovation in French Public Libraries: Communities of Practice and Knowledge Production
}

\author{
Susan Kovacs \\ University of Lille, France, susan.kovacs@univ-lille.fr
}

Public libraries in France, as elsewhere, are currently undergoing important changes as a result of evolving digital technologies, regional territorial restructuring initiatives and changing modes of knowledge and information exchange and transfer. In this context, and in an attempt to reinvigorate the social and political role of the library today, French municipal libraries have begun experimenting with new collaborative and participatory devices and projects which tend to blur the boundaries between the roles of different actors as they co-construct library services. While recent publications have explored the phenomenon of the Fab Lab in various settings (urban centers, museums) as it fosters new forms of knowledge transfer (Ferchaud, Dumont, 2017; Lhoste, Barbier, 2016), and while a number of studies have evaluated the opportunities and limits posed by participatory culture through innovation in North American or UK libraries (Moulaison, 2015; Cavanagh, 2015; Castelnovo, 2016; Deodato, 2014), detailed analysis of municipal library maker spaces and participatory projects in France has yet to be undertaken. This paper will explore the ways in which new socio-technical forms of collaboration and participation in French municipal libraries contribute to the production, sharing and appropriation of knowledge and competencies at the intersection of information and science literacy. My primary research objective is to understand the modes of learning, exchange and sociability that are developed through creative workshops and maker initiatives, and in so doing, to identify the ways in which collaborative and participatory practices tend to promote information and science literacy. The main hypothesis of this study is that such participatory initiatives, which seek to integrate the societal, educational and informational missions of the library, emulate and adapt models and methods of entrepreneurial start-up culture, adapting them to specific local concerns and priorities. In order to analyze the ways in which innovative participatory projects are planned, conceived and carried out in relation to particular local goals and challenges, I have undertaken ethnographic case studies within three municipal libraries in the Lille area of Northern France, as well as within two libraries outside France, one in the UK (in Exeter) and one in the US (Philadelphia). In this paper I will present preliminary results of this project, as obtained through semi-structured interviews with library professionals, analysis of program statements and communication artifacts as well as through ethnographic observations of workshops and maker or collaborative spaces. Results suggest that recent initiatives in France, often exploratory and modest in nature, seek to modernize the image of the public library, with particular attention given to the needs of the young. These initiatives draw on methods of design thinking to foster flexible learning environments which address information literacy issues indirectly, as they emerge through experience and practice. While limited in scope and duration, such initiatives offer spaces of creation and creativity which contribute to refashioning the role of the French public library as a place of engagement and informal learning.

\section{References}

Castelnovo, W. (2016). Co-production makes cities smarter: Citizens' participation in smart city initiatives. In M. Fugini, E. Bracci, \& M. Sicilia (Eds.), Co-production in the Public Sector: Experiences and Challenges (pp. 97-117). Cham: Springer.

Cavanagh, M. F. (2016). Micro-blogging practices in Canadian public libraries: A national snapshot. Journal of Librarianship and Information Science, 48(3), 247-259.

Deodato, J. (2014). The patron as producer: Libraries, web 2.0, and participatory culture. Journal of Documentation, 70(5), 734758.

Ferchaud, F., \& Dumont, M. (2017). Les espaces de fabrication et d'expérimentation numérique sont-ils des tiers-lieux?. Territoire en mouvement Revue de géographie et aménagement, 34. doi: 10.4000/tem.4203

Lhoste, É., \& Barbier, M. (2016). FabLabs: L'institutionnalisation de Tiers-Lieux du 'soft hacking'. Revue d'anthropologie des connaissances, 10(1), 43-69.

Moulaison, H. L. (2015). L'autoédition au sein de la bibliothèque publique: Étude de cas d'une nouvelle génération de bibliothèque participative. Retrieved May 22, 2018 from http://codabox.org/150/1/MOULAISON-AIFBD2014_Actes.pdf

Keywords: public library, participatory culture, maker space, scientific and technological literacy, digital literacy, information culture, knowledge transfer 


\title{
Copyright Literacy of LIS Students in the Czech Republic
}

\author{
Pavla Kovářová \\ Masaryk University, Brno, Czech Republic. kovarova@phil.muni.cz
}

\begin{abstract}
Research Background
The basic service of libraries and other cultural heritage institutions is to make information accessible. But at the same time information is (or was) protected by copyright. Correct handling of author's' works requires a sufficient level of copyright literacy. It "include[s] identifying copyright-protected materials, navigating fair use and fair dealing, obtaining permissions and licenses where necessary, and recognizing infringement of copyright law." (Harris, 2017) Expansion of digital technologies has brought new needs which should be reflected in copyright literacy (Morrison \& Secker, 2015). Tania Todorova (Bulgaria) initiated an international research team whose aim has been to map copyright literacy among librarians since 2013. The results showed that copyright literacy is an important topic and a part of library practice. But at the same time, the study identified shortcomings in the competencies of librarians (Todorova et al., 2017). Preparing for a job in library and information services is the goal of Library and Information Science (LIS) departments. Therefore, the extended research group focused on LIS students in 2017.
\end{abstract}

\section{Objectives and Methodology}

The aim of the paper is to present the results of the survey focused on the knowledge and opinions of LIS students in relation to copyright literacy in the Czech Republic. The results will allow us to revise the LIS curriculum to fit current needs. This research study is part of a multinational survey. It strives for better national and international standardization of the competencies of LIS students, and consequently, also of staff in libraries, the cultural heritage sector and in both commercial and noncommercial information services, as well as cooperation in improving their copyright literacy.

Data collection took place via an online questionnaire in LimeSurvey between 9th November 2017 and 31 st January 2018. The questionnaire link was distributed to all LIS students in the Czech Republic via the communication channels of individual departments, where the managers were asked to cooperate on distribution. We received 199 responses covering all three universities (and grades) where LIS is taught in the Czech Republic. The research sample included both students educated and not educated in analyzed topics.

\section{Outcomes}

This research study has identified a number of problems with student knowledge. Students did not know about copyright protection of specific types of works - some not closely connected with libraries (dance, choreography and pantomime - incorrectly answered by $30.7 \%)$. In addition, however, problems were noted with databases $(27.1 \%$ incorrect answers) or unpublished works (e.g. theses, 16.1\%). Students rated fairly negatively their copyright literacy competences (especially the international context), even though copyright is a topic in a mandatory subject in all three universities, and $89.9 \%$ of respondents agree that librarians must be familiar with copyright issues. A majority, $61.3 \%$ of the respondents, also stated that it is necessary to include intellectual property rights in the LIS curricula, with $77.4 \%$ placing it at the bachelor level. Students would welcome the extension of their education in copyright literacy as opposed to continuing in the current state, especially in the international context, and along with more detailed solutions of practical issues (e.g. digitization or e-learning).

\section{References}

Harris, L. E. (2017). Copyright literacy and translating copyright to a life skill. Retrieved February 5, 2018 from https://www.copyrightlaws.com/copyright-literacy-copyright-life-skill/

Morrison, C., \& Secker, J. (2015). Copyright literacy in the UK: A survey of librarians and other cultural heritage sector professionals. Library and Information Research, 39(121), 75-97.

Todorova, T. Y. et al. (2017). Information professionals and copyright literacy: A multinational study. Library Management, 38(6/7), 323-344.

Keywords: LIS education, information literacy, copyright literacy, research, Czech Republic 


\title{
Information Literacy of Masaryk University Students and Evaluation of Campus-wide Course
}

\author{
Pavla Kovářová \\ Masaryk University, Brno, Czech Republic. kovarova@phil.muni.cz
}

\section{Research Background}

Information literacy helps students in their academic and personal life (Shao \& Purpur, 2016). A nationwide selfevaluation in information literacy identified a lot of problems in competencies of Czech university students (Landová, Prajsová, \& Tichá, 2016). The question is how to correlate self-evaluation and objective evaluation. Competencies in awareness of information needs, its acquisition, critical evaluation, and effective use should be included in courses with consideration of information technology (Framework for Information Literacy for Higher Education, 2015). Information literacy education can be embedded in field curricula, long-term or one-shot sessions, where the first two approaches and connection with the real life of individual students have better results (Anderson \& May, 2010). Elearning helps students choose the time and topics that suit their needs, but the role of tutor is important (Nichols Hess \& Greer, 2016).

\section{Objectives and Methodology}

This research had two related goals. The primary goal was to determine the level of information literacy of Masaryk University students by means of a test. This level could be improved by the campus-wide information literacy course. Therefore, the second goal was to identify changes in competencies of students after the semester online course by comparing the pre-test and post-test results. Both results should be reflected in field curricula or the evaluated course to strengthen education in areas identified as insufficient competencies.

Data was collected using an online questionnaire in autumn semesters in 2016 and 2017 (pre-tests in the first two weeks of each semester, post-tests after the studying period in December to February). Both tests were distributed to all students enrolled in the course at the time of data collection. We received 1287 responses in pre-tests and 550 responses in post-tests from all nine faculties at Masaryk University.

\section{Outcomes}

In self-evaluation, students felt they were best at Internet searching, defining the topic, and formal text processing. On the other hand, working with databases, creation of text, and sharing of one's own work received the worst selfevaluation. In the pre-test, students had the most problems with library services, self-presentation, and visualization, while suitability of resources, social networks, and structure of document were the least problematic topics. After the course, the worst results were in response to questions about type of text, search query, form of a text, and visualization. On the contrary references, data storage and backup, resource evaluation, and orientation in a document had the best results. The paired t-test showed a statistically significant improvement of competencies.

\section{References}

Anderson, K., \& May, F. A. (2010). Does the method of instruction matter? An experimental examination of information literacy instruction in the online, blended, and face-to-face classrooms. The Journal of Academic Librarianship, 36(6), 495-500.

Association of College and Research Libraries. (2015). Framework for Information Literacy for Higher Education. Retrieved September 23, 2016 from http://www.ala.org/acrl/sites/ala.org.acrl/files/content/issues/infolit/Framework_ILHE.pdf

Landová, H., Prajsová, J., \& Tichá, L. (2016). Information literate or not?: A nationwide survey among university students in the Czech Republic. In S. Kurbanoğlu et al. (Eds.), Information Literacy: Key to an Inclusive Society, The Fourth European Conference on Information Literacy, ECIL 2016, Prague, Czech Republic, October 10-13, 2016: Revised Selected Papers (pp. 317-326). Cham: Springer International Publishing.

Nichols Hess, A. K., \& Greer, K. (2016). Designing for engagement: Using the ADDIE model to integrate high-impact practices into an online information literacy course. Communications in Information Literacy, 10(2), 264-282.

Shao, X., \& Purpur, G. (2016). Effects of information literacy skills on student writing and course performance. The Journal of Academic Librarianship, 42(6), 670-678.

Keywords: information literacy, university education, research, Czech Republic 


\title{
Data Literacy and Research Data Management Practices of Academics and Research Students in Australian Universities
}

\author{
P. Thomas Lacey \\ RMIT University, Melbourne, Australia, s3643561@student.rmit.edu.au

\section{Katherine Howard} \\ Flinders University, Adelaide, Australia, katherine.howard@flinders.edu.au
}

The availability and volume of scientific data has grown exponentially in recent years, and increasingly, research funding bodies are requiring data management plans to be included in funding applications. Research data management (RDM) is about "the organisation of data, from its entry to the research cycle through to the dissemination and archiving of valuable results" (Whyte and Tedds, 2011). It consists of a number of processes such as the design and creation of data, storage, security, preservation, retrieval, sharing, and reuse (Cox and Pinfield, 2014). Storage, organisation, and access of data and data sets for reuse provides many advantages such as efficient use of resources, repeatability, and verification of the research and the reuse of data for different purposes. Thus, RDM and data practices of academics and researchers have become extremely important (Tenopir, et al. 2011).

This situation creates a need for training in data literacy and RDM to enable academics and researchers to access, interpret, critically assess, manage, handle and ethically use data (Prado, 2013). To date, and as far as has been determined, no study has been undertaken of academics and/or researchers in Australian universities to determine their current levels of data literacy or RDM knowledge. A related study was undertaken by Corrall, Kennan and Afzal (2013) to determine the data support activities of libraries in selected locations. More recently, Gekara et al. (2017) have called for a 'national digital skills framework' to be developed in Australia, which should include competence in the area of information and data literacy.

The aim of the study is to collect information about the data literacy and RDM practices of academics and research students in higher education institutions in Australia. The responses will assist in fully understanding the current levels of awareness and gaps in knowledge that will help to develop appropriate data literacy training for the higher education community.

The current study is a standalone piece of research, however it is part of the Data Literacy Multinational Study and therefore used the same on-line questionnaire designed by an international research team (Chowdhury et al., 2016), which was hosted on the Lime Survey platform. The self-administered questionnaire consisted of 25 closed questions (5 demographic questions) and was sent to all 43 universities in Australia for distribution to academic staff and PhD students.

\section{References}

Chowdhury, G. et al. (2016). Information practices for sustainability: Information, data and environmental literacy. In S. Špiranec et al. (Eds.), The Fourth European Conference on Information Literacy (ECIL): Abstracts, October 10-13, 2016, Prague, Czech Republic (p. 22). Prague: Association of Libraries of Czech Universities.

Corrall, S., Kennan, M. A., \& Afzal, W. (2013). Bibliometrics and research data management services: Emerging trends in library support for research. Library trends, 61(3), 636-674.

Cox, A. M., \& Pinfield, S. (2014). Research data management and libraries: Current activities and future priorities. Journal of Librarianship and Information Science, 46(4), 299-316.

Gekara, V. et al. (2017). Developing appropriate workforce skills for Australia's emerging digital economy. Retrieved February 7 , 2017 from https://www.ncver.edu.au/_data/assets/pdf_file/0035/968813/Developing-appropriate-workforce-skills.pdf

Prado, J. C., \& Marzal, M. Á. (2013). Incorporating data literacy into information literacy programs: Core competencies and contents. Libri, 63(2), 123-134.

Tenopir, C. et al. (2011). Data sharing by scientists: Practices and perceptions. PloS One, 6(6). Retrieved from http://journals.plos.org/plosone/article?id=10.1371/journal.pone.0021101

Whyte, A., \& Tedds, J. (2011). Making the case for research data management. DCC Briefing Papers. Edinburgh: Digital Curation Centre.

Keywords: research data management, data literacy, higher education, academics, research students, Australia 


\title{
Academic Writing Centers as Tools for Information Literate Students
}

\author{
Ane Landøy
}

University of Bergen Library, Norway, ane.landoy@uib.no

Natalia Cheradi

Academy of Economic Sciences, Chisinau, Republic of Moldova, cheradi@lib.ase.md

Angela Repanovici

Transilvania University of Brasov, Romania, arepanovici@unitbv.ro

\section{Silvia Ghinkulov}

Academy of Economic Sciences, Chisinau, Republic of Moldova, gsilvia@lib.ase.md

Universities and their libraries utilize centers for academic writings as tools for enabling students to gain an education of higher quality (Denchuk, 2011; Milewicz, 2009). At the same time, academic writing centers come in many different forms and formats: They can be organized by the university library or an academic discipline, placed in the library or outside the library, and staffed by librarians, academics, Master students or a mix.

In this paper, the authors present a study of 35 academic writing centers from the USA and Europe based on information found on their institutional web sites and show how this has inspired the development of academic writing centers in Norway and in the Republic of Moldova. The method is information analysis to determine organizational and practical differences, and look for patterns, similarities and best practices.

Against this background, a survey of attitudes and practical concerns of the library leaders in academic libraries in the Republic of Moldova shows their confidence in several areas. They are certain that creating academic writing centers will maximize the libraries' contribution to research and enhance the quality. This will strengthen the library's role in the framework of the academic knowledge system. The instrument used for the survey is a self-administrated questionnaire provided online by SurveyMonkey.

\section{References}

Denchuk, A. (2011). The role of language and academic literacy in the success of generation 1.5 students at two Canadian universities (Thesis). Retrieved from ProQuest Dissertations \& Theses Global. (1022335734)

Milewicz, E. J. (2009). "But is it a library?" The contested meanings and changing culture of the academic library (Thesis). Retrieved from ProQuest Central; ProQuest Dissertations \& Theses Global. (305092448)

Keywords: Moldova, Norway, Academic writing center, academic library 


\title{
Artificial Intelligence and Labor: Media and Information Competencies Opportunities for Higher Education
}

\author{
Jesus Lau \\ Universidad Veracruzana, Veracruz, México / CETYS Universidad, jlau@uv.mx \\ José Luis Bonilla and Alberto Gárate \\ CETYS Universidad, Baja California, México, \{joseluis, albertogarate \}@ cetys.mx
}

Artificial intelligence is emerging in our daily lives, making wiser robots and new machine learning a reality (Borrego, 2017). Some of our important decisions, either professional or personal, such as entertainment, are already predetermined by the algorithms of artificial intelligence, such as Facebook friends news, Spotify music choices, airplane flights, and vacuum cleaning, and other applications. Such artificial intelligence actions unconsciously influence and "manipulate" our personal actions. Our society and our workforce, including university graduates will soon if not now face unanticipated challenges in the labor market, not to mention their daily routines, due to new "learned" machine actions (Brynjolfsson and Syverson, 2017). Educational systems have the challenge and opportunity to train and re-train the new cadre of professionals in the development of more cognitive skills, among them, information competencies -- the knowledge tools of any cognitive human action -- that will enable them to compete in the job arena (World Economic Forum, 2018). In this conceptual paper, the basic role of information competencies in the development of cognitive skills demanded by the new "artificial intelligence decision-making economy and the shifting of standard jobs into new ones" (Daron and Restrepo; Korinek, A., Stiglitz, 2017), and the opportunities for higher education will be discussed. The basis of the paper will be to review current literature to identify information literacy (IL) demands and potential strategies that can be deployed in higher education to enhance students' cognitive skills.

\section{References}

Borrego Díaz, J. (2017). Inteligencia Artificial y el futuro: De la percepción a la realidad. Revista Libre Pensamiento, 89, 53-59.

Brynjolfsson, E., Rock, D., \& Syverson, C. (2017). Artificial intelligence and the modern productivity paradox: A clash of expectations and statistics. Retrieved April 3, 2018 from http://www.nber.org/papers/w24001.pdf

Daron Acemoglu, D., \& Restrepo, P. (2017). Artificial intelligence, automation and work. Retrieved April 3, 2018 from http://www.nber.org/papers/w24196.pdf

Korinek, A., \& Stiglitz, J. E. (2017). Artificial intelligence and its implications for income distribution and unemployment. Retrieved April 3, 2018 from http://www.nber.org/papers/w24174.pdf

World Economic Forum \& Boston Consulting Group. (2018). Towards a reskilling revolution: A future of jobs for all. Retrieved April 3, 2018 from https://www.weforum.org/reports/towards-a-reskilling-revolution

Keywords: information literacy, artificial intelligence, machine learning, professional skills, information competencies, higher education 


\title{
Information Overload of Academic Staff in Higher Education Institutions in Estonia
}

\author{
Liia Lauri and Sirje Virkus \\ Tallinn University, Estonia, liia.lauri@archimedes.ee, sirje.virkus@tlu.ee
}

\section{Objective and Value}

Information overload is the condition where the amount of potentially available relevant information is a barrier to effective information use. This is not a new phenomenon, however, in the digital age, individuals and organizations face new challenges. It has been stated that information overload is rather the "co-product" of other problems in the digital age (Savolainen, 2007), namely, overload of work-tasks, lack of time, and fragmentation of actions (Bawden \& Robinson 2009). Misla \& Stokols (2012) have also analysed the health outcomes of information and technological overload.

In this paper we focus on perceived information overload of academic staff (teaching faculty) in the context of the information culture of higher education institutions (HEIs) in Estonia. The aim of this study was to explore the relationship between the perception of information overload, information management, and information literacy. The aim is to give recommendations to HEIs for the development of information culture and information literacy skills that support coping with the information overload.

\section{Methodology}

Our research used a web-based questionnaire survey. The study used data that was gathered for the study of information culture of HEI (Lauri, Heidmets \& Virkus 2016). The questionnaire consisted of 39 questions, both closed and open-ended, thus yielding both quantitative and qualitative data. We presented most items as statements and respondents indicated their agreement on a scale of 1 (strongly disagree) to 5 (strongly agree). A total of 144 academics from 12 HEIs (four universities and eight professional HEIs) completed the survey.

\section{Outcomes}

More than $60 \%$ of academic staff admit that it has been hard for them to cope with information overload during the last month. At the same time, only $38 \%$ have been involved in developing their information literacy skills. Almost half of the respondents haven't used new information channels or software during the last month. The main barriers to work-related information seeking and use that were outlined were lack of time, information overload, and information that was too unstructured, scattered between different sources. Analyses of the empirical study results revealed differences in information management, sharing and use in different types of HEIs. The higher education system in Estonia consists of universities and professional HEIs. Professional HEIs provide higher education programmes in the first and second cycles of higher education, and are more oriented towards the labor market. The information sharing practices have been more formalised in professional HEIs. People cooperate more frequently within the HEI and members of the academic staff are more satisfied with the organisation and availability of information in these institutions. According to the previous study of information culture in HEIs (Lauri, Heidmets \& Virkus 2016), an integrated information culture is the prevailing form of information culture in professional HEIs. However, further study is needed in order to understand the impact of the information culture for coping strategies with information overload.

\section{References}

Bawden, D., \& Robinson, L. (2009). The dark side of information: Overload, anxiety and other paradoxes and pathologies. Journal of Information Sciences, 35(2), 180-191.

Lauri, L., Heidmets, M., \& Virkus, S. (2016). The information culture of higher education institutions: The Estonian case. Information Research, 21(3), 722.

Misra, S., \& Stokols, D. (2012). Psychological and health outcomes of perceived information overload. Environment and Behaviour, 44(6), 737-759.

Savolainen, R. (2007). Filtering and withdrawing: Strategies for coping with information overload in everyday contexts. Journal of Information Sciences, 33(5), 611-621.

Keywords: information overload, information culture, information literacy, higher education institutions, Estonia 


\title{
Students on a Social Media 'Detox': Disrupting the Everyday Practices of Social Media Use
}

\author{
Krista Lepik and Maria Murumaa-Mengel \\ University of Tartu, Estonia, krista.lepik@ut.ee
}

We set out to explore how disruption of habitual social media use reshapes the information needs and practices of young adults. We were particularly interested in people's perceptions of passing time: its pace, and connections between perceptions of time and sustaining peer relationships. Drawing on Poirier \& Robinson (2014) with the main focus on temporal aspects of new technology and information culture, we have framed our research with ideas of the Slow Movement, described as a response to the general increased pace of life. The pace of life is here coupled with social media use that has invisibly pervaded people's everyday life and is increasingly time-consuming. Simultaneously, although reflexivity has been a recognized component of both information literacy and 'new' literacies (Buschman, 2009), there is less time to reflect upon the information acquired. Nevertheless, Rheingold (2010) sees attention as fundamental part of literacies - to be aware and present, knowing when to be alert and when to block out distractions.

In the fall semester of 2017, we asked BA-level students enrolled in the "Information society and new media" course at the University of Tartu to stop using social media for five consecutive days. The students kept personal diaries about this experience and were offered a choice to submit their diaries for our study. 29 submitted diaries were analyzed using within-case and cross-case qualitative text analysis, more specifically thematic qualitative text analysis (Braun \& Clarke, 2006).

Participants expressed anxiety brought on by the non-usage and perceived slowing of time. Although non-usage is temporary here, it can be described as "a condition of inclusion or exclusion in the "community of practice" (Schmidt 2014: 7). The participants often found solace in getting back to 'normality' soon, to binge-scroll everything after the five-day-abstinence. Slowing of time was often perceived as negative, meaning boredom and 'fear of missing out' while being inaccessible to their peers. Alternatively, many participants expressed fulfillment and a sense of serenity from the absence of constant availability. To conclude, temporal aspects of information culture shape a notable part of students' information behavior and by disrupting the norm, we can enable and facilitate self-reflexivity about the accelerated social time.

\section{References}

Braun, V., \& Clarke, V. (2006). Using thematic analysis in psychology. Qualitative Research in Psychology, 3(2), 77-101.

Buschman, J. (2009). Information literacy, "new" literacies, and literacy. The Library Quarterly, 79(1), 95-118.

Poirier, L., \& Robinson, L. (2014). Informational balance: Slow principles in the theory and practice of information behavior. Journal of Documentation, 70(4), 687-707.

Rheingold, H. (2010). Attention, and other 21st-century social media literacies. Educause Review, 45(5), 14-16.

Schmidt, J. H. (2014). Twitter and the rise of personal publics. In K. Weller et al. (Eds.), Twitter and Society (pp. 3-14). New York: Peter Lang.

Keywords: information behavior, slow movement, social media use, students 


\title{
Usability of Social Network Analysis in Assessing Libraries' Community Roles. Proof of Concept
}

\author{
Helena Lipkova, Tomáš Diviak, Adéla Jarolímková, Barbora Drobikova and Hana Landova \\ Charles University, Prague, Czech Republic, helena.lipkova@ff.cuni.cz, tomas.diviak@gmail.com, \{hana.landova, \\ adela.jarolimkova, barbora.drobikova\}@ff.cuni.cz
}

\section{Overview}

The concomitant phenomenon of contemporary society's development is the radical transformation of information and communication processes, the disruption of traditional social ties and an increase in distrust. This situation also influences the role of libraries in society, with particular impact on public libraries. Public libraries fulfil their traditional cultural function by providing access to information, but they also perform an increasingly important community role. Thus public libraries can significantly contribute to forming and consolidating trust in the society at the mezzo-level between macro and microsphere, strengthen social cohesion, and consolidate relations between stratified groups of the society at the local level (Halpern, 2005; Vårheim, 2017).

An essential condition for fulfilling the community role is a thorough understanding of the position of the public library in the local social network. The approaches used by libraries so far are based on partial, intuitive forms of assessment. In our study, we prove that the analysis of such networks can be based on a theoretically as well as methodologically rigorous approach. This article outlines the possibilities of using a specific sociological method - Social Network Analysis (SNA) - in the field of library and information science (LIS), specifically to analyze the position of the library in the local community and the community itself as a whole (Robins, 2015; Scott, 2013).

\section{Method and Outcomes}

The main contribution of this study is the pilot verification of SNA implementation in a local library in a small town environment, in this case Sedlčany town in Central Bohemia (population 7,000). In the framework of the study, a socio-centric approach of the "whole network" as a system of social relations among local organizations, firms and public institutions is carried out. It examines: 1) the centrality of individual nodes (identifying the most important as well as the least important nodes and bridging nodes), 2) cohesion of the whole network (compact/fragmented, density of the relationships) 3) nodes subgroups in the network (identifying clusters of mutually linked nodes) etc. Data for the analysis will be gathered from publicly available resources (e.g., newspapers, web presentations, calendars of cultural events). A subjective perception of community relations will be identified in cooperation with the library director using mind-maps and semi-structured interview. In the end, both outcomes will be compared in order to prove usability of the SNA in the process of assessing libraries' community role. A visualisation software tool is used for the final presentation of the network structure.

The article identifies the benefits and limitations of SNA in the process of a) defining the library's community role, and b) building its strategy for development in local conditions. The resulting map of nodes, relationships and links in the local social network can serve as a basis for community development, so that the individual elements together form a meaningful, comprehensive and targeted strategy to help increase the integrity of the local community, reduce social exclusion, better integrate all inhabitants into the key activities of the community, consolidate mutual trust in society, and cultivate local interpersonal relationships.

\section{References}

Halpern, D. (2005). Social capital. Cambridge, UK; Malden, MA: Polity Press.

Robins, G. (2015). Doing social network research. London: SAGE Publications.

Scott, J. (2013). Social network analysis. London: SAGE Publications.

Vårheim, A. (2017). Public libraries, community resilience, and social capital. Information Research, 22(1), 1-14.

Keywords: social network analysis, SNA, community role, libraries, analysis 


\title{
The Everyday Information Experiences of Breastfeeding Mothers: A Literature Review
}

\author{
Hayley Lockerbie \\ Robert Gordon University, Aberdeen, UK, h.lockerbie@rgu.ac.uk \\ Konstantina Martzoukou \\ Robert Gordon University, Aberdeen, UK, k.martzoukou@rgu.ac.uk
}

\section{Introduction and Rationale}

This paper examines everyday life health information literacy (IL) experiences and practices of breastfeeding mothers. The World Health Organisation recommends that babies be fed breastmilk exclusively for the first six months, and as part of their diet for their first two years (WHO 2017). Yet breastfeeding rates in low-, middle- and high-income countries are low, with social attitudes cited as a major barrier (Boseley, 2017).

\section{Methodology}

A literature review was conducted (March to April 2017), using broad search terms, "breastfeeding" and "breastfeeding AND information", using databases from the library and health domains (LISTA, Emerald, Web of Science, CINAHL, Intermid, ScienceDirect, and Cochrane Library) to identify any research addressing IL aspects in existing literature. A total of sixty-nine papers addressing broader aspects of information related behaviour were identified and a final set of thirty papers were selected focusing on aspects of IL. The thematic analysis was conducted using the categories of knowledge construction, deconstruction and extension which form part of the socio-cultural lens of an emerging model which examines everyday life IL (Martzoukou and Abdi 2017).

\section{Results and Discussion}

The results highlight that women's exposure to a variety of informal information via their immediate social network, their home environment, and online sources have expanded their ability to inform themselves without relying only on formal healthcare practitioners during the ante- and post-natal periods. Mobile technologies have also enabled easier interpersonal communication without the need to physically meet other mothers. Additionally, a significant source of information for breast-feeding women is their own embodied experiences (Lloyd 2006) of interacting with their babies (knowledge construction). However, encountering information via a myriad of sources may lead women to question what they already know as they receive well-intentioned but conflicting or outdated advice. This may lead them to reinterpret what their experiences tell them, to encounter information overload, trigger loss of trust with healthcare practitioners, or manifest a tension in relation to expectations vs the reality of breastfeeding. Therefore this paper argues that breastfeeding women are exposed to a complex but rich information environment, which enables the creation of collective knowledge domains (knowledge extension) by women sharing information and individual embodied experiences of breastfeeding, deconstructing prior knowledge gained via formal sources (knowledge deconstruction). Interventions around breastfeeding have focused on supporting the initiation and continuation of breastfeeding and the authors would argue that such interventions should be underpinned by IL support which includes an understanding of the breast-feeding mother's rich and transitional information experiences.

\section{References}

Boseley, S. (2017). UK attitudes to breastfeeding must change, say experts. The Guardian. Retrieved from https://www.theguardian.com/lifeandstyle/2017/aug/01/uk-attitudes-to-breastfeeding-must-change-say-experts

Lloyd, A. (2006). Information literacy landscapes: An emerging picture. Journal of Documentation, 62(5), 570-583.

Martzoukou, K., \& Abdi, E. S. (2017). Towards an everyday life information literacy mind-set: A review of literature. Journal of Documentation, 73(4), 634-665.

WHO. (2017). Breastfeeding. Retrieved February 8, 2017 from http://www.who.int/topics/breastfeeding/en/

Keywords: breastfeeding, information literacy, health literacy, everyday life, women 


\title{
Information Literacy and Open Science: Before and After the New ACRL Framework
}

\author{
Carlos Lopes \\ ISPA - Instituto Universitário, Lisboa / Applied Psychology Research Center, Portugal, clopes@ispa.pt
}

\author{
Maria da Luz Antunes \\ Escola Superior de Tecnologia da Saúde de Lisboa / Instituto Politécnico de Lisboa / Applied Psychology Research \\ Center, Portugal, mluz.antunes@estesl.ipl.pt
}

\section{Tatiana Sanches}

Instituto de Educação / Universidade de Lisboa / Applied Psychology Research Center, Portugal, tsanches@fpie.ulisboa.pt

In 2000, ACRL published the Information Literacy Competency Standards for Higher Education, clarifying and describing specific learning objectives for higher education students (ACRL, 2000). The document recognized the role of librarians who had long been informally developing these practices. Over the years, many disciplines have been inspired to formulate their specific objectives (Giarlo, 2005). But the Standards have evolved to be reviewed and reevaluated in terms of their relevance and application. In 2016, the ACRL adopted the new Framework for Information Literacy for Higher Education (ACRL, 2016), which sustains a metamorphosis. Information literacy remains a pattern of integrated competencies that encompass the reflexive discovery of information, the understanding of how information is produced and valued, and the use of information in the ethical and legal creation of new knowledge. But the new Framework is based on a set of interconnected and flexible implementation concepts, whose frames are: Authority is constructed and contextual; Information Creation as a process; Information has Value; Research as inquiry; Scholarship as conversation; Searching as strategic exploration. The new Framework suggests a different approach to integrating information literacy into Open Science, emphasizing knowledge about skill acquisition. Based on a literature review, this study discusses the challenges and practical implications that the new Framework has in Open Science, its flexibility, the relevance for the privacy and rightful authorship of scientific data, and the new steps of the academic libraries to become involved as key players for Open Science contents. The conclusion is that this relationship opens the way for librarians, teachers and other institutional partners to reshape training, courses and even curricula (Foster, 2017); it associates information literacy with successful student initiatives (Corrall, 2014); it collaborates pedagogically in research and involves students in this process (Basili, 2017); and it broadens dialogue within and outside higher education about learning, assessment, and academic communication (Steinerová, 2016). Finally, academic libraries need to be involved more in advocacy, encouraging scientists and other stakeholders in the scientific research process, which gives them the confidence to embrace Open Science.

\section{References}

Association of College and Research Libraries. (2000). Information literacy competency standards for higher education. Chicago: American Library Association.

Association of College and Research Libraries. (2016). Framework for information literacy for higher education. Retrieved May 21, 2018 from www.ala.org/acrl/standards/ilframework

Basili, C. (2017). Information literacy requirements for open science. In D. Sales, \& M. Pinto (Eds.), Pathways into Information Literacy and Communities of Practice (pp. 229-248). Amsterdam: Chandos.

Corrall, S. (2014). Designing library for research collaboration in a network world: An exploratory study. Liber Quarterly, 24(1), $17-48$.

Facilitate Open Science Training for European Research. (2017). Definition: Open science. Retrieved May 21, 2018 from www.fosteropenscience.eu/foster-taxonomy/open-science-definition

Giarlo, M. J. (2005). The impact of open access on academic libraries. Retrieved May 21, 2018 from www.lackoftalent.org/michael/papers/532.pdf

Steinerová, J. (2016). Open science and the research information literacy framework. In S. Kurbanoğlu et al. (Eds.), Information Literacy: Key to an Inclusive Society, The Fourth European Conference on Information Literacy, ECIL 2016, Prague, Czech Republic, October 10-13, 2016: Revised Selected Papers (pp. 277-285). Cham: Springer International Publishing.

Keywords: information literacy, open science, open access, ACRL Framework, higher education 


\title{
Digital Competence for Digital Citizenship: an Emerging Agenda for Students, Academics and Libraries in Partnership
}

\author{
Konstantina Martzoukou \\ Robert Gordon University, Aberdeen, Scotland, k.martzoukou@rgu.ac.uk \\ Crystal Fulton \\ University College Dublin, Dublin, Ireland, crystal.fulton@ucd.ie
}

\section{Introduction and Rationale}

Various groups have defined digital literacy abilities and competencies. IFLA describes 'digital literacy' as "the ability to harness the potential of digital tools" and the Internet to its "fullest effect - efficiently, effectively and ethically - to meet information needs in personal, civic and professional lives" creatively, safely and with respect to rights and diversity (IFLA 2017). The EU has identified the necessity to improve citizens' digital competencies for work and employability, learning, leisure, consumption and participation in society, addressing critical thinking and reflection and life-long learning, information and data literacy, communication and collaboration, digital content creation, safety, and problem solving (Carretero Gomez et al., 2017). In the university context, however, previous research has found that students may not engage in practices associated with digital citizenship, such as e-democracy and e-government or sourcing and using online legal and financial information. The gap in students' digital literacy highlights a lack of such skills as evaluating credibility of information and developing digital resilience. Although students are transferring into their educational environments habitual, self-taught and superficial digital behaviours, they remain perceived by their educators as digital natives who have mastered essential digital competencies. University learning strategies do not necessarily holistically explore everyday digital citizenship experiences brought into education from an increasingly interconnected and changing everyday digital world. In addition, there is still a need for "increasing communication between academic faculty, academic support staff and librarians to better understand each other's roles and remits, and find areas for effective collaboration" (Karnad 2017 p.17). Finally, academics' and librarians' own digital literacies may require ongoing development by expanding professional educational opportunities and developing synergistic efforts, as well as "agile curricula" that address current and emerging trends (Bertot et al. 2016).

\section{Research Scope and Objectives}

This paper offers a scoping review of terminologies and literature around digital literacies and competencies, specifically examining four areas: the direction of current digital competencies initiatives; the development of digital competencies as a synergistic endeavour; the potential for setting a common agenda for conducting qualitative and quantitative research on the digital competencies of stakeholder groups; and the sharing of cross-institutional knowledge, expertise, practices for the teaching of digital citizenship skills addressing everyday life experiences.

The culmination of this work is a proposed framework for considering overlapping needs of students, information professionals, and academics for developing digital citizenship skills through curriculum design, testing, and evaluation.

\section{References}

Bertot, J. C., Sarin, L., \& Jaeger, P. (2016). Re-envisioning the MLS: The future of librarian education. Public Libraries. Retrieved from http://publiclibrariesonline.org/2016/01/re-envisioning-the-mls-the-future-of-librarian-education/

Carretero Gomez, S., Vuorikari, R., \& Punie, Y. (2017). DigComp 2.1: The digital competence framework for citizens with eight proficiency levels and examples of use. Luxembourg: European Commission, EU Science Hub.

IFLA International Federation of Library Associations. (2017). IFLA statement on digital literacy. Retrieved May 15, 2018 from https://www.ifla.org/publications/node/11586

Karnad, A. (2013). Embedding digital and information literacy into undergraduate teaching. London, UK: Centre for Learning Technology.

Keywords: digital literacy, digital competence, everyday life, university students, academic libraries, partnership 


\title{
Unique or Ubiquitous? Information Literacy Instruction Outside Higher Education
}

\author{
Miriam Matteson \\ Kent State University, Columbus, OH, USA, mmattes1@kent.edu \\ Beate Gersch \\ The University of Akron, OH, USA, bgersch@uakron.edu
}

Information literacy (IL) is the ability to recognize the need for information, to effectively find information to meet that need, and to use information for some purpose or goal. Historically, information literacy was important for wellinformed, civic discourse, as well as for preparing people to be productive workers (O'Connor, 2009). More recently, critical perspectives have emerged that view IL as a way for learners to understand systems of power around information and develop a critical consciousness of learning (Elmborg, 2006).

Both academic and public libraries in essence believe that understanding and using information critically and effectively bring gains to an individual and to society. However, they diverge in how and why they engage in IL instruction, partly due to differences in mission and user base. The purpose of the academic library, to support the mission of the university, is more formally linked to instruction than that of a public library, even though many public libraries describe themselves and their purpose with education-based language such as being the people's university, or supporting lifelong learning. The value libraries place on their educational role, as well as their understanding of patrons' motivation and purpose, will direct why and how they facilitate IL instruction. Academic libraries operate under formal structures evidenced by "instruction librarian" job titles, formal courses, modules, and teaching materials, and shared definitions and frameworks for operationalizing information literacy. In contrast, public library IL instruction may be less structured with greater freedom and creativity. Both types of libraries fulfill important functions in fostering an engaged citizenry, and many patrons experience both of these environments at different times, or even simultaneously, in their lives.

Our study explores how public libraries address IL and to what degree these programs align with, enhance, or prepare patrons for the goals of academic IL instruction. Our guiding questions are: 1) how does public library programming incorporate ideas of information literacy and 2) how do notions of empowerment and advocacy connect to IL in a public library. To that end, we will conduct a content analysis of programming published on public libraries' websites. We will also analyze a sample of reflective work diaries provided by public librarians who offer programs and/or instruction at their libraries. Through these methods we hope to identify the unique needs in public library IL instruction in contrast to academic libraries. For example, gap-based models of information literacy that focus on patron deficiencies are problematic. Public libraries may benefit from invoking a theory and praxis of information literacy that is user-centered and oriented around individuals' ways of knowing and lived experiences using information as opposed to imparting a fixed set of IL skills (Todd, 2017). Not being bound by formalized IL structures may be an opportunity for public libraries to approach IL in new, creative ways (Chan, 2009; Partridge, Bruce, \& Tilley, 2008). Finally, we will explore how to effectively prepare librarians for IL instruction in public libraries, focusing on understanding the community, instructional design principles, and creative instructional delivery.

\section{References}

Chan, J. (2009). Information literacy and public libraries. InCite, 30(1/2), 18-19.

Elmborg, J. (2006). Critical information literacy: Implications for instructional practice. Journal of Academic Librarianship, 32(2), 192-199.

O'Connor, L. (2009). Information literacy as professional legitimation: A critical analysis. Journal of Education for Library \& Information Science, 50(2), 79-89.

Partridge, H., Bruce, C., \& Tilley, C. (2008). Community information literacy: Developing an Australian research agenda. Libri: International Journal of Libraries \& Information Services, 58(2), 110-122.

Todd, R. J. (2017). Information literacy: Agendas for a sustainable future. Journal of Information Literacy, 11(1), 120.

Keywords: information literacy instruction, public libraries, critical information literacy 


\title{
Thinking Youth Popular University as a Participative Space: Focus on a Speakers' Corner Experience, between Participatory Culture, Citizen Commitment and Political Empowerment
}

\author{
Yolande Maury and Asmaa Azizi \\ Lille SHS University, France, yolande.maury@univ-lille3.fr, aziziasmaa@gmail.com
}

This paper draws on the first results of an ongoing research (2017-2021), on the implementation of a Youth Popular University (YPU) in a French metropolitan area (Northen France). Our objective is to study the actions developed under this project, and specifically, during the first phase, how young people (18-30 years old) are mobilizing, in particular when involving in speakers' corner experiences.

Few studies exist on YPUs, but are numerous on popular education. Many of them highlight a youth participation "through action", and a commitment "by doing"; they refer to a political vision tending to "the promotion of activation and empowerment of users", at the opposite of a consumerist approach (Loncle et al, 2008). In this perspective, "speakers' corners" (SC) are seen as opportunities, in non-formal environments, to live rich and complex experiences. Recent studies insist on their role as "meeting places", where actors can interact, debate, verbalize their experiences...; and as "potential spaces", promoting problematization of knowledge from experiences, along with the development of social and informational skills. Seen through the lens of knowledge, it is part of "participatory culture" (Fortin \& al., 2014; Jenkins, 2016), and closely related to the ability of "critical consciousness", essential to the building of a coherent and reasoned vision of reality (Elmborg, 2006). However, studies point out that participation is not equally educative, it does not necessarily create opportunities for deeper learning and broader thinking.

What can we say about the speakers' corner experience and its role in citizen commitment and political empowerment? What do the actors' practices reveal about its potential? To what extent does it contribute to the development of participatory and critical (information) culture(s)?

In terms of methodology, we use a qualitative and comprehensive approach, collecting field data in immersion, close to the actors (young people, facilitators), to better understand their experiences.

The results are based on the data collected throughout the SC implementation process: from the reflection on a previous SC experience (strengths, limitations), to the mobilization of young people during a training phase until the key moment of its effective implementation. In an anthropological perspective, we consider the SC as an evolutive process, paying attention, beyond their narratives, to their "ways of being", between individual and collective, sensible and intelligible.

\section{References}

Elmborg, J. (2006). Critical information literacy: Implications for instructional practice. Journal of Academic Librarianship, 32(2), 192-199.

Fortin, C., Neustaedter, C., \& Hennessy, K. (2014). The appropriation of a digital speakers' corner: Lessons learned from the inthe-wild deployment of megaphone. In Proceedings of the Conference on Designing Interactive Systems, June 21-25, Vancouver, BC, Canada (pp. 955-964). New York: ACM Press.

Loncle, P. et al. (2012). Youth participation in Europe: Beyond discourses, practices and realities. Bristol: Policy Press.

Keywords: speakers' corner, participatory culture, critical information culture, empowerment, citizen commitment, Youth Popular University, non formal experience 


\title{
The Data and Information Literacy of Runners: Quantifying Diet and Activity
}

\author{
Pamela McKinney, Andrew Cox and Laura Sbaffi \\ University of Sheffield, UK, \{p.mckinney, a.m.cox, 1.sbaffi $\} @$ sheffield.ac.uk
}

\begin{abstract}
We report on a quantitative study that aimed to discover the data and information literacy of using mobile apps to monitor diet and fitness among people who run for pleasure. Self-monitoring of physical activity, diet and other aspects of health through web sites, apps and devices have seen a rapid growth in the last five years (Bert et al., 2014). This voluntary self-tracking can lead to improved health outcomes and contribute to disease prevention (Dallinga et al., 2015), and respond to patient-centred models of healthcare (Handel, 2011). However, the information and data literacy aspects of logging have been relatively neglected. A previous small-scale qualitative study by the authors (Cox et al., 2017) found that information literacy (IL) in this landscape includes how people choose apps, their practices around the recording and monitoring of their diet and exercise data, how and with whom they share them, and awareness of the privacy of information stored and shared.in the apps. Food loggers were much less likely to share data than those who logged exercise, although accurate data entry and developing nuanced understandings of the information provided by the apps were common to both groups.
\end{abstract}

A self-selected questionnaire was distributed through Parkrun (http://www.parkrun.org.uk/), a charity that organises free to enter, weekly $5 \mathrm{~km}$ races across the UK for over $1.5 \mathrm{~m}$ members. 143 complete responses were received. The demographics of respondents show a fairly distinct group with the majority being well educated females $(67.8 \%)$ in the 35-54 age bracket (65.4\%), having been running for five years or less $(73.4 \%)$, and who run between two and four times/week (79\%). Popular reasons for logging were to improve performance $(77.6 \%)$, to manage weight $(54.5 \%)$, and to better understand how the body works (35\%). Logging is an enjoyable aspect of running. Use of multiple apps, devices and web sites was common, and participants recorded various aspects of their running practice such as counting steps and recording time/distance, and monitoring heart rate. A significant minority was also using a food logging app (30\%). Runners reported high levels of self-assessed IL: the majority (59\%) responded that they were confident in choosing the right app, and reported being careful about data entry $(81.1 \%)$. They were confident in interpreting the outputs of logging $(84.6 \%)$. They did look at long term trends $(79.7 \%)$ and this data analysis, often combining data from different sources, was a pleasurable aspect of becoming fitter and improving performance. Respondents were likely to share data with friends and family, and this social aspect of logging was mentioned as a "motivator" in the qualitative responses. Some respondents had concerns around how the platform might use their data in the quantitative responses (28\%), however the qualitative responses reveal that a very few respondents had serious concerns around data privacy.

Based on data from these two studies, we conclude that people who use apps to monitor their fitness become adept at learning how to use the data aspects of the apps, and find this useful for health management, but are naïve about their data privacy. It is this aspect of IL that is in need of development.

\section{References}

Bert, F. et al. (2014). Smartphones and health promotion: A review of the evidence. Journal of Medical Systems, 38(1). Retrieved from https://www.researchgate.net/publication/259353052_Smartphones_and_Health_Promotion_A_Review_of_the_Evidence

Cox, A. M., Mckinney, P. A., \& Goodale, P. (2017). Food logging: An information literacy perspective. Aslib Journal of Information Management, 69(2), 184-200.

Dallinga, J. M. et al. (2015). App use, physical activity and healthy lifestyle: A cross sectional study. BMC Public Health, 15(1). Retrieved from https://bmcpublichealth.biomedcentral.com/articles/10.1186/s12889-015-2165-8

Handel, M. J. (2011). mHealth (mobile health): Using apps for health and wellness. Explore, 7(4), 256-261.

Keywords: information and data literacy, activity logging, food logging, mobile applications, runners 


\title{
Character Building in Children's Online Information Behaviours: Applying a Virtue Epistemology Perspective to Information Literacy
}

\author{
David McMenemy and Steven Buchanan \\ University of Strathclyde, Glasgow, Scotland, \{d.mcmenemy, steven.buchanan\}@ strath.ac.uk
}

\section{Objectives}

This paper advances our understanding of the theoretical and practical challenges of developing character in children's online information behaviours. Character, understood as "the comprehensive set of ethical and intellectual dispositions of a person" (Meyer, 2015), is a topic of significant societal concern. Issues in the online information behaviours of children are reported globally, ranging from access (e.g. seeking) to use (e.g. application) to conduct (e.g. respect). For example, a major UK study reports common issues of misinformation, hate speech, sexting, and cyberbullying amongst children (OFCOM, 2017), and a further UK study reports one in four have experienced cyberbullying from peers (NSPCC, 2018). Similar rates are seen in other countries, including Australia (Bullying. No Way, N.D.), the USA (CDC, 2015), South Africa, to $43 \%$ in Serbia, and 77\% in Argentina (UNESCO, 2017).

We argue that issues such as cyberbullying and misuse of information extend information literacy education beyond considerations of ability (i.e. skills) to considerations of intellectual character (i.e. desirable or virtuous dispositions), and draw attention to the importance of cultivating virtuous character traits in children's online behaviours. However, Dow (2013) has argued that "there is a striking lack of familiarity with matters of intellectual character and virtue at the academic and popular levels" within education (p.16). Consequently, this paper asks two key research questions: (1) What are the desirable character traits applicable to children's online information behaviours? (2) How is the development of desirable character traits currently addressed within information literacy frameworks?

\section{Methodology}

Our novel interdisciplinary theoretical framework applies a subset of virtue ethics, virtue epistemology, to information literacy, exploring shared concepts of knowledge acquisition. Virtue epistemology, in the knowledge acquisition context, "requires that we think, reason, judge, evaluate, read, interpret, adjudicate, search, or reflect in various ways" with particular attention to aspects of personal and intellectual character (Baehr, 2011, p.18). Desirable intellectual character traits include curiosity, intellectual autonomy, intellectual humility, attentiveness, intellectual carefulness, intellectual thoroughness, open-mindedness, intellectual courage, and intellectual tenacity (Educating for Intellectual Virtues, N.D). We identify and examine virtuous character traits in the context of children's online information behaviours, specifying desirable traits, and examining commonly cited information literacy frameworks for the presence of, and degree of prescriptive guidance offered, related to these traits.

\section{Outcomes}

We apply a classical perspective to a contemporary challenge, advancing our understanding of the nature of the problem, and appropriate approaches to potential interventions. This study answers an important question: are issues of detrimental online behaviours in children sufficiently addressed within information literacy theory and practice?

\section{References}

Baehr, J. (2011). The inquiring mind: On intellectual virtues and virtue epistemology. Oxford: Oxford University Press. Bullying. No way. (n.d.). Retrieved May 28, 2018 from https://bullyingnoway.gov.au/WhatIsBullying/FactsAndFigures CCDC. (2015). Youth risk behavior surveillance: United States, 2015. Surveillance Summaries, 65(6).

Dow, P. E. (2013). Virtuous minds: Intellectual character development. Downers Grove, IL: Intervarsity Press. Intellectual Virtues.org (n.d.). Educating for intellectual virtues. Retrieved May 28, 2018 from http://intellectualvirtues.org/

Meyer, M. J. (2015). Character. In R. Audi (Ed.), The Cambridge Dictionary of Philosophy (3rd ed.). Cambridge: Cambridge University Press. Retrieved May 28, 2018 from https://search.credoreference.com/content/entry/cupdphil/character

NSPCC. (2018). Online abuse: Facts and statistics. Retrieved May 28, 2018 from https://www.nspcc.org.uk

OFCOM. (2017). Children's media lives: Year 4 findings. Retrieved May 28, 2018 from https://www.ofcom.org.uk UNESCO. (2017). Measuring cyberbullying and online risks for children. Retrieved May 28, 2018 from https://en.unesco.org/

Keywords: digital citizenship, virtue ethics, information literacy, virtue epistemology, children 


\title{
Young People's Digital Safety and Wellbeing: Findings from the Philippines and Qatar
}

\author{
Virgilio G Medina Jr \\ Qatar National Library, Qatar, vmedina@qnl.qa
}

\section{Ross J. Todd}

The State University of New Jersey, NJ, USA, rtodd@ rutgers.edu

This study seeks to examine students' conceptions in relation to digital safety and what it means to be safe as they engage in an online world.

The study emphasizes the critical role of libraries as a catalyst in fostering digital literacy and digital wellbeing of young people as they participate in the collaborative digital and information landscape of which they are a part. Libraries in the $21^{\text {st }}$ century are called to fulfill its role by addressing how students can be empowered and equipped to become effective online users and participate in safe ways and to ensure that their social and digital wellbeing is supported.

Approximate 350 high school students from the Philippines and Qatar participated in the study through a library instruction. Students worked in groups to brainstorm various ideas about digital safety, digital practices, and understanding of unsafe websites. As an output, they were asked to record their ideas through a collective mind map and present it in the class. The mind map showcased their ideas and terms relating to digital safety and unsafe websites.

With the support of evidence-based action plan (Medina \& Todd, 2016), the researchers use this as a guideline to facilitate the digital literacy instruction that seeks to educate participants developing their digital and safety skills and emphasizing various risks from the digital world.

The findings highlight some specificity of technical terms that students use in engaging and participating in an online world. The findings show diverse conceptions about digital safety, and identify digital practices that might be considered inappropriate, harmful, and risky, and raising concerns about their digital safety and digital wellbeing and impact of their personal, academic and social roles and identities.

The study seeks to bring awareness of digital practices of young people to information literacy educators, librarians, policy makers about the continuous increase of students' engagement with the digital world and various online risks that harm students' digital safety. This paper also provides opportunities to revamp the role of librarians in a borderless world of information in unleashing students' skills to become responsible and safe digital users specifically through evaluating, analyzing, synthesizing, and organizing information from the online world.

\section{References}

Medina, V., \& Todd, R. (2016). Empowering students for a digital world: Global concerns, local school evidence and strategic actions. In Proceedings of the 45nd International Conference incorporating the 20th International Forum on Research in School Librarianship (IASL 2016). Tokyo: Meiji University. Retrieved June 29, 2018 from https://www.iaslonline.org/resources/Pictures/RP11_MedinaTodd_2016IASLTokyo.pdf

Keywords: digital literacy, digital safety, internet safety, library instruction 


\title{
Information Literacy as a Material Culture? Ordinary Practices of Knowledge in Academic Libraries
}

\author{
Béatrice Micheau \\ ESPÉ Lille Nord de France - GERiiCO, Villeneuve d'Ascq, France, beatrice.micheau@cue-lillenorddefrance.fr
}

\section{An Anthropological Approach of Information Literacy}

The purpose of this paper is to explain how we could consider information literacy as a material culture. We conducted an ethnographic research about students' practices in academic libraries over two years. The purpose of this research project was to understand the diverse students' practices according to different spaces of their libraries, to analyze how the students make these spaces their own. This project was also a way to continue to build an anthropological approach of information literacy (Després-Lonnet et al. 2017). With such an approach, information literacy is thought of as a culture where practices, representations, and norms interweave. This approach of information literacy follows the heritage of the concept of literacy as it was defined by Jack Goody in his anthropological work about written culture (Goody, 1979). Good's work provides us with a means to understand the articulations between different ways to produce, exchange, and use information and different ways to grasp and represent the world, by considering the diversity of social practices of knowledge. To satisfy these purposes, we studied the ordinary practices in academic libraries as symbolic practices of knowledge (De Certeau, 1990). In this communication, we were especially interested in understanding how the material aspects of ordinary knowledge practices are not only a framework for information literacy but an entire dimension of it.

\section{An Ethnographic Study about Students' Practices in a Network of Academic Libraries}

First, we conducted semi-directed interviews with librarians. Then, we made ethnographic observationsin the different areas of the libraries. And finally, we conducted semi-directed interviews with students.

\section{How to Dwell in a Library,Corporal Hexis, Knowledge Gestures and Information Literacy}

We observed French students mostly engaged in law and medicine training. Their disciplinary acculturation is built more through the labour of memorization and the rehearsal of scholar tasks than by autonomous research information. So, for them, to be information literate is less related to use of library or Internet resources and more involved with learning how to read the texts of their discipline, take notes, organize documents, write as it iss expected, andcreate and share memory techniques. Still, the students created and appropriated knowledge gestures from their experiences in the library spaces. The symbolic practices of information literacy are embodied by the hybridization between knowledge gestures and library's corporal hexis (Bourdieu, 1972).

\section{What Kind of Places is the Computer? Materialities of Digital Culture}

Inside the library, the students negotiated the ways to read, create, and manage documents between objects and the apparatus of written culture, digital or not. But not all the digital devices have the same roles, rules, and users. The computer is a material object. But it works like a porous border between academic information literacy and everyday life information literacy (Savolainen, 2008), between the inside and the outside of the library. The students build, live, and formalize their information literacy in the temporalities of their life, in the rhythms of their social body, and by making the experience of the materiality of texts and library's apparatus.

\author{
References \\ Bourdieu, P. (1972). Esquisse d'une théorie de la pratique: Précédé de Trois études d'ethnologie kabyle. Genève: Droz. \\ De Certeau, M. (1990). L'invention du quotidien: 1. arts de faire. Paris: Gallimard. \\ Després-Lonnet, M. et al. (2017). Enquête sur les pratiques des étudiants 2015-2016: Rapport de recherche. Villeneuve d'Ascq: \\ Université de Lille. \\ Goody, J. (1979). La raison graphique: La domestication de la pensée sauvage. Paris: Les Éditions de Minuit. \\ Savolainen, R. (2008). Everyday information practices: A social phenomenogical perspective. Lanham: Rowman \& Littlefield.
}

Keywords: information literacy, material culture, academic libraries 


\title{
Foundations of Information Literacy Trends: A Textual Data Based Analysis on International Frameworks
}

\author{
Florent Michelot and Bruno Poellhuber \\ Université de Montréal, Canada, \{florent.michelot, bruno.poellhuber\} @umontreal.ca
}

Since the concept's emergence during the 1970s, an amazing quantity of literature has been developed on and about information literacy, especially in Anglo-Saxon countries (Bruce, 2011; Rader, 2002; Sparks, Katz, \& Beile, 2016). But the globalization of the debate about the scope and meaning of the phrase 'information literacy' contributed to the appearance of non-Anglo-Saxon frameworks. Furthermore, they contributed to the identification of local and cultural particularities. For example, standards of culture informationnelle or culture de l'information (Information culture or Culture of information) appeared in French authors' considerations since the 1990s (Baltz, 1998; Serres, 2007). This approach builds bridges with information literacy concepts, while nurturing a debate which involves media education (Kerneis, 2010; Kerneis \& Lanhers, 2015) or a criticism of utilitarian visions (Simonnot, 2009). That said, these concepts have not been fully adopted in other French-speaking countries, like in Québec. Considering this conceptual evolution, this presentation will review some of the cleavages in recent literature. For this, we studied texts based on lexical proximity in English (73\%) and French (27\%) skills frameworks. 135 documents (related to 21st century skills or information literacy and digital literacy) have been selected based on their relevance. They have been chosen among professional or school standards, academic frameworks as well as "meta-frameworks" (frameworks based on frameworks) or scientific reviews of frameworks. We will explain how they have been manually categorized according to their origin, language, nature of the audience, educational level and hierarchical organization type. In addition, we will also expose how this review was operated with IRaMuTeQ (Ratinaud, 2017), a statistical and textual analysis free software (GNU/GPL): frameworks have been systematically prepared and coded for IRaMuTeQ, which allows us to schematically bring out recurrence frequency and lexical proximity to analyze use contexts of major expressions or concepts. Finally, results seem to reflect significant differences depending on the language of the model (in French or in English). For example, French-speaking countries frameworks emphasize teachers and the use of technology, whereas those in English-speaking countries highlight learners and learning. These results appear to qualify or contradict some assumptions made in the early 2000s, for example, the fact that digital solutions are considered much more a panacea in Anglo-Saxon countries than other countries (Bundy, 2002). In conclusion, this review proposes several hypotheses to explain these inclinations considering trends that reflect cultural and organizational specificities in literacy models.

\section{References}

Baltz, C. (1998). Une culture pour la société de l'information?. Documentaliste, 35(2), 75-82.

Bruce, C. (2011). Information literacy programs and research: An international review. The Australian Library Journal, 60(4), 326333.

Bundy, A. (2002). Growing the community of the informed: Information literacy: A global issue. Australian Academic \& Research Libraries, 33(3), 125-134.

Kerneis, J. (2010). Didactique de l'éducation aux médias et culture informationnelle. In É. Delamotte, \& F. Chapron (Eds.), Éducation à la culture informationnelle (pp. 269-277). Paris, France: Presses de l'ENSSIB.

Kerneis, J., \& Lanhers, L. (2015). Une éducation aux médias intégrée à la formation professionnelle en alternance des professeursdocumentalistes en France. Colloque Éducation aux médias et pratiques pédagogiques innovantes. Paris, France. Retrieved from https://hal.archives-ouvertes.fr/hal-01143540

Rader, H. B. (2002). Information literacy 1973-2002: A selected literature review. Library Trends, 51(2), $242-259$.

Serres, A. (2007). Questions autour de la culture informationnelle. The Canadian Journal of Information and Library Science, $31(1), 69-85$.

Simonnot, B. (2009). Culture informationnelle, culture numérique: Au-delà de l'utilitaire. In A. Serres (Ed.), Penser la culture informationnelle (pp. 25-37). Paris, France: Hermes science publications: Lavoisier.

Sparks, J. R., Katz, I. R., \& Beile, P. M. (2016). Assessing digital information literacy in higher education: A review of existing frameworks and assessments with recommendations for next-generation assessment. ETS Research Report Series, 2016(2), 133.

Keywords: information literacy, lexical and discourse study, IRaMuTeQ, international frameworks, international comparison 


\title{
Migration of Clusters from Pre-session to Post-session: An Analysis of Elderly Students' Perceived Digital Literacy
}

\author{
Makiko Miwa, Emi Nishina, Hideaki Takahashi, Yoshitomo Yaginuma, Yoko Hirose and Toshio Akimitsu \\ The Open University of Japan, Chiba-shi, Japan, \{miwamaki, nishina hide, hirose, yaginuma, akimitsu $\} @$ ouj.ac.jp
}

\section{Objective}

The Open University of Japan (OUJ) has offered a face-to-face digital literacy training course (DLT) every semester at all 50 study centres since October 2010. Students attending DLT complete a checklist at the beginning and end of their course (Miwa et al., 2013; Miwa et al., 2016). The objective of this study was to identify how students migrated from one cluster to another, representing their self-reported perceived digital literacy skills pre- and post-course. The outcomes are relevant to the amendment of course content and student aftercare.

\section{Methodology}

We analysed responses from 1417 students who attended DLT between Semester 2, 2014 and Semester 2, 2016 and completed all 20 items of both the pre- and post-course checklist. We developed clusters for pre- and post-course ability, based on each student's reported ICT skill levels on each of the 20 checklist dimensions, using k-means and the Hartigan-Wong algorithm. We also analysed how each of the pre-course clusters were shifted to post-course clusters using a Sankey diagram. We also analysed students' post-course checklist comments on DLT using a cooccurrence network method.

\section{Outcome}

Four clusters (A, B, C, D) were developed from the pre-course checklist. Cluster A represents students who reported having high-level skills on all 20 items at the beginning of the DLT course. Cluster D represents students who were unfamiliar with personal computers at the beginning of the course. Clusters B and C lie in between. Four clusters (X, $\mathrm{Y}, \mathrm{Z}, \mathrm{W})$ were developed from the post-course checklist. Cluster X represents students who reported having high-level ICT skills on all 20 items at the end of the course. Cluster W represents those who reported a low level of ICT skills on all 20 items. Clusters $\mathrm{Y}$ and $\mathrm{Z}$ were in between.

A Sankey diagram was developed to identify how students migrated from their pre-course cluster to their post-course cluster. Almost all members of Cluster A (high-level ICT skills) migrated to Cluster X (high-level skills at course end). About half the students in Cluster B migrated to Cluster Y, and the other half to Cluster Z. One-third of Cluster C students migrated to Cluster X, Y, or Z. A portion of Cluster D migrated to Cluster W. These results indicate that real beginners, who had never used a personal computer or the Internet before attending the DLT course, were left behind. We need to develop a framework for supporting students who migrate from Cluster D to Cluster W.

The co-occurrence analysis of students' remarks showed themes of course value, and feelings of appreciation and anxiety.

\section{References}

Miwa, M. et al. (2013). Digital literacy training for elderly students at the Open University of Japan. In S. Kurbanoğlu et al. (Eds.), Worldwide Commonalities and Challenges in Information Literacy Research and Practice, European Conference on Information Literacy, ECIL 2013, Istanbul, Turkey, October 22-25, 2013: Proceedings (pp. 205-211). Cham: Springer International Publishing.

Miwa, M. et al. (2018). Changing patterns of ICT skills perceived by elderly learners. The LIBRES, 27, 1. Retrieved July 16, 2018 from. https://www.libres-ejournal.info/2525/

Keywords: digital literacy, elderly students, ICT skills 


\title{
A Critical Praxis in the LIS Education Classroom Using the ACRL Framework for Information Literacy for Higher Education
}

\author{
Shehaamah Mohamed \\ University of the Western Cape (UWC), Cape Town, South Africa, shmohamed@uwc.ac.za
}

Introduction

It is imperative that the educator's teaching praxis fosters such critical engagement between the learner and the educator to develop critical thinking learners who add their voices to the courses that they pursue. Using the 2015 ACRL Framework for Information Literacy for Higher Education (the Framework), the University of the Western Cape Library introduced an alternative, nuanced approach to information literacy (IL) by transforming librarians' teaching and learning pedagogy. To this end, a specialist Senior Librarian has designed and coordinated the Information Literacy module.

The Framework presents a new approach to teaching and learning and is built around six frames, each consisting of a threshold concept that is central to information literacy. The knowledge practices and dispositions that accompany the threshold concepts foster deep learning and develop learners as creators of information, not just consumers. Each frame encourages thinking about what learners need to know, to experience and how they should behave to demonstrate their understanding of the discipline.

The university's Library and Information Science (LIS) Department invited the Senior Librarian to teach the Information Literacy Education module to postgraduate students. This paper demonstrates how the Senior Librarian revised the module to teach prospective librarians to use the Framework in order to enhance critical thinking and to create a more dynamic interaction between librarian and student.

Objectives of the Study Show:

- how the ACRL Framework is embedded in an Information Literacy Education module;

- how the Framework is used to develop and enhance critical thinking and agency in research; and,

- how the Framework is a viable tool for critical praxis in the LIS classroom

Methodology

The Senior Librarian selected two cohorts of students during the years 2015 and 2017 as her study participants. Various assessment artefacts such as online blogs, group presentations, posters, and essays were examined in a qualitative approach to provide her with evidence for the study's objectives.

\section{Outcomes}

The study shows that the concepts of the ACRL Framework can be embedded in various learning activities and assessments in IL education. The paper also shows that the Framework facilitates critical thinking and, finally, that the Framework is feasible for implementing critical praxis in the classroom.

The paper therefore illustrates an educator's perspective for engendering the ACRL Framework into the LIS curriculum. This research is valuable for academic libraries as it recommends ways in which librarians may transform their information literacy instruction so that it may guide students to become experts in their disciplines.

\section{References}

Association of Research and College Libraries. (2016). The framework for information literacy for higher education. Retrieved May 9, 2018 from http://www.ala.org/acrl/standards/ilframework

Keywords: ACRL Framework for Information Literacy for Higher Education, critical praxis, information literacy education, critical thinking, constructivist theory, inquiry-based learning 


\title{
Teacher's Resistances to Mobile Learning in Turkey and Spain: What Similarities? What Differences?
}

\author{
Tugba Mutlu \\ Gumushane University, Gumushane, Turkey, tugbamutlu@gumushane.edu.tr \\ Cristina Aliagas \\ Universitat Pompeu Fabra, Barcelona, Catalonia, Spain, cristina.aliagas@upfe.edu
}

\begin{abstract}
During the last decades, governments around the world have been increasingly investing in learning technologies through national technology programmes with the belief that teachers and students will eventually benefit from them. However, these investments have not yet produced desired results, neither with the speed nor direction expected (Cuban, 2011). Although there are multiple factors that may explain this undesired complex situation, it seems that teachers' negative attitudes is one of the key elements in integrating technology into instruction practices (Liu, 2011). Thus, understanding the motives behind resistance is a crucial factor for technology acceptance. Teacher resistance has been studied from the psychological stance and through quantitative methodologies based on statistical analysis, cognition, beliefs or personality tests (e.g. Kopcha, 2012; Liu, 2011). However, in this paper we attempt to tackle the topic through the data we obtained from qualitative interviews. By looking at the teacher's perspectives we claim that their opinions and feelings need to be placed in the centre of the debate on the digitalization of education.
\end{abstract}

The aim of this paper is to present, through a comparative analysis, the data on teachers' resistance gathered through interviews in the frame of two distinct studies on the implementation of a technology program in distant socio-cultural and educational contexts, in Turkey (Mutlu, 2016) and in Catalonia, North-West Spain (Aliagas \& Castellà, 2014; Vázquez \& Cassany, 2016). Although the studies were designed separately, they shared a common rationale and goal, which were to understand what teachers as the agents of education really thought about the process of digitalization of learning/teaching process, and how do they make sense of this new educative reality. In both cases, interviews were conducted with the teachers who positioned themselves as resistant to the use of technology in education. In Turkey, tablets were introduced to secondary schools through the Movement of Enhancing Opportunities and Improving Technology (FATIH Project) as a part of the national program, while in Catalonia, small laptops were introduced in secondary education through the program EduCAT 1x1/Escuela 2.0.

This comparative analysis shows that teachers holding a resistant stance in distant educational contexts mainly resist educational change and the government, although they differ slightly in the underlying assumptions supporting their resistance. Their discourses on technology in schools have settled into a "discourse of uncertainty" where negative attitudes were compensated with slightly positive comments about digital artefacts as a tool for teaching/learning. Findings also indicate that teachers, regardless the educational context they work in, have assumed the "discourse of inevitability" (Ferneding, 2003) that dominates viewpoints concerning technology and education.

\section{References}

Aliagas, C., \& Castellà, J. M. (2014). Enthusiast, reluctant and resistant teachers towards the one-to-one program: A multi-site ethnographic case study in Catalonia. In M. Stochetti (Ed.), Media and Education in the Digital Age: Concepts, Assessments, Subversions (pp. 237-258). Frankfurt am Main: Peter Lang Publishers.

Cuban, L. (2001). Oversold and underused. London: Harvard University Press.

Ferneding, K. A. (2003). Questioning technology. New York: Peter Lang.

Kopcha, T. J. (2012). Teacher's perceptions of the barriers to technology integration and practices with technology under situated professional development. Computers \& Education, 59, 1109-1121.

Liu, S. (2011). Factors related to pedagogical beliefs of teachers and technology integration. Computers \& Education, 56, 10121022.

Mutlu, T. (2016). Understanding students' and teachers' approaches to tablet use in Turkish secondary schools: A model based approach (Thesis). University of Sheffield, Sheffield.

Vázquez, B., \& Cassany, D. (2016). Language learning actions in two 1x1 secondary schools in Catalonia: The case of online language resources. In A. Pareja-Lora, C. Calle-Martínez, \& P. Rodríguez-Arancón (Eds.), New perspectives on teaching and working with languages in the digital era (pp. 73-82). Oxford: Oxford University Press.

Keywords: teacher's beliefs, teacher's resistance to technology, technology-driven educational reforms 


\title{
Collaboration Building between Teaching Faculty and Librarians: Based on a Case Study on Field Librarians at the University of Michigan
}

\author{
Tayo Nagasawa \\ DIHER / Mie University, Tsu, Japan, nagasawa.tayo@ mie-u.ac.jp
}

\begin{abstract}
As a result of recent higher educational reforms, universities have included information literacy among their graduate attributes in order to help undergraduates build a foundation of information literacy in everyday life for their future. In this context, building relationships between teaching faculty and librarians has been recognised as an important factor contributing to the success of information literacy instruction, and helping to enhance information literacy learning outcomes for students (Julien et al., 2009; Fazal, 2016). In order to build a successful collaboration between teaching faculty and librarians, novel models of university librarians, such as embedded librarians and blended librarians, have been proposed and introduced into such university settings. Based on a literature review of embedded librarians, Schulte revealed activities of embedded librarians such as those embedded in course management systems and physical co-locations with patrons (Schulte, 2012). However, the building of a collaboration between teaching faculty and embedded librarians itself was not analysed. Most previous studies also did not focus on analysing teaching faculty-librarian relationships themselves. The purpose of this paper is to investigate the building of collaboration between teaching faculty and embedded librarians in university settings.
\end{abstract}

Based on a literature review of building collaboration between teaching faculty and librarians in higher education, previous studies have provided some research perspectives, such as librarians' strategic approaches to teaching faculty, and library, institutional and social contexts (Nagasawa, 2017). The research questions are "What are librarians' main approaches to teaching faculty which they could promote to build a collaboration between teaching faculty and themselves?" and "What are the intervening conditions in library, institutional and social contexts which could promote collaboration between teaching faculty and librarians?" In order to answer these questions, a qualitative case study of field librarians at the University of Michigan was conducted based on purposeful sampling, in particular maximum variation sampling. In 2002, the University Library introduced three field librarians who did not work in library buildings but were embedded in schools and faculties (Haines, 2004; Johnstone, 2007). Their main mission was to provide learning, instructional and research support both to students and teaching faculty in these schools and faculties (Nagasawa, 2013). The data was collected from interviews with field librarians, library managers and teaching faculty and from observations of physical artifacts, and analysed by a thematic coding approach based on theoretical coding in a grounded theory approach.

As the result of the analysis, "building interpersonal relationships", "customised services for individuals", "part of departmental programmes" and "anytime, anywhere" were discovered to be categories of librarians' strategic approaches to teaching faculty. Similarly, "support by university administrators", "support by schools and faculties", "small community", "leadership of library managers" and "librarians' competencies" were discovered to be categories of intervening conditions in library and institutional contexts.

\section{References}

Fazal, S. (2016). Library strategic planning for middle states accreditation. Journal of Library Administration, 56(1), 27-40.

Haines, A. (2004). Out in the field: The benefits of field librarianship for studio arts programs. Art Documentation, 23(1), 18-20.

Johnstone, B. L., \& Alexander, L. A. (2007). In the field. Library Journal, 132(2), 38-40.

Julien, H., \& Pecoskie, J. (2009). Librarians' experiences of the teaching role: Grounded in campus relationship. Library and Information Science Research, 31(3), 149-154.

Nagasawa, T. (2013). A case study on learning and instructional support provided by the University Library at the University of Michigan: Focusing on field librarians. Library and Information Science, 70, 177-217.

Nagasawa, T. (2017). A systematic literature review on building collaboration between teaching faculty and librarians in university education. Library and Information Science, 77, 51-86.

Schulte, S. (2012). Embedded academic librarianship: A review of the literature. Evidence Based Library and Information Practice, 7(4), 122-138.

Keywords: faculty-librarian relationships, collaboration, information literacy instruction, field librarians, embedded librarians, qualitative case study, University of Michigan 


\title{
Information Literacy in Portuguese School Libraries: A Longitudinal Study of Master Degree Dissertations
}

\author{
Ana Novo \\ Universidade Aberta, CIDEHUS-UÉ1, Lisboa, Portugal, anovo@uab.pt \\ Glória Bastos \\ Universidade Aberta, Lisboa, Portugal, gloria.bastos@uab.pt
}

During these first two decades of the $21^{\text {st }}$ century, a rapid growth in access to information and communication technologies has been observed in Portugal as well as in other European countries. The Portuguese Technological Plan for Education (2007) has been playing an important role in the educational context, fostering schools and teachers to open classrooms to new technologies and to prepare pupils to the challenges of the knowledge society. In fact, it is necessary that pupils have an active intervention in the learning process, and teachers must help them to improve the reflected and active construction of personal knowledge. This is a primary condition for the challenges of contemporary society. Schools need to focus on enabling students with transferable skills, which in turn will allow them to play a full role in the information society. This context also requires the promotion of different ways of working within schools: collaborative work among teachers and the integration of transversal competencies, like information literacy (IL), stimulating the cohesion within the educational program and/or between the different subjects. In this framework school libraries (SL) play a fundamental role as they have been increasingly considered by school communities as an essential resource, as well as teacher librarians (TL) who, in Portugal, saw their role institutionalized in 2009 .

The adopted methodology for this study was a meta-analysis of the results of a body of master dissertations on the context of a master course in Information Management and School Libraries, at Universidade Aberta, Portugal. It is a longitudinal study as it analyses dissertations completed between 2007 and 2017. In this master course all students are TL who want to acquire specific formation in the field to increase their knowledge and competencies. From the very beginning of the master course, in 2005, one of its research objectives was to improve knowledge on the concepts and practices of TL concerning IL in school libraries.

The results obtained show some characteristics of the route being taken in Portuguese SL concerning IL's competencies development. A first group of the analyzed dissertations indicated that, in general, TL misunderstood the concept of IL and were still not aware of its importance. Most of their work was still related to traditional library activities such as organizing information and introducing the library to students through guided visits. In more recent years we have identified some important improvements in Portuguese SL and in research studies evidence of that progress is shown.

These results are then crossed with important and recent developments in the context of Portuguese schools. For example, the legislation institutionalizing TL as a fulltime job, recognizes and explicitly mentions the significance of their work and its integration into the pedagogical activities of the school. The self-evaluation model, launched in 2009 by the Portuguese School Libraries Network is also a new element that brings more visibility to the work of the SL and to the advantages of linkage between TL and other teachers, specifically in what concerns the development of student's competencies in IL.

\section{References}

Portugese Ministry of Education. (2007). Technological plan for education. Retrieved May 8, 2018 from http://www.pte.gov.pt/pte/PT/OPTE/index.htm

Keywords: teacher librarians, school libraries, information literacy, Universidade Aberta, Portugal

\footnotetext{
${ }^{1}$ This work is financed by national funds by FCT - Foundation for Science and Technology under the project UID/HIS/00057/2013 (POCI-010145-FEDER-007702), FCT/Portugal, COMPETE, FEDER, Portugal 2020.
} 


\title{
Collaborative Knowledge Building to Enhance Information Literacy in Health Education
}

\author{
Tuula Nygård, Laura Palmgren-Neuvonen, Noora Hirvonen, Anna-Maija Huhta and Maija-Leena Huotari \\ University of Oulu, Finland, \{tuula.nygard, laura.palmgren-neuvonen, noora.hirvonen, anna-maija.huhta, maija- \\ leena.huotari\}@oulu.fi
}

\section{Objectives}

Information seeking is a common-and authentic-learning task at school. From the perspective of educational sciences, it is included in collaborative knowledge building, referring to the discursive process of shared meaning making. Such task contexts are sites of collaborative learning (Knight et al. 2017), where 'searching to learn collaboratively' is likely to enhance learners' competencies needed to access, evaluate, and use information, included in the notions of information literacy and multiliteracy (FNBE 2016). This concerns specifically complex health-related information, contradictory across various sources, thereby making it challenging to know what to believe and who to trust in everchanging information environments (Niemelä et al. 2012). As research has revealed adolescents facing difficulties in information practices need to learn to search. They should, for example, engage in credibility evaluation before searching to learn. We sought to undertand answers to the following questions in our interdisciplinary study in the health education context, combining concepts from educational sciences and information studies:

1. How did collaborative information seeking and knowledge building emerge in learning communities of teachers and students?

2. What kinds of evaluative negotiations of information content and its credibility occurred in the collaborative knowledge building projects?

\section{Method}

Three collaborative knowledge-building projects were implemented by health education teachers in Grades 8 and 9 . We observed and recorded all project activities and interviewed the participants. Our initial thematic analysis informed us to focus on talk functions contributing intrinsically to the process of collaborative knowledge building. We modified our analysis framework to identify in what terms participants evaluate information or knowledge linked to the topic.

\section{Outcomes}

An adequately challenging task level seemingly promoted collaborative information seeking and knowledge building, whereas a low level generated little information seeking. Collaborative knowledge building negotiations were guided by implicit norms of information use and the appearance of the outcome. The groups working collaboratively managed to make sense of complex health terms, but evaluative talk on the information content and credibility remained scarce.

The degree of information seeking and evaluation apparently depended on the depth and guidance of the task, the teachers more or less expecting the groups to learn information seeking independently. The students' competencies in collaborative knowledge building and information and credibility negotiation need improvement. This can be addressed by employing the ideas of multiliteracy in health education and in teacher education and training. We will discuss how the aspect of 'information' is taken into account in the Finnish health education based on our findings.

\section{References}

FNBE. (2016). National core curriculum for basic education 2014. Helsinki: FNBE.

Knight, S. et al. (2017). The orchestration of a collaborative information seeking learning task. Information Retrieval Journal, 20(5), 480-505.

Niemelä, R. et al. (2012). A screening tool for assessing everyday health information literacy. Libri 62(2), 125-134.

Keywords: collaborative knowledge building, information literacy, multiliteracy, health education 


\title{
Advocacy in Everyday Life: The Role of Information Literacy Skills
}

\author{
Peggy Nzomo and Paul Fehrmann \\ Kent State University, OH, USA, \{pnzomo, pfehrman\}@kent.edu
}

\section{Background}

Advocacy is becoming increasingly common in everyday life; it is a phenomenon that transcends socio-economic, political, and geographic boundaries. Advocacy is broadly defined as any action that seeks to speak in favor of, recommends or argues for a cause or a person or group of people. Self-advocacy, the most prevalent form, is defined as an "individual's ability to effectively communicate, convey, negotiate or assert his or her own interests, desires, needs, and rights. It involves making informed decisions and taking responsibility for those decisions" (Van Reusen, Bos, Schumaker, \& Deshler, 1994, p.1). The advocacy roles of professionals in library and information science (LIS) are well documented: examples show advocating for causes such as information literate societies (Bundy, 2002; Rivano Eckerdal, 2017), open access, intellectual freedom, and social justice. However, there is a paucity of research examining the role that information literacy plays in advocacy.

The paper examines what role information literacy skills play in making one an effective advocate by drawing on everyday life situations that involve advocacy such as self-advocacy, social advocacy, patient advocacy, parent advocacy, and policy advocacy.

\section{Objectives}

The current research sought to identify what information literacy skills are closely associated with skills, knowledge, and behaviors (SKBs) in advocacy.

\section{Methodology}

Methods promulgated by the Cochrane Rapid Reviews Methods Group were adapted for the current research. The paper provides a rapid review of articles published in the last ten years (2008-2018), primarily in library and information science that link advocacy and information literacy. First, a search in Academic Search Complete, a multidisciplinary database was used to identify what skills, knowledge, and behaviors are deemed essential for everyday life situations that involve advocacy. Second, a search in two LIS databases, namely Library \& Information Science \& Technology Abstracts and Library Literature \& Information Full Text, was used to determine what information literacy skills can be associated with the SKBs mentioned in advocacy engagement. Charting of the literature was used to map the skills, knowledge, and behaviors mentioned in relation to advocacy to those often mentioned in relation to information literacy.

\section{Results}

Results show how the knowledge component in advocacy engagement is closely associated with various information literacy skills such as finding information, evaluation of information and sharing information.

\section{Originality / Value}

This article supports advocacy for information literate societies from a unique standpoint by identifying associations between information literacy skills and the skills, knowledge and behaviors (SKBs) needed for effective advocacy engagement.

\section{References}

Bundy, A. (2002). Growing the community of the informed: Information literacy - A global issue. Australian Academic \& Research Libraries, 33(3), 125-134.

Rivano Eckerdal, J. (2017). Libraries, democracy, information literacy, and citizenship. Journal of Documentation, 73(5), 10101033.

Van Reusen, A. K. et al. (1994). The self-advocacy strategy for education and transition planning. Lawrence, KS: Edge Enterprises.

Keywords: advocacy, information literacy, skills, knowledge, behavior, rapid review 


\title{
Biographical Space, Digital Death and Information Literacy Skills: Current Issues
}

\author{
Paula Ochôa and Leonor Gaspar Pinto \\ Universidade NOVA de Lisboa, Portugal, poc.paula@gmail.com, lgpinto@sapo.pt
}

The concept of biographical space integrates the confluence of several contemporary autobiographical discursive genres, related to personal experiences and to the public exposure of intimacy. This includes the most traditional - such as letters, diaries, memoirs and (auto)biographies - to media and digital media, with a variety of uses and interactive practices of "presence technologies" with interactive audiences (e.g. interviews, profiles, testimonies, life stories, talk shows and reality shows). Mediated memories, diaries and lifelogs are instruments of self-formation, as well as vehicles of connection, future memory and identity.

This vast biographical space also allows the creation of new subjectivities and the development of networks of interchange and sociability, confirming the tendency for existence in a single person of segmented and multiple identities in the various situations of their life, gaining a confessional dimension and a digital identity that will persist even after death.

This digital identity is like an autobiographical book that counts with the participation of all the individuals in the list of friends (through comments and publications) and we can study three types of contributions that will persist after the biological death: (1) "what I say about myself", (2) "what others say about me" and (3) the continuity of participation in the profile in which each new contribution (publication, comment, photograph, etc.) will format the collective memory of the sphere that accesses it.

The current concept of digital death and the management of its legacy poses new questions about information literacy related to personal information management and digital assets, belonging to a person and susceptible of being transmitted to future generations, namely her/his own websites, e-mail accounts and files in any format (collections of documents, photographs, videos, but also music and movies, blogs, vlogs, etc.).

For this reason, there is a pressing need for personal data management, not only throughout life, but also after the death of their holders. Nowadays, the current digital legacy management systems allow their holders to plan ahead for the future of their data and digital collectionsn (Bellamy et al., 2013), thus integrating the thanatology (the study of death) and digital immortality in the informational behavior subjects to be investigated within Information Science (Jacobsen, 2017).

The purpose of this paper is to explore the concept of digital death in information literacy and data skills using the evidence of an ongoing study on Portuguese librarians' memorial practices (2017-2018). We do this by examining how it corresponds to, and differs from, existing concepts and practices such as health literacy and the DigComp model, offering a conceptual framework that interrelates information literacy with current biographical practices.

\section{References}

Bellamy, C. et al. (2013). Death and the Internet: Consumer issues for planning and managing digital legacies. Melbourne: University of Melbourne.

Jacobsen, M. H. (2017). Postmortal society: Towards a sociology of immortality. London: Routledge.

Keywords: information literacy. biographical space, digital death 


\title{
Conceptions of Information Literacy and Multiliteracies from the Perspectives of Teachers and Librarians in the Context of the Finnish National Core Curriculum
}

\author{
Anu Ojaranta \\ Åbo Akademi University, Turku, Finland, anu.ojaranta@abo.fi \\ Siinamari Tikkinen and Riitta-Liisa Korkeamäki \\ University of Oulu, Finland, siinamari.tikkinen@gmail.com, riitta-liisa.korkeamaki@oulu.fi
}

In Finland, the national core curriculum (2016, NCC) determines a framework for schools to be applied into local curricula and education. The learning philosophy and methods propose collaboration between schools and libraries in the areas of information literacy [IL] and in multiliteracy which is a new concept in the NCC. Furthermore, the NCC presents the library as a learning environment and as a collaborative partner. Interestingly, the NCC uses the term information managing instead of the term IL. The purpose of this presentation is to discuss teachers' and librarians' understanding of the conceptions of IL and multiliteracies in two case studies. The presentation will also convey how the participating professionals share the mutual educational aim of literacies proposed in the NCC and how they have adjusted their working methods to correspond this aim.

The proposed presentation reports two case studies conducted in library-school settings. The first author analyzed the conceptions of IL in the NCC and interviewed five teachers and five school librarians to study their conceptions of IL. The second author studied multiliteracies in seven local curricula and interviewed 12 teachers' and seven librarians' understanding of the particular concept. These teachers and librarians participated and worked together in implementing multiliteracies in Joy of Reading program (2012-2015) funded by the Finnish Ministry of Education and Culture.

The results of the analysis of the NCC show that it offers abstract descriptions of the joint work between schools and libraries but does not include descriptions of the work to be implemented in practice. According to the analyses, the libraries had two roles: (1) First, they were seen mostly as a provider of services and, (2) Second, they were considered a physical learning environment for schools rather than a companion in instruction.

The studies revealed that IL is not well understood and described in the local curricula. It was described as mere 'information seek instruction'. Based on the interviews, IL as a term was not recognized by the teachers. Interestingly, multiliteracy was a term for which school librarians were uncertain. This might be because three out of five interviewed school librarians stated that they had not read the NCC. In addition, some public librarians felt that the concept was too extensive to understand and that their role in supporting multiliteracies was unclear. Teachers understood the multimodal aspects of multiliteracy but did not connect these aspects to information managing issues. Technology was emphasized in the conceptions; two teachers even perceived multiliteracies only as technological issue. Teachers and librarians agreed that basic literacy skills, such as the ability to read fluently and to understand reading, formed a base for multiliteracies.

Keywords: Finnish national core curriculum, information literacy, multiliteracies, public library, school library 


\title{
Which Approaches and Methods are Most Appropriate for Exploring Health Information Behavior?
}

\author{
Marianne Paimre \\ Tallinn University, Estonia, marianne.paimre@tlu.ee
}

\section{Background}

In a contemporary welfare society, people are expected to make adequate decisions regarding their health (Cao et al., 2015). The Internet has proven to be a readily accessible source for retrieving health information with ease and anonymity. In Estonia, where the majority of the adult population is avid users of the Internet, the number of health issues caused by wrong lifestyle choices has never been more apparent (Praxis, 2017). Thus, the patterns of online health information seeking behavior (OHISB) should be rigorously monitored. But which should be the preferred methods?

\section{Aims}

The aim of this presentation is to give an overview of the approaches and methods in studying OHISB. It will focus on the following aspects: 1) how studies on OHISB could be grouped subject to the approaches and methods used and 2) which methods enable to explore OHISB in all its complexity?

\section{Method}

Using a method of content analysis, I studied 70 most relevant articles on OHISB and eHealth literacy published and entered in the EBSCO databases during the last ten years. The results were statistically processed using the SPSS program.

\section{Outcomes}

Multidimensional and complex nature of the research on OHISB and eHealth literacy (eHL) has given rise to a variety of methodologies and approaches. Cluster analysis enabled me to distinguish between five major groups of studies: 1) Quantitative research on OHISB that usually focuses on the associations of various determinants and the context of OHISB, comprised $39 \%$ of the articles analyzed. These studies usually rely on big datasets and use statistical analysis in order to identify associations between OHISB and eHL and various demographic factors (for example, gender, age, ethnicity, and other aspects) and/or other aspects (for example, users' health condition, type of illness, and social engagement). 2) In the qualitative research (25\%) on OHISB, interviews (usually semi-structured) or focus group interviews and experiments are the preferred methods for assessing people's logic, beliefs, values, skills, and difficulties in finding relevant information. 3) The authors seemed to favor the mixed methods design because this approach allowed them to explore the object in a multidimensional setting and to study the phenomenon in all its complexity. Unfortunately, only 6 articles out of 70 made use of both quantitative and qualitative methods in their study. 4) Meta-analysis and overviews comprised 10\%. 5) The fifth group consisted of articles that did not correspond to any of the clusters mentioned above.

\section{Conclusions}

Many quantitative studies that constituted the bulk of the analyzed studies also emphasized the need to explore OHISB from a qualitative point of view. Subject to the analyzed literature, it may be concluded that the mixed methods seem to have generated the most comprehensive approach for studying OHISB in all its variety and complexity. However, this approach was, in fact, the least used in studies compared to quantitative and qualitative methods.

\section{References}

Cao, W. et al. (2015). Modelling online health information-seeking behaviour in China: The roles of source characteristics, reward assessment, and Internet self-efficacy. Health Communication, 31(9), 1105-1114.

Praxis. (2017). Tervis peaks olema prioriteet kõigis poliitikavaldkondades. Retrieved December 28, 2017 from http://www.praxis.ee/kajastused/tervis-peaks-olema-prioriteet-koigis-poliitikavaldkondades/

Keywords: health information, online health information behavior, eHealth literacy, methods, approaches, studies 


\title{
Copyright Literacy among Students of Information Science at the University of Iceland
}

\author{
Ágústa Pálsdóttir \\ University of Iceland, Reykjavík, Iceland, agustap@hi.is
}

\section{Objectives}

As part of their work, librarians and information specialists often need to deal with copyright issues and act as intermediaries between the consumers and the authors or producers of material. It is therefore important that information science students receive education that allows them to become copyright literate. The aim of the study is to investigate knowledge of and attitudes about copyright issues as well as the opinion about education about copyright, among graduate information science students. This is the first time that this subject is being studied in the country involved and the findings will therefore fill a gap in the knowledge about the copyright literacy of the students. To do so, answers to the following main research question will be sought: 1) What ares the students' opinions and knowledge about copyright issues? 2) What are the students' opinions about the education that they receive and/or should receive about copyright?

\section{Methodology}

This is an international online survey conducted among students at the Department of Information Science at the University of Iceland. The same questionnaire, which was translated from English to the students' mother tongue, was used by all participating countries. The measurement instrument consisted of 13 questions in all. A total of nine questions emphasized knowledge about copyright, awareness of where information about it can be found, the students opinion about copyright issues, what they have learned about copyright, and what, in their opinion, they should learn about it. In addition, the questionnaire consisted of four background questions. The online system Lime Survey, an open source software, was used for data collection. Data collection started in January 2018 and lasted for three weeks, with two reminder e-mails sent out. The Information Science program is exclusively taught at a graduate level with an enrolment of 54 students. A total of 22 students replied to the survey, a 41 percent response rate. Data processing and analysis ares still ongoing.

\section{Outcomes}

Future librarians and information specialists need to be capable of interpreting copyright law as well as licensing agreements. It is important to recognize the students' level of knowledge and attitudes towards the issue of copyright, as well as their opinion about how much education is needed about the topic. This may be of value for designing relevant educational material and in order to develop a curricula for their training. The study is particularly important because so far no knowledge has been available about the copyright literacy of students of Information Science in the country. It may therefore shed some light on the current situation and what improvements are needed in the students' education.

Keywords: copyright literacy, copyright education, information science, graduate students 


\title{
Privacy Literacy and the Everyday Use of Social Technologies
}

\author{
Zablon Pingo and Bhuva Narayan \\ University of Technology Sydney, Australia, zablonbosire.pingo@student.uts.edu.au, bhuva.narayan@uts.edu.au
}

In the current digital economies, data is generally represented as raw material (Lupton, 2015) but the rise of Big Data, facilitated by the self-documenting nature of digital social media and self-archiving alongside the increased adoption of the Internet of Things (IoT) is raising privacy discussions and concerns globally. These concerns necessitate that individuals have information literacy skills to critically evaluate their information sharing practices, understand how the data they produce is used, and how their personal information is shared. This paper frames this type of information literacy as privacy literacy.

Privacy literacy is related to users' attitudes regarding the collection, processing, distributing and use of personal data (Veghes, Orzan, Acatrinei, \& Dugulan, 2012). Privacy literacy can be seen as a sub-set of information literacy for it requires individuals to have some level of understanding, knowledge, skills and ability to assess the risks and rewards of sharing personal information. Privacy research takes multiple perspectives on this issue including legal, technological, and philosophical among others, but there is less research around users' perspectives and their information practices in regard to sharing of personal information.

This study uses the Communication Privacy Management Theory (Petronio, 2002) and the Contextual Integrity Theory (Nissenbaum, 2004) to understand how consumers understand and manage their own and others' personal information. We used a qualitative approach and interviewed twenty users of digital and social media technologies, Internet of Things, and consumer loyalty cards, alongside an online observation of SNS (social network services), a privacy settings walkthrough, and tracing online footprints of users.

The findings indicate that people have limited privacy concerns when using consumer loyalty cards and fitness trackers due to the unknown nature of the risks associated with the information collected or shared, compared to how people manage privacy on social networking sites. Many participants managed their privacy on social networking sites through data minimisation, blocking others, unfriending, declining friend requests (from unknown people, work colleagues, some family members) but many were also willing to share personal information in exchange of certain benefits, which required continual management and negotiation.

Findings also indicate a disparity between people's privacy expectations and the literature in regard to privacy risks; lack of choice in privacy negotiation tools (privacy policies, settings, etc.) was also a factor. The findings also suggest a general lack of awareness of privacy risks due to the complexity of information flows between individuals and service providers in which individuals have no way to anticipate how the personal data is used, either by their friends and family or by organisations. The implications of the study point to a need for privacy literacy education and awareness among users of digital and social media technologies. We propose that information literacy models and information literacy education should also take into account people's privacy literacy.

\section{References}

Lupton, D. (2015). Digital sociology. Oxford, UK: Routledge.

Nissenbaum, H. (2004). Privacy as contextual integrity. Washington Law Review, 79(1), 119-158.

Petronio, S. (2002). Boundaries of privacy: Dialectic of disclosure. New York: SUNY Press.

Veghes, C. et al. (2012). Privacy literacy: What is and how it can be measured?. Annales Universitatis Apulensis: Series Oeconomica, 14(2), 704-711.

Keywords: privacy, privacy literacy, information literacy, contextual integrity theory, communication privacy management theory, social media, internet of things 


\title{
The Attitudes of teachers-in-training towards Information Literacy Skills and the Inclusion of Mobile Devices in the Process of Teacher Education
}

\author{
María Pinto \\ Universidad de Granada, Granada, Spain, mpinto@ugr.es \\ David Caballero-Mariscal \\ Centro de Magisterio La Inmaculada, Granada, Spain, davidcaballero@ugr.es \\ Rosaura Fernández-Pascual \\ Universidad de Granada, Granada, Spain, rpascual@ugr.es \\ Dora Sales \\ Universidad Jaume I, Castellón de la Plana, Spain, dsales@uji.es \\ David Guerrero-Quesada \\ Universidad de Granada, Granada, Spain, dguerrero@ugr.es
}

\begin{abstract}
The main focus of this paper is to analyze the relation between information literacy and the use of mobile devices in the process of learning and teaching in university students, specifically, teachers-in-training. For this purpose, a group of students belonging to the last semester of the education degree $(\mathrm{N}=42)$ at the University of Granada were selected for a qualitative-descriptive study, based on a focus group, using the techniques of the thinking aloud and semistructured interviews (Harrell \& Bradley, 2009); and a brief quantitative questionnaire using a Likert-Scale (Schulze, 2003). With these two procedures we tried to measure attitudes towards information literacy and the influence that mobile devices exert on its acquisition. Both results (qualitative and quantitative) were compared in order to check the consistency of the information offered by the students. After we analyzed the data, we conclude the following: 1 . There is a generalized use of mobile devices in the process of learning and teaching. The use of digital technologies for communication and learning purposes is obviously a part of the identity of young people and, in particular, of university students. (Margaryan, Littlejohn \& Vojt, 2011). 2. The increase of these devices is related to a change of attitudes which includes distraction, the use of new technologies for other purposes (non-academic) and a lack of critical outlook. 3. Age is a relevant factor for the development of attitudes and skills related to critical and independent thinking. Nevertheless, significant differences were not observed as far as the use of mobile devices and the acquisition of digital information skills were concerned. 4. To a greater or a lesser extent, students demand the use of new technologies combined with a traditional methodology on the basis of master classes, discussion groups, dialogue and interactions, and practicum (Hwang \& Chang, 2011). It is also remarkable that an excessive use of mobile devices may hinder and overwhelm the acquisition of literacy skills. 5.Data analysis identified gaps in the information literacy of teachers-in-training despite their constant access to information via mobile devices. Therefore, we propose that appropriate information literacy training be a key priority in teacher education. 6. Concerning to the use of mobile techologies in the classroom, this research suggests both a positive impact and disadvantages.
\end{abstract}

\section{References}

Harrell, M. C., \& Bradley, M. A. (2009). Data collection methods. Semi-structured interviews and focus groups. Santa Monica, CA: Rand Corporation.

Hwang, G. J., \& Chang, H. F. (2011). A formative assessment-based mobile learning approach to improving the learning attitudes and achievements of students. Computers \& Education, 56(4), 1023-1031.

Margaryan, A., Littlejohn, A., \& Vojt, G. (2011). Are digital natives a myth or reality? University students' use of digital technologies. Computers \& Education, 56(2), 429-440.

Schulze, S. (2003). Views on the combination of quantitative and qualitative research approaches. Progressio, 25(2), $8-20$.

Keywords: information literacy, mobile learning, attitudes, focus group, teachers-in-training 


\title{
The Health of a Musician: Identifying Musicians' Unrecognized Health Information Needs
}

\author{
Loriene Roy and Yan Zhang \\ The University of Texas at Austin, TX, USA, \{loriene, yanz $\} @$ ischool.utexas.edu
}

\section{Objectives}

One local non-profit in Austin, Texas, USA is HAAM (Health Alliance for Austin Musicians). HAAM assists musicians by providing no- or low-cost health coverage along with dental, hearing, and vision care. Programs include Hepatitis-C testing and treatment and discounted wellness services (acupuncture/chiropractry/massage). Without HAAM, $31 \%$ of Austin musicians would be without health insurance.

In 2016 HAAM collaborated with the UT-Austin Dell Medical School to evaluate HAAM services and measure depression, pain interference, physical function, and social engagement/social isolation. HAAM staff need more details on musicians' barriers to receiving health care. The aim of this paper is to examine the results of this study to identify musicians' stated health care needs. Results note, for example, that the most common health challenge of musicians is anxiety, followed by shoulder pain.

\section{Methodology}

Taylor (1968) identified four levels of information needs: visceral, conscious, formalized, and compromised. We intend to investigate musicians' health information needs, both conscious and unrecognized needs, focusing on testing methods that attempt to elicit musicians' unrecognized/unstated needs.

First, HAAM has agreed to share data from the 2016 survey. Second, we will involve graduate students in our spring 2018 courses to develop resources for HAAM clients. Students in the "Library Instruction and Information Literacy" course will develop instructional videos for HAAM. Students in "Information Architecture and Design" will critique the HAAM website. These videos will be completed by May 2018 and will cover topics including self-care, insurance basics, audiology care, and general HAAM services.

This information will help us with further data collection. These include conducting focus groups with musicians and people who have knowledge about musicians' health information needs and who have first-hand experience of living with musicians and of caring for their health. In addition, we will observe musicians' public performances, taking notes about the physical demands of performance, the late hours of the work, the possible noise/loudness of the environment, and conversations the musicians enter into. We will also analyze the content that musicians post on their public websites and Facebook groups.

\section{Outcomes}

The results of these explorations will help us to: (1) examine the effectiveness of methods to shed light on musicians' health information needs; (2) establish research protocols for focus groups and performance observation; and (3) inform the design of a future semi-structured interview protocol and a survey questionnaire.

\section{References}

Taylor, R. S. (1968). Question-negotiation and information seeking in libraries. College \& Research Libraries, 29(3), $178-194$.

Keywords: health information literacy, musicians, literacy in everyday life, health needs, service learning, graduate education 


\title{
Drop Out Factors in Data Literacy and Research Data Management Survey: The Vilnius University Experience
}

\author{
Jurgita Rudžionienė and Vincas Grigas \\ Vilnius University, Lithuania, jurgita.rudzioniene@kf.vu.lt, vincas.grigas@gmail.com
}

\begin{abstract}
"And then there are these other files that are just, like, numbers. Arrayed. Numbers and dates and numbers and numbers and dates. And, numbers and... I think that's the shit, man. The raw intelligence." (Coen \& Coen, 2008). A survey is quite a popular method to collect data in social sciences. Researchers are interested mostly in full answers and often consider these as the data. However, there is another kind of data that could be interesting to analyse, those from respondents who dropped out a questionnaire at the very start or middle of the survey. There are various factors that affect the response rates of web surveys such as: Content, presentations of questions, contact delivery modes, the design of invitations, the use of pre-notification and reminders, incentives (Fan \& Yan, 2010). Also, Baruch found that the average response rate in academic studies was 55.6 with a standard deviation of 19.7 (Baruch, 1999). There could be more factors that impact dropping out of an already started survey.
\end{abstract}

The purpose of this paper is to develop an understanding about factors that represent respondents who decided to drop out of a survey they started but did not complete. We decided to take as a case study a questionnaire on data management at Vilnius University implemented during 2017.

The data for the analysis was collected using a questionnaire that was used in a multinational research study on Data Literacy and Research Data Management. Serap Kurbanoglu and Joumana Boustany initiated this study that has been expanded to a group of researchers in more than ten countries. The survey instrument consists of 24 questions arranged into two groups: (1) awareness of data management issues and (2) demographic information. The purpose of this research was to find current levels of awareness and gaps in knowledge of data literacy and management of academic staff and doctoral students.

This paper describes the preliminary phase of the research by presenting a pilot study analysing 237 unfinished and 202 finished surveys. We intend to find out if there is any gender, experience, science field, or job position factors that could indicate the impact on willingness to drop out of the survey. Also, we analyse at which part of the questionnaire most of the dropouts have happened to ascertain how long the respondents persistend in completing the survey before they decided to quit.

The collected data were analysed using descriptive and inferential statistical tests through IBM SPSS Statistics ver. 19.

We present the data acquired in the pilot survey and their possible interpretations. We discuss the approach we followed in finding out what impacts individuals' deciding to drop out of the survey.

The researchers hypothesize that the most significant reasons for deciding not to finish the survey were the topic of the survey, the length of survey, and their scientific field of study. We found no statistically significant difference between those who finished the survey and those who did not when we examined the data by gender, experience, and job position.

\section{References}

Baruch, Y. (1999). Response rate in academic studies: A comparative analysis. Human Relations, 52(4), 421-438.

Coen, E., \& Coen, J. (2008). Burn after reading. USA: Focus Features. Retrieved May 7, 2018 from https://www.imdb.com/title/tt0887883/?ref_=fn_al_tt_1

Fan, W., \& Yan, Z. (2010). Factors affecting response rates of the web survey: A systematic review. Computers in Human Behavior, 26(2), 132-139.

Keywords: survey, data management, information literacy, University of Vilnius 


\title{
Influence of Leadership Behaviour on Information Culture Typology within Higher Education Institutions: A Multiple Case Study
}

\author{
Anmar Salman and Sirje Virkus \\ Tallinn University, Estonia, \{anmar.salman, sirje.virkus $\} @$ tlu.ee
}

The purpose of this paper is to present the results of a study that explored how leadership behaviour influences information culture typology in higher education institutions. The study examined how thirteen aspects of leader behaviour, found to be associated with effectiveness at departmental level, are in relation with the main five attributes by which, according to Choo (2013), any information culture type can be characterised: the primary goal of information management; information values and norms; information behaviours in terms of information needs, information seeking, and information use.

Oliver (2011) argues that information culture is a part of the whole organisational culture and is inextricably intertwined with it. Curry and Moore (2003) believe that the synthesis of information culture and organizational culture is an integral part of the process of becoming a knowledge-based organization. Virkus (2011) reports that one of the dominant features of successful development of information literacy (IL) is effective leadership and good management. Several other researchers have highlighted the importance of leadership and organizational culture within an organisation and their relationship with information culture. Findings from previous research suggest that the part of organizational culture that deals specifically with information: perceptions, values, behaviour, and norms that people have about creating, sharing, and managing information, has significant relations to information use in organizations (Lauri et al, 2016). Although leadership and management have received some attention in different IL frameworks and guidelines and by some IL authors, it is not an issue has received much attention in IL and information culture research (Virkus and Mandre, 2015). Therefore, this study is designed to investigate the influence of leadership on information culture within higher education institutions in Estonia.

A qualitative method approach is used in the study. The researchers take a constructivist approach and employ a multiple case study research strategy. Semi-structured interviews are used for data gathering from academic staff of higher education institutions. The interview protocol was developed by the researchers on the basis of the previous research.

The results of the research project show that leadership behaviour influences information culture typology in higher education institutions.

\section{References}

Choo, C.W (2013) Information culture and organizational effectiveness. International Journal of Information Management, 33,5, 775-779.

Curry, A., \& Moore, C. (2003). Assessing information culture: An exploratory model. International Journal of Information Management, 23(2), 91-110.

Lauri, L., Heidmets, M., \& Virkus, S. (2016). The information culture of higher education institutions: The Estonian case. Information Research, 21(3). Retrieved from http://InformationR.net/ir/21-3/paper722.html

Oliver, G. (2011). Organizational culture for information managers. Oxford: Chandos Publishing.

Virkus, S. (2011). Development of information-related competencies in European higher open and distance learning: An exploration of contextual factors (Thesis). Manchester Metropolitan University, Manchester.

Virkus, S., \& Mandre, S. (2015). Information literacy, leadership and management. In S. Kurbanoğlu et al. (Eds.), Information Literacy: Moving Toward Sustainability, Third European Conference on Information Literacy, ECIL 2015, Tallinn, Estonia, October 19-22, 2015: Revised Selected Papers (pp. 80-89). Cham: Springer International Publishing.

Keywords: information culture, information literacy, leadership, organizational culture, higher education, case study research 


\title{
Changing Roles for Research and Information Skills Development: Librarians as Teachers, Researchers as Learners
}

\author{
Tatiana Sanches \\ Universidade de Lisboa, Portugal, tsanches@fpie.ulisboa.pt
}

\begin{abstract}
Librarians' pedagogic roles assume more and more protagonism in daily life. With the digital age, new opportunities arise for librarians to act as protagonists, advocates and pioneers of a new way of handling information, beyond the traditional roles of keepers and caretakers of collections (Brown, 2013). Researchers, on the other hand, as stated by the Working Group on Education and Skills under Open Science (European Commission, 2017), need to prepare themselves for the Open Science movement, by acquiring new skills. The commitment of higher education libraries to support research and science has been pursued in several ways: digital data management, institutional repository maintenance, close linkage between technology services and library services, digital archiving of content aggregators that allow interaction and interoperability between databases (Carter, 2013; Raju, 2014). However, this support should also be provided through more direct actions that encourage the acquisition and development of skills by researchers and the good use of tools that improve their day to day (Bendriss, Saliba \& Birch, 2015). Based on a literature review that underpins a case study, the study seeks to contribute to this reflection, explaining training strategies aimed at researchers, particularly with regard to tools and skills that can contribute to the research, organization and presentation of information. The case study describes how an academic library responds every day to the challenges of Open Science, taking three paths: providing tutorial support to teachers and researchers; investing in electronic resources and training for their proper use; and developing and disseminating an online publication that seeks to improve their skills in both knowledge and practices relating to Open Science. The library thus seeks to advocate for Open Science, giving the teachers and researchers greater confidence by promoting transversal competences, which facilitate greater participation in the global dissemination of scientific knowledge. The conclusion shows that these are fundamental partnerships (Salem Jr., 2017; Junisbai, Lowe, Tagge, 2016) and that the actions librarians can develop at this level are vital, for they are the basis for the creation and development of transversal skills in lifelong learning, particularly in higher education' changing landscape.
\end{abstract}

\section{References}

Bendriss, R., Saliba, R., \& Birch, S. (2015). Faculty and librarians' partnership: Designing a new framework to develop information fluent future doctors. The Journal of Academic Librarianship, 41(6), 821-838.

Brown, M. L. (2013). The role of the research library. In D. Shorley, \& M. Jubb (Eds.), The Future of Scholarly Communication (pp. 158-168). London: Facet.

Carter, I. M. (2013). Changing institutional research strategies. In D. Shorley, \& M. Jubb (Eds.), The Future of Scholarly Communication (pp. 145-155). London: Facet.

European Comission. (2017). Providing researchers with the skills and competencies they need to practise Open Science: Report of the Working Group on Education and Skills under Open Science. Retrieved May 12, 2018 from https://cdn1.euraxess.org/sites/default/files/policy_library/ec-rtd_os_skills_report_final_complete_2207_1.pdf

Junisbai, B., Lowe, M. S., \& Tagge, N. (2016). A pragmatic and flexible approach to information literacy: Findings from a threeyear study of faculty-librarian collaboration. The Journal of Academic Librarianship, 42(5), 604-611.

Raju, J. (2014). Knowledge and skills for the digital era academic library. The Journal of Academic Librarianship, 40(2), 163-170.

Salem Jr., J. A. (2017). Open pathways to student success: Academic library partnerships for open educational resource and affordable course content creation and adoption. The Journal of Academic Librarianship, 43(1), 34-38.

Keywords: information literacy training, university libraries, open science, researchers, information skills, higher education 


\title{
Multi-literacies and Social Sustainability
}

\author{
Egbert John Sanchez Vanderkast
}

National Autonomous University of Mexico, Mexico, egbert@unam.mx

In order to succeed, sustainable development must be seen as an integrative matter. In this particular point of view, social sustainability can be seen as "a life enchancing condition within communities and as a process within communities that can achieving that condition" (Chowdhury, 2014; p.19). Some characteristics of social sustainability are those that reli on thekind of users we have at our infomation centre, the quality of service we provideat the information centre, the kind of information system, and the specific content they manage. All the above mentioned will help to build a community where civic or any kind of literacy should be taught to empower the community and to motivate its members to reach some kind of civic literacy which, according to Milner, should be understood as "the ability manifesting itself in the form of political knowledge and the willingness in the form of political participation" (Milner; 2002).

In this sense, Koltay, Spiranic and Karvalics (2016, p.63) provide the following definition of information literacy as "the adoption of appropiate information behavior to obtain, through whatever channel or medium, information well fitted to information needs, together with critical awareness of importance of wise and ethical use of information in society." In a community we should look for those elements that: connect with information; interact with information; and also make use of information. On one hand we have those dynamics of information literacy and, on the other hand, we have those elements of social sustainability.

The aim of this paper is to identify those variables of social sustainability, like access to resources, education, gender equity, health, leadership, and quality of life that will drive us to understand and link with civic literacy. The result will direct us to proposals of policy choices to promote civic literacy.

\section{References}

Chowdhury, G. (2014). Sustainability of scholarly information. London: Facet.

Koltay, T., Špiranec, S., \& Karvalics, L. Z. (2016). Research 2.0 and the Future of Information Literacy. Amsterdam: Chandos. Milner, H. (2002). Civic literacy. Hanover: University Press of New England.

Keywords: multi-literacies, civic literacy, social sustainability, information poverty, information literacy, information policy 


\title{
Critical Information Literacy Teaching in Canadian Academic Libraries
}

\author{
Debbie Schachter \\ University of Edinburgh, Scotland / Capilano University, North Vancouver, Canada, debbieschachter@capilanou.ca, \\ debschachter@shaw.ca
}

The 2016 publication of the ACRL Framework for Information Literacy led to extensive discussions in the academic library community on the theories and practices related to information literacy teaching in higher education. In particular, discussions regarding librarians' understanding of new critical perspectives on information literacy have come to the forefront. Following a literature review on the concept of critical information literacy and library pedagogy, a gap was identified regarding the understanding of information literacy teaching theory and practices in higher education in Canada and, in particular, in the province of British Columbia (B.C.).

This paper will provide an overview of research and findings related to the application of critical information literacy theory in B.C. higher education library practices. It explores how librarians apply a critical lens to their information literacy practices, such as addressing concepts of social justice and indigenizing library practices, both within a Canadian context, and beyond. It emerges from research conducted with librarians in higher education, as part of the thesis work for the credential of Doctor of Education, through the University of Edinburgh.

In the autumn of 2017, research was conducted to address the question: How are librarians in B.C. higher education applying critical information literacy in their practice? The mixed methods study involved participant librarians from the 25 public higher education institutions in the province who provide leadership for their institution's information literacy programmes. The first phase of the research involved a survey probing existing practices and librarian understanding of theory underpinning those practices with a focus on the concept of critical information literacy. Twenty four survey responses were received from 22 institutions of the total population of 25 public institutions. For the second phase, 13 individuals, representing 13 different institutions of the total population of 25 institutions agreed to follow-up, semi-structured interviews. The in-depth interviews were conducted across institution types, sizes, and geographic regions in the province. Information related to awareness and application of theory in practice was gathered. An inductive approach was taken to analysing the qualitative data in both the surveys and the interviews, with the survey data forming the basis for the further exploration of themes emerging from the surveys. Quantitative data collected related to the particular institutions provided an opportunity to compare and contrast data between institutions and to determine whether institution type and location has an impact on the application of critical information literacy in higher education teaching. Themes arising from the research provide an understanding of how and why practices occur as they do and recommendations for further research and information sharing are identified by the researcher and the participants. This information will be useful to librarians teaching information literacy in tertiary institutions and researchers who are interested in further questions regarding the development of critical information literacy practices.

Keywords: critical information literacy, library instruction, mixed methods research, higher education, British Columbia, higher education, Canada 


\title{
Using Constructive Alignment to Support Metaliteracy in International Classrooms
}

\author{
Kristen Schuster \\ King's College London, UK, kristen.schuster@kcl.ac.uk \\ Kristine N. Stewart \\ Zayed University, Abu Dhabi, United Arab Emirates, kristine.stewart@zu.ac.ae
}

Diverse classrooms provide unique opportunities for students (and teachers) to learn from one another. Applying metaliteracy frameworks can help instructors synthesize module content with literacy instruction. For instance, prompting students to discuss their information seeking practices with peers promotes critical reflective practices about how they are using information to communicate. While there are theories and frameworks for building and assessing metaliteracy skills, we argue that they do not account for culturally diverse understandings of analytical or reflective assessment and intellectual property. Thus, it is necessary to explore methods for adapting metaliteracy frameworks so that we acknowledge and incorporate diverse language, cultural and disciplinary perspectives into the delivery of module content and assessment of student learning.

We propose two strategies for supporting the development and application of metaliteracy for international students: Learning oriented assessment (LOA) and constructive alignment. Carless (2007) proposes LOA as a method for balancing formal (marked) and informal (unmarked) activities so that students experience a range of assessment types and receive continuous and diverse feedback on their learning. The dynamic types of work and feedback students experience allows them to synthesize technical skills, theoretical and pre-existing skills and encourages students to structure their own learning, which, in turn, offers opportunities for module tutors to identify and adapt to student's interests and abilities. In terms of literacy instruction and benchmarking LOA offers opportunities for English as a second language (ESL) students to practice the critical reflective elements promoted in metaliteracy theories and to integrate these practices into their engagement with English language materials and academic frameworks. This process presents opportunities to integrate cultural awareness into metaliteracy frameworks. Constructive alignment offers a theoretical framework for using LOA to expand the potential for using metaliteracy frameworks. Drawing on Biggs and Tang's (2011) research, we understand constructive alignment as a conscious effort to create a holistic curriculum and, thus, provides opportunities to implement metaliteracy frameworks while simultaneously acknowledging the biases and assumptions express in IL and metaliteracy research.

To situate the compatibility of these theories, we present a case study based on longitudinal observations of a group of international postgraduate students in an interdisciplinary department at a UK Russell Group college. Whilst the department fosters a dynamic learning environment, module formats and assessment criteria can pose challenges for ESL students. We describe how theories of constructive alignment supported the development and implementation of learning outcomes, both for the module's entire curriculum and for weekly lectures and seminars. Discussing learning outcomes as the cornerstone for lecture topics and seminar exercises will contextualize methods for engaging students in LOA, and how these opportunities framed metaliteracy practices based on the use of peer feedback in summative assessments. We will draw conclusions about the roles LOA and metaliteracy can play in constructive alignment the module's based on analyses of student feedback and peer review for quality assessment purposes.

\section{References}

Biggs, J., \& Tang, C. (2011). Teaching for quality learning at university. New York, NY: McGraw-Hill Education.

Carless, D. (2007). Learning oriented assessment: Conceptual bases and practical implications. Innovations in Education and Teaching International, 44(1), 57-66.

Keywords: metaliteracy, learning oriented assessment, ESL instruction, international classrooms 


\title{
Impact of Intrinsic Motivators on Knowledge Sharing in Virtual Environments: Implications for Workplace Information Literacy and Collaborative Practices
}

\author{
Rajesh Singh \\ St. John's University, New York, NY, USA, singhr1@ stjohns.edu
}

\begin{abstract}
Workplace information literacy refers to the ability to recognize, access, and apply relevant information for performing various job-related tasks at work (Kirton \& Barham, 2005). Collaboration is widely recognized as an important jobrelated activity that contributes to innovation and improvement in organizations. This suggests that collaboration could be considered as one of the critical workplace information literacy skills. The recent Educause Horizon Report (2016) highlights the findings of a survey of 400 organizations, demonstrating $96 \%$ of employers want prospective graduates to "have higher education experiences that teach them to solve problems collaboratively with people whose views are different from their own, with a strong emphasis on the importance of applied learning and teamwork" (Johnson, et al., p. 32). However, simply putting students into teams may not always result in increased levels of collaboration and enhanced quality of knowledge creation.

Although knowledge sharing is considered a crucial process in collaborative projects, individual factors that may motivate or undermine knowledge sharing are not well understood. Factors such as extrinsic reward systems are inadequately studied (Durmusoglu et al., 2014) and appear to indicate inconclusive findings (de Almeida, Lesca, \& Canton, 2016; Lin, 2007). This study examines the impact of intrinsic motivators on knowledge sharing in virtual environments. More specifically, the study aims to understand the role of trust, mutual influence, and personal outcome expectations in knowledge sharing in virtual environments. The data was collected from 169 library and information science students across seven blended courses in 2011. There were a total of 40 teams ranging from 2 to 7 students, who were assigned to a collaborative learning project in their courses. The ANOVA test was used to compare the means of the perceived quality of knowledge creation into three levels: (1) enhanced; (2) moderate; and,(3) baseline. The role of intrinsic factors, namely, trust, mutual influence, and personal outcome expectations was found to be critical in facilitating knowledge sharing and enhancing knowledge creation. Although the study was conducted in an educational context, the findings can be extrapolated in developing workplace information literacy instructions about collaborative practices across a variety of organizations.
\end{abstract}

\section{References}

De Almeida, F. C., Lesca, H., \& Canton, A. W. P. (2016). Intrinsic motivation for knowledge sharing: Competitive intelligence process in a telecom company. Journal of Knowledge Management, 20(6), 1282-1301.

Durmusoglu, S. et al. (2014). The quasi-moderating role of organizational culture in the relationship between rewards and knowledge shared and gained. Journal of Knowledge Management, 18(1), 19-37.

Johnson, L. et al. (2016). NMC Horizon Report: 2016 Higher Education Edition, Austin, Texas, The New Media Consortium. Retrieved May 7, 2018 from https://library.educause.edu/ /media/files/library/2016/2/hr2016.pdf

Kirton, J., \& Barham, L. (2005). Information literacy in the workplace. The Australian Library Journal, 54(4), 365-376.

Lin, H. F. (2007). Effects of extrinsic and intrinsic motivation on employee knowledge sharing intentions. Journal of Information Science, 2(2), 135-149.

Keywords: knowledge sharing, intrinsic motivators, online collaboration, workplace information literacy 


\title{
Adapting the New ACRL Framework to IL Teaching at Tampere University of Technology
}

\author{
Miikka Sipilä \\ University of Tampere, Finland, miikka.sipila@uta.fi \\ Mervi Miettinen and Johanna Tevaniemi \\ Tampere University of Technology, Finland, \{mervi.miettinen, johanna.tevaniemi\} @tut.fi
}

In 2016, the TUT Library adopted the new ACRL Framework for Information Literacy (IL) for Higher Education for its information literacy education. The new framework introduces the idea of threshold concepts, and approaches learning as a change in understanding and ways of thinking, as opposed to the idea of learning a set of measurable skills. ACRL encourages libraries to deploy the frames to best suit their own situation and needs, and accordingly, the TUT Library has adapted the frames to better suit the needs of its technical students and researchers. This paper will present the ways in which the TUT Library has adapted the Framework to teaching information literacy, how partnership with teaching staff members was built through active collaboration, and the initial results of these changes as evaluated by both students and faculty teaching staff.

IL teaching at TUT has undergone significant changes, as IL studies became mandatory for all TUT students at certain stages of their studies in 2016. During this process, IL teaching was standardized, so that all students received the same content throughout the university according to their level of studies. The new framework was included in the new curriculum. We regard it as crucial to actively involve the teaching staff from every faculty and department in developing the contents of the Library's new IL teaching curriculum.

Involving the faculty from each department in developing the IL teaching was essential, as the TUT Library is committed to viewing information literacy as a key competence for the entire university. The Library retains responsibility for IL teaching, but the faculty also has a chance to give its views on field-specific issues. The initial results of this collaboration have been positive, and the Library continues to seek active partnership with the various faculty members involved in teaching at TUT. Additionally, this collaboration has resulted in better visibility of the Library's role and its other services within the university.

In our paper, we will introduce discussions about IL teaching and the new Framework (e.g. Zhang et al., 2015 and Foasberg, 2015). We will also present the results of questionnaires given to both students and faculty teachers regarding the students' IL competency pre- and post-IL teaching.

\section{References}

ACRL. (2015). Framework for information literacy for higher education. Retrieved January 26, 2017 from http://www.ala.org/acrl/standards/ilframework

Foasberg, N. M. (2015). From standards to frameworks for IL: How the ACRL framework addresses critiques of the standards. Libraries and the Academy, 15(4), 699-717.

Zhang, Q., Goodman, M., \& Xie, S. (2015). Integrating library instruction into the course management system for a first-year engineering class: An evidence-based study measuring the effectiveness of blended learning on students' information literacy levels. College and Research Libraries, 76(7), 934-958.

Keywords: information literacy, ACRL framework, higher education, academic libraries, collaboration, teaching 


\title{
Data Literacy Perception and Practices in the Information Environment
}

\author{
Jela Steinerová and Miriam Ondrišová \\ Comenius University in Bratislava, Slovakia, \{jela.steinerova, miriam.ondrisova $\} @$ uniba.sk
}

\begin{abstract}
The aim of this paper is to address conceptual issues of data literacy perception and to present first results of a survey on research data practices in Slovakia. Data can be regarded as representations of objects, measured inputs / parameters, and entities used as evidence in the research (Borgman 2015). Data literacy represents a process of becoming aware of different modalities of how to acquire, process, use and interpret data. Types of research data include big data, open data, qualitative and quantitative data, and experimental, observational, sensory, cultural, simulated, or referential data (Borgman 2015). Research data literacy has been explained by Schneider (2013) and Koltay et al. (2016). Research data practices emerge in data-intensive sciences and research data management (Tenopir et al. 2015). In this context we ask the questions: Which factors influence the concept and typology of research data? What is the perception of data literacy and data practices by Slovak researchers?
\end{abstract}

A case study of research data literacy in Slovakia is presented as part of a multinational survey on Data Literacy and Research Data Management. We conducted an online survey of data literacy practices in 10 selected Slovak universities and the Slovak Academy of Sciences distributed through the LimeSurvey tool (December 2017 - January 2018). The analysis of the 257 completed answers shows that majority of subjects were academic staff $(71.21 \%)$, including natural sciences $(40.47 \%)$, social sciences $(17.12 \%)$ and engineering $(16.34 \%)$. Limitations of the survey are low response rate and self-selection of subjects.

First findings point to positive perception of data practices by the researchers, involving willingness to share and reuse research data (52\%). The majority of subjects claimed that their data is available upon request (56.42\%). However, they expressed concerns about misuse (40.86\%), misinterpretation of data and data ethics (63\%). Differences across disciplines were noted. $73 \%$ of subjects have never used data management plan for their research, about $60 \%$ think that universities should have a data management plan. $65 \%$ are familiar with metadata standards, but $53.86 \%$ of subjects have never used metadata tagging for their data. Most subjects are interested in research data management education.

The study proved that data management needs of researchers are embedded in practice of disciplines. Main factors of research data literacy are data needs, access, evaluation, sharing, citation, data use and re-use. Other factors are tools, resources, social structures, publishing strategies, technology, and digital scholarship. We propose the perspective of data ecosystems, data literacy education, and research data management services of academic libraries. It is suggested to develop data infrastructures and data management policies with recognition of the different cultures of disciplines.

\section{References}

Borgman, C. L. (2015). Big data, little data, no data: Scholarship in the networked world. Cambridge: MIT Press.

Koltay, T., Špiranec, S., \& Karvalics, L. Z. (2016). Research 2.0 and the future of information literacy. Amsterdam: Chandos.

Schneider, R. (2013). Research data literacy. In S. Kurbanoğlu et al. (Eds.), Worldwide Commonalities and Challenges in Information Literacy Research and Practice, European Conference on Information Literacy, ECIL 2013, Istanbul, Turkey, October 22-25, 2013: Proceedings (pp. 134-140). Cham: Springer International Publishing.

Tenopir, C. et al. (2015). Changes in data sharing and data reuse practices and perceptions among scientists worldwide. PloS ONE, 10(8). Retrieved from http://journals.plos.org/plosone/article?id=10.1371/journal.pone. 0134826

Keywords: data literacy perception, research data literacy, Slovak researchers, research data management 


\title{
\#MuslimTravelBan: A Semantic and Social Network Analyses of Executive Order 13769 on Twitter
}

\author{
Kristine N. Stewart \\ Zayed University, Abu Dhabi, United Arab Emirates, kristine.stewart@zu.ac.ae
}

Executive Order 13769, Protecting the Nation from Foreign Terrorist Entry Into the United States, was issued on January 27, 2017 and was in effect until March 16, 2017. The Order, issued by President Donald Trump, temporarily banned travel to the U.S. by refugees and immigrants from several Muslim-majority countries (Martin, 2017). During the hours following the signing of the Order, documents describing how airports and government officials were to implement the Order had not been released, leading to chaos at airports, legal challenges, and protests throughout the country.

Executive Order 13769 began to trend on social media shortly after its announcement. News can lack accuracy and policy documents are often far too complex for the layman to understand. Social media, however, has become a forum for people from diverse backgrounds and from all over the world to share their perceptions and opinions of topics and current events. In the shift to new forms of media, social media platforms such as Twitter have become valuable resources for analysing social and linguistic phenomena on current events and headline news stories (Cody, Reagan, Mitchell, Dodds, \& Danforth, 2015).

In this study, Tweets concerning Executive Order 13769 were analysed to:

- determine the use of Twitter in response to Executive Order 13769,

- $\quad$ analyse the information behaviours of Twitter users (for example, were users expressing original opinions, interacting with other users, or merely reusing dialogue?),

- identify relationships and influence among individuals and groups sharing information regarding the Order on Twitter.

As noted by Frechette and Williams (2016, p. 1), approaches to media literacy often "overemphasize the end-goal of accessing digital media content" through the use of various digital technologies, rather than grasping and evaluating how media is created, used, and shared. As such, this study examines the role of social media in enabling active self, social, and civic participation.

The present study is a mixed method analyses of Tweets on the topic of Executive Order 13769, from its date of issue to when it was superseded by Executive Order 13780. The study utilized a methodological design based on a study by Lycariao and Alves dos Santos (2017) that combined semantic and social network analysis to measure "opinion leadership." Critical discourse analysis provided a methodological foundation for the semantic analysis and a theoretical framework guiding this study. Tweets that contained hashtags associated with Executive Order 13769, including: \#EO13769, \#TrumpsTravelBan, \#MuslimTravelBan, \#MuslimBan, and \#TravelBan, were collected from Twitter using the qualitative software, NVivo 11 Pro. A critical discourse analysis of a random sample of these Tweets was then conducted to understand their role in the process of evaluating information and legitimising identities and social movements (Fairclough, 1989).

Findings revealed the rise of influential communities, insight into the original and (un)original content shared by users, and the information seeking and sharing behaviours of Twitter users regarding Executive Order 13769. Crucial abilities and competencies for engaging in active citizenship will be illuminated using examples from this study.

\section{References}

Fairclough, N. (1989). Language and power. London: Longman.

Frechette, J., \& Williams, R. (Eds.). (2016). Media Education for a Digital Generation. New York: Routledge.

Lycariao, D., \& Alves dos Santos, M. (2017). Bridging semantic and social network analyses: The case of the hashtag \#precisamosfalarsobreaborto (we need to talk about abortion) on Twitter. Information, Communication, \& Society, 20(3), 368385.

Martin, P. L. (2017). President Trump and US migration after 100 days. Migration Letters, 14(2), 319-328.

Keywords: media literacy, Twitter, social media, critical discourse analysis, travel ban, active citizenship, network analysis 


\title{
Understanding Health Literacy through the Lens of Phronesis: The Case of Coronary Artery Disease Patients
}

\author{
Venkata Ratnadeep Suri \\ Indraprasta Institute of Information Technology, New Delhi, India, ratan.suri@iiitd.ac.in \\ Shaheen Majid and Schubert Foo \\ Nanyang Technological University, Singapore \\ Hannah Trinity Dumaual-Sibal \\ Ngee Ann Polytechnic, Singapore \\ Yun-Ke Chang \\ Higher Colleges of Technology, United Arab Emirates
}

Objective-In research projects as well as in clinical settings, health literacy is often measured using self-rated psychometric instruments. The results from such measurement strategies classify patients in high or low health literacy categories dependents on the scores patients receive. A number of scholars have highlighted the importance of differentiating between the concepts of patient's health literacy and patient's empowerment (Schulz, \& Nakamoto, 2013). Research has also shown that though patients perform poorly on health literacy measures overtime, they tend to develop skills and strategies to empower themselves to manage their chronic disease conditions (Camerini, \& Schulz, 2015).

In this study we use phronesis as a conceptual framework. Phronesis is defined as the practical wisdom that is often developed through experience and enacted by patients that can shed light on the capacities of patients to make healthrelated decisions and engage in healthy behaviors (Rief, Mitchell, Zickmund, et al., 2013; Rubinelli, Schulz, \& Nakamoto, 2009). Specifically, the study explores how patients enact various strategies for evaluating and using health information by drawing upon their experiences from their "patient journey," that empowers them to manage their chronic disease condition.

Methodology-We used qualitative research methods to collect data. 6 focus groups were conducted in which 30 patients from coronary artery disease patient population took part. It was assumed that these participants were most likely to appraise and use health information regularly and, therefore, are more likely to enact information practices to resolve their health issues. Data were analyzed using grounded theory methodology (Anselm, \& Corbin, 1998).

Outcomes-Results show that patients enact a number of strategies that reflect phronesis in terms of sourcing, analyzing and applying health information to manage their chronic condition. Findings from this study are discussed in context to evaluate phronesis as an important concept for understanding successful chronic disease self-management, and the concept's potential usefulness for developing educational interventions, and enabling participants to enact positive health related behaviors.

\section{References}

Anselm, S., \& Corbin, J. (1998). Basics of qualitative research: Techniques and procedures for developing grounded theory. Thousand Oaks, CA: Sage Publication.

Camerini, A.-L., \& Schulz, P. J. (2015). Health literacy and patient empowerment: Separating con-joined twins in the context of $\begin{array}{lllllll}\text { chronic low back Pain. } & \text { PLOS } & \text { Retrieved } & \text { from }\end{array}$ http://journals.plos.org/plosone/article?id=10.1371/journal.pone.0118032

Rief, J. et al. (2013). Promoting patient phronesis: Communication patterns in an online lifestyle program coordinated with primary care. Health Education \& Behaviour, 40(3), 311-322.

Rubinelli, S., Schulz, P. J., \& Nakamoto, K. (2009). Health literacy beyond knowledge and behaviour: Letting the patient be a patient. International Journal of Public Health, 54(5), 307.

Schulz, P. J., \& Nakamoto, K. (2013). Health literacy and patient empowerment in health communication: The importance of separating conjoined twins. Patient Education and Counselling, 90(1), 4-11.

Keywords: health literacy, phronesis, coronary artery disease, chronic conditions, critical health literacy 


\title{
Investigating Knowledge Management Practices at OpenStack
}

\author{
José Apolinário Teixeira, Helena Karsten and Gunilla Widén \\ Åbo Akademi University, Finland \{jteixeira, ekarsten, gwiden\}@abo.fi
}

\section{Introduction}

Knowledge work, as argued by Drucker (2017); Davenport and Prusak (2000); and others, is comprised of specialists who collaborate via exchange of expertise and skills to develop products and services. As noted by Awazu and Desouza (2004), this is exactly what open-source communities do. In such communities, both professionals and hobbyists leverage each other's knowhow and skills to develop software in a virtual and globally distributed fashion (Fitzgerald, 2006). This is a prime example of digital work as digital artifacts are developed mostly by digital means.

In this study, we address some of the information-intensive knowledge management practices of a large and wellknown open source community known as OpenStack - a community of individuals and organizations that jointdevelop an open source cloud-computing infrastructure for big data. More specifically, we take the theoretical notion of information literacy landscapes (see Lloyd, 2017) to analyze the day-to-day information-intensive work practices in the OpenStack open source community.

\section{Methods}

We take a cross-disciplinary approach to leverage the distinct disciplinary orientation of the authors (from 'Software Engineering' to 'Information Systems' and 'Library and Information Science') with the focus on digital work practices (see Rafols et al., 2010). We employ a case study research strategy (Yin, 1994). We collect and analyze naturally occurring trace data derived from this OpenStack project. The initial online sources (i.e., departure points) take into consideration the key guidelines on how to conduct empirical research online (Kozinets, 2009). We then follow many links to collect information related to knowledge management practices in OpenStack.

\section{Outcomes}

We identify a set of ten information-intensive work practices that in our view merit to be reported and explained to an audience that is interested in information literacy in digital work but not necessarily in software development. These ten practices are branching, committing, fetching, pushing, merging, reviewing, continuously integrating, gating, release management and landing. While most of these practices cannot be carried out in non-digital environments, the increasing trend towards the digitalization of work practices reiterates the importance of studying the informationintensive knowledge management practices in digital work.

\section{References}

Awazu, Y., \& Desouza, C. (2004). Open knowledge management: Lessons from the open source revolution. Journal of the American Society for Information Science and Technology, 55(11), 1016-1019.

Davenport, T., \& Prusak, L. (2000). Working knowledge: How organizations manage what they know. Boston: Harvard Business Review Press.

Drucker, P. (2017). The age of discontinuity: Guidelines to our changing society. New York: Taylor \& Francis.

Fitzgerald, B. (2006). The transformation of open source software. MIS Quarterly, 30(3), 587-598.

Kozinets, V. (2009). Netnography: Doing ethnographic research online. London, UK: Sage.

Lloyd, A. (2017). Information literacy and literacies of information: A mid-range theory and model. Journal of Information Literacy, 11(1), 91-105.

Rafols, I., Porter, L., \& Leydesdorff, L. (2010). Science overlay maps: A new tool for research policy and library management. Journal of the American Society for Information Science and Technology, 61(9), 1871-1887.

Yin, R. (1994). Case study research: Design and methods. Thousand Oaks, CA: Sage.

Keywords: digital work, information landscapes, information literacy, open source software, virtual communities, work practices 


\title{
Research Data Management Findings at ULSIT
}

\author{
Tania Todorova, Rositza Krasteva and Elisaveta Tsvetkova \\ University of Library Studies and Information Technologies, Sofia, Bulgaria, \{t.todorova, r.krasteva, \\ e.cvetkova\}@unibit.bg
}

In 2017 a team of researchers from the University of Library Studies and Information Technologies (ULSIT) joined an international scientific survey on Data Literacy and Research Data Management (RDM) (Chowdhury et al, 2016). In the period January-March 2017, a translation of the questionnaire was carried out, a respondents' list was created, and the survey was disseminated via an online survey. In ULSIT the study was conducted on the basis of systematic random sampling with stratification of $10 \%$ of all professors under basic employment contracts at the university and $10 \%$ of the doctoral students currently trained. The general group consists of 41 effectively surveyed lecturers and doctoral students.

In the research paper we examine the current state of data literacy, data sharing and reuse perceptions and practices among researchers. The survey results reveal differences in practices and perceptions across age groups, gender, status, and subject disciplines. The findings indicate low levels of data literacy, RDM awareness, knowledge, and skills among surveyed participants. The majority of researchers are uncertain about RDM related issues. Respondents are not well informed about the existence of the Data Management Plan (DMP) at the university, as well as about the implementation of such a plan. Encouraging is the fact that most of them (63.4 percent) believe that the DMP effectively helps scientists manage their research data. Respondents also have positive opinions on the importance of metadata training; according to $80.5 \%$, it would be useful for the quality of research data management. The respondents show a keen interest in and desire to conduct similar trainings. Based on an understanding of the current levels of awareness and gaps in knowledge of the research community at ULSIT, the study includes recommendations regarding appropriate data literacy training in the near future, according to international experiences and standards.

The analysis of the findings resulted in elaboration of a document with recommendations for further reflection on the institutional policy and specific improvements to the Quality of Education Management System at ULSIT. The systematized conclusions are provided to all individuals and groups responsible for the quality standards design. The implementation of the survey was timely, necessary, and useful in line with the current discussions on the Project of Law for amending and supplementing the Act for the Development of the Academic Staff in the Republic of Bulgaria (2013).

\section{References}

Chowdhury, G. et al. (2016). Information practices for sustainability: Information, data and environmental literacy. In S. Špiranec et al. (Eds.), The Fourth European Conference on Information Literacy (ECIL): Abstracts, October 10-13, 2016, Prague, Czech Republic (p. 22). Prague: Association of Libraries of Czech Universities.

European Commission, Research \& Innovation. (2013). The act for the development of the academic staff in the Republic of Bulgaria. Retrieved January 29, 2018 from https://rio.jrc.ec.europa.eu/en/library/act-development-academic-staff-republicbulgaria

Keywords: research data management, higher education, ULSIT 


\title{
Information Seeking Behavior of Primary Teachers in Estonia: An Exploratory Study
}

\author{
Sirje Virkus and Marit Mathiesen \\ Tallinn University, Estonia, sirje.virkus@tlu.ee, maritmathiesen@hotmail.com
}

The Estonian school system is high-performing and has accomplished significant achievements in the past years. Coverage rates in pre-primary education are high and participation in schooling is almost universal (Santiago et al., 2016, p.3). PISA 2015 showed that Estonia's basic school students rank among the best in the world while being at the absolute top in Europe (Estonian Ministry of Education and Research, 2017). Significant initiatives to improve the quality of the education system include adjustments to the mechanisms of school financing, the establishment of the Estonian Lifelong Learning Strategy 2020, the 2011 curricular reform in general education, the 2013 new standard for vocational education and the introduction of a new competency-based career system for teachers (Santiago et al., 2016, p.3). In this context, there is a desire to explore how competencies of teachers might influence the student performance.

During the last decade methods, tools and resources for information seeking and retrieval have changed dramatically. In order to help students in the process of seeking and retrieving information it is believed that teachers should be information literate themselves. However, there is a lack of research on teachers' perceptions and patterns of information seeking and retrieval (Garoufallou et al., 2016). Garoufallou et al. (2016) conducted a study that explored primary school teachers' perceptions of information literacy (IL), their IL skills, the sources and tools they use to share information and their usage of libraries in two Greek regions, the Region of Crete and Central Macedonia. The aim of this research was to replicate the study of Garoufallou et al. (2016) in Estonia and to explore the information seeking and retrieval practice of Estonian primary school teachers.

\section{Methodology}

A questionnaire was used as a method to collect data on primary school teachers' information seeking and retrieval behaviour. The questionnaire consisted of open, closed-ended and Likert scale questions and was divided into four sections: a) demographics, b) the use of computers and libraries as tools to search, locate, and retrieve information, c) use and evaluation of sources, and d) the use of online IL programs. Also, micro-qualitative data was collected from teachers. Fifty four primary school teachers in Estonia were investigated in this study. Descriptive analysis was applied to the questionnaire survey data, while the qualitative data was analyzed using a constant comparative method of data analysis.

\section{Findings}

The study contributes to the understanding of information behavior of primary school teachers and identifies the main problems and challenges they face, and the knowledge and skills needed to teach information seeking and retrieval. It also enables to compare the information seeking and retrieval behavior of primary school teachers in Estonia and Greece (see Garoufallou et al., 2016).

\section{References}

Estonian Ministry of Education and Research. (2017). PISA. Retrieved May 21, 2018 from https://www.hm.ee/en/activities/statistics-and-analysis/pisa

Garoufallou, E. et al. (2016). How primary teachers in Greece seek information: Use and initial appraisal of information resources. In S. Kurbanoğlu et al. (Eds.), Information Literacy: Key to an Inclusive Society, The Fourth European Conference on Information Literacy, ECIL 2016, Prague, Czech Republic, October 10-13, 2016: Revised Selected Papers (pp. 202-215). Cham: Springer International Publishing.

Santiago, P. et al. (2016). OECD reviews of school resources: Estonia 2016. Retrieved May 21, 2018 from http://dx.doi.org/10.1787/9789264251731-en

Keywords: information seeking, information retrieval, information seeking behavior, information behavior, primary school teachers, teachers' perceptions, digital skills, information literacy, digital literacy 


\title{
Information Culture at the Statistics Estonia: An Exploratory Study
}

\author{
Sirje Virkus \\ Tallinn University, Estonia, sirje.virkus@tlu.ee
}

\section{Olga Albrecht}

Statistics Estonia, Tallinn, Estonia, olga.albrecht@stat.ee

Information culture is an important component of an organization. Every organisation, no matter how large or small it is, regardless of type and function, wherever in the world it is situated, has an information culture. Information culture is a part of the whole organisational culture and is inextricably intertwined with it (Oliver, 2011, pp.9-10).

There are several definitions of information culture. Choo (2002, p.54) notes that "information culture is reflected in the organization's values, norms, and practices with regard to the management and use of information." Curry and Moore (2003, p.94) define information culture as "a culture in which the value and utility of information in achieving operational and strategic success is recognised, where information forms the basis of organizational decision making and Information Technology is readily exploited as an enabler for effective Information Systems." Thus, information culture constitutes socially-shared assumptions, patterns of behaviour, and norms and values that people have about creating, sharing, and managing information in an organization (Lauri et al., 2016).

This paper reports the results of the study that explored information culture at the Statistics Estonia. Statistics Estonia is the Estonian government agency responsible for producing official statistics regarding Estonia. The agency has approximately 400 employees. The main task of Statistics Estonia is to provide public institutions, business and research circles, international organisations and individuals with reliable and objective information on the economic, demographic, social and environmental situation and trends in Estonia.

The aim of this study was to identify the characteristics of information culture at the Statistics Estonia. The qualitative case study method was chosen as a research strategy for its in-depth analysis potential. Interviews and document analysis were the main data collection methods. Fourteen in-depth semi-structured face-to-face interviews were conducted with the employees of the Statistics Estonia in spring 2015. The range of documents collected and analysed included an organizational mission plan and strategy documents and any other official or unofficial documents related to information and knowledge management available in case study organization. The study was informed by the model of information culture of Curry and Moore (2003). The questionnaire of Wright (2013) informed the interview design. The data was analysed using a constant comparative method of data analysis.

The results of the study revealed the characteristic features of information culture at the Statistics Estonia and the aspects that would require further development. For example, more effective use of vertical and horizontal information and communication flows, as well as the systematization and timely archiving of documentation would help to accelerate the process of achieving the organization's goals. It was also found that the organization of the internal system of training would help to increase the level of satisfaction of employees with the information environment of the organization. On the basis of this study recommendations were made to the Statistics Estonia and an intervention program was designed to take into account conclusions of the survey, trying to improve habits and behaviours of the staff.

\section{References}

Choo, C. W. (2002). Information management for the intelligent organization: The art of scanning the environment. Medford, NJ: Information Today.

Curry, A., \& Moore, C. (2003). Assessing information culture: An exploratory model. International Journal of Information Management, 23(2), 91-110.

Lauri, L., Heidmets, M., \& Virkus, S. (2016). The information culture of higher education institutions: The Estonian case. Information Research, 21(3). Retrieved from http://InformationR.net/ir/21-3/paper722.html

Oliver, G. (2011). Organizational culture for information managers. Oxford, UK: Chandos.

Wright, T. (2013). Information culture in a government organization: Examining records management training and self-perceived competencies in compliance with a records management program. Records Management Journal, 23(1), 14-36.

Keywords: information culture, information literacy, Statistics Estonia, case study, qualitative research 


\title{
Using Open Badges to Foster Information Literacy: An Action Research Approach
}

\author{
Sirje Virkus \\ Tallinn University, Estonia, sirje.virkus@tlu.ee
}

Open badges or digital badges are visual symbols that provide a validated indicator of achievements and communicate skills and knowledge packed with data and evidence that can be shared across the web. Open badges empower individuals to take their learning with them, wherever they go, building a rich picture of their lifelong learning journey (https://openbadges.org/). Open badges are particularly useful as part of a formative assessment process, providing constant feedback and tracking of what has been learned (Brown, 2015; Casilli and Hickey, 2016, Reid and Ross, 2017). Open badges can be successfully used in order to assess information literacy (IL) that our learner's need in order to enter the workplace.

This paper discusses an action research strategy used to examine the planning and implementation of open badges in a master level course at Tallinn University to foster IL. In the implementation process, the badge system was revised according to the learner's feedback. Special focus was on the different learning styles and the different learning paths the learners can choose. This paper will discuss the design patterns for developing badge systems for IL.

\section{Methodology}

An action research (AR) strategy was chosen in order to examine the relevance and use of open badges within the master level course at Tallinn University. The AR strategy is particularly suited to research in the field of education as it helps researching teachers to resolve their own teaching challenges. This strategy was well suited to our goal of using open badges to foster IL. The researcher was alsothe designer of the course, as well as a lecturer delivering content in the module.

The present research addresses the following questions:

- How can open badges be implemented in the course to master IL?

- What are the barriers to implementation?

- What are the potentials for implementation?

- How might they be overcome/implemented?

\section{Findings}

The study contributes to the understanding of using open badges in assessment to foster IL and identifies the main problems and challenges, and the knowledge and skills needed to use open badges in the assessment of IL skills developed within the course. Open badges, multiple learning pathways, and personal learning contracts form a triangle of educational tools that complement each other when used together. However, more research is needed in this area.

\section{References}

Brown, S. (2015). Learning, teaching and assessment in higher education: Global perspectives. New York: Palcrave Macmillan.

Casilli, C., \& Hickey, D. (2016). Transcending conventional credentialing and assessment paradigms with information-rich digital badges. The Information Society, 32(2), 117-129.

OpenBadges. (2016). Retrieved May 16, 2018 from https://openbadges.org/

Reid, M., \& Ross, M. (2017). Formative assessment with open badges. In P. Marchbank et al. (Eds.), Computing Education from Enrolment to Employment (pp. 87-95). Southampton, UK: BCS.

Keywords: digital badges, open badges, information seeking, information literacy, digital literacy, research methods 


\title{
Scientific Literacy Education Outside the Classroom: A Study in Acquisition of Knowledge and Skills about Science in Public Libraries in Croatia
}

\author{
Radovan Vrana \\ University of Zagreb, Zagreb, Croatia, rvrana@ffzg.hr
}

\begin{abstract}
The relevance of science to the future of society is likely to be more far-reaching and will likely provide solutions to many problems society is confronting today (Kaptan \& Timurlenk, 2012). To become fluent in matters of science, one needs to participate in some type of education. Education in science usually is related to the formal education in schools and at universities, starting from an early age and pre-school, continuing in elementary and high school and ending typically with education at university. The outcome of science education is science literacy, the capacity to understand and apply scientific knowledge for the personal betterment and betterment of society (OECD, 2002). However, there are many problems related to science education like insufficient physical conditions of schools (mostly due to the lack of funds), and the intensive curriculum but insufficient time allocation for science education (Kaptan \& Timurlenk, 2012). Science can be also taught outside classrooms for people of all ages in many places including public libraries. Public libraries are often community centers, which attract people of different age and of different interests who are seeking different types of information, participate in cultural events, pursue hobbies and educate themselves in science. Public libraries are also places in which library patrons access scientific information, participate in science workshops and lectures, and do simple experiments among other activities. Little is known about science education in libraries in Croatia. The aim of this paper is to disclose possibilities of public libraries in science education in order to make such education more popular and accessible to the people of all ages interested in science. Currently, public libraries undoubtedly possess the potential for carrying out some of the scientific literacy learning but need more substantial support in terms of equipment, access to scientific information resources and staff education.
\end{abstract}

\section{Objectives}

The objective of the research is to collect data from public libraries in Croatia, about the possibilities and resources available for organizing and carrying out education in science in their premises. Research aims to provide answers to three problems: 1.) what are public libraries' views on education in science in library premises? 2.) do public libraries possess enough resources (human, financial, technical) to carry out education in science? and 3.) what is the expected outcome of their engagement in education in science for them and on society in general?

\section{Methodology}

The paper will use a literature review to introduce the topic of acquisition of scientific knowledge and skills to achieve scientific literacy. A survey will be used as the principal method for the research to collect data from heads of public libraries in Croatia after which statistical analysis, comparison and description will be used to present results of the research.

\section{Outcomes}

Topics of acquisition of scientific knowledge and skills are relevant for the development of society in general and as a support to lifelong learning. By discovering views and opinions about actual and possible education in science in public library, we will be able to create a picture about science education outside classroom and the importance and role of public libraries in science education. The research results will help public libraries in educating their patrons in science and in popularization of science.

\section{References}

Kaptan, K., \& Timurlenk, O. (2012). Challenges for science education. Procedia - Social and Behavioral Sciences, 51, $763-771$. OECD. (2002). Education at a glance. Retrieved January 15, 2018 from http://www.oecd.org/education/skills-beyondschool/educationataglance2002-home.htm

Keywords: science education, scientific literacy, public libraries, Croatia 


\title{
Measuring the Psychophysiology of Information Literacy
}

\author{
Geoff Walton
}

Manchester Metropolitan University, Manchester, UK, g.walton@mmu.ac.uk

\section{Andy Wilkinson and Martin Turner}

Staffordshire University, Stoke-on-Trent, UK, w022829a@student.staffs.ac.uk, m.turner@staffs.ac.uk

\author{
Matt Pointon \\ Northumbria University, Newcastle upon Tyne, m.pointon@northumbria.ac.uk \\ Jamie Barker \\ Loughborough University, Loughborough, j.b.barker@lboro.ac.uk
}

Deception is often used to great effect in psychology experiments but not in the study of information literacy. This paper describes an experiment involving deception to test psychophysiological reactions to mis-information. People aged 18-24 are the most likely users of the Internet including social media (ONS, 2017) and therefore more likely to be exposed to mis-information. Booker (2016) found that frequency of use of social media in young people is linked to their level of happiness (well-being). For this reason it was thought appropriate to target this group. Due to the variability in which males and females use ICT (Ford, 2004) we decided to use males only ( $\mathrm{n}=48$ ). It is not known to what extent mis-information (e.g., fake-news) affects the psychophysiological responses of young males aged 18-24 and to what extent information discernment (in other words., the ability to make complex judgments about information (Walton, 2017)) protects against ill-being. This experiment seeks to demonstrate that information discernment level moderates the relationship between mis-information and cardiovascular reactivity in stressful social situation(s). Challenge and threat theory maintains that individuals respond to stressful situations with either an adaptive (challenge) or maladaptive (threat) response (Blascovich \& Mendes, 2001). This experiment involved deceiving participants into believing they were helping a fellow student win a prize. In fact they were given a task that was impossible to complete to create mild stress. Participants completed a pre-test questionnaire that measured their information discernment level. Two physiological measures were taken: cardiovascular responses using a Finometer to monitor heart rate and eye-tracking to monitor eye movements. Participants were randomly assigned to one of two conditions (control) or (experimental). In the experimental group participants were deceived into believing that they were working with someone with extreme religious views (mis-information). The working hypothesis was that those who scored highly in the information discernment questionnaire would react in a challenged way to stress and those with low scores would show a threat response. Results indicated that there is a relationship between information discernment and psychophysiological responses. Mean scores suggest that, when provided with mis-information, higher information discernment equated to a larger positive challenge and threat index and low information discernment equated to a lower negative index score. Also, higher levels of information discernment resulted in a healthier (adaptive) emotional response to a stressful task even when an individual was provided with mis-information. Eye-tracking data indicated that those with high information discernment tended to interrogate information more intensely than those with low information discernment. This added dimension of well-being indicates that these results have implications for policy makers and educators especially in the context of mis-information such as 'fake news'.

\section{References}

Blascovich, J., \& Mendes, W. B. (2001). Challenge and threat appraisals: The role of affective cues. In J. P. Forga (Ed.), Feeling and Thinking: The Role of Affect in Social Cognition (pp. 59-82). Cambridge: Cambridge University Press.

Booker, C. (2016). Managing social media. Society Now, 24, 13.

Ford, N. (2004). Towards a model of learning for educational informatics. Journal of Documentation, 60(2), 183-225.

Office for National Statistics. (2017). Internet users. Retrieved March 20, 2018 from https://www.ons.gov.uk/businessindustryandtrade/itandinternetindustry/datasets/internetusers

Walton, G., \& Hepworth, M. (2013). Using assignment data to analyse a blended information literacy intervention: A quantitative approach. Journal of Librarianship and Information Science, 45(1), 53-63.

Keywords: information discernment, psychophysiology, well-being, experiment, eye-tracking 


\title{
Exploring the Information World of Non-Resident Informal Carers
}

\author{
Sheila Webber and Pamela McKinney \\ University of Sheffield, UK, \{s.webber, p.mckinney\}@sheffield.ac.uk
}

We report on research investigating the information worlds of non-resident informal carers (NICs) (i.e. carers who do not live with the cared-for person (cfp). This scoping study focused on expert insights of people in seven government and charity agencies supporting carers of elderly people in the city of Sheffield, England. The study's aim was to identify perceived information needs and factors affecting the NICs' information experience. Informal carers are defined as people looking after family members etc., "because of long-term physical or mental ill health or disability, or care needs related to old age." (Department of Health 2016). National policies mean greater numbers of elderly people remain at home (Milligan, 2016), requiring care from family carers. The UK's Care Act tasks local government with provision of information for adults needing care and their carers. However, social care evaluations identify serious issues surrounding information provision in Sheffield (Sheffield City Council 2016), England's third-largest district authority. Whilst there have been studies of the information behaviour of carers, most research focuses on carers living with the cfp (e.g. Alzougool, Chang \& Gray, 2017), leaving a research gap regarding the experience of those caring at a distance.

Seven semi-structured individual or group interviews, including 10 respondents from care agencies, were undertaken in 2017. Interviews were transcribed, and initial analysis was undertaken through coding in NVivo and manual coding. Analysis focused on: evidence of information problems and barriers; reported carer information needs; existing or desired solutions to information problems and needs; and specifically needs and problems of NICs. Additionally, Information Worlds theory (Burnett and Jaegar, 2015) was used to frame analysis and discussion.

One theme was that NICs did not see themselves as carers (NHS England's figure of 2 years to self-identify as carers was quoted by some respondents). This has serious implications for NICs' ability to engage with the varied "small worlds" (Chatman 1999) of the formal carers. Tensions between these small worlds are evident in the desire of NICs to obtain recommendations for care providers, set against the requirements of the Care Act for local government to provide neutral information. The information environment was reported as complex and difficult to navigate, even for the expert respondents representing a significant information literacy challenge. Specific information problems for NICs emerged, namely: (1) NICs lacked information about the cfp and their daily life, emotional state and any interactions with formal carers (aggravated by data confidentiality issues, or the cfp's memory problems). (2) Missing out on opportunities proactively to ask questions of formal carers. (3) Where the NIC and the cfp live in different local government areas; reconciling information and service provision between the different areas. (4). Finding out about local facilities and options such as local carers and tradespeople, finding a care home, day centres and activities. (5) If the NIC is a substantial distance away, additional problems with balancing work and family commitments: there are specific problems for "sandwich generation" (Grundy \& Henretta 2016) carers of children and parents. In conclusion there were specific needs for non-resident carers requiring the development of IL in this particular landscape.

\footnotetext{
References

Alzougool, B., Chang, S., \& Gray, K. (2017). The effects of informal carers' characteristics on their information needs: The information needs state approach. Informatics for Health and Social Care, 42(3), 261-273.

Burnett, G., \& Jaeger, P. T. (2015). The theory of information worlds and information behavior. In A. Spink, \& J. Heinstrom (Eds.), New Directions in Information Behaviour (pp. 161-180). Bingley, UK: Emerald.

Chatman, E. (1999). A theory of life in the round. Journal of the American Society for Information Science, 50(3), 201-217.

Department of Health. (2016). How can we improve support for carers? Retrieved May 21, 2018 from https://tinyurl.com/h8ad9w4

Grundy, E., \& Henretta, J. C. (2016). Between elderly parents and adult children: A new look at the intergenerational care provided by the 'sandwich generation'. Ageing \& Society, 26, 707-722.

Sheffield City Council. (2016). Adult social care outcomes framework benchmarking. Retrieved May 21, 2018 from http://democracy.sheffield.gov.uk/documents/s25834/Adult\%20Social\%20Care\%20Outcomes\%20Framework\%20Benchmarki ng.pdf
}

Keywords: information worlds, information behaviour, informal carers, health 


\title{
"Who Wants the Power?": A Foucaultian View of Authority in Developing Information Literacy
}

\author{
Andrew Whitworth \\ University of Manchester, UK, drew.whitworth@manchester.ac.uk
}

In studying information literacy in higher education (HE), assertions are often made that IL can positively impact students' employability, their active citizenship and participation in democratic processes, and their membership of community groups. Simultaneously, these are considered desirable 'graduate outcomes', and evidence that a university education 'adds value'. This compels the conclusion that students should develop information literacy within HE in ways that both enhance their academic achievements and are transferable beyond the end of their studies into their workplaces and communities. The pedagogical question is therefore: how can boundary zones be established that allow the development of IL practices in these transferable ways? In the first instance, this paper describes research into an HE course on which groups of students work on online collaborative discussion tasks; the intended learning outcomes of this activity including transferable digital and information literacy skills.

The principal aim of the paper, however, is to use this case to reflect on the role of power and authority in developing IL skills within a boundary zone. Traditional power relations in HE are asymmetrical. Both by the institution and the students, the 'lecturer' has authority invested in them, having the power to define core elements of the learning environment such as syllabi, assessments, and criteria for judging student performance. The power to define these parameters is therefore a most significant factor when it comes to shaping learners' information landscapes and practices. Yet the proposal that becoming more information literate is empowering for students as a positive quality that they can apply to work and community life forces the same conclusion reached earlier. That is in given contexts, effective IL education in HE must have two foci: put simply, the academic and the non-academic. Considered in the light of the broadly accepted notion that IL develops differently depending on the context, this gives rise to many potential tensions.

To understand how these tensions can be overcome requires the adoption of a specific view of power and its role in IL. Notions of a "critical information literacy" have gained traction in the literature in recent years, particularly in the US. The base argument of critical IL is to position the librarian as particularly suited to serve as a 'neutral' arbiter of information claims in the pedagogical setting. The ideal outcome is a broad distribution of authority over information practice.

However, when records of student discussions on the case study programme are subjected to qualitative textual analysis, they reveal a quite different role for power in the dialogues through which the students form transferable IL practices. The data show power operating in a Foucaultian sense, as something that is constantly present, and shifting, in discourse. Knowledge structures arise out of this flux in more-or-less durable ways. Power in this view is an enabling quality of IL, rather than a force that is oppressive.

What the case study suggests is that IL educators should not seek to 'nullify' power in the classroom, but recognise how their power and authority to define academic IL practice is simultaneously resisted by the learners as they define non-academic practices. Both are essential, and can be taken forward by learners into the realms of work and community life.

Keywords: higher education, power, Michel Foucault, transferable skills, online learning 


\title{
Information Problems Encountered by Asian Students at the European Universities. A Case of Poland
}

\author{
Zuzanna Wiorogórska \\ University of Warsaw, Poland, z.d.wiorogorska@uw.edu.pl
}

\section{Problem Statement}

For about a decade, we observe the internationalization of European universities. They want to go global both in the field of research and didactics. They open their doors for the students from beyond the EU, hence currently we observe a growing number of Eastern and Southeastern Asian students at European universities. Asian students coming to European universities face several information and communication challenges due to a different socio-cultural and educational background (Wiorogórska, n.d.). Cultural and linguistic differences can affect information literacy (AlMuomen, Shaw, \& Courtney, 2016). The topic of information literacy in cultural context is one of the current trends in studies of information users and still remains to be discovered deeply. Much has been done already in Australia and North America. However academic environments of those countries have a common denominator; English i,s the official language, so is the language of didactics and all the tools in educational milieu (e.g., library catalogs or information resources). In Europe the situation is different. English is not widely spoken in the majority of EU countries, so incoming international students and university staff must communicate in the language which is not a mother tongue for either part of the didactic process. For the purpose of this study, the target group will be Vietnamese students who come to study in Poland.

\section{Methods}

A qualitative approach was chosen to collect data. Quantitative research begins with a theoretical framework established from the literature review (Pickard, 2007). A survey of literature covering the issues related to international students was completed, paying particular attention to literature covering the issues of information literacy, information behavior, and information needs of Asian students at Western universities. From this framework a hypothesis and a set of interview questions was designed to obtain the richest and the most detailed data. Then, Vietnamese students will be interviewed to find out their experiences. They will be also asked to share any informationand library-related experiences or problems they encountered while studying in Warsaw. The interviews could not be conducted earlier since the first term finishes in mid-February and I decided to explore students' experiences and opinions not earlier that after the first 15 weeks of their studies in Poland. Interviews will be manually coded, using the elements of grounded theory to create codes and construct categories from collected empirical data. In sum, I intend to interview $15 \mathrm{MA}$ and PhD students enrolled at the University of Warsaw.

\section{Results}

Data analysis and complete results of the study will be reported at the ECIL 2018 conference in September. I hope my study will contribute to better understanding of Asian students' information behavior, their information needs and expectations towards academic libraries. It will also help establish an information literacy education tailored for this group of users. I believe that the application of information literacy concepts and tools, theories of information studies and cross-cultural psychology, as well as research methods in LIS and, more widely, in the social sciences, might lead academic libraries to establish a successful program of support for Asian students, to assist in their study adventure at European universities, and in a life-long learning process after completion of their university education.

\section{References}

Al-Muomen, N., Shaw, D., \& Courtney, M. (2016). "How will I know?" engagement with information resources: A comparison of undergraduates at Indiana and Kuwait Universities. Library Review, 65(4/5), 242-254.

Pickard, A. (2007). Research methods in information. London: Facet.

Wiorogórska, Z. The importance of information literacy for Asian students at European universities: Outlines. Paideia [Accepted for publication].

Keywords: cultural differences, information literacy, higher education 



\section{DOCTORAL PAPERS}




\title{
The Role of Intuition in the Development of MIL as a Cultural Practice
}

\author{
Maryna Gallardo-Romagnoli, Jesus Lau and Carlos Arturo Torres Gastelú \\ Universidad Veracruzana, Veracruz, Mexico, zS17000036@estudiantes.uv.mx, \{jlau, ctorres $\} @ u v . m x$
}

UNESCO (2017) has promoted and studied media and informational skills (MIL) as part of its mission to promote the free flow of information (UNESCO, 2017). Nevertheless, despite the varied efforts generated, among them the creation of indicators for the evaluation of said skills in the Global Media and Information Literacy (MIL) Framework (UNESCO, 2013), UNESCO (2017) estimates that citizens do no't know how to recognize on their own the importance of information and means of communication as part of their daily activities. This is because individuals are generally consider information literacy in terms of technological applications. With this in mind, we proposed the study of MIL taking as a backbone Gladwell (2005)'s 《Thin-Scling》 with the objective of describing the conduct of making quick decisions under limited information. The goal was to study the formation of competent citizens who might detect, analyze, and solve problems in a rational and immediate manner.

The present proposal has as a goal the construction of a new MIL conceptual framework that identifies the determining factors for the development and measurement of a culture of intuitive information at an institutional and community level. We followed a mixed methodological perspective (qualitative and quantitative)/. We selected our sample from the population section with the highest educational attainment. The sample size will be made up of conveniently chosen institutions with different characteristics in regards to their financial and nationality. We will conduct the investigation through five phases: 1. Construction of the conceptual framework MIL and measuring instrument; 2 . Observation of the MIL practices in the selected cases; 3. Application of the MIL conceptual framework in the selected cases; 4. Stratified surveys that will be given to the various different groups that make up the institutions; and 5. Collection and analysis of data. We will analyse the data collected from the interviews with descriptive and inferential statistics. We will follow a qualitative analysis of the observations.. We hoped that, through the application of the conceptual framework MIL, the superior education institutions will have a conceptual framework of factors of an informative culture. This will be seen in the presence of citizens who will be able to identify their informative needs and satisfy them through the access, evaluation, and critical use of media and information.

\section{References}

Gladwell, M. (2005). Inteligencia intuitiva: ¿Por qué sabemos la verdad en dos segundos?. Madrid: Taurus Ediciones.

UNESCO. (2013). Global media and information literacy assessment framework: Country readiness and competencies. París: UNESCO.

UNESCO. (2017). R\&D for media information literacy expansion and media - information - communication of next standard [Unpublished]. París: UNESCO.

Keywords: MIL, intuition, Thin-Scling, higher education, informative culture 


\title{
Why Information Literacy Integration Doesn't Work: Exploring the Experience of Academic Staff
}

\author{
Hiroyuki Ida \\ UCL Institute of Education, London, UK, h.ida.14@ucl.ac.uk
}

This research explores the idea of 'integration', which focuses on incorporating IL into the HE curriculum. Major frameworks and relevant research (e.g. ACRL, 2000; Derakhshan \& Singh, 2011; SCONUL Working Group on Information Literacy, 2011) have proposed approaches for integration into disciplinary curricula, and collaboration between librarians and academics. However, in these frameworks, the process of how to incorporate IL within disciplinary curriculum development has been underspecified. Research has primarily been practice-based, describing individual cases and lacking a wider theoretical foundation in curriculum theory. In this research, I will criticize these models, and then use new empirical data to offer an alternative perspective. In this paper, I will analyze the verbal accounts of academic staff for specifying processes of curriculum development, and propose new theories to guide practice. I will suggest the perspective of integration for academic librarians to design the curriculum.

\section{Methodology}

I employed a case study methodology in a single social science institution in the UK. Semi-structured narrative interviews were conducted with academic staff involved in teaching a core undergraduate course to see how they implement IL in the core course and also in other disciplinary curriculum. The participants were recruited by snowball sampling. Five academic staff were interviewed (all from the field of social science). The interviews were audiorecorded and lasted for about 30-45 minutes. The interviews were transcribed and analyzed thematically, with themes emerging from the close reading of transcripts. This study received institutional ethical clearance and followed approved procedures for informed consent, including guarantees of anonymity and confidentiality.

\section{Finding}

IL was mainly discussed in team meetings, at which librarians were not present. During these meetings, IL was recognized as significant by the module leader. In reality, however, each academic teaches IL in their own module, and does not prioritise IL over disciplinary content or research methodology. For graduate courses, however, the academic staff sought to incorporate IL into their modules or tutorials. A convener in a particular discipline attempts to integrate IL aspects of a workshop into the course methodology, but in the end, she encourages colleagues to integrate those IL aspects into the tutorial, instead. As this illustrates, curriculum development is strongly rooted within the disciplinary culture and enhanced through informal chat among colleagues (Burrell, Cavanagh, Young, \& Carter, 2015). For academic librarians, the lack of attention to the prioritization of content over IL has not been addressed in current frameworks. However, for academic staff, 'espoused theory' (IL frameworks) and 'theory-in-use' for IL development are disjointed in this institution (Argyris \& Schön, 1974). For mutual benefit, academic librarians need to join team meetings in order to influence decision making. Building on such informal communication, theory construction should deductively be conducted at each institution level toward constructive integration.

\section{References}

ACRL. (2000). Information literacy competency standards for higher education. Retrieved May 14, 2018 from https://alair.ala.org/bitstream/handle/11213/7668/ACRL\%20Information\%20Literacy\%20Competency\%20Standar ds $\% 20$ for $\% 20$ Higher\%20Education.pdf?sequence $=1 \&$ is Allowed $=y$

Argyris, C., \& Schön, D. A. (1974). Theory in practice: Increasing professional effectiveness. San Francisco, CA: Jossey-Bass.

Burrell, A. R. et al. (2015). Team-based curriculum design as an agent of change. Teaching in Higher Education, 20(8), $753-766$.

Derakhshan, M., \& Singh, D. (2011). Integration of information literacy into the curriculum: A meta-synthesis. Library Review, 60(3), 218-229.

SCONUL Working Group on Information Literacy. (2011). The SCONUL seven pillars of information literacy: Core model for higher education. Retrieved May 14, 2018 from https://www.sconul.ac.uk/sites/default/files/documents/coremodel.pdf

Keywords: integration of information literacy, curriculum design, curriculum in coherence, espoused theory, theoryin-use 


\title{
Information Literacy Education as a Lens to Understand Inquiry-based Learning amongst Universities in East Asia
}

\author{
Qianxiu Liu and Hiroshi Itsumura \\ University of Tsukuba, Japan, s1730536@s.tsukuba.ac.jp, hits@slis.tsukuba.ac.jp
}

Recent shifts in educational paradigms, coupled with rapid technological developments have revolutionized the way students consume knowledge. All these changes have created the need for a reconceptualization of the roles and responsibilities of libraries and librarians. Being the heart of the university, library and librarians support curriculum development, guide instructors to appropriate learning content, and assist with research. In this context, information literacy (IL) education has become an issue in many academic libraries.

Similar to Liu, et al. (2018), the current study was set out with the same belief that "Inquiry- Based Learning (IBL) should be made an integral part of any student's learning, especially at the university level, that is one simply has to be a skillful, and effective user of the library in order to become a true independent learner" (p. 1). In other words, IBL and active/competent library use simply go hand in hand. The ability to synthesize information, and create new knowledge are competencies that lie at the heart of IBL, where students ideally are given the space to generate genuinely new knowledge through the process of research (McKinney, 2010). Alongside the ongoing shifts from traditional delivery learning and teaching modes to more student-centered approaches, IL is moving up some institutional agendas as a focus for strategic and pedagogical development (McKinney \& Levy, 2006).

The research design was the mixed method with the questionnaire and interview. The questionnaire and group interview will be conducted with students from Peking University and the University of Tsukuba. Also, a semistructured interview will be conducted with the librarians in order to develop a deeper understanding of IL and its relation with IBL practices. This study was set up with the aim of revealing the practice of IBL and its relations to IL in the context of higher education in Asia. The theory used in this research is authentic learning theory and mode of inquiry-based learning (Levy, P., \& Petrulis, R., 2012). This study is guided by the following research questions:

- RQ1. To identify students' overall attitudes and perceptions towards the series of IL education programs carried out by their respective university libraries;

- RQ2. To examine if there are significant differences in students' perceptions towards the series of IL programs and the IBL practice;

- RQ3. To what extent these students at the three universities are incorporating the services and resources provided by their university libraries into their current research practices and formal learning in the context of IBL.

The researchers plan to report on a pilot study and discuss in detail the various sociocultural and educational factors affecting students' perceptions of the importance of these IL services. The results obtained from this study will help library managers in understanding users' own perceptions of their needs in IL - thereby reducing the gaps between user perceptions and expectations of the desired quality of library services from a cross-cultural view.

\section{References}

Levy, P., \& Petrulis, R. (2012). How do first-year university students experience inquiry and research, and what are the implications for the practice of inquiry-based learning?. Studies in Higher Education, 37(1), 85-101.

Liu, Q., Lo, P., \& Itsumura, H. (2016). Measuring the importance of library user education: A comparative study between Fudan University and the National Taiwan Normal University. The Journal of Academic Librarianship, 42(6), 644-654.

Liu, Q. et al. (2018). Library user education as a window to understand inquiry-based learning in the context of higher education in Asia: A comparative study between Peking University and the University of Tsukuba. College and Research Libraries [Accepted for publication].

McKinney, P., \& Levy, P. (2006). Inquiring-based learning and information literacy development: A CETL approach. Innovation in Teaching and Learning in Information and Computer Sciences, 5(2), 1-13.

McKinney, P. (2010). Inquiring-based learning and information literacy: A meta-analytical study. Retrieved May 14, 2018 from https://www.sheffield.ac.uk/polopoly_fs/1.122797!/file/IL_meta-analysis_PM-FINAL.pdf

Keywords: inquiry-based learning, information literacy education, higher education 
BEST PRACTICE 


\title{
Use of Open (Research) Data in Teaching (UDIT): An Open Online Resource
}

\author{
Helene N. Andreassen and Torstein Låg \\ UiT The Arctic University of Norway, Tromsø, Norway, \{helene.n.andreassen, torstein.lag\}@uit.no \\ Harrie van der Meer \\ University of Amsterdam / Amsterdam University of Applied Sciences, Amsterdam, the Netherlands. \\ h.a.l.van.der.meer@hva.nl
}

\section{Mijke Jetten and Monique Schoutsen}

Radboud University, Nijmegen, The Netherlands, \{m.jetten, m.schoutsen $\} @ u b n . r u . n l$

In higher education and research there is a growing awareness on information literacy, Research Data Management $(\mathrm{RDM})$ and the benefits of openly sharing educational resources. Libraries play an important role in these areas, and are in a good position to promote the cross-fertilization of the above-mentioned topics.

Based on a first inquiry, one aspect that is little explored is how to facilitate and stimulate the use of open research data in teaching. Three universities (UiT The Arctic University of Norway, University of Amsterdam/Amsterdam University of Applied Sciences and Radboud University) have recently started a collaborative development of an online, open resource, UDIT: Use (open) research data in teaching. The international teaching community - both libraries and faculties - could benefit from this.

The objective of UDIT is to support teachers by offering an inspiring, generic lesson-plan package focusing on the use of open research data in higher education. The main content of the lesson-plan package is an introduction to the concept of open science, references to existing teaching resources on research data (literacy), best practices, example lesson plans and learning activities.

By inspiring and guiding teachers across fields in using open research data in their teaching, we intend to further the Open Access movement. By publishing our lesson plan package under a Creative Commons License (CCBY) we intend to contribute to the Open Educational Resource movement.

The development of UDIT is still in progress. It will be placed on a dynamic website, (http://site.uit.no/opendatainteaching/), with planned test release in Fall 2018.

In this conference session, we will present the project, the website, and reactions from the disciplinary teacher community. We invite the library community present at the conference to contribute with comments and ideas, as collaboration is crucial to make this resource successful and widely used.

Keywords: research data literacy, information literacy, teaching, open science, open educational resources 


\title{
It's Universal: Librarians, Student Digital Devices, and Universal Design Create a Winning Combination for a New Era
}

\author{
Catherine Baldwin \\ University of Pittsburgh at Bradford, PA, USA, cab137@ pitt.edu
}

\begin{abstract}
Digital tools and access to digitized information are necessity rather than luxury for today's undergraduate students, most of whom are digital natives. However, faculty often view digital devices, such as mobile phones, as causes of disruption within a classroom setting. Conversely, digital devices may serve as aids to education rather than hindrances to learning (Reese, 2013; Bomhold, 2013). University librarians are now entrenched within the digital world of information, often serving as liaisons between technology, faculty, and students. Therefore, librarians must embrace digital devices as cost effective, powerful classroom tools. Instruction services librarians may take advantage of these free resources to provide efficient, active instruction to promote deep learning (Dolničar, Podgornik, \& Bartol, 2017). Applying technology through engaging, active learning utilizes students' inherent technological skills and interests (Webb \& Hoover, 2015; Margolin \& Haydn, 2015). The use of cell phones as learning tools also enables elements of Universal Design for Learning, thereby meeting the needs of today's diverse student population (Nall, 2015; Tobin, 2014). This presentation will examine instruction services librarians' perceptions of phone use within the academic classroom. It will address the benefits and challenges of integrating student smartphones into information literacy instruction sessions for university undergraduate students; it will examine the smartphone as a powerful and economical instruction tool; and it will explore the integration of smartphones with Universal Design for Learning methods as instructional "best practice." Anecdotal evidence gleaned from information literacy instruction sessions with traditional, undergraduate university students will be shared in light of the following: student engagement, time on task, degree of disruption, and success in student learning.
\end{abstract}

\section{References}

Bomhold, C. (2013). Educational use of smart phone technology: A survey of mobile phone application use by undergraduate university students. Program, 47(4), 424-436.

Dolničar, D., Podgornik, B., \& Bartol, T. (2017). A comparative study of three teaching methods on student information literacy in stand-alone credit-bearing university courses. Journal of Information Science, 43(5), 601-614.

Margolin, S., \& Hayden, W. (2015). Beyond mechanics: Reframing the pedagogy and development of information literacy teaching tools. The Journal of Academic Librarianship, 41(5), 602-612.

Nall, C. (2015). Academic libraries and the principles of universal design for learning. College \& Research Libraries News, 76(7), 374-375.

Reese, C. B. (2013). Educational use of smart phone technology: A survey of mobile phone application use by undergraduate university students. Data Technologies and Applications, 47(4), 424-436.

Webb, K., \& Hoover, J. (2015). Universal Design for Learning (UDL) in the academic library: A methodology. College \& Research Libraries, 76(4), 537-553.

Keywords: universal design, information literacy, student-centered learning. teaching tools, inquiry-based research, pedagogy 


\title{
Playing for Knowledge
}

\author{
Anna Callejón Mateu
}

Sciences Po library, Paris, France, anna.callejonmateu@ sciencespo.fr

Sciences Po is a private academic university specializing in social sciences studies. It's library's main mission is to support the university's teaching and research.

For more than 20 years the library has offered methodological and information literacy courses to the freshmen in different programs. One of them is designed for foreign college students, which follows an introduction program during the week before the year starts, called Welcome Program. This Program is organized twice a year, on August and January.

Until January 2017 the library was giving a non-interactive presentation of the research tools and a very quick visit of the library. This method was very passive and did not inspire much interest among students and professionals.

This is the reason why the library's information literacy team, helped by the pedagogical researchers of the Sciences Po «Centre d'expérimentation numérique », has worked on an escape game to encourage students' autonomy and motivation through learning by doing in situ (manipulating objects, moving inside the library, etc.).

This presentation will focus on the process of building the escape game at Sciences Po library, the inside logistics, the global evaluation and its evolution.

The project took 5 months. It began in February 2017 and peaked in May with a 15 hour' game jam. This intensive brainstorming session helped put together the pedagogical objectives (finding a book on shelves, request a book from closed stacks, borrow, ask help, print) with a storyboard and game elements. It involves Marcel, the cat of Sciences Po, who has taken a dangerous object that needs to be defused in a short time. Different riddles were created and linked to the 5 objectives: clues are hidden in books, boxes, internet messages, and videos in order to save the world.

Participants in several workshops created all the game materials. The game was tested 3 times with external people, teachers, students and library staff.On the whole, it took more than 200 work hours to be ready. The first game day took place the last week of August before courses began, and a second was held before the beginning of the second semester in January 2018. Very few changes were done between the sessions.

However, in both cases, players were asked to evaluate the game. It included an ante and post-session self-evaluation requesting the perceived confidence in the process of different information literacy points (linked to the 5 pedagogical objectives). The escape game evaluation also included questions concerning the satisfaction about the game (storyline, participation, etc.).

An increasing satisfaction rate by the students (8.20 in 2017 - 8.44in 2018), encourages the Sciences Po library staff to continue developing the game: the next session will be longer and -include a new clue to discover the electronic resources webpage as well as an adaptation of the game as interactive video.

Keywords: escape game, information literacy, user training, training assessment, instruction, active pedagogy, learning by doing 


\title{
Using Metacognition to Address the 'Illusion of Knowing' among First Year Students in How to Determine Credible Sources of Information Received via Social Media
}

\author{
Leslin H. Charles \\ Rutgers University, Piscataway, NJ, USA, leslin.charles@ rutgers.edu
}

\begin{abstract}
The information age has democratized the dissemination of and access to information. Social media provides a voice to all and can be used to blur the lines of fact and fiction. How do first year students filter through information on social media to gain accurate knowledge? To what extent does their familiarity with social media platforms influence their 'self-perceived knowledge' of how to evaluate information? Using metacognition, the author, through a first-year course titled, 'Truth or Fiction?' is sensitizing college students on how they interact with, create, and disseminate information via social media, thereby allowing them to realize their 'actual knowledge'. The course content and structure allow students to periodically utilize metacognition to reflect on their social media habits to reveal behaviors like confirmation bias. Students are thus able to confront their 'illusion of knowing' and to take steps to close the gap between 'self-perceived knowledge' and 'actual knowledge'.
\end{abstract}

Park (2001) has noted, "News media exposure might not increase actual knowledge as much as it might enhance the impression of one's own knowledge, or self-perceived knowledge" (p. 419). He explains, "Feeling knowledgeable does not necessarily imply any concrete knowledge" (p. 419). Many millennial students (digital natives) get their news via social media platforms. Therefore, the author asked the question: Are first year students at XX University aware of their 'actual knowledge' vs. their 'self-perceived knowledge' as it relates to current events and their interaction on social media? This exploration is heightened by the current era of post-truth where fake news proliferates. Levels of 'selfperceived knowledge' vs. 'actual knowledge' regarding the evaluation of information via social media are being investigated in this course through topics that include 'post truth', 'fake news', 'alternative facts', 'truthiness', 'truthinews', and 'social media and mass media'.

Students must also consider 'optimism bias' which Oglesby (2016) reports as "the idea that we all think other people are more vulnerable than we are" (p. A10). He further explains that optimism bias is "associated with risk-taking and failure to heed precautionary advice" (p. A10). Those ages 18-24 are more than three times likely to be scammed by a fraud scheme than baby boomers (Oglesby). This 'optimism bias' or 'invulnerability illusion' exacerbates 'selfperceived knowledge' making metacognition a valuable and necessary tool.

Furthermore, this course aligns with the ACRL (2016) frame, Authority is Constructed and Contextual. It allows students to develop knowledge practices. More broadly, to "understand the increasingly social nature of the information ecosystem where authorities actively connect with one another and sources develop over time" (p. 4). Additionally, through the realization of their 'actual knowledge', they develop "their own authoritative voices in a particular area and recognize the responsibilities this entails, including seeking accuracy and reliability, respecting intellectual property, and participating in communities of practice" (p. 4) more specifically.

Attendees will discover approaches that can assist digital natives in reflecting on their own social media behavior to reveal their 'actual knowledge'. Students can then employ useful strategies to realize 'self-perceived knowledge' and to increase their 'actual knowledge'.

\footnotetext{
References

Association of College and Research Libraries. (2016). Framework for information literacy for higher education. Retrieved May 5, 2018 from http://www.ala.org/acrl/standards/ilframework

Oglesby, B. (2016). Invulnerability illusion: Millennials more likely to get scammed than boomers. The Banner, p. A10. Retrieved from https://infoweb-newsbank-com.proxy.libraries.rutgers.edu

Park, C. (2001). News media exposure and self-perceived knowledge: The illusion of knowing. International Journal of Public Opinion Research, 13(4), 419-425.
}

Keywords: social media, fake news, metacognition, evaluation of information 


\title{
School-Work Alternation: Work the Information to Turn it into Knowledge
}

\author{
Elena Collina and Rita Patregnani \\ University of Bologna, Italy, \{elena.collina, rita.patregnani\}@unibo.it
}

\section{Objectives}

The aim of school-work alternation is to motivate and guide young people and spread the culture of work.

Specifically, these projects are carried out with the aim of implementing flexible learning arrangements that link classroom training with practical experience: to favor the orientation of young people; to enhance their personal vocations, interests and individual learning styles; and to correlate the training offered to the social and economic context of the territory.

The alternation between school and work is based on an integrated conception of the educational process in which the training moment and the application moment merge.

\section{Methodology}

The Rimini Campus Central Library joined the "Alternanza-scuola-lavoro" program provided by Italian law 107/2015, so that high school students can integrate the training program with direct experience in the world of library work byconsidering the Library as the internship company. Since Alternation is a training methodology, a real learning method based on active teaching for the acquisition of strategic skills, our participation took place within the Information Literacy context carried on as a University Team.

The proposed activities were designed to allow students to follow the flow of knowledge contained in the various documents managed by libraries: acquisition, cataloguing, shelf-marking, research, fruition. As an added value we moved to a more creative activity that aims to develop in young people the useful knowledge to publish in Wikipedia, increasing their specific skills to become supporters of an open and collaborative culture.

The recipients were two 17 years-old students of class IV of the Lyceum Cesare-Valgimigli.

The activities were held at the Rimini Campus Central Library.

The project took place from the 22 January to the 2 February, for 2 weeks, for 50 hours, divided into mornings of 5 hours each. There were two training tutorials, internal and external, with the task of monitoring, evaluating and supervising the activities.

\section{Outcomes}

Students received training on the institutional tasks of the Library, the internal organization, the management of documents and the functioning of services. In the meantime they acquired skills in the search for information, in the use of libraries and online information sources.

The alternation between school and work turned out to be a complete expression of the integration between educational institutions and the productive world.

The library became an educational reference point for the school, taking an active role in updating the school on the professional profiles and skills required in the world of work.

Companies andlibraries that participate in alternating school-work paths have the opportunity to enhance their training capacity, invest in the qualification of young people, and establishing a real educational alliance with the school. Positive outcomes include: enhancement of individual vocations; development of relational attitudes; and research of new modes of communication. Critical issues: increased workload for the staff involved; difficulty in scheduling the activities; difficulty in managing students from the quantitative point of view.

Keywords: school, work, alternation, training, learning 


\title{
Coinfo-Inclusion Model - Cards for Teacher Training to Work with Inclusive Education
}

\author{
Célia Revilândia Costa Seabra \\ University of Brasília, Brasília, Brazil, celiarevilandia@gmail.com
}

This article describes the main characteristics of an experimental course aimed at developing the abilities to seek information in the perspective of inclusive education (Costa Seabra, 2017). It presents the results obtained after the conclusion of the course, according to the performance of 17 teachers. Sampling was built by the "snowball" technique and, therefore, not probabilistic. The teachers worked with children in the $5^{\text {th }}$ year at a public elementary school in Brasília (Brazil's Federal District). The Problematization Methodology was utilized, inspired by the contributions from Maguerez's Arch (Maguerez, 1960, 1970) and its re-readings (Bordenave \& Pereira, 1982; Berbel, 1995, 1996), which propose an intervention in reality, from a cyclical logic applied to the learning process throughout life. Made under this influence, the Co-info-Inclusion model uses illustrated cards containing a visual resource (an illustration of a type of deficiency typology) on the obverse and a provocative text (challenge) on the verse. Altogether, there were ten challenges which were distributed in three stages. In the first stage, (Pre-Search) two challenges were created including the resolution of a quiz elaborated by Mantoan (2006) and the production of a mental map as a strategy of reflection and planning, respectively. In the second stage (Search for Information) six challenges related to basic informational demands of educational practice (which include audiovisual, imagery, legislation information, as well as information on the use of technology) were used. In the third stage (After Search) two challenges related to the production and communication of information were created. The results showed that during the first stage, the collective solving of the quiz instead of an individual solving it, significantly alters participation and time management. Still at this stage, it was possible to observe that even though more than $90 \%$ of the teachers did not know how to use the mental map software. This did not impede the activity, which was designed with a predominance of institutional $(25.9 \%)$ and virtual (14.8\%) references, followed by interpersonal (11.1\%) and pedagogic (7.4\%) references, conditioning the informational needs with teaching practice. The challenges of this stage are examples of strategic use of information for creating meaning, building knowledge, making decisions and mobilizing knowledge, according to what was proposed by Choo (2003) and Tardif (2002). In the second stage, the search on databases for academic and audiovisual information revealed: a strong "googlization" (Vaidhyananthan, 2011), weak incidence of official symbols (27\%) and terminological incomprehension in the search for information on legislation. In the search for filmic information, there was a predominance of searches based on spoilers. The results from the third stage were not evaluated because they demand a longitudinal study whose results cannot be expressed in such a brief manner. We conclude that the didactic resource of the challenge letters was unique because it did not focus only on the use of technologies and provided a fun, mediated, communicative and collaborative experience creating an environmental ecology in information (Stereirenová, 2010). The results allow us to conclude that there are changes in the attitudes and perceptions of teachers in relation to informational issues, such as the improvement in the identification, value and use of sources and information services.

\section{References}

Berbel, N. A. N. (2014). Metodologia da problematização: Respostas de lições extraídas da prática. Semina: Ciências sociais e humanas, 35(2), 61-76.

Choo, C. A. (2003). A organização do conhecimento: Como as organizações usam a informação para criar significado, construir conhecimento e tomar decisões. São Paulo: SENAC.

Costa, C. R. (2017). A Competência em Informação (Coinfo) na perspectiva da educação inclusive (Thesis). Universidade de Brasília, Brasília.

Mantoan, M. T. É. (2006). Teste seu Poder de Inclusão. In V. A. Arantes (Ed.), Humor e alegria na educação. São Paulo: Summus (pp. 169-178).

Steirenová, J. (2010). Ecological dimensions of information literacy. Information Research, 15(1). Retrieved from http://www.informationr.net/ir/15-4/colis719.html

Tardif, M. (2002). Saberes docentes e formação profissional. Petrópolis, RJ: Vozes.

Vaidhyanathan, S. (2011). A googlelização de tudo (e por que devemos nos preocupar): A ameaça do controle total da informação por meio da maior e mais bem-sucedida empresa do mundo virtual. São Paulo: Cultrix.

Keywords: coinfo inclusion, teacher trainning, information literacy, inclusive education 


\title{
Five Years of Plagiarism School: Lessons \& Impact
}

\author{
Vanessa J. Earp \\ Kent State University, Kent, OH, USA, vearp@kent.edu
}

\section{Introduction}

According to the International Center for Academic Integrity (n.d.), many people would be astounded by the number of university students who admit to cheating or plagiarizing on papers. Over the past 12 years 71,300 responded to surveys dealing with cheating and plagiarism. Of those 71,300 students, $68 \%$ reported cheating or plagiarizing.

In 2012 Kent State University launched a unique program to address professor's' growing concerns about student plagiarism. Plagiarism School is a remediation program that aims to educate students about plagiarism. At Kent State if a student has plagiarized and the professor believes it was unintentional, the student can be offered the opportunity of attending Plagiarism School. If a student successfully completes the program, then the original sanction (failing the assignment or even the class) is removed.

Librarians were able to work with the university's faculty senate to incorporate Plagiarism School into the official Administrative Policy Regarding Student Cheating and Plagiarism (Kent State University, 2015). In addition to the faculty senate, the library has also worked closely with the Office of Student Conduct; this has allowed for the collection of data on students who have completed Plagiarism School, as well as students who did not attend Plagiarism school, and whether or not there were repeat offenders of the policy.

Plagiarism School has been heavily used, which was unexpected by the library. Adjustments had to be made in the management of the program to accommodate the number of students referred to the program. The library has implemented new proactive measures to combat plagiarism. A number of workshops have been developed that address plagiarism, academic integrity, and citation styles. Another way the library is assisting students is by offering a service that allows student papers to be run through plagiarism detection software.

Over the past five years the librarians at Kent State have developed a comprehensive plan to deal with issues of student plagiarism. By taking an educational, rather than a punitive, approach the librarians are seen by the students as a neutral party in the issue of plagiarism, and are able to forge relationships with students that last throughout their time as a Kent State students.

\section{Objectives}

To introduce the concept of plagiarism school and how it was implemented across campus.

To demonstrate how plagiarism school has helped students.

To demonstrate that there is a normalized educational approach to deal with student plagiarism.

\section{Methodology and Outcomes}

The purpose of this study was to explore how plagiarism school has been implemented at Kent State University and how the library has evolved to meet the challenges presented. This paper uses a case study design. According to Creswell (2014), case studies are often used to examine and evaluate programs.

Participants will be able to take information on plagiarism school back to their home institutions. Librarians will be able to discuss with teaching faculty how the library can help their students in relation to areas of plagiarism.

\section{References}

Creswell, J. W. (2014). Research design: Qualitative, quantitative, and mixed methods approaches (4th ed.). Los Angeles, CA: Sage.

International Center for Academic Integrity. (n.d.). Integrity: Statistics. Retrieved May 2, 2018 from https://academicintegrity.org/statistics/

Kent State University. (2015). Administrative policy regarding student cheating and plagiarism. Retrieved May 2 , 2018 from http://www.kent.edu/policyreg/administrative-policy-regarding-student-cheating-and-plagiarism

Keywords: plagiarism, plagiarism school program, case study, academic partnerships 


\title{
Copyright Law and Copyright Literacy in Germany
}

\author{
Fabian Franke \\ University Library Bamberg, Germany, fabian.franke@uni-bamberg.de
}

\begin{abstract}
A new copyright law entered into force on March $1^{\text {st }} 2018$ in Germany (Bundesministerium der Justiz und für Verbraucherschutz, 2017). It contains several copyright limitation provisions for education and science and therefore has powerful implications for students, teachers, researchers and libraries. For example, German copyright law allows digitization and publication of journal articles and $15 \%$ of a book for courses and lectures, digitization and publication of whole books for the use at terminals in the library and text and data mining under specific conditions. It is an important task of university libraries to support students, teachers and researchers in all questions regarding the copyright law as well as related topics like open access and creative commons licenses in order to strengthen their copyright literacy (Universitätsbibliothek Bamberg, 2018). Copyright issues are incorporated in the competencies "Know terms of use", "Mark citations" and "Reference sources" of the Reference Frame "Information Literacy" of the German Library Association (2016).
\end{abstract}

In this best-practice contribution we present the limiting provisions of the new legislation in detail and the fight of librarians and scientists for a science- and education-friendly copyright law in Germany. Based on the results of a survey among teaching librarians we discuss the copyright literacy of the librarians, the role of the academic librarians and the integration of copyright education into information literacy programs. We show best-practice examples of library initiatives to raise the awareness of copyright and open science issues. Activities include the implementation of copyright, creative commons and open access into courses for students, seminars within programs of Further Education Centers for University Teaching, consultations for researchers and services as "Book a Librarian."

Analyzing the best practice examples this contribution argues that the promotion of copyright literacy and creative commons must be an essential part of the publication consulting and information literacy programs of academic libraries.

\section{References}

Bundesministerium der Justiz und für Verbraucherschutz. (2017). Gesetz zur Angleichung des Urheberrechts an die aktuellen Erfordernisse der Wissensgesellschaft (UrhWissG). Retrieved February $14, \quad 2018$ from https://www.bmjv.de/SharedDocs/Gesetzgebungsverfahren/DE/UrhWissG.html

German Library Association. (2016). Referenzrahmen Informationskompetenz. Retrieved February 15, 2017 from http://www.informationskompetenz.de/index.php/referenzrahmen/

Universitätsbibliothek Bamberg. (2018). Informationen zum Urheberrecht. Retrieved February 14, 2018 from https://www.unibamberg.de/ub/urheberrecht/

Keywords: copyright literacy, Germany 


\title{
Going Local: Designing a Homegrown Information Literacy Test for Your Own Institutional Context
}

\author{
Susan Gardner Archambault \\ Loyola Marymount University, Los Angeles, CA, USA, susan.archambault@1mu.edu
}

\section{Objectives}

This "best practices" session will present a case study of how one university in the United States designed a homegrown test to measure the information literacy and digital literacy learning outcomes at their institution, while also mapping all questions to the Association of College and Research Libraries (ACRL) Framework for Information Literacy for Higher Education. Librarians identified five information literacy and digital literacy learning outcomes from the curriculum at the university, program, and course levels of our institution consisting of conceptualizing a research strategy, evaluating information, locating, and accessing information, selecting and using information to provide relevant evidence, and citing sources. Performance indicators were developed to measure these outcomes, and then test questions using multiple choice scenarios were developed that embodied the indicators. All questions connected to corresponding frames from the ACRL Framework. Librarians also developed two new learning outcomes outside of the curriculum for being a digital citizen and being an empowered learner of current digital technologies. The new outcomes have corresponding performance indicators, multiple choice scenario questions, and frames from the $A C R L$ Framework. This session will cover the development of the test instrument and its implementation on a sample of students.

\section{Methodology}

Librarians designed a 25 question multiple-choice test in Qualtrics to measure designated information literacy and digital literacy learning outcomes. Questions were substantially revised from an earlier draft implemented as a pilot in 2016 to improve the validity and reliability of the questions. Correct answers were assigned point values so that the test would automatically score itself upon submission. Seventy-five students in their last semester at the university were recruited to take the test from an original stratified random sample of 300 students to control for gender, ethnicity, and major. Library staff proctored the test, and participants received an incentive. Librarians will identify low scoring areas and address them through the library's instruction program.

\section{Outcomes}

Librarians will analyze the results to determine low-scoring areas. They will share this analysis with faculty teaching relevant courses containing the learning outcomes measured by the test. Assessment of information literacy and digital literacy learning outcomes leads to greater communication between librarians and faculty. Test results will also lead to improvements in the information literacy and digital literacy curricula at this university. The test will be shared in CORA (Community of Online Research Assignments), an open educational resource for librarians and faculty, to allow for its free use and repurposing by other educators. This "best practices" session will lay the foundation for attendees to discuss the best ways to measure information literacy and digital literacy within their own instructional environment. It will also give attendees a concrete example of assessing student learning outcomes in ways compatible with the "threshold concepts" approach to information literacy contained in the ACRL Framework for Information Literacy for Higher Education.

Keywords: information literacy, digital literacy, learning outcomes, assessment, performance indicators, ACRL framework 


\title{
Upsizing and Upskilling Library Student Assistants: Experiences from SMU Libraries
}

\author{
Sumita Govindan, Siew Khim Lim and Vincent Ong \\ Singapore Management University, Singapore, \{ sumitag, sklim, vincentong\}@smu.edu.sg
}

\section{Introduction}

Student Assistants (SAs) play an invaluable role at the Singapore Management University (SMU) Libraries. Investing in SAs is a win-win for both the library and students as peer-to-peer learning becomes more important. In this presentation, participants will learn how we improved the skills of the Student Assistants (SAs) in order to increase the service quality delivered at the desk and helped them acquire skills for their wider professional development. Often the first point of contact at the Library's services desk, it is critical that SAs hired have the necessary skills and competencies needed to perform their tasks efficiently. Thus, the Library designed a training program to equip them with the skills needed to manage the services desk independently. Two key components comprise the training program: lecture sessions and on-the-job training. The former provides the SAs with an understanding of the various library policies, library management system, and its resources. The latter, where they shadow a librarian, allows them to gain crucial work experience at the desk before being deployed solo.

\section{Objectives}

While this training was a good precursor to handling desk enquiries and library operations, more could be done to improve their skills and professional image, goals which resulted in the Student Assistant Upskilling project. The objectives were to assess students' skills and knowledge attained from the initial training program, reinforce key learning objectives and intervene where necessary, and to improve and "upsize" their capabilities and professional image, being in line with the Library's goal of professional development and talent management, as the SAs are part of the greater library family.

\section{Methodology}

The project team first identified the expected learning outcomes. These ranged from being able to conduct a simple reference interview to proper desk etiquette. IT, computer related and complex research queries were determined to be out of the scope for this project. We looked at various modes by which we could deliver this new training program. We identified a few challenges with delivery modes such as classroom or lecture style training or a complete e-learning module approach. Therefore, we decided on an asynchronous e-learning model combining elements of email, telephone and electronic resources. As evidenced by Hrastinski (2008) and Welsh et al., (2003) this approach allowed students the flexibility to complete the tasks and resulted in responses that were more refined and thoughtful. We devised a series of "missions" for the students to solve incorporating the various learning outcomes as clues. An element of gamification was added to the upskilling program to make it more engaging through problem-based learning. Participants will hear more details about these activities in the presentation.

\section{Outcomes and Future Recommendations}

The upskilling program was piloted with a batch of newly hired SAs two months after their initial training. We gathered their feedback and further refined the program. Currently the team is developing a competency-based training program to equip the SAs with not just library and information searching skills learnt in Phase I, but also with skills that will be useful to them when they join the workforce.

\section{References}

Hrastinski, S. (2008). Asynchronous and synchronous e-learning. Educause Quarterly, 31(4), 51-55.

Welsh, E. T. et al. (2003). E-learning: Emerging uses, empirical results and future directions. International Journal of Training and Development, 7(4), 245-258.

Keywords: student assistants, asynchronous e-learning, skills-based training, academic libraries, workplace literacy 


\title{
Flipped Classroom Teaching Method in Information Skills Courses
}

\author{
Riitta Holopainen \\ University of Eastern Finland Library, Joensuu, Finland, riitta.s.holopainen@uef.fi
}

This presentation explores how to use a flipped classroom method in information skills courses. The purpose of this presentation is to illustrate how to create learning materials, such as out-of-class videos and pre-class exercises, use face-to-face class time for active learning, and apply formative evaluation during the course. The presentation also brings out good practices and challenges in flipped classroom teaching, analyses learning results, and summarizes the feedback from the students.

In the flipped classroom teaching method, what is traditionally done in class and as homework, are switched or flipped. Students learn the primary course content online by themselves. This offers a teacher the possibility of redesigning contact lessons so they are more learner-centered. The role of the teacher becomes a "guide on the side" more than a "sage on the stage" (King 1993). The aim is to promote student-centered active learning.

Eighty-eight students from the University of Eastern Finland attended two discipline-specific information skills courses, which were designed using the flipped classroom method. The courses were integrated in the students' curriculum as a part of a Bachelor's thesis seminar. Traditionally, the courses contained a contact lesson, two hours of database practice, and a final assignment. Using the flipped classroom method, the teacher-centered lessons were replaced with short video clips. Each clip contained pre-class exercises for which the students received personal written feedback. In database practice sessions, the students already knew the core elements of information searching, which enabled the sessions to be more practical. At the end of the course there was a final assignment describing the information searching process for the student's own Bachelor's thesis subject. The final, summative evaluation of the course was offered in video form.

One challenge of the flipped classroom method is to determine the core elements of the course: what are the most important things to present in the pre-class material? Another challenge is to think of active learning strategies to use in classroom activities. Additionally, one crucial goal is to engage the students in pre-class material and to commit them to take their own responsibility for learning.

The good learning that results from these two courses demonstrated that the flipped classroom teaching method is suitable for information skills teaching. Students' feedback from the courses was positive. Students liked the ability to work at their own pace and time, and they felt that out-of-class videos and pre-exercises prepared them well for the classroom activities. Formative evaluation and personal feedback from the final assignment also received a very positive reception.

\section{References}

King, A. (1993). From sage on the stage to guide on the side. College Teaching, 41(1), 30.

Keywords: flipped classroom, teaching methods, information literacy teaching, information skills courses 


\title{
Teaching Critical Information and Media Literacy through the Black Power Movement and Documentary Film
}

\author{
Viola Huang \\ University of Passau, Germany, viola.huang@uni-passau.de
}

In an age of digitalization and information overflow, the acquisition and production of knowledge is changing rapidly. These developments challenge society in educational, economic, cultural, and social terms. Thus it is of particular importance to enable future teachers to become literate in the digital age by empowering pre-service teachers to collect, sort, critically evaluate, and subsequently produce and distribute information. Additionally, the awareness of and the reflection on the role of the media is just as essential, thus, media literacy education is a crucial part in this endeavor.

I will show what information and media literacy education can look like in practice. As part of a teacher education project, in one of our interdisciplinary and co-taught seminars, we investigated how documentaries can shape the perception of history by looking at the Black Power Movement in the U.S. Students in this class were pre-service teachers, studying different subjects, such as English, History, Sport, or Business. They will go on teaching different age groups, from elementary to high school. In the first part of the seminar students familiarized themselves with the historical context of the Black Power Movement as well as the genre of the documentary. The second half of the course then focused on two selected documentary films and their representation of the Black Power Movement. This phase of the seminar consisted of an interactive course project and engaged in alternative approaches to teaching and learning. In this part of the course, students were not mere consumers but became producers of knowledge by conceptualizing and leading class sessions themselves. Working in teams, they not only supported each other with ideas and methods, but also had to master the challenge of working together, which subsequently taught students the meaning of responsibility as well as community and their individual role in it. Ultimately, students were required to produce (digital) knowledge in the form of lesson plans, (digital) exhibitions, podcasts, or videos. For example, based on the German curriculum for elementary schools, one of the students produced an interactive website and an accompanying handout about the Black Power Movement and the role of race, racism, and empathy for their future students. The student explained in their reflection paper that this production allowed them to reflect on and become literate in the various aspects of knowledge creation and distribution.

In order to enable students to become literate and subsequently critical, active, and participating citizens in society, this project does not only take into account the importance and the relationship between different literacies, but it also works interdisciplinary. As a result, educators in the project not only conceptualize courses together, but they also teach together, emphasizing the importance of an interdisciplinary approach to information and media literacy. Thus, this case study of teaching the Black Power Movement, the genre of documentary film as well as critical information and media literacy provides a crucial lens through which to reassess the role of education and additionally provides an example for teaching for social change and active citizenship.

Keywords: critical information and media literacy, black power movement, documentary film, teacher education, interdisciplinarity 


\title{
Using Authentic Passions to Inspire Curiosity
}

\author{
Daniel Ireton and Ellen Urton \\ Kansas State University, Manhattan, KS, USA, \{dli6873, erurton\}@ksu.edu
}

In a world of increased connectivity but fewer connections, two academic librarians put the humanity back into their daily interactions by living and working through quirky yet earnest personal brands of librarianship. Given the advantages of online, solo research pursuits, a growing global culture of detachment, and the divisive drawbacks of academia's pecking order, they realized that something different was necessary to achieve their goals of reaching students where they are and inspiring them to pursue their research with the kind of passion that emerges from placing a greater intrinsic value on the work itself. They identified barriers and developed strategies to overcome them, seeking to not only maintain, but also solicit new opportunities for instruction and reference, deliver help and support where needed, become more accessible, and talk about what really matters to patrons. Presenting themselves as case studies, the authors demonstrate their shared philosophy: that one can forge deeper and more meaningful connections with student, faculty, and community groups through the sharing of one's authentic interests. In ways both small and grand, they attempt to become part of communities as well as create community through outreach, reference, research, and instruction interactions, presenting their truths as curious hobbyists and human persons who care about aspects of life and the world. They worked to develop community within their library system, campus and town through expressions of genuine interest, enthusiastic participation, and leadership, believing that an academic's extracurricular activities can be used to bridge artificial gaps between student and faculty, between those with access to knowledge, skills and resources, and those seeking to access to same. Whether an instructor or librarian has a common or rare passion, from broad categories like the creative arts or board games, to niche interests in metaphysics or sword fighting, what matters is that one utilizes their passion and shares it in one's work. Even if common interests are not to be found, the person seeking knowledge has a passion of their own, an interest that can motivate them to take a deeper look into the information landscape, that drives them to seek rich veins of information that might remain otherwise untapped. This in and of itself will form a connection to break down some of the barriers that all too often exist between people and the academic labels we subscribe to. The largest gap many information seekers face in being successful is asking for help at critical intervention points in their search process. This view into the instructor's inner world helps to break down such barriers. In this session, the authors will advocate for a little transparency, encouraging others to be seen as a whole person, beyond job categorizations. They will discuss their personal authentic passions and provide examples of how they have integrated them in a variety of patron interactions, highlighting the outcomes of their forays into openness. Participants are welcome to share their own interests and reflect upon future opportunities to bridge gaps between themselves and patrons.

Keywords: information literacy, student motivation, intrinsic motivation, authentic instruction 


\title{
Building Bridges: Using Information Literacy to Support High School to University Transitions
}

\author{
Zoe Jarocki \\ San Diego State University Library, CA, USA, zjarocki@mail.sdsu
}

How can academic librarians help ensure that entering students are prepared for the academic challenges of higher education? This presentation discusses the role information literacy instruction can play in easing the transition from high school/secondary education to university education. This presentation includes a review of best practices, an examination of the literature and a case study from San Diego State University (SDSU), a large, public university in California. The project, which is on-going, is a collaboration between the library, the university and a local high school district that has an admissions agreement with SDSU. This agreement, called Compact for Success, supports academic rigor in the high school curriculum to ensure that students are well-prepared and college-ready and guarantees admission to the University to students who fulfill certain benchmark requirements. The program began in the year 2000 and since then has admitted more than 2,500 students. Compact for Success involves a number of campus visits and events, including campus visits in grades 7 and school presentations in grade 10. In the Fall of 2016, librarians at San Diego State University collaborated with the Compact for Success program to bring groups of 10th graders from all 12 school district high schools for sessions in the library. The objectives for the visits are two-fold; to teach the students some basic information literacy concepts and to make them feel more comfortable both in an academic library setting and on campus at SDSU. More than 1,800 students have visited during the two years of this library program. The visits involve a tour of the library, with a focus on library collections and services and hands-on, active-learning small-group assignments. After the session, student complete a paper assessment that asks them questions related to the learning objectives, their prior experience in academic libraries and an affective question about the visit. The results show that a vast majority felt comfortable or neutral about being in an academic library after the session, though the results of the information literacy assessment questions were more mixed. Similar to the findings of Smith et al (2013) and Burhanna (2007), students are not familiar with the concept of scholarly authority, common academic library terms and with articulating information needs. These findings demonstrate the value of collaborating with high schools to introduce these topics earlier to better prepare students for the academic expectations of university life, as well as create a relationship between the community and the university. Jackson and Hansen (2006), report that high school and college librarian collaborations may increase levels of student recruitment to the university. This presentation will describe the project, share the results and give advice on how to implement similar programs in other communities.

\section{References}

Burhanna, K. (2007). Instructional outreach to high schools: Should you be doing it? Communications in Information Literacy, $1(2), 74-88$.

Jackson, L., \& Hansen, J. (2006). Creating collaborative partnerships: Building the framework. Reference Services Review, 34, $575-588$.

Smith, J. et al. (2013). Information literacy proficiency: Assessing the gap in high school students' readiness for undergraduate academic work. Library \& Information Science Research, 35, 88-96.

Keywords: high school, outreach, higher education, college readiness, information literacy instruction 


\title{
Heffalumps and Woozles: Facing the Copyright Elephant in the Room
}

\author{
Marion Kelt \\ Glasgow Caledonian University, UK, m.kelt@gcu.ac.uk
}

Copyright literacy can be regarded as an integral part of information literacy, especially when considering the ethical use of information. However, this is an unpopular topic and people try to avoid thinking about it. This means that they can often delay considering copyright at the start of a project, and then panic when faced with it towards the end!

Often copyright advice can be part of a wider job which can be a problem at times of high demand.

To help ease this problem and provide basic advice on a 24-7 basis, we have created the GCU online copyright advisor ${ }^{1}$. The idea came from our list of frequently asked questions kept for quick reference. We wondered if we could make these available online, so people could find the answers to basic questions themselves. This would free staff to deal with more complex queries.

We already had a subscription to iSpring, so we decided use it to build the advisor. It covers seven main types of material:

- Audio files

- Book chapters

- Computer code

- Images (including mind maps and diagrams)

- Journal articles

- Maps

- Video files

The hardest part of the project was creating the text and workflows. We started with two people, but quickly found that it was better to have a larger team made up of those with knowledge of the different copyright areas and strengths in web page creation. Our group contained the copyright advisor, and members of the repository, library website, and systems teams. It took a long time to create text and workflows that were clear and consistent. Once we had done this, we decided to share them as an open educational resource. ${ }^{2}$

After we agreed on the content, we got to the fun part, which was building the web resource. This took a few attempts! The main problem with iSpring is that the user cannot' go back if they click the wrong button. This can be addressed by restarting the session by refreshing the browser, but information on how to do this has to be made obvious to the user.

Once we had ironed out these problems, the online advisor was thoroughly tested and proofread. We added a "traffic light" system to the answers to further guide the user, so if they get an amber light, the text tells them what actions to take next. We aimed for a positive tone, so rather than saying "this is not allowed", we advise them to contact the copyright team for further help.

We aim to launch the advisor in early 2018 and have already made it available for use, download and repurposing under a creative commons licence.

We have plans to apply for a grant to have a professional web designer add some style to what is a very plain product, so we have high hopes that the final product will help chase away the scary copyright heffalumps and woozles!

Keywords: copyright literacy, ethics, web-based resources, open educational resources

\footnotetext{
${ }^{1}$ https://edshare.gcu.ac.uk/3608/2/index.html

${ }^{2}$ https://edshare.gcu.ac.uk/id/eprint/2706
} 


\title{
Decision Based and Learner Driven: The EconBiz Online Tutorial Guided Walk
}

\author{
Nicole Krüger \\ ZBW - Leibniz Information Centre for Economics, Kiel / Hamburg, Germany, n.krueger@zbw.eu
}

The headline "Write your best assignment" invites users of the search portal EconBiz ${ }^{1}$ to enhance their information literacy in the field of economics and business studies, in a learner centered decision and game based online tutorial. As EconBiz is an international portal, the Guided Walk ${ }^{2}$ is not tailored to a certain library, but open to all users in the field.

The Guided Walk follows a learner centered teaching approach. Users take full control over their steps and their learning outcomes. The learning is achieved solely by actions of the users, and their experience during the use of the Guided Walk. Written explanations, lengthy texts, or 'lecturing' are avoided where possible. In a fun way students are also offered the choice of drinking a coffee first, to quit and organize a procrastination self-help group, or to get individual help from a librarian via chat. They can find out three quick facts on referencing, while they cook spaghetti or wait for the theatre movie to start, or they can scan their own papers in plagiarism software.

The Guided Walk is developed in close co-operation with members of the EconBiz academic advisory board, university professors and instructors from the field of economics and business studies as well as information sciences. They identified the following topics as most crucial for students in their attempt to work with information for assignments:

- $\quad$ Finding the most qualitative and up to date information on a topic;

- Learning that free access should not' be the selection criterion for scholarly information and that libraries provide access to qualitative materials that are paid for;

- $\quad$ Being able to avoid plagiarism and learn the scholarly practice of citing sources.

Led by these ideas, the Guided Walk was arranged in three separate pillars: "search and evaluate", "access to full texts", and "cite correctly."

As of now (March 2018), the Guided Walk is game-based insofar as users can take quizzes and get instant feedback on their results, they can 'win badges' when they get to the last page of a module, can work through parts of the content in three levels, and can interact with a librarian via chat. But the Guided Walk is not' a programmed game, yet. A master student project of the Web Science research team of ZBW, which will be finished by June 2018, aims at enhancing and realizing gamification elements for the Guided Walk in order to better motivate student learning.

This best practice presentation will focus on the instructional design and the technical realization of the Guided Walk, as well as on gamification elements, and on collaboration with researchers and instructors.

Keywords: gamification, e-learning, blended learning, good practice, higher education, citing, quality of information

\footnotetext{
1 www.econbiz.de

2 https://www.econbiz.de/eb/en/gw/
} 


\title{
Reflective Practice as a Pathway towards Information Literacy for Future English Teachers
}

\author{
Karin Lach \\ Vienna University, Austria, karin.lach@univie.ac.at
}

A two European Credit Transfer and Accumulation System class on information and research literacy was introduced in 2014 due to curricular restrictions on available ECTS points in the new B.Ed. curriculum for future English teachers at Vienna University. The author has taught or co-taught the class every semester since March 2015 (Lach 2015). Despite student numbers of 50 to 100 students per class the class has been taught as a class with mandatory attendance and a number of compulsory and optional online and face-to-face components from October 2015. This requirement was set in order to discourage rote learning and to encourage an active engagement with the class topics and learning goals. An important part of the students' class work is keeping a learning diary and sharing important milestones in their learning and information literacy journey.

There are four learning objectives:

1) Students know fundamental concepts and strategies of academic work with a special focus on literature and information research.

2) They are familiar with the many information resources relating to English and American Studies and are able to make informed choices as to which to use when addressing academic problems.

3) They know about the requirements of academic best practice.

4) They are able to understand the relevance of information literacy for their future professional practices.

Goal Four takes students beyond their own immediate needs as students beginning to engage with academic work to the potential information literacy needs of their future students and their own responsibility towards them beyond academic work (Lach 2015).

One focus of this best practice paper will be on what activities and assignments have been used to steer students away from a practice of rote learning towards using reflection to think about their own learning, towards applying metacognition, and towards applying reading and writing as tools of learning. Can this class work as a foundation or stepping stone for its students' best learning, teaching, and information literacy practices in the context of their present and future educational, professional, and personal lives? In order to consider this issue, the students' activities and assignments will be discussed in light of the role of reflective practice for language teachers (e.g. Benitt 2015) and in information literacy models and practices (e.g. Mackey, T.P. \& Jacobsen, T.E. 2014).

A second element of this best practice paper will address the author's own role as a reflective practitioner, a role much influenced by C. Booth's suggestions for library educators (2011).

\section{References}

Benitt, N. (2015). Becoming a (better) language teacher: Classroom action research and teacher learning. Tübingen: Narr.

Booth, C. (2011). Reflective teaching, effective learning: Instructional literacy for library educators. Chicago, IL: American Library Association.

Lach, K. (2015). Information literacy for future English teachers at Vienna University. Retrieved February 15, 2018 from https://de.slideshare.net/karinlach/lach-karin-pecha-kucha-ecil-2015-information-literacy-for-future-english-teachers-at-viennauniversity

Mackey, T. P., \& Jacobsen, T. E. (2014). Metaliteracy: Reinventing information literacy to empower learners. London: Facet.

Keywords: information literacy, metaliteracy, reflective practice, teacher education, English for teaching purposes 


\title{
Starting Off on The Right Foot: A Common Curriculum for an Introductory Program
}

\author{
M. Sara Lowe \\ IUPUI, Indianapolis, IN, USA, mlowe@iupui.edu \\ Sean M. Stone \\ Indiana University School of Dentistry, Indianapolis, IN, USA, smstone@iu.edu
}

To have a meaningful Information Literacy program, it should be scaffolded throughout the curriculum so that upperlevel students are taught more complex concepts than introductory students (for example, Brasley, 2008). Scaffolding increases learning and reduces repetition of teaching which can lead students to "tune out" during a library instruction section. Educational services at our library developed a common curriculum (based on library and institutional learning outcomes) for students participating in a two-week course prior to starting their first-year at the university. This program requires a light research assignment to prepare students for the research that will be required in the first-year. Named Bridge, the course is similar to first-year experience programs, which have been proven to be high impact practices (Kuh, 2008). Importantly, creating a common curriculum has allowed subject liaisons to know exactly what Information Literacy concepts entering first-year students will have, regardless of their major. As students do not always stay with their original major, this foundation allows for better scaffolding of Information Literacy concepts through the general education curriculum and into the majors. Using assessment best practices (e.g., the assessment instruction cycle, Oakleaf, 2009) in developing the curriculum resulted in an evidence-based program with clear educational "wins" for the library. For example, student work in this high-impact practice demonstrate concept understanding and have improved each year that the common curriculum has been taught. In addition, faculty program coordinators, some of whom had been in favor of removing the research component, kept it based on positive reports of student learning.

This presentation will take participants through the development, implementation, assessment, and revisions of the curriculum, which went through its third cycle in Fall 2017. Regardless of the presence of a program similar to this at attendees' institutions, the curriculum concept can still be adapted in the first-year or within a major to create a more impactful Information Literacy program. Interestingly, at our institution, the curriculum is not required, but is used extensively. This presentation will cover getting buy-in from colleagues who may not be eager to change their practices, including a case study from a librarian who implemented the curriculum in their Bridge section. The presentation will outline programmatic teaching best practices and participants will leave with a roadmap for developing a common curriculum at their home institution.

\section{References}

Brasley, S. S. (2008). Effective librarian and discipline faculty collaboration models for integrating information literacy into the fabric of an academic institution. New Directions for Teaching \& Learning, 2008(114), 71-88.

Kuh, G. D. (2008). High-impact educational practices: What they are, who has access to them, and why they matter. Washington, DC: American Association of Colleges \& Universities.

Oakleaf, M. (2009). The information literacy instruction assessment cycle: A guide for increasing student learning and improving librarian instruction skills. Journal of Documentation, 65, 539-560.

Keywords: first-year students, curriculum mapping, transferable instruction 


\title{
Maximizing the Learning Value of e-Textbooks: Practice Recommendations Based on a Quasi-Experiment
}

\author{
Teresa MacGregor and A. M. Salaz \\ Carnegie Mellon University, Doha, Qatar, teresam@qatar.cmu.edu, asalaz@cmu.edu
}

Prior research shows that in many types of academic reading and learning tasks, e-reading creates suboptimal learning and information retention outcomes when compared to print reading (Singer \& Alexander, 2017). In general, learners do not remember or comprehend as much information when reading digitally as when reading hard copy. However, etextbooks are becoming increasingly popular in higher education contexts for their cost and access advantages (deNoyelles, Raible, \& Seilhamer, 2015). The challenge for educators and librarians is to identify the deployment and use practices of e-texts in higher education that maximize learning efficiency so that students can take advantage of the convenience and affordability of digital texts without sacrificing learning.

One method for improving the learning performance of e-textbooks that has been suggested in prior studies is the provision of more effective training on the interactive tools provided within e-reading platforms. This session presents the findings of a quasi-experiment testing the impact of e-textbook platform training on the self-reported behaviors and preferences of undergraduate university students. For the study, two groups of approximately 100 students enrolled in courses utilizing e-textbooks were sequentially surveyed about their e-textbook reading behaviors and preferences. The first group was not offered training on the features or usage of their e-textbook platform; the second group received training. Responses from each group about their self-reported behaviors and preferences are compared and analyzed in light of prior research on e-book reading, preferences, and behavior in a tertiary educational setting.

The results of the study are presented along with recommendations for librarians on how to implement platform training as a standard part of the e-textbook adoption process. Integrating the library into this aspect of course development benefits students and instructors, while providing librarians with expanded opportunities for interactions and cross-promotions.

\section{References}

DeNoyelles, A., Raible, J., \& Seilhamer, R. (2015). Exploring students' e-textbook practices in higher education. Educause Review. Retrieved from https://er.educause.edu/articles/2015/7/exploring-students-etextbook-practices-in-higher-education

Singer, L. M., \& Alexander, P. A. (2017). Reading on paper and digitally: What the past decades of empirical research reveal. Review of Educational Research, 87(6), 1007-1041.

Keywords: e-textbooks, e-reading, e-literacy, higher education 


\title{
Navigating the Maze: Collaborating with Teachers to Meet Information Literacy Challenges
}

\author{
Olga Martinová and Pavlína Tassanyi \\ Czech National Library of Technology, Prague, Czech Republic, \{olga.martinova, pavlina.tassanyi\}@ techlib.cz
}

\begin{abstract}
This paper proposes expanding existing services of the National Library of Technology (NTK) for high schools (Tvrdá $\&$ Martinová, 2017). These services previously focused on information literacy (IL) workshops for students. Therefore, we are now also training high school teachers who will then transfer these skills to their students.
\end{abstract}

Until recently, IL concepts included in Czech high school curricula (Research Institute of Education, 2007) have only focused on Information Technology (IT), specifically on computer and basic software skills (Czech School Inspectorate, 2015). Now, two new developments clearly indicate a shift in the concept of IL for high schools.

First, several Czech high schools now include academic writing, for example, writing a research paper, to educate their students about the research process and to develop their organisational skills. Second, in November 2014, the Ministry of Education proposed their Digital Education Strategy Until 2020 (STRATEGIE DIGITÁLNÍHO VZDĚLÁVÁNÍ DO ROKU 2020; Ministry of Education, Youth and Sports of the Czech Republic, 2014) based on several recommendations from the European Commission (Ferrari, 2013; European Parliament and the Council of the European Union, 2006). These guidelines suggested revising Czech school programs to broaden IL education. Consequently, the Czech School Inspectorate (CSI) published a new method for revising IL support to schools with specific indicators that can be applied across curricula (CSI, 2015).

However, until recently, didactics programs overlooked IL, thereby hindering the implementation of new, studentfocused strategies (CSI, 2015). Thus, to overcome this problem, we created a series of pilot workshops for high school teachers in 2017. These workshops used blended learning concepts and were supported by the Central Bohemian regional government. Considering our limited knowledge about the problems facing teachers in public high schools, our pilot workshops focused on peer-to-peer discussions. As a result, both teachers and members of the NTK high school support team learned from each other, particularly in discussions about our previous experiences with high school students. IL topics, such as search, evaluation of information, plagiarism, and media education issues, were also addressed. By the end of the series, we were able to define future areas for collaboration, including additional workshops and openly available online IL support tools for high school teachers and students.

Further inclusion of IL in Czech high school curricula—both mandated by the Ministry of Education and supplemented by multidisciplinary efforts such as ours - should not only help high school students to develop the critical thinking and research skills they require for university study, but also to transfer soft skills, thus laying a solid foundation of problem-solving skills and evidence-based decision-making (Naik \& Padmini, 2014).

\section{References}

Czech School Inspectorate. (2015). Metodika pro hodnocení rozvoje informační gramotnosti. Retrieved January 29, 2018 from http://www.niqes.cz/Metodika-gramotnosti/Metodika-pro-hodnoceni-rozvoje-informacni-gramotno

European Parliament and the Council of the European Union. (2006). Doporučení Evropského parlamentu a rady ze dne 18. prosince 2006 o kličových schopnostech pro celoživotni učení. Retrieved January 17, 2018 from http://eurlex.europa.eu/LexUriServ/LexUriServ.do?uri=OJ:L:2006:394:0010:0018:cs:PDF

Ferrari, A. (2013). Digcomp: A framework for developing and understanding digital competence in Europe. Retrieved January 17 , 2018 from http://publications.jrc.ec.europa.eu/repository/bitstream/JRC83167/lb-na-26035-enn.pdf

Ministry of Education, Youth and Sports of the Czech Republic. (2014). Strategie digitálního vzdélávání do roku 2020. Retrieved January 15, 2018 from http://www.msmt.cz/uploads/DigiStrategie.pdf

Naik, M. M., \& Padmini. (2014). Importance of information literacy. International Journal of Digital Library Services, 4(3), 92100.

Research Institute of Education. (2007). Rámcový vzdělávaci program pro gymnázia. Retrieved February 5, 2018 from http://www.nuv.cz/file/159_1_1/

Tvrdá, P., \& Martinová, O. (2017). Partners in class: A needs-based approach to high school curricular support at the National Library of Technology in Prague. In S. Špiranec et al. (Eds.), The Fifth European Conference on Information Literacy (ECIL): Abstracts, September 18-21, 2017, Saint-Malo, France (p. 195). Saint-Malo: Information Literacy Association.

Keywords: information literacy, high school teachers, instructional services 


\title{
The Postgraduate Information Literacy Survey and Instructional Design: A Case Study in University Chinese Academy of Science
}

\author{
Wu Ming \\ National Science Library, Chinese Academy of Sciences / University of Chinese Academy of Sciences, Beijing, \\ China,wum@mail.las.ac.cn
}

As the explosion of mass information and the emergence of information technologies continues, information literacy has shifted from the concept of simple training to the provision of the skills and competencies that are critical to the improved use of information. The skills and strategies to obtain and use information in the web world have become new challenges for everyone, especially for postgraduates in science and engineering disciplines (ACRL, 2006). They spend a considerable amount of time retrieving a wide variety of information (Pinto, et al. 2010; Nazari, 2010). Therefore, there are some concerns about how the academic library can be involved in graduate instruction of knowledge and skills of information (Julien, 2005; Booth, 2015). The National Science Library (NSL) is an academic library attached to the Chinese Academy of Sciences (CAS). In recent years, NSL initiated a Subject librarian system and set up a full time subject librarian's team with diverse subject background. One important aspect of subject librarians changing the traditional role of librarians is to design an information literacy course embedded into the University CAS (UCAS) curriculum. The information literacy course provides fundamental information literacy skills for future graduate level research when graduates in science and engineering spend their first-year on campus studying various courses necessary for their degrees. So, this study describes a postgraduate information literacy survey and instructional design. The practice is conducted in three parts. Part one involves a survey. The survey questionnaire content is based on the ACRL Information Literacy Competency Standards for Higher Education and the ACRL Information Literacy Standards for Science and Engineering/Technology. The questionnaire release before students completed the information literacy course, response collection and data statistical analysis were completed by means of a free online questionnaire survey platform. 279 postgraduates of Chemistry faculty and material faculty participated in the survey. The survey' outcomes reveal the current status and requirements of postgraduate information literacy. Part two focuses on the two-pattern workflow of information literacy course design and practice. Pattern one involves ability development, which includes search tips, tutorials, instructions, and use-guides of science resources. Pattern two involves subject professional skills training to support chemistry and materials fields special needs. Part three focuses on a course evaluation after course completion. Postgraduates complete the evaluation in course evaluation space online, including about ten evaluation items regarding teaching methods and suggestions for improving critical thinking. The study more clearly reveals the statuses of postgraduate's information literacy through response collection and statistical analysis of self-assessment results. And the results not only provide best practices for improvement of postgraduate's' information literacy in other science and technology disciplines, but also achieves much useful information for future subject librarians' incorporation into information literacy course, especially for academic library instruction for science and engineering postgraduates.

\section{References}

ACRL. (2006). Information literacy standards for science and engineering/technology. Retrieved May 2, 2018 from http://www.ala.org/acrl/standards/infolitscitech

Booth, C. et al. (2015). Degrees of impact: Analyzing the effects of progressive librarian course collaborations on student performance. College and Research Libraries, 76(5), 623-651.

Julien, H. (2005). A longitudinal analysis of information literacy instruction in Canadian academic libraries. The Canadian Journal of Information and Library Science, 29(3), 289-312.

Nazari, M. (2010). Design and process of a contextual study of information literacy: An Eisenhardt approach. Library \& Information Science Research, 32(3), 179-191.

Pinto, M., Cordón, J. A., \& Gómez Díaz, R. (2010). Thirty years of information literacy (1977-2007): A terminological, conceptual and statistical analysis. Journal of Librarianship and Information Science, 42, 3-19.

Keywords: information literacy, postgraduate survey, instructional design 


\title{
The Hague Fact Checking Factory; Towards Civic Literacy
}

\author{
Fenneke Mink and Jos van Helvoort \\ The Hague University of Applied Sciences, The Hague, the Netherlands., f.m.mink@hhs.nl
}

\section{Introduction}

Information literacy is essential for the operation of a civic society in which all people may participate (Catts \& Lau, 2008). The aim of the Fact Checking Factory (FCF) is to accomplish cooperation between students and local citizens. The students and lecturers of The Hague Univiersity of Applied Siences aim to create together an agenda for local decision-makers with the project objectives of fact-checking local news.

\section{Objectives}

During 2017 the FCF project was implemented for the City of The Hague in the Duindorp district. We worked together with local citizens to set up an information center where news and online social media messages relating to the neighborhood were collected and checked for accuracy. At the same time, the FCF was set up online while the layout and the sufficiency of the working method were both being studied.

The students gained the following learning outcomes with this project:

- The students investigated the role of journalism of truth finding in our society by checking on the truthfulness with which professional journalists and content creators, using IT, collected news reports and rumors.

- The students built a digital environment where research on the neighborhood news was presented to a general audience.

- $\quad$ The students used the working method of professional journalists and content creators when checking news and facts relating to the neighborhood.

\section{Methodology}

To obtain sound information in the physical and digital realm, we explored and selected variations, initiatives. and tooling of the journalism fact-checking process by conducting desk research and platform selection. Next, for each fact check the same standard procedure was followed in a lab setting using the Fact-Checking online platform. Students and local citizens checked and verified findings through examining sources and claims online. When a fact check was performed the fact-checking procedure were outlined to provide insight into how the fact check was conducted to warrant transparency.

\section{Results}

The research outcomes resulted in local community platforms that have the potential to increase young people's information literacy, as stated by Montagni \& Tzourio (2017). We involved local citizens by ambassadorship in increasing civic prevalence within the gathering, conforming, and revising of local news online as well in local meet ups where the most suitable online environment was presented resulting in knowledge exchange between the students and local citizens. As well the citizens' writing, products can be reviewed in the information platform and improvements can be suggested. The FCF can therefore make a positive contribution towards civic information literacy by stimulating collaboration and gaining public awareness in the public spheres (Van Helvoort, 2018).

\section{References}

Cats, R., \& Lau, J. (2008). Towards information literacy indicators. Paris: Unesco.

Montagni, I., \& Tzourio, C. (2017). Evidence of the effectiveness of a digital tool to guide health services information seeking in the young. In S. Spiranec et al. (Eds.), The Fifth European Conference on Information Literacy (ECIL): Abstracts, September 1821, 2017, Saint-Malo, France (p. 101). Saint-Malo: Information Literacy Association.

Van Helvoort, J. (2018). Four spaces of civic literacy education: A literature review. In S. Kurbanoğlu et al. (Eds.), Proceedings of the The Sixth European Conference on Information Literacy (ECIL), September 24-27, 2018, Oulu, Finland, September 24-27, 2018. CCIS. Cham: Springer International Publishing [Accepted for publication].

Keywords: fact checking, fake news, civic literacy, active participation 


\title{
Evidence Based Practice: Accessing and Assessing Evidence: Course Development Proposal at Implementation Phase
}

\author{
Mbachi Ruth Msomphora \\ UiT The Arctic University of Norway, Troms $\varnothing$ Norway, mbachi.msomphora@uit.no
}

Based on the questions we get from our students and researchers at the University in Troms $\varnothing$ (UiT), I (on behalf of the University Library) recognised the need for introducing a course about "Evidence based practice: Accessing and Assessing Evidence", within the Department of Clinical Dentistry (IKO), Faculty of Health and Science at UiT.

The goal of the course is to facilitate in making IKO students better dental practitioners by using evidence-based knowledge and transfer it into dental practice. It will also help them understand how to find and choose quality studies, which they can use in scientific writing and/or their thesis at both Master and Bachelor of Science level, but more so, during their clinical practices/duties.

After consultation and meetings with the leadership at both the UiT Library and the IKO, it was agreed that the education-course should be given during the school hours, spread from sixth to eighth Semester. Which means, as we shall also see during the oral presentation, the course has currently (January 2018) been implemented. However, it is expected to be in full swing next year. According to the plan, the course will be taught by teachers/lecturers from both the University Library (UB) and IKO. We hope that such an integrated participation-based teaching may improve our communication between UB and IKO, while strengthening our students' ability to locate, evaluate, and effectively use the accessed information (evidence-based knowledge), and transfer it into dental practice, and/or use the knowledge effectively in their research work. This, in turn, should strengthen assurance for qualitative learning for our future experts in dentistry at both national and international level.

For development of better educational support services, it is planned that the course will be evaluated in collaboration between the scientific community from IKO and UB colleagues, apart from the students themselves.

Nevertheless, the aim of my presentation of this course proposal at the European Conference on Information Literacy (ECIL) is to hear feedback from those who are already working on similar education courses or are planning to develop an Information literacy course offering similar to the education course described here. Among other points, it would be interesting to know:

- What is currently offered in Evidence Based Practice with the main focus on Accessing and Assessing information in support of good understanding and use in academic and clinical practices?

- How does the course offering work?

- Can the offering be better adapted to the needs of today's groups of BSc., MSc., and PhD candidates?

Keywords: evidence-based practice, course development, university library (UB), Department of Clinical Dentistry $(I K O)$ 


\title{
Information Literacy Concepts in Swedish Legislation, Methods of Teaching and Their Impact on the Design of Library Instruction Sessions at Linköping University
}

\author{
Magdalena Öström \\ Linköping University, Sweden, magdalena.ostrom@liu.se
}

The purpose of this case study is to inform and inspire the international librarian community, regarding how to improve library instruction sessions in response to Swedish legislation and teaching methods. The Swedish Higher Education Act (Högskolelag (1992:1434)) contains sections which correspond to several information literacy concepts, including "[students] shall develop the ability to:

- make independent and critical assessments,

- identify, formulate and solve problems autonomously."

Law students need a variety of documents and information sources, such as laws, preparatory works, case laws, legal doctrine - both on the national and international level, to be found in many different resources. Fulfillment of these demands and needs requires good skills in structured information searching. Therefore, students at the Commercial and Business Law Programme at Linköping University have been obliged to have library instruction sessions since the programme started in the early 90's. All library sessions are mandatory and incorporated in the programme's courses. Over the years, library instruction sessions evolved from a traditional teacher-centered and passive learning approach to a student-centered and active learning approach. Student-centered learning requires students to be active - learning by doing, often in peer-to-peer interaction- which benefits learning. Teachers must take into consideration individual differences in learners and act more as facilitators rather than instructors of learning. Students participate in a diversity of library courses with an increasing level of complexity such as tours and orientation sessions, courserelated library instruction, workshops, and students' assignments, all based on student-centered learning approach. The library instruction sessions will evolve over time in symbiosis with both forthcoming evidence in pedagogy and technological development.

\section{References}

Klipfel, K. M., \& Cook, D. B. (2017). Learner-centred pedagogy: Principles and practice. London: Facet Publishing.

Løkse, M. et al. (2017). Teaching information literacy in higher education: Effective teaching and active learning. Cambridge, MA: Chandos Publishing.

Rieh, S. Y. et al. (2016). Towards searching as a learning process: A review of current perspectives and future directions. Journal of Information Science, 42, 19-34.

Vakkari, P. (2016). Searching as learning: A systematization based on literature. Journal of Information Science, 42, 7-18.

Zhang, P., \& Soergel, D. (2016). Process patterns and conceptual changes in knowledge representations during information seeking and sensemaking: A qualitative user study. Journal of Information Science, 42, 59-78.

Keywords: information literacy sessions, legislation, teaching methods, active learning, searching as learning, higher education 


\title{
Information Literacy as an Integrative Part of Academic Projects: Partnership with Stakeholders of the University
}

\author{
Kristyna Paulova and Jana Rimanova \\ Czech University of Life Sciences, Prague, Czech Republic, \{paulova, rimanova\}@ sic.czu.cz
}

Librarians consider information literacy (IL) to be something axiomatic and self-explainable. On the other hand, faculty members often perceive it as redundant. Our aim was to change this perception and to integrate the IL as a vital part of long-term university education programme.

This presentation will show the crucial steps of our journey to successful partnership with university stakeholders as well as obstacles we encountered on this journey. These steps include

- Preparation of the high-quality portfolio of lectures and courses;

- Start-up of the IL lectures/courses and building up professional relationship with the individual faculty members;

- Regular presentation of long-term perspective of IL to the university stakeholders; and,

- Transformation of the courses on-demand to the stable of IL curriculum.

In 2017, we had become partners on university projects. The first project "PhD school" focuses on the soft skills development of PhD students, including IL. The second project, "Adaption of the Study Environment, Information and Study Counseling" was developed to mitigate this risk and increase student retention. It was intended for pregradual students, mainly first year student at the university. These students have the highest risk of non-compliance of their university responsibilities and thus they are most-likely to prematurely end their study.

Integration of IL into the regular university curriculum offers benefits for all actors involved. The students are better oriented in the scientific approach requested by their study (MacDonald, 2017) and the academicians can focus on their expertise during mentoring their students and the high-quality IL enables the high quality scientific outcomes of the university. The university library gets a significant credit within the university and thus supports its position for any negotiation in the future.

\section{References}

MacDonald, H. (2017). Library impact on student retention is often not well documented or communicated. Evidence Based Library and Information Practice, 12(4), 265-267.

Keywords: student retention, partnerships in education, integration of IL to university curriculum, communication with university stakeholders 


\title{
From Information Literacy to the Learner Journey: Using What Academics Really Think to Develop the Teaching Offer at the University of Worcester
}

\author{
Sarah Pittaway \\ University of Worcester, Worcester, UK, s.pittaway@worc.ac.uk
}

Information literacy is not a term used in the everyday life of the average academic or student in the UK. Despite having had currency in the library world for many years, with underpinning frameworks that articulate our contribution to our universities, talking the language of information literacy often does not result in the library's contribution being recognised or valued.

At the University of Worcester, we were keen to increase the visibility and impact of our teaching, and decided on a practical, new tool - a 'menu' of teaching - that would help academic colleagues understand how we could support their curricula. It quickly became apparent that such a tool needed to be underpinned by academic understanding of students' skills and development, in a much broader sense than just information literacy. Thus the learner journey project was born, in which Academic Liaison Librarians conducted informal interviews with staff asking such questions as:

- What assumptions do course teams make about the skills students have at the start of their course?

- What expectations do they have about how these skills should develop throughout the degree programme?

- How are these expectations articulated to students?

Consciously avoiding the term 'information literacy', librarians questioned academic staff about the broad skill base that students bring with them and develop at university, mapping their view of the student learner journey from preentry through to graduation.

Although starting out as a small-scale project, it soon piqued the interest of senior management at the university, and grew into a much larger piece of work. Through focusing on broader skills' development, we have developed a body of evidence and data that has wide interest and application for both academic Institutes and other professional services (e.g. Disability \& Dyslexia). Alongside highlighting themes, the data has demonstrated inconsistencies across the university and even within departments, with disparate staff attitudes towards such topics as progression, student confidence, and learner independence. These results have been shared widely across the university, raising Library Services' pedagogic profile.

This session will:

- Share data from the project: overarching themes and inconsistencies. Delegates may find this useful evidence to inform conversation in their institutions.

- Showcase our refreshed teaching offer and supporting action plan, encouraging delegates to think about how teaching is promoted and organised in their institutions.

- Encourage delegates to consider the issue of terminology, and whether taking a different linguistic/semantic approach can further the cause of information literacy in their institutions.

- Demonstrate the additional benefits of undertaking this kind of work, from empowering library staff, to tapping into institutional narratives, inspiring delegates to undertake their own research projects or consider new ways to interact with faculty and senior management.

Keywords: learner journey, academics' views, student-centred 


\title{
Murder in the Library - Using Escape Rooms for Information Literacy Teaching
}

\author{
Essi Prykäri and Riikka Sinisalo \\ Lahti University of Applied Sciences, Finland, \{essi.prykari, riikka.sinisalo\}@lamk.fi
}

One of the main challenges in information literacy (IL) instruction in higher education is to find a right way to equip students with higher level, transferable, information skills. Game-based learning may be one route to address this challenge, for the creative explorations that play encourages can help the students to become information literate in a way that is not currently widely addressed in Higher Education Institutions (Walsh, 2015).

Game-based learning (GBL) usually refers to using digital games to teach knowledge and skills, however Clarke et al. (2017) point out, that GBL can also mean using non-digital games, such as cards, role playing or escape rooms, to achieve defined learning outcomes. In an escape room game, teams of players must discover clues, solve puzzles, and accomplish tasks in order to achieve a specific goal, like escaping from the room, in a limited amount of time (Nicholson, 2015). Escape rooms are fitting for information literacy teaching as evaluating information often requires detective work, discovering clues and solving puzzles. The tasks presented often require applying knowledge, which is at the heart of information literacy, hence rendering superficial learning useless (Gynther \& Prykäri, 2017).

\section{The Design Process}

The staff at Lahti Academic library started designing an information literacy escape room in spring 2017. The design process started with defining clear learning outcomes derived from the information literacy curriculum, followed by planning puzzles and tasks, and writing a narrative for the game. Murder in the library was play-tested on two small groups before being used in a classroom setting. The testing phase helped to further improve the narrative and weed out some inconsistencies according to the feedback collected from test group.

\section{Our Experiments in Using Escape Rooms in IL teaching}

The students found this way of learning fun and exhilarating. We also observed that the students discussed the information literacy topics such as authority and quality of publications in more detail than they would in a traditional lecture, thus enhancing the socio-constructivist element of the class. The feedback collected was generally positive, and the learning outcomes were met. The students also found the escape room method suitable for information literacy teaching and would recommend it to their fellow students.

We' are planning to develop the game so that it covers all the key concepts from the information literacy frames (ACRL, 2015) and thus further improves the students' transferable information skills and helps them to become increasingly information literate.

\section{References}

ACRL. (2015). Framework for information literacy for higher education. Retrieved February 14, 2018 from http://www.ala.org/acrl/standards/ilframework

Clarke, S. J. et al. (2017). EscapED: A framework for creating educational escape rooms and interactive games for higher/futher education. International Journal of Serious Games, 4(3), 73-86.

Gynther, R., \& Prykäri, E. (2017). Pako kirjastosta: Kuka murhasi opiskelijan?. Kreodi. Retrieved from https://www.kreodi.fi/en/20/Artikkelit/384/Pako-kirjastosta-kuka-murhasi-opiskelijan.htm

Nicholson, S. (2015). Peeking behind the locked door: A survey of escape room facilities. Retrieved February 14, 2018 from http://scottnicholson.com/pubs/erfacwhite.pdf

Walsh, A. (2015). Playful information literacy: Play and information literacy in higher education. Nordic Journal of Information Literacy in Higher Education, 7(1), 80-94.

Keywords: information literacy, game-based learning, escape rooms, higher education, teaching 


\title{
Towards Digital Literacy: The Case of Adult Users at Lithuanian Public Libraries
}

\author{
Jurgita Rudžionienè \\ Vilnius University / Martynas Mažvydas National Library of Lithuania, Vilnius, Lithuania, \\ jurgita.rudzioniene@kf.vu.lt
}

\section{Introduction}

Information and media content created and shared using new information and communication technologies (ICT) is increasing rapidly. Due to this reality, citizens are facing challenges and require adequate competencies to tackle them. Media and information providers offer new possibilities for social, economic, and political development. Nowadays, a need for a new approach to variety of literacies isneeded and ICT possibilities require skills and competences using them. Developing a new set of critical competencies (skills, knowledge, and attitudes) for citizens is vital. The UNESCO Global Media and Information Literacy Assessment Framework points out the importance of comprehensive assessments of the information and media environment and monitoring the extent to which citizens have acquired media and information literacy competencies (UNESCO Global MIL Assessment Framework, 2013). Digital literacy, an integral part of overall information literacy, is the awareness, attitude, and ability of individuals to appropriately use digital tools and facilities to manage digital resources and create and communicate new knowledge (Martin A., Grudziecki J., 2006).

\section{Research Objectives}

There are several objectives of the research: 1. Analyze the digital literacy of adult Lithuanian public libraries' users'. 2. Find out the awareness on digital literacy and the existing and potential extent ICT use. 3. Prepare recommendations for public libraries in order to develop the awareness and skills of the digital literacy of public library users.

\section{Methodology}

I used a surveying, asking respondents to complete a questionnaire. The survey was designed to gather data about the preferences of respondents in their use of different technological tools, devices, and equipment as well as to indicate their purposes for using them. I conducted the research was performed during the period of September-November 2017. I chose twelve public libraries for this research that represented all municipalities and fit the different geopolitical criteria of the state. The survey instrument consisted of 24 questions, including demographic information.

Adult public libraries' users are the target group for this research. A total of 323 questionnaires were completed. Respondents were chosen both at the central libraries as well as in their branch libraries to get more precise data about remote public library users' digital competences.

Results

Results of the research showed the situation of public library adult users' competence, practice, and aims of using digital means, devices, and ICT possibilities in order to meet their professional and personal information needs. The results and outcomes of the research revealed the problems and gaps thatshould attract attention of Lithuanian public libraries in order to arrange adequate training.

\section{References}

Martin, A., \& Grudziecki, J. (2006). DigEuLit: Concepts and tools for digital literacy development. Innovation in Teaching and Learning in Information and Computer Science, 5(4), 1-19.

UNESCO. (2013). Global MIL assessment framework. Retrieved February 21, 2018 from http://www.unesco.org/new/en/communication-and-information/media-development/media-literacy/unesco-global-milassessment-framework/

Keywords: information literacy, digital literacy, public libraries, adult library users 


\title{
Best Practices: Librarians, Journalists, and Allied Professionals Working to Challenge Fake News
}

\author{
Laura Saunders \\ Simmons College, Boston, MA, USA, laura.saunders@simmons.edu \\ Lisa Janicke Hinchliffe \\ University of Illinois at Urbana-Champaign, IL, USA, ljanicke@illinois.edu
}

\begin{abstract}
Access to reliable and trustworthy information is essential to everyday-life decision making and to full participation in a democratic society. However, people's access to such information is confused and even threatened by the proliferation of mis- and disinformation, often collectively referred to as "fake news."
\end{abstract}

Although not a new problem, fake news is receiving increased global attention due in part to the rise of partisan news outlets, and the speed and ease with which news is created and shared on social media. The issue was highlighted by suggestions that hackers might have helped to spread fake news in order to influence the outcome of the 2016 United States presidential election and, since that time, concerns of fake news impacting national elections has spread throughout Europe and other parts of the world.

The issues of mis- and dis-information are relevant to librarians, whose job it is to gather, organize and facilitate access to information, and to assist patrons in navigating and evaluating information, but they are not the only professionals impacted by these issues. Journalists struggle to share reliable information and build public trust while providing access to all points of view. Social media and technology companies are considering how their sites could be contributing to the spread of fake news. Educators are struggling to determine how to help students develop the information and media literacy competencies necessary to evaluate information for research and everyday life decision-making. While different disciplines and fields are all developing responses to fake news, they are often working in silos and are not actively sharing information or considering how their approaches could complement each other. Finding effective collaborative approaches is a particularly challenging and important task as fake news moves easily across national regulatory boundaries through social media.

In April of 2018, the presenters hosted a day and half long symposium that brought together more than 70 professionals from librarianship, journalism, and allied fields to discuss responses to the challenges of mis- and disinformation. Symposium participants engaged in small and large group discussions and brainstorming to discuss how each profession assesses for and signals authority, and how they engage with the public to build trust. Participants worked across disciplines to identify responses to the issue of fake news that could be implemented using libraries as living laboratories for launching these ideas. In this session, we will share best practices and recommendations that emerged from this symposium, with a focus on how librarians, journalists, and allied professionals can cross boundaries, leverage each other's resources, and build on each other's expertise to develop more robust and far-reaching responses to the challenges of fake news. We will focus on cross-disciplinary approaches to identifying and sharing authoritative information and to building public trust.

Keywords: news literacy, misinformation, disinformation, information literacy, journalism 


\title{
Information Literacy MOOC: An Experience and Learners' Perspective
}

\author{
Vilve Seiler and Lilian Neerut \\ University of Tartu, Estonia, \{vilve.seiler, lilian.neerut $\} @ u t . e e$
}

The aim of this contribution is to present the experience of setting up and running the first information literacy MOOC (Massive Open Online Course) in Estonia and to analyze learners' reflections.

University of Tartu subject librarians have been providing information literacy e-courses for university students, librarians and for secondary school teachers and students for 10 years (Seiler, Miil, \& Lepik, 2012); now we want to share our skills and knowledge with the general public. This is also in line with the library's mission to support lifelong learning. In the spring of 2017, we conducted the Estonian-language MOOC titled "Information Literacy." The course was fully developed and managed by the library staff.

Our main target audience were the secondary school students who must find reliable information sources for their research papers, the teachers who have to supervise their students, and the librarians to whom the students also turn for help. But, naturally, we welcomed everyone who wished to develop their information competence to be more proficient in finding the information necessary for everyday life. In order to participate in the modern information society and lifelong learning, all people need to develop the skills to find, evaluate and responsibly use information. 372 participants came from very different spheres of life and the percentage of graduates of the first course was $65 \%$.

The full set of course materials and self-assessment tests with feedback are freely accessible for everyone to study at their own pace. Registered participants who want to receive the certificate have to pass quizzes with multiple choice and short answer questions in the Moodle learning environment. Moodle also provides online discussion forums for getting help and advice from tutors. The course in Moodle is divided into four weeks and the participants get one ECTS credit point for the course. The course team consists of four librarians and one specific team member is responsible for each course week.

We will describe the structure and contents of the course and share our experiences and challenges in building and delivering the course. We will also introduce the results of our analysis of student reflections about the course. Feedback from participants was collected by an optional and anonymous survey. $72 \%$ of the graduates of the first course completed the survey. Initial results show that in general the learners appreciated the knowledge and skills gained from the course and the course fulfilled its purpose. The learners liked the flexible timetable, clear and understandable learning materials, well thought-through tests, forums, quick feedback and helpful tutors. The next course will start in March 2018 and the performance of this course will also be analysed.

\section{References}

Seiler, V., Miil, K., \& Lepik, K. (2012). How to fit teaching of information literacy in with students' needs: An on-line credit course model from the University of Tartu Library. Liber Quarterly: The Journal of European Research Libraries, 22(1), 42-63.

Keywords: $M O O C$, information literacy, e-learning 


\title{
On Campus and Beyond: A Multipronged Approach to Information Literacy
}

\author{
Priyanka Sharma \\ Yale NUS College, Singapore, priyanka.sharma@yale-nus.edu.sg
}

Yale NUS College is the first liberal arts college in Singapore and one of the few in Asia offering a four-year undergraduate degree in a fully residential campus setting. Students can select from 14 available majors to graduate with a Bachelor of Arts degree with Honours or a Bachelor of Science degree with Honours. This presentation will highlight an information literacy programme for History majors at Yale NUS College that I designed, and that contained the following elements:

- Course integrated instruction designed in collaboration with faculty, and after consulting the Capstone research project proposals that had been submitted, as well as the results of a pre-survey;

- Visit to the National Archives of Singapore with an archival literacy session conducted by an assistant archivist;

- Workshop by the National Oral History Centre for students who were collecting/using oral history resources;

- One-on-One research consultations with students.

The main objective of this project was to equip History majors with the skills and competencies needed to conduct research for their Capstone projects. These skills were identified as:

- Information literacy skills including an introduction to subject specific resources and tools;

- Archival literacy skills to successfully locate and use information available at the National Archives of Singapore and beyond;

- An optional session on collecting and working with oral history; and

- One-on-one consultations to address research and information related queries specific to each project.

Methodology

The first three elements of the project were developed in consultation with the Head of study for History, as well as archivists at the National Archives of Singapore and the Oral History Centre, respectively. Faculty made the one-onone consultations a course requirement. The project utilized tools such as PPT slides, LibGuides and field trips to the National Archives. It also employed a pre-survey to gauge needs and topics, and a post survey to gauge impact.

\section{Outcomes and Contribution}

The outcomes were observed/reported via a post survey, email messages and face to face conversations:

- The faculty member involved, as well as the students, found the in-class session to be very beneficial in building the requisite IL skills;

- The field trip to the National Archives, as well as the archival literacy session, was considered very useful as this was the first time that the majority of students were visiting archives;

- The training session conducted by the national oral history centre equipped students with field research skills that were needed for some projects; and

- An unexpected outcome: a few students expressed interest in Librarianship and Archival Studies.

This approach underscores the importance of a multipronged approach that develops the various IL skill sets needed by undergraduate students to successfully accomplish a major research project. The project exemplifies how skills needed for capstone research can be packaged into a comprehensive IL programme.

Keywords: information literacy, archival literacy, Capstone, oral history, liberal arts, academic libraries 


\title{
Text, Lies, and Video Tutorials: Examining Format Preference and Effectiveness in Blended IL Instruction
}

\author{
Tara Stieglitz and Lindsey Whitson \\ MacEwan University, Edmonton, Canada, \{stieglitzt, whitsonl2\} @ macewan.ca
}

Information literacy (IL) has long been integral to first-year chemistry at our university, originally comprising written instructions in the lab manual and a 60-minute, librarian-delivered lecture. Increased enrollment rendered this model unsustainable, so collaboration ensued between the library and the chemistry lab coordinator to develop a blended learning model. Students were given the option of watching the same content via a short video tutorial or reading it within their lab manual, followed by a 15-minute in-class librarian-led review session. Our current study examines the relative effectiveness of the two modes of instruction and whether students see the tutorial and written instructions as complementary resources or unnecessary duplication.

Regarding format preferences, there are long-standing beliefs around the concept of learning styles: Individuals differ in what mode of instruction works best for them, and optimal learning is a matter of tailoring instruction accordingly. However, Pashler, McDaniel, Rohrer, and Bjork (2008) critically reviewed the literature around this concept and found it lacked credible evidence. Cuevas (2015) reviewed subsequent research and arrived at similar conclusions.

Scholarship is divided on the relative merits of written instructions versus video tutorials. Some firmly assert the superiority of video tutorials as a means of IL instruction (Scales \& Johnson, 2014). Others found that video tutorials hold no advantage, with better student outcomes occurring with written instructions (Bowles-Terry, Hensley, \& Hinchliffe, 2010; Turner, Fuchs, \& Todman, 2015).

Our approach to examining student preferences for and usage of written instructions versus video tutorials was threepronged. First, we used an in-class questionnaire to ascertain student preferences. Thereafter, we used Google Analytics to track actual student use of the tutorials before, during, and after their class period. Finally, we examined the effectiveness of the two modes of instruction by observing non-chemistry students working through a chemistry task after either watching a tutorial video or reading the lab manual text instructions.

Our presentation will speak to our multi-modal approach to students' learning preferences and showcase findings of our mixed-methods study. It will illuminate student behaviours towards different forms of IL instruction.

\section{References}

Bowles-Terry, M., Hensley, M. K., \& Hinchliffe, L. J. (2010). Best practices for online video tutorials in academic libraries: A study of student preferences and understanding. Communications in Information Literacy, 4(1), 17-28.

Cuevas, J. (2015). Is learning styles-based instruction effective? A comprehensive analysis of recent research on learning styles. Theory and Research in Education, 13(3), 308-333.

Pashler, H. et al. (2008). Learning styles: Concepts and evidence. Psychological Science in the Public Interest, 9(3), $105-119$.

Scales, B., Nicol, E., \& Johnson, C. (2014). Redesigning comprehensive library tutorials. Reference \& User Services Quarterly, 53(3), 242-252.

Turner, B., Fuchs, C., \& Todman, A. (2015). Static vs. dynamic tutorials: Applying usability principles to evaluate online point-ofneed instruction. Information Technology and Libraries, 34(4), 30-54.

Keywords: blended learning, student engagement, science librarianship 


\title{
Developing Best Practices for International Student Information Literacy Instruction
}

\author{
Sean Stone \\ Indiana University School of Dentistry Library, Indianapolis, IN, USA, smstone@iu.edu
}

\author{
M. Sara Lowe \\ IUPUI University Library, Indianapolis, IN, USA, mlowe@iupui.edu
}

The information literacy (IL) needs and skills of international students are similar to domestic students but often include additional challenges that must be addressed. In 2014, the IU School of Dentistry created the International Dentist Program (IDP) which allows dentists from outside the United States to more quickly attain a Doctorate of Dental Surgery degree with an abbreviated curriculum. These students are practicing dentists in their home countries and have excellent clinical skills but are often significantly lacking in information literacy, research, and related skills since many have never matriculated through US or even Western universities. In the beginning, these students often have IL skills similar to intermediate undergraduates. International students, in general, tend to be less familiar with, and less effective at using library resources, and exhibit greater reliance on open internet sources than domestic students. Library instruction as an IL intervention is well received by international students and more effective than orientations and tours (Houlihan, et al., 2017). It is critical to embed well-timed information literacy instruction into the curriculum to address student needs (Munn and Small, 2016).

Over the past few years, we have been identifying deficiencies in IDP student competencies as well as opportunities for expanded, embedded information literacy instruction to better prepare students for more advanced research. This has involved adapting and adding to existing programmatic, undergraduate IL instruction to existing higher-level, searching and evidence based information instruction in the dense IDP DDS curriculum. With 2018, we have created what we believe to be an optimal (given the various limitations) integration of IL instruction into the IDP curriculum. IDP students are gradually (re)introduced to increasingly complex IL and research concepts which prepares them for advanced research and the use of evidence based medical information in a clinical setting. This session will present a systematic approach to identifying IL deficiencies and embedding additional IL instruction across an existing curriculum. This session is applicable for anyone who deals with a student population with additional needs beyond the standard cohorts of students, regardless of academic level or presence of existing programmatic embedded IL instruction.

\section{References}

Houlihan, M., Walker Wiley, C., \& Click, A. B. (2017). International students and information literacy: A systematic review. Reference Services Review, 45(2), 258-277.

Munn, J., \& Small, J. (2017). What is the best way to develop information literacy and academic skills of first year health science students? A systematic review. Evidence Based Library and Information Practice, 12(3), 56-94.

Keywords: international students, embedded, instruction 


\title{
Collaboration in Teaching Open Science Skills
}

\author{
Katin Syvälahti and Taina Kettunen \\ Helsinki University Library, Helsinki, Finland, \{kati.syvalahti, taina.kettunen $\} @$ helsinki.fi
}

The basic principle of the research has always been openness. Rapid technological changes offer new opportunities for the way research is conducted. It is important to consider what kind of skills students need in the foreseeable future. In this presentation, we will focus on a pilot project initiated by the Helsinki University Library. The aim of the pilot project is to find concrete examples and best practices for teaching open science skills to university students.

The University of Helsinki is a Finnish multidisciplinary research university with more than 40000 students and staff members combined. There are 32 study programmes at the bachelor level and 60 at the master's level. Open science is one of the University's top strategic development areas. While there has been a significant amount of progress in promoting openness in publishing and research data management, open science themes still remain less visible in the current student curricula. For this reason, a pilot project was initiated at the end of 2017 by the Helsinki University Library.

Open research process will require a cultural change in science. Openness forces researchers, teachers and students to evaluate and improve their work processes. We argue that open science should not be an independent extra course or component which will be added to the existing curriculum. The best way for students to acquire open science skills is to integrate the teaching of such skills into existing courses. For example, courses may include basics of open publishing, how to enhance the workflow of the research, legal aspects of open science along with how to organize, manage, and preserve your data. Learning elements could be small and simple, especially at the beginning studies.

During the initial phase of the project we contacted all bachelor's and master's level study programmes at our university. Study programmes from seven different disciplines participated in the project, and developed open science in their curricula in collaboration with experts from the library. In this presentation, we will discuss the preliminary outcomes of the pilot project and we will share some practical examples on how to integrate open science elements into the courses.

Keywords: collaboration, students, academic libraries, open science, skills, teaching 


\title{
Online Reading Lists: Encouraging Staff Engagement to Improve Student Information Literacy
}

\author{
Allie Taylor \\ University of Worcester, Worcester, UK, alison.taylor@worc.ac.uk
}

What makes a good reading list? What do students do with reading lists? What helps them make the most of the reading list for a module?

Many institutions now use software to provide online reading lists. At the University of Worcester (UW) we have Talis Aspire, and have worked hard to engage both staff and students with the resource. While usage and feedback have been good, and many academics have become adept at updating and publishing their lists, there is work to be done in answering the above questions and ensuring that academics engage with reading lists at more than just a surface level. Research shows that, properly used, reading lists can help promote information literacy and help lecturers communicate with students (Brewerton 2014; Miller 1999; Siddall \& Rose 2014). Alongside information literacy sessions, they can also play a key role in helping students to avoid library anxiety (Van Scoyoc 2003). Yet many academics remain wary of giving too much information, spoon feeding students and not allowing the students enough freedom to research their own topics, or, at the other extreme let their lists lie fallow as "static records of the tutor's own reading experience" (Stokes \& Martin 2008).

This session asks participants to examine the areas they would expect academics to consider when creating a reading list; types of content, format, length and layout. We then continue with recreating a 45 -minute session given to academic staff at the UW Learning and Teaching Conference and as part of the Post-Graduate Certificate in Learning and Teaching in Higher Education, using polling software (Poll Everywhere and TurningPoint). We examine how to encourage lecturers to maximise the impact of their reading lists and increase library use. We consider the pedagogy of reading lists, how to engage students with reading and how academic staff and the library can support students in using the resources available, drawing on best practice from academic colleagues at UW. The presentation showcases some of the best academic engagement with reading lists, and the outcomes for student satisfaction, learning, and reading habits as measured by the National Student Survey and individual module feedback.

This session will give a practical illustration of how to encourage academics of the need to engage and persuade with reading lists. It will be useful to anyone hoping to further engage academic colleagues with online reading list systems or hoping to breathe new life into departments where enthusiasm is flagging.

\section{References}

Brewerton, G. (2014). Implications of student and lecturer qualitative views on reading lists: A case study at Loughborough University, UK. New Review of Academic Librarianship, 20(1), 78-90.

Miller, B. (1999). An integrated taxonomy of student reading and learning development. Journal of Further and Higher Education, 23(3), 309-316.

Siddall, G., \& Rose, H. (2014). Reading lists - time for a reality check? An investigation into the use of reading lists as a pedagogical tool to support the development of information skills amongst Foundation Degree students. Library and Information Research, $38(118), 52-73$.

Stokes, P., \& Martin, L. (2008). Reading lists: A study of tutor and student perceptions, expectations and realities. Studies in Higher Education, 33(2), 113-125.

Van Scoyoc, A. (2003). Reducing library anxiety in first-year students, Reference and User Services Quarterly, 42(2), 329-341.

Keywords: reading, reading lists, academic engagement, library technology, higher education 


\title{
An Educational Program on Research Competence Offered by a Faculty Library
}

\author{
Anne-Lise Van der Meulen and Paul Buschmann \\ Faculty Library of Arts and Philosophy, Ghent University, Belgium, annelise.vandermeulen@ugent.be
}

In Flanders (Belgium), pupils finishing secondary education have to meet certain 'attainment targets'. These attainment targets are imposed by the Flemish Ministry of Education and apply to all pupils and schools in Flanders. The attainment targets can focus on either knowledge, skills, or attitudes. Furthermore, the attainment targets can be classified as being either domain-specific or multidisciplinary. One of the attainment targets focusing on skills is called 'research competence'. This skill is defined as the ability of pupils to be able to:

a) investigate and explore a research problem by searching for and collecting specific information and to organize and edit this information;

b) prepare a research assignment and to execute and evaluate it; and to

c) report on the research outcomes and conclusions and to confront these with other points of view.

The University of Ghent (UGent) has a special service that offers an educational program for teachers and pupils of secondary schools in Flanders. By means of this program, UGent wants to share its creative and fascinating environment with teachers and pupils. It wants to offer its future students the chance to become acquainted with scientific practice and research in an academic context. The library of the Faculty of Arts and Philosophy joined this service and now offers a program that directly links to the attainment targets of 'research competence'. During a halfday program, the pupils, together with their teachers, are taken on a tour through the world of scientific information. A skilled guide shows them different catalogues, bibliographic and full-text databases. The participants learn handson different search strategies and try out engines like Google Scholar and other scientific resources on the WWW. This workshop has been welcomed enthusiastically by the students and their teachers because it provides variety in the program delivery through a combination of presentations, a guided tour, and a hands-on working session.

The presentation will give a detailed overview of the components of a session as it is provided by the library. Additionally, it will discuss on how it tries to immediately relate to the attainment target 'research competence' and in this way afford the necessary support for teachers in reaching their educational target. The presentation will also explain on how the library adjusts the session to the different research subjects from which schools can choose (for example, history, literature, languages, and the arts). Finally, an overview will be given of three years of experience through answering questions such as the following. Was it a success story? Has the library encountered pitfalls? What were the lessons learned?

Besides being an interesting PR-tool, the program offered by the library is an important element in the university's ambition to be a relevant actor in the field of bringing the sciences to the general public.

Keywords: secondary school, educational program, research competence, search strategy 


\title{
The Delphi Model: Transforming Flemish Libraries into User-oriented Points of Information
}

\author{
Patrick Vanden Berghe \\ Public Library of Pittem, Flanders, Belgium, patrick.vandenberghe@pittem.be
}

Flemish libraries have historically been praised by visitors and valued by the general public, but since the turn of the century, they have seen a decline in usage. So, libraries felt the need to rethink their future role. Following examples from abroad, some Flemish local administrations have chosen to restyle libraries by adding a coffee-corner, a café, or game rooms for teens. Or libraries have been brought closer to the public by incorporating them into cultural or administrative centers.

For some librarians these alterations did not address the core concerns. If libraries want to survive their role their should be even more substantially reevaluated. Libraries operate in an environment where the ability to work with digital resources is becoming vital. Enhancing digital literacy will be a major task for libraries. A group of libraries in Flanders believed in a new role. They embarked on the 'Delphi Project' to establish methods for libraries to become centers of their local communities by focusing on the information needs of their customers. Central within this model was to change the function of the library from a material-lending institution to an information center. This shift has implications for collection, design, and organization. All of these aspects have to focus on information brokering, rather than on lending. At the focal position is the term 'user-oriented'. The new model starts from the idea that the overall organization of the library should be dedicated to the user and user needs. Through the introduction of selflending machines, staff can spend more time on the work floor, while the use of a user-friendly shelving system will help customers find information more efficiently. As such, more time can be spent together with the customer who is assisted in his/her search for information. The customer learns how to use the catalogue, how to find relevant information on the net, how to check the information offered and so on. A central element here is 'self-reliance'. The final result is a higher degree of information literacy.

The emergence of technology supported this shift. In addition to customer service training, online tools have helped staff reach library users. An online tool called the 'Bronnenwijizer' combines searching the local library catalogue, provincial and state catalogues, and the Internet. The tool also supports the creation of 'baskets' for a patron's information needs that can be shared with other staff. Delphi libraries have also used 'Infopleinen'. Web-based guides to topics featuring printed media and online sources. Over half the libraries in West-Vlaanderen are entitled to call themselves Delphi Libraries, and the philosophy is being disseminated more broadly through the Delphi Project Web site. While it is difficult to measure in which way this approach has led to a higher degree of information literacy, library staff have acknowledged a higher degree of self-confidence in helping people.

The presentation will focus on the elements that contributed in the way Delphi Libraries have been able to change their focus in areas such as training of staff, introduction of new ways of displaying resources, user-oriented service, registration of questions.

Keywords: user-oriented libraries, Delphi model, information brokering 


\title{
Voluntary or Mandatory? Assessing Two Ways to Disseminate Information Skills Using a MOOC
}

\author{
Lieselot Verryckt and Steven Laporte \\ Vrije Universiteit Brussel, Brussels, Belgium, \{lieselot.verryckt, steven.laporte\} @ vub.be
}

This research is a follow-up study of a presentation given at the ECIL2017 conference in Saint-Malo. At that occasion we demonstrated a clear-cut and cost-effective approach to building a MOOC (Massive Open Online Course) on information skills, using our experience at the Vrije Universiteit Brussel (Laporte \& Verryckt, 2017). With this study we want to share the results of using the MOOC, one year after it was introduced to the student population.

The main focus of this new research is to assess the differences in learning patterns and learning outcomes (if any) between students who followed the program voluntarily, and those who participated as a part of a mandatory course. Making this comparison is possible due to the integration of the MOOC in the curriculum of the humanities department, next to the open and unrestricted access that is inherent to the MOOC framework.

To evaluate the results, we make use of the data provided by the Canvas Network environment - the host of the MOOC - and complement this with information that was compiled through a general online survey and in-depth interviews with the students.

The Canvas dataset allows us to monitor the students' progress as they navigate the different modules of the MOOC, the time needed to complete the course, and the results of the different tests. From the outset the MOOC purposely features a test at the beginning and one at the end of the course, both of which cover similar topics. We use these tests to assess the progress in aptitude before, and after completing the course.

In addition to the information gathered from the MOOC itself, an online survey provides feedback on the appraisal of the content in relation to student expectations, as well as information about shifts in skill levels. Finally, in-depth interviews give a detailed view of how the course material was processed by the students of both the compulsory course, and the voluntary students.

These findings can provide a useful insight in the different ways in which students process the content of online information skills programmes. Additionally, they allow us to assess the impact of the context in which the programme is presented.

\section{References}

Laporte, S., \& Verryckt, L. (2017). MOOC improve your research skills. Retrieved May 26, 2018 from https://www.canvas.net/browse/vub/courses/improve-research-skills

Keywords: $M O O C$, self-learning, guided learning, information skills 

PECHA KUCHA 


\title{
Digital Literacy vs. Computer Learning: Social Representations of Information and Communication Technologies (ICT) among Middle School Students
}

\author{
Laure Bolka-Tabary and Florence Thiault \\ University of Lille, Villeneuve d'Ascq, France, \{laure.bolka-tabary, florence.thiault \}@univ-lille3.fr
}

We want to question how social representations about ICT (Information Communication Technologies) are developed by middle school students. The strongly masculine dimension of computer culture invites us to adopt a gendered approach, which helps to understand the discriminatory character of certain representations and their impact on the orientation towards the digital sector.

All the scientific studies since the 90's (Chabaud-Rychter \& Gardey, 2002; Lignon, 2015; Collet, 2006) converge towards the same observation of a male hegemony in the computer science field. Digital literacy, which is defined by many authors as a participatory culture, is embodied in the masculine. We can mention for example, contributions on Wikipedia, communities of gamers or open access movement. The Web is a place where the male hegemony is prolonged and crystallized. It therefore seems important to think of digital culture through the prism of gender and to analyze in this way both the digital practices of students in and out of school (Cordier, 2016), and their cultural practices and representations of digital.

Students develop representations based on "dominant" cultural references concerning technologies and gender, both in the personal sphere and at school. In the absence of accurate knowledge of the skills required to work in the digital sector, these representations can be barriers to computer knowledge and to choices of professionalisation.

We will mobilize different research fields on the experimental use of a digital tools in middle-school (Minecraft, Scratch, the introduction to coding). Our methodology combines an ethnographic approach and investigation in order to address students' attitudes and discourses. We will see if gender and digital practices are determining factors for the attraction to the computing field.

\section{References}

Chabaud-Rychter, D., \& Gardey, D. (Eds.). (2002). L'engendrement des choses. Des hommes, des femmes et des techniques. Paris: Edition des archives contemporaines.

Collet, I. (2006). L'informatique a-t-elle un sexe?: Hackers, mythes et réalités. Paris: L'Harmattan.

Cordier, A. (2016). Pratiques translittéraciques juvéniles et imaginaires croisés d'acteurs: Une question de genre?. Revue de recherches en littératie médiatique multimodale, 4. Retrieved from http://litmedmod.ca/pratiques-translitteraciques-juveniles-etimaginaires-croises-dacteurs-une-question-de-genre

Cossetta, A. (2012). Que donnent les femmes sur le Web?. Revue du MAUSS, 39, 391-404.

Lignon, F. (2015). Genre et jeu vidéo. Presses Universitaires du Midi.

Keywords: digital culture, students, représentations, ICT, discrimination 


\title{
IL for Bachelor's Students at University of Oulu: Best Practices
}

\author{
Kaisu Clarot, Ursula Heinikoski and Pertti Martinmäki \\ Oulu University Library, Oulu, Finland, \{kaisu.clarot, ursula.heinikoski, pertti.martinmaki\}@oulu.fi
}

Oulu University Library offers information literacy skills courses at all levels of university studies. Bachelor's level students form the major group of course participants. An IL skills course is compulsory for them either as a standalone course or embedded in a Bachelor's thesis seminar course. We will outline the best practices and methods we have used to enhance students' motivation so as to offer them a meaningful course and to provide flexible ways to study information literacy skills.

Our purpose is to provide the student with an understanding of how a topic gradually becomes a final thesis. The major topics covered in the courses include the scientific information retrieval process, evaluating information sources, reference management and uploading the thesis in the publication system. The ACRL Framework for Information Literacy for Higher Education has been applied to the course contents and structure.

Learning by doing is the main idea of our information literacy courses. Courses are comprised of lectures, practical training and online learning material. A flipped classroom is used when students are learning the basics of information retrieval such as Boolean operators and truncation. Cognitive apprenticeship has proved to be a functional way to teach the use of databases, reference managing tools and evaluation. Action-based learning methods are also used in lectures. We also use collaborative learning, for example, in group and pair discussions and written tasks. Students learn the information searching process in practice by working with their own topic, evaluating references, and making citations using a reference management tool.

The online learning materials are freely available in a LibGuides platform. The materials are frequently updated and are directly applicable to the student's own work. All the instructions for the courses, exercises, and their solutions can be found in the Optima learning environment.

The implementation and the pedagogic methods vary a little by discipline. Some of the courses are designed together with a subject teacher. There are several groups for the course during the semesters and also summer courses. The students can compensate for their absences by working with another group. It is also possible to do individual compensating exercises. Within the limits of teacher resources, students can choose an online course if their schedules or their life situation so require.

A relaxed and trusting atmosphere encourages students to discuss and ask for help in the classroom. In some courses, students are given personal feedback. Individual guidance is available for students with learning difficulties or those in need of extra help.

Keywords: information literacy skills, university students, pedagogic methods, libraries, courses 


\title{
How to Integrate Visual Literacy in Adult Second Language Training?
}

\author{
Noémi Cobolet \\ Franc-Parler, Renens, Switzerland, noemi.cobolet@laposte.net
}

Visual literacy is the ability to critically view, use, and produce visual content. As a volunteer, I give training to adults seeking to learn French as a second or a third language. The courses are taught once a week in the city of Renens, Switzerland where $50 \%$ of the habitants are foreigners.

The adults have different learning strategies than children do (Malcolm S. Knowles, 1990; St. Clair, 2015): they appreciate to learn applied knowledge. Their goal is to find a job where French language is required, as it is the case in Renens, in the French speaking part of Switzerland. Some learners also want to learn French because their children are learning French at school. Others are new in the country and they want to know more about the Swiss culture and to meet people.

Depending on these needs, I started to use pictures selected from real life. For example, I proposed map reading activities:

1) Which place is represented on the map?

2) Which common words can be found written on the map? (road, forest, lake); and,

3) Which symbols are used on the map and what do they mean?

Learners have to choose an itinerary, draw it on their map and subsequently write it in French. Next, the participants exchange their text with others and are asked to reconstitute the itinerary of their peers.

Reading scientific literature on the use of pictures at school, I knew that the use of pictures is particularly relevant for language learners (Wright, 2004). It facilitates the comprehension of a specific context. I noticed in practice that learners are also focused on cultural aspects of the pictures. Each time I used pictures, I brought with me the whole book or the whole comics. Learners liked to consult the whole contents and to discover new books in French.

I adapted the activities so that visual contents have become the core content of my course. Pictures stimulate discussions amongst the learners - as was observed during gamified art trainings. The learners were asked to choose a picture, and to describe the artwork step-by-step with cards (for example, http://lesmotsduclic.com/) followed by an exercise to write a textual description about the chosen artwork. Learners demonstrated pride in their work while reading their text to their peers. The readability of pictures can be questioned, owing to differences in cultural biases. Developing visual literacy skills among language learners is a key for integration. The next step will be to make learners produce their own visual content.

In this presentation, I will share various visual literacy activities with adult learners in the context of second language learning. I will compare qualitative data to the final exams results, to assess their visual literacy skills. I will add to this analysis some comments issued from the discussions taken with cultural mediators and language teachers.

\section{References}

Knowles, M. S. (1990). The adult learner: A neglected species. Building blocks of human potential (4th ed.). Houston [etc.]: Gulf Publishing Company.

St. Clair, R. (2015). Creating courses for adults: Design for learning. San Francisco, CA: Jossey-Bass.

Wright, A. (2004). Pictures for language learning. Cambridge: Cambridge University Press.

Keywords: visual literacy, adult learners, pictures 


\title{
Content Curation for Every-day Life Citizen Journalism and Beyond
}

\author{
Gilbert C. Faure \\ CREM Centre de recherche sur les médiations, Université Lorraine, Nancy, France, gilbert.faure @univ-lorraine.fr
}

\section{Background}

Historically, journalism as well as the printed press was an individual endeavor. Citizen Journalism, that is, collection, analysis and dissemination of news and information by the general public, especially via the Internet, appeared as a rather new concept facilitated by Web 2.0 blogging and social networking. It is mainly associated with special events (e.g., accidents, emergencies) news publication. In parallel, many users of social media prefer that sort of reporting to the classical printed press for local or global news reading, particularly Facebook and YouTube which are reshaping news and information.

\section{Objectives}

Evaluation of Content Curation usage in this "approach", particularly with tools allowing aggregation, elevation, commenting, and posting of information as well as creation.

\section{Methods}

Analysis of Web 2 .0 everyday life journalism by various individuals in France with different usages, and focus principally, but not exclusively, on Scoop.it. This curation tool indeed allows not only collection of information, but also illustration, commenting, and creation, and facilitates sharing on different social networks. It concentrates on individuals being persistently active for many years in this field.

\section{Results}

Some citizens, as their main interest, publish almost daily, news "content hubs" using blogs, social networks and curation to cover in detail local information (e.g., weather, sports, politics, meetings, arts, culture) from a geographical region. Others, either professional or amateur photographers, regularly publish pictures, photos, or videos of their home city, creating visual memories of everyday life for the future, on sites such as Instagram, Facebook, You Tube, Daily Motion. It can be compared to the editorial cartoons in newspapers, also offered on the Internet by their authors. Likewise, others pursue other personal interests (e.g., environment, education, cybersecurity) and/or in their jobs such as librarians, teachers, with magazine-like coverage of web information about their city, community, metropoles or country. Administrative groups sometimes do it with the same tools regarding local information. Audiences and followers of such "content hubs" can be very significant, reaching thousands of posts and hundreds of thousand views.

\section{Discussion}

Citizen journalism, through selecting, framing and amplifying information should be recognized as a publishing act. They are documenting everyday life, editorializing, usually in a positive way, local interesting information (e.g., cultural, economical) deserving, indeed, memorization and archiving. They participate actively in so-called place branding, a recent concern, covering as much as, or even more material than tourism offices or local and regional development agencies. They sometimes maintain this activity more consistently over time than official instances submitted to organizations. These individual persistent bloggers and curators are sometimes retired people from various professions actively involved benevolently in the life of their area. Some are researchers, educators, librarians and others, complementing their mandatory day-to-day follow-up of their own professional interests. However, they all share psychological qualities making them efficient information specialists, collectors and archivists sharing their work and findings, such as curiosity, tenacity and altruism.

\section{Conclusion}

Individual citizens reinvent journalism using social networks and curation tools, publishing either local daily news or web-magazines and building content hubs and archives of information related to everyday life of territories.

Keywords: content curation, citizen journalism, place branding, social networks 


\title{
Incorporating Information Literacy Threshold Concepts into Disciplinary Instructional Contexts
}

\author{
Samantha Godbey \\ University of Nevada, Las Vegas, NV, USA, samantha.godbey@unlv.edu
}

In 2015, the Association of College and Research Libraries (ACRL) officially filed the Framework for Information Literacy for Higher Education (Framework), which offers a set of "interconnected core concepts" and takes a conceptual approach to information literacy instruction that contrasts with the standards (the internationally-adopted Information Literacy Competency Standards for Higher Education) it replaces. Since early drafts of this document, librarians have participated in discussion and inquiry about how to apply the six core concepts in the Framework to their particular professional contexts. In this presentation, I share highlights and themes from an edited volume in which over 30 academic librarians describe their experiences with engaging with the concepts from the Framework in their instruction and beyond (Godbey, Wainscott, \& Goodman, 2017). The authors included in this volume provide instruction and support research in a variety of disciplines, including the humanities, social sciences, life sciences, and physical sciences, with a range of students, from first-year undergraduates to doctoral students. The ideas from the Framework are discussed in terms of the defining characteristics of threshold concepts. Contributors describe their experiences with negotiating the core concepts from the Framework and provided suggestions for addressing the six frames within specific disciplines. This narrated slideshow format will be used to provide an explanation of threshold concepts and showcase examples of how information literacy threshold concepts can be used to facilitate deeper student learning that is meaningful and poised for learning transfer. Attendees will acquire ideas for instruction and assessment of the core concepts in the ACRL Framework and identify additional resources for further reading on this topic.

\section{References}

Association of College and Research Libraries. (2015). Framework for information literacy for higher education. Retrieved February 15, 2018 from http://www.ala.org/acrl/standards/ilframework

Godbey, S., Wainscott, S. B., \& Goodman, X. (Eds.). (2017). Disciplinary Applications of Information Literacy Threshold Concepts. Chicago: Association of College and Research Libraries.

Keywords: ACRL Framework, information literacy, instruction, threshold concepts 


\title{
Visual Resources and Social Media: Leveraging Everyday Practices to Teach Information Literacy
}

\author{
Chelsea Heinbach \\ University of Nevada, Las Vegas, NV, USA, chelsea.heinbach@unlv.edu \\ Krystyna K. Matusiak \\ University of Denver, CO, USA, krystyna.matusiak@du.edu
}

Visual literacy represents a set of essential competencies for students in academic and everyday information contexts (ACRL, 2011). Being surrounded by visual media does not necessarily mean that students know how to find appropriate images, understand their meaning and cultural context, and provide adequate image attribution in their academic work. While information literacy emphasizes citation guidelines for textual resources, students are rarely given the opportunity to understand citation contextually, and visual materials are often overlooked in library and classroom instruction. This paper presents a research project on students' visual literacy skills and asks how we might leverage students' expertise in social media etiquette to teach information literacy.

This project builds upon a previous empirical study where the researchers used the Consensual Qualitative Research method to examine university students' visual literacy skills by investigating the way students use images in academic work (Matusiak, Heinbach, Harper, \& Bovee, in press). The findings of the study, which included questionnaires, interviews, and content analysis of visual evidence, indicate that students treat images differently than text resources, especially in regard to ethical and legal aspects of use. While students use a variety of visual resources in their presentations, they rarely check sources or understand that images require attribution. However, in everyday activities on social media platforms such as Facebook, Instagram, and Twitter, students thrive in a visually rich environment and unknowingly practice visual literacy skills.

For example, Instagram etiquette includes practices such as "DO: Ask for permission before reposting someone else's photo!" and "DON'T: Use someone else's photo without tagging them." (Haupert, S, 2017). Instagram users frequently "cite" other accounts when reposting by tagging their username. Creators of memes include a watermark of their username to discourage others from stealing it without attribution. Users reuse, remix, and create new images at ease. These are prime examples of ACRL Visual Literacy Competency Standards for Higher Education and these practices have developed organically by users in these communities. Instructors and librarians can use student experiences in the social media environment to encourage transfer of skills and ethical behaviors to an academic setting.

Using the findings of the previous study as a starting point, the presenters will discuss the visual literacy skills that students struggle with and explore practical methods to address them by leveraging practices occurring on social media in everyday life.

\section{References}

Haupert, S. (2017). Instagram etiquette: Do's and don'ts. Retrieved May 4, 2018 from https://bloguettes.com/instagram-etiquettedos-donts/

Matusiak, K. K. et al. Visual literacy in practice: Use of images in students' academic work. College \& Research Libraries [Accepted for publication].

Visual Literacy Standards Task Force. (2011). ACRL visual literacy competency standards for higher education. Retrieved May 4, 2018 from http://www.ala.org/acrl/standards/visualliteracy

Keywords: visual literacy, everyday life practices, ACRL framework, social media 


\title{
Access to Information as Prerequisite for Information Literacy Skills: Case Eritrea-Finland Cooperation Project in Higher Education
}

\author{
Päivi Helminen \\ University of Helsinki, Helsinki, Finland, paivi.helminen@helsinki.fi
}

Joint development projects between libraries provide excellent opportunities to compare work and to learn from each other. At the Helsinki University Library, we gained experience in joint projects with African libraries. Helsinki University Library and Eritrea Institute of Technology had a joint Digital Library Services project between December 2015 and June 2018. The project was funded by the Ministry for Foreign Affairs of Finland.

The main aim the project was to improve learning and teaching by providing a better access to information. In the first phase, the project concentrated on basic infrastructure: equipment, library system, and access to e-resources and printed materials. Development of a basic infrastructure was essential because power cuts were frequent and the slow internet connection prevented the use of open access online materials. Therefore, offline e-resources were purchased. In the later stage of the project, the importance of developing information literacy skills was more apparent. The project clearly revealed how information literacy education should be integral part of the curricula and dependent on the teaching methods and traditions. The new offline e-resources enabled the adoption of new teaching methods but change process takes time and the project period has not been long enough the measure the change in learning outcomes.

\section{Mutual Learning}

In the project, we noticed that academic libraries with huge differences share common issues and benchmarking was an eye-opening experience for all participants. Helsinki University Library benefitted from the project in many ways: it forced the Finnish experts to learn more, to acquire more international contacts, and to learn to be content with the services in their own university and to concentrate on developing those.

In my PechaKucha presentation, I will present lessons learned in the project both in Eritrea and in Finland. I will also discuss how the experiences can be applied to in future projects and everyday work.

Keywords: Eritrea, Africa, Finland, digital library services, development projects, development cooperation, mutual aid 


\title{
Trust, Engagement, and the $21^{\text {st }}$ Century Learner
}

\author{
Martha J. Hoff \\ University of Rochester, Rochester, NY, USA, martha@mhoff.org, martha.hoff@warner.rochester.edu
}

Today's youth have cell phones/smart phones in their bags and back pockets. With mobile technology seemingly ubiquitous and youth actively engaged with those devices, we make the assumption that they are currently involved, ready, and willing to engage in a wide range of new spaces. Digital spaces are built upon the concept of participatory cultures-a willingness to participate, cooperate, and collaborate with others not known to us in a physical sense (Jenkins, 2006). Little is known about how low social-economic status youth navigate within and across on- and offline spaces. This paper draws on sociological theories of generalized trust (Glanville, Anderson, Paxton, 2013) and new literacies (Knobel \& Lankshear, 2014) to examine the impact that trust/distrust had on the digital space engagement of six low income, urban youth, 16-18 years of age, who self-identified as active users of mobile technology. Participants were observed, interviewed, kept journals, and had remote monitoring software installed on their devices.

While mobile technology can lead us to doors that open into new spaces and places, the how and why of one's trust, determines not only if that door is opened but the type and level of engagement and interaction entered (Nepal, Sherchan, \& Paris, 2012). When distrust is present, the ethos of participatory cultures (engage, participate, collaborate, cooperate, and disperse knowledge) is undermined. Distrust represents strong negative feelings and insecurity about individual's motivation, intention, and behavior; the individual is not willing to expose him/her self to or depend on others with any sense of confidence (Chang \& Fang, 2013). Low trust and distrust, bifurcations of trust, have different implications for the engagement and collaborative processes in both on and offline spaces. We cannot assume that because youth have technology and seemed to be constantly engaged with it means they are willing to participate, collaborate, cooperative in all places and spaces. To realize the benefits of mobile learning and online and classroom spaces characterized by collaboration, social connection, and distributed knowledge, we must acknowledge the diversity of engagement. Understanding why and where an individual's trust/distrust is situated is important to understanding how and why they choose to engage in online spaces as well as why they engage/disengage and succeed/flounder in both formal and informal learning spaces.

\section{References}

Chang, Y. S., \& Fang, S. R. (2013). Antecedents and distinctions between online trust and distrust: Predicting high- and low-risk Internet behaviors. Journal of Electronic Commerce Research, 14(2), 149-166.

Glanville, J. L., Anderson, M. A., \& Paxton, P. (2013). Do social connections create trust: An examination using new longitudinal data. Social Forces, 92(2), 545-562.

Jenkins, H. (2006). Fans, bloggers, and gamers: Exploring participatory culture. New York: NYU Press.

Knobel, M., \& Lankshear, C. (2014). Studying new literacies. Journal of Adolescent and Adult Literacy, 58(2), 97-101.

Nepal, S., Sherchan, W., \& Paris, C. (2012). Building trust communities using social trust. In L. Ardissono, \& T. Kuflik (Eds.), Advances in User Modeling (pp. 243-255). Berlin: Springer.

Keywords: trust, distrust, engaged learning, participatory cultures, diversity of engagement 


\title{
The Algorithmic Intersection of Scholarly Communication, [Un]informed Citizenship, and Information Literacy: The Preprint as a Case Study
}

\author{
Christopher Hollister \\ University at Buffalo, Buffalo, NY, USA, cvh2@buffalo.edu \\ Robert Schroeder \\ Portland State University, Portland, OR, USA, schroedr@pdx.edu
}

Efforts to globalize and democratize scholarly information are being deterred in a variety of ways: intimidation, disregard, censorship, and perhaps most insidiously, the deployment of biased algorithms. We live in a time that permits instantaneous transmission of information to billions of people and their devices worldwide, and yet that information is being funneled through and even manipulated by a small number of algorithmically engineered information service colossi: namely, Google, Facebook, Twitter, and the like. These services rely on clicks to generate revenue. Herein resides the problem: The nature of scholarly communication is unsensational, which does not align with the click-driven models of major information services. The leading sponsors of these services are commercial and political interests, which characteristically produce more biased, sensationalized, and clickable content that is packaged and algorithmically transmitted to predetermined information consumers. Ultimately, the citizenry is affected by virtue of the biased information pipeline that leads to its communication devices, and by the authoritative information that fails to connect. This is the new reality and it is incumbent upon librarians, with their information literacy expertise, to help the citizenry in recognizing this dynamic and its consequences.

The community of researchers and scholars is generally charged with producing information for the advancement of local and global communities in ways that impact and positively change the world. However, the means for communicating scholarly information, originally developed to leverage the benefits of the digital research environment, are being subsumed and manipulated by major information services and their algorithmic forms of information dissemination. Consider the preprint, for example. Formerly a print-based version of a peer-reviewed journal article given to authors to distribute among their colleagues, the preprint has morphed into an online paper, yet to pass through mitigating peer review or editorial processes, but posted on an open access repository. As a result of its free accessibility, the preprint is easily discovered and shared among a variety of information consumers, academic and non-academic alike. Importantly, there is an assumed credibility given to scholarly papers; to laypersons, they might represent legitimate research findings or other facts that could potentially influence their views. Furthermore, commercial and political interests often sponsor the research behind the production of preprints. Therefore, there is great potential danger with unvetted preprints that are captured and algorithmically broadcasted across high visibility information services.

The presenters will argue that the work of librarians includes more than traditional information literacy instruction. In the algorithmically manipulated digital environment, that work also includes activism, advocacy, and dedicated work to renovate the system of scholarly communication.

\section{References}

Anderson, K. (2017). Puppetmasters - Who is pulling the string in the new information economy? The Scholarly Kitchen. Retrieved February 3, 2018 from https://scholarlykitchen.sspnet.org/2017/11/13/puppetmasters-pulling-strings-new-information-economy/

Keywords: scholarly communication, preprints, information services, algorithms, citizenship, information literacy, activism 


\title{
The Survey of Information Literacy among Pupils and Teachers in Junior High School
}

\author{
Kazuyuki Sunaga \\ Kokugakuin University, Tokyo, Japan, sunaga@kokugakuin.ac.jp
}

\section{Information Literacy in Japan}

The Ministry of Education, Culture, Sports Science and Technology (MEXT) in Japan published the policy and guideline of information literacy in June 2002. However, there are few school teachers who consider information literacy even though they perform often cross learning, because most of them rarely get an opportunity to learn information literacy. The aim of survey of information literacy is to clarify the information skills which teachers want to teach their pupils, and the information skills which the pupils expect to learn. It will be useful for improving the instructive methods of information literacy in the future.

\section{Questionnaires Related to Information Literacy}

We have already conducted two questionnaires related to information literacy. The first was among university students and teachers in Japan two years ago and the second was among pupils and their teachers in senior high school located in the suburbs of Tokyo last year. This year we distributed the same questionnaires among pupils and teachers in junior high school in the suburbs of Tokyo. Questions were about what teachers and pupils consider information literacy, which skills they themselves require acquiring, and which skills teachers will teach to their students. The purpose of this questionnaire is not to judge the abilities of teachers and students concerning information literacy, but to consider their interests and necessities.

This year's survey focuses on the relevance of teacher's' teaching style and pupil's' learning style concerning information literacy in a junior high school. The critical questions are, which skills teachers $(\mathrm{N}=26)$ will instruct to their students and which skills the students $(\mathrm{N}=427)$ will acquire. Information skills we adopted in the questions for teachers and pupils are mainly based on the PLUS model published by James E. Herring in 1996 and 2010. The model includes four steps: Purpose, Location, Use, and Self-evaluation.

Van Dijk and Van Deursen (2014) argued that less attention has been paid to information skills, the ability to search, select, and evaluate information in digital media. When pupils and students become adults and work in society, it is important to explore, select and evaluate information. We would like to improve the teaching method by analysing the surveys. We will reflect on the results of the analysis in information literacy education.

\section{References}

Herring, J. E. (1996). Teaching information literacy skills in schools. London: Library Association.

Herring, J. E. (2010). Improving students' web use and information literacy: A guide for teachers and teacher librarians. London: Facet Publishing.

Van Deursen, A. J. A. M., \& Van Dijk, J. A. G. M. (2014). Digital skills: Unlocking the information society. New York: Palgrave Macmillan.

Keywords: information skills, survey, teachers, pupils, junior high school 


\title{
A Literature Review on the Linkages between Digital Inclusion and Information Literacy
}

\author{
Sharon Wagg, Louise Cooke and Boyka Simeonova \\ Loughborough University, UK, \{s.wagg, 1.cooke, b.simeonova \} @lboro.ac.uk
}

Digital Inclusion (DI) is of global importance as government digital-by-default agendas increasingly recognise the need for society to possess strong digital skills and capabilities to fully benefit from living in a digital world. At a national level, 4.8 million UK adults (9.2\%) had never used the Internet in 2016 (ONS, 2016); and 28\% of rural areas in the UK remain without mobile coverage (Ofcom, 2015). But, as stated by Anderson and Johnston (2016), the development of "information literacy (IL) is a vital enabling factor in ensuring that the benefits of digital participation in society, the economy and education are fully realised" and without it "the benefits of digital participation will be significantly diminished" (p.8).

In an aim to explore how DI and IL have been linked and to understand how IL encourages digital participation and increased levels of DI, a systematic literature review was performed. The review was conducted on journal literature and conference proceedings, excluding PhD theses and book chapters reporting primary research published worldwide in English language sourced from the Web of Science and Scopus databases and Google Scholar. Search terms included combinations of the phrases information literacy, digital inclusion, digital participation, digital inequalities, digital divide, mobile technology combined with keywords communities, and inclusion, appearing in the topic. Using a combination of the search terms, 90 journal articles were accepted in the final set, once duplicates, non-English language, and articles with limited relevance were excluded.

Thematic analysis was used to categorise the studies and to identify and refine themes and sub-themes for coding. The researcher then revisited the analysis to incorporate constructs from Activity Theory (Engeström, 1987) to reveal a deeper understanding of the literature including contradictions and tensions.

Preliminary results identified from the review reveal that there is limited, fragmented research where the concepts of IL and DI have been brought together, and so warrants further research to nurture a robust understanding. The review is therefore of importance for future research in both digital inclusion and information literacy domains and the common area between both concepts, and will recommend a future research agenda for further exploration of this research topic.

This review is particularly of importance since it will help us understand the diversity and best practice of DI initiatives; the benefits gained by those who were previously digitally excluded and information poor; and the extent to which they develop critical thinking and information literacy.

\section{References}

Anderson, A., \& Johnston, B. (2016). From information literacy to social epistemology: Insights from psychology. Cambridge: Chandos Publishing.

Engeström, Y. (1987). Learning by expanding: An activity-theoretical approach to developmental research. Helsinki: OrientaKonsultit.

Ofcom. (2015). Connected nations report 2015. Retrieved July 27, 2017 from https://www.ofcom.org.uk/_data/assets/pdf_file/0028/69634/connected_nations2015.pdf

Office for National Statistics. (2016). Statistical bulletin: Internet users in the UK: 2016. Retrieved July 27,2017 from https://www.ons.gov.uk/businessindustryandtrade/itandinternetindustry/bulletins/internetusers/2016

Keywords: digital inclusion, information literacy, technology 


\section{POSTERS}




\title{
Digital Literacy Competencies of English Teachers in Kuwait Schools
}

\author{
Reham AlHuraiti \\ University College London, UK, reham.alhuraiti.17r@ucl.ac.uk
}

\section{Background and Aim of the Study}

Digital literacy is an important characteristic of today's education systems and policies, aiming to enable students to adapt effectively to contemporary environments. Digital literacy includes using technologies to recognize information needs, identify sources of information, utilize information from a range of sources and formats, connect new information to old knowledge, and transfer knowledge from one setting to another via digital platforms effectively, efficiently, and ethically (Bawden, 2001; IFLA, 2017; O'Brien \& Scharber, 2008). In Kuwait, as in other countries, the government intends to develop digitally literate students through the education system. The objective of this policy is to contribute to the development of an educated population which is able to successfully participate in the new knowledge economy. This Masters-level research explores how teachers of English in Kuwaiti schools have responded to this new requirement, and how they incorporate digital technologies and approaches in their teaching practice, in order to provide guidance to stakeholders about how digital literacy can be further developed across the schools sector in Kuwait.

\section{Methods}

A qualitative approach was adopted in this study. To realize the research goal, the researcher conducted interviews using a purposive sampling technique, 34 English schoolteachers in Kuwait were selected from different levels of schools (primary, secondary and high school), to examine their digital literacy capabilities. The interviews were mainly conducted via international calls and recorded for analysis. They were then anonymised, transcribed, and read through carefully to identify themes and patterns in the responses.

\section{Outcomes}

The results showed that digital literacy is a new concept in learning and teaching amongst these participants. The study found that most of the teachers who took part in the study were computer literate or possessed digital skills but were not digital literate. Although most of the participants were aware of the benefits associated with integrating technology in teaching, the uptake of digital programmes in Kuwait schools was still low. This fact was attributed to lack of resources and digitally illiterate teachers. Nevertheless, the study found that several attempts were being made by teachers to integrate technology in their teaching practice. To conclude, the study recommended a comprehensive national sector-specific digital literacy strategy that encompasses all facets of learning for Kuwait schools.

\section{References}

Bawden, D. (2001). Information and digital literacies: A review of concepts. Journal of Documentation, 57(2), $218-259$.

IFLA. (2017). IFLA statement on digital literacy. Retrieved March 22, 2018 from https://www.ifla.org/publications/node/11586

O'Brien, D., \& Scharber, C. (2008). Digital literacies go to school: Potholes and possibilities. Journal of Adolescent \& Adult Literacy, 52(1), 66-68.

Keywords: digital literacy, curriculum, pedagogy, school, teacher, Kuwait 


\title{
Media Education Technologies in Developing Students' Professional Competence
}

\author{
Volodymyr Biletsky
}

National Technical University 'Kharkiv Polytechnic Institute', Kharkiv, Ukraine, ukcdb@i.ua

\author{
Anna Onkovych \\ Kyiv Medical University, Kyiv, Ukraine, onkan@ukr.net

\section{Olha Yanyshyn} \\ Ivano-Frankivsk National Technical University of Oil and Gas, Ivano-Frankivsk, Ukraine, \\ yanyshyn_olha@nung.edu.ua
}

Our goal is to draw attention to using new media education technologies — social networks-based 'pedagogical' author's pages, Knyhospalah didactics, Wikididactics — in the professional training of university students.

The analysis of the issue-relevant research shows that media education technologies and techniques proved their effectiveness in training professionals to-be (economists, editors, IT specialists, petroleum engineers, and translators) in Ukrainian higher education (Onkovych et al., 2013; Yanyshyn, 2014). We define 'pedagogical' author's pages for education and self-education at social networks (blogs and social networking sites) as 'pedagogical blog-didactics', 'scientific blog-didactics', or 'pedagogical scientific blog-didactics'. Kept by practical educators, they are a professionally-oriented and effective way to inform students and colleagues of innovative know-how and applied methods of scientific cognition, to perform research and to improve cognitive and personal competence. The term 'Wikididactics' concerns another branch of media education - Internet technologies (Onkovych, 2017) dealing with using Wikipedia articles in the education process and involve the concepts 'wiki-media developer', 'wikipedists', 'wikiteacher', and 'wiki-didacticist'. Such processes are monitored on the Facebook-page 'WICIDIDACTICS' ('ВІКІДИДАКТИКА'1). New Ukrainian Facebook-pages 'Education by the Specialty 'Petroleum Engineering and Technology' ('Освіта за спеціальністю 'Нафтогазова інженерія та технологіі' $)$ and 'Petroleum Education' ('Нафтогазова освіта' ${ }^{3}$ ) aim at making petroleum engineering education popular in Ukraine and are first 'pedagogical pages' kept by 'techies' groups. They feature multi-media didactics and Internet didactics, are integrative, cover a wide range of disciplines concerning petroleum engineering and technologies, use English chat for fast real-time text messaging, enable online lectures and link to various online courses on several platforms, though substantially differ from the international site 'Drillers Club Knowledge Box'4.

As the analysis of the Ukrainian national experience shows, media education technologies and self-elaborated media education techniques, social networks-based 'pedagogical' author's pages, 'pedagogical blog-didactics', 'scientific blogdidactics', Knyhospalah didactics, and Wikididactics proved effective in the professional training.

\section{References}

Onkovych, G. et al. (2013). Media didactics in higher school: Courses curricula. Kyiv: Логос.

Onkovych, G. (2017). New in media education: Wikididactics. In S. Špiranec et al. (Eds.), The Fifth European Conference on Information Literacy (ECIL): Abstracts, September 18-21, 2017 (p. 250). Saint-Malo: Information Literacy Association.

Yanyshyn, O. K. (2014). Enhancing would-be translators' information and technological aspects of media literacy by using the web resource citation machine. Zhytomyr Ivan Franko State University Journal, 75, 97-103.

Keywords: information literacy, professionally oriented media education, media education technologies, higher education media didactics, pedagogical blog-didactics, pedagogical scientific blog-didactics, Wikididactics

\footnotetext{
${ }^{1}$ https://www.facebook.com/groups/1796426670616724/

2 https://www.facebook.com/groups/145315129579851/?hc_location=group

3 https://www.facebook.com/groups/866495553505940/about/

${ }^{4}$ https://www.facebook.com/groups/drillersclub/about/
} 


\title{
The Role of Academic Libraries in Teaching Information Literacy: From the Students' and Professors' Perspective
}

\author{
Mojca Brenko-Puzak and Lahorka Crnković \\ University of Zagreb, Croatia, \{mbrenko, lcrnkovic\}@fpz.hr
}

This poster deals with the idea of incorporating information literacy courses into university education through the library. Since information literacy is the basis of lifelong learning, it is naturally closely connected to the sphere of education. Experts in the field of information (i.e. librarians) should teach students how to recognize their need for information, and then how to find, evaluate and use credible information - a vital skill which will, in turn, make them better experts in their own respective fields.

The first part of the paper introduces the four ways in which information literacy can be taught in universities with the help of libraries and library staff (as an entire standalone university course, as a valuable part of a university course, as an addition to a university course, or as an online or face-to-face library program outside of class).

The second part of the paper presents two studies carried out among the students and the professors of the Faculty of Transport and Traffic Sciences. The studies aimed to discover the needs and attitudes towards the role of academic libraries in teaching information literacy.

The students were asked what sources and strategies for information gathering they use, whether it's hard for them to find and recognize useful information, whether they know about and use the library databases offered to them, and how much they know about (and respect) the rules when it comes to plagiarism, ethics and proper ways of citing sources. In the end, they were asked whether they believe their library can and should help them in developing this set of skills further, and which type of education they would prefer (a lecture, a class, or an online set of tutorials).

The professors were asked whether their students' efforts successfully meet their expectations, whether their students use information efficiently and ethically, and whether they would be interested in joining the library to help students build information literacy skills - in which case, whether they would be open to leaving some room in their syllabi for a visiting lecture on information literacy by the library staff.

At the moment, the Faculty does not have an organized education program for its students. The results showed to what extent the students and professors value the importance of information literacy, how much they already know about it, and whether they are interested in collaborating with the library. This will be helpful in determining the further course of action for the staff members, as well as in helping to build a collaborative learning environment between the library, the students, and the employees.

Keywords: academic libraries, higher education, information literacy programs, learning 


\title{
An Academic Library as a Partner in LIS Students' Education
}

\author{
Hana Holoubková \\ Central Library of the Faculty of Arts of Masaryk University, Brno, Czech Republic, holoubkova@phil.muni.cz
}

This poster introduces an example of a good practice where an academic environment connects with an academic library practice within library and an information science (LIS) development. By creating a compulsory subject for LIS students, a library participates in the educational process of future librarians. The library itself has access to professional news and trends through students' knowledge and provides feedback. Due to the synergistic effect of this connection, it builds new knowledge on both sides, which brings benefits to the users in particular.

The Central Library of the Faculty of Arts of Masaryk University (CL) has been cooperating with the Division of Information and Library Studies for a long time and moreover, it has been involved in teaching their students. The students in the fourth and fifth semester of the Bachelor degree program pass a compulsory practical training in the subject of Reference Services (RS) 1 and 2 in the CL. They participate actively in the CL operation, help with its running and get to know library services in practice, its users and their information needs.

The range of the subjects is are learned in 25 hours of a guided practical training in one week for three credits. Each week of the semester there are 2 to 3 students at the same time in the library. There are approximately 50 students per semester. The students hold a position of reference librarians and fully replace them. Each student has their own mentor who trains them at the beginning of the training and is available to them throughout the training. The mentors are permanent reference librarians.

Part of the training is also an individual task, a search on a given topic that is based on the CL's current needs. An introductory lecture precedes the training at the beginning of the semester. The lecture for the RS1 students introduces a library catalogue, library services, databases and soft skills. The students of the RS2 have to get familiar withlearn about citation databases and predatory journals and publishers.

The aim of the RS1 is to enable students to acquaint with an environment of a particular academic library and apply the knowledge gained in other subjects in practice. After completing the training, the students should be able to:

- $\quad$ be well aware of the CL's collection and services

- $\quad$ orientate themselves in electronic resources of Masaryk University

- deal with information requests of users

- conduct a reference interview

- discuss chosen issues related to academic librarianship

The aim of the RS2 is to deepen the students' competencies in the reference librarian skills mentioned above.

Ongoing students' assessment is based on their attendance, quality of their work and the individual task.

At the end of each semester the students have an opportunity to comment on the training in an evaluation questionnaire. Results of the questionnaires from the spring and autumn semester 2017 show that 79\% (23/29) of respondents perceive the RS1 as beneficial but only $41 \%$ (7/17) of respondents evaluated the RS2 positively. A 5-point scale was used. The lower rating of the RS2 is, among other things, probably influenced by the higher difficulty of the individual task. For most of the students this practical training is the only way to become familiar with the library and its services from inside the institution. We modify the form of the subjects every year following the students' feedback.

Keywords: LIS students, academic libraries, practical training 


\title{
Developing Data Literacy and Research Data Management in University of Eastern Finland Library
}

\author{
Anne Karhapää, Katja Hyvärinen and Kaisa Hartikainen \\ University of Eastern Finland, Kuopio, Finland, \{anne.karhapaa, katja.hyvarinen, kaisa.hartikainen\}@uef.fi
}

Data policy of the University of Eastern Finland (UEF) aims at promoting open science and data management. Open data advances research and enables efficient reuse of research data. However, open data is useless without mature metadata and data literacy skills by the potential users of data. This poster describes how data literacy and research data management skills and services are developed in the University of Eastern Finland Library (UEF Library).

The library supports the researchers in all phases of research data management; planning, documenting, storing, and sharing data. The library is currently building a metadata repository for research data. Researchers can store and open data in national or international data repositories. The metadata repository of the University (UEF eRepository) will harvest the metadata from different sources and services.

The library has strongly focused on improving research data services and data skills of librarians in recent years. Some of the library work has been reorganized and teamed up, and some new recruitments were made related to open science and open research data. Research Support Team specialises in offering services to researchers. Research data management is also increasingly included in the work of subject librarians.

In this poster we will give an overview on developing data skills in the UEF Library. Firstly, reskilling the library staff is crucial to take on the new data related tasks. Librarians have enhanced their data skills in national seminars and through national and international open materials. Collaborative training and learning has been significant in the process of learning. The library's internal training to further enhance the data skills of librarians begun in January 2018 . It consists of Skype meetings, independent study of discipline specific knowledge and collaborative work. Information technology and research funding experts of the University participate in the training. Thus, the training offers a chance for collaboration and sharing knowledge in developing the data services of the University.

In order to improve open science and data management skills, the library offers tailored training to the university staff. The training of the researchers in 2018 focuses especially on how to open research data. For graduate students the library offers a Research Information Retrieval and Management course where one of the seven modules concentrates on research data. The library offers subject specific courses on information retrieval for master degree students and open science is included in the content of the course.

Keywords: data literacy, research data management, data skills, open science, open data 


\title{
Let Them Bloom! The Library Cultivating New Ground for Learning in Third Space
}

\author{
Riitta-Liisa Karjalainen, Eerika Kiuru, Arja Kunnela, Elina Laineenoja, Mari Mäkynen and Sanna \\ Savolainen \\ Pedagogy Working Group, AMKIT-Consortium, Finland, riitta-liisa.karjalainen@kamk.fi, eerika.kiuru@ hamk.fi, \\ arja.kunnela@jamk.fi, elina.laineenoja@samk.fi, mari.makynen@tritonia.fi,sanna.savolainen@oamk.fi
}

In the digital age, learners are not to be abandoned. The web is attractive and addictive but also distancing and isolating. The library offers a safe physical and digital space where learners and teachers can meet while the information specialists support growth in learning by providing online guidance.

The digitalization of library collections and services emphasises the importance of libraries in a new way. For example, with data curation, digital collections are being opened and displayed 24/7. Learning requires the right information and at the right time, when students need it. Within the data curation process, the information specialist works in partnership with teachers. National strategies and the digital planning of educational institutions are also increasing the demand for digital materials and online guidance in using them (Ministry of Education and Culture, 2017a; 2017b).

Thus, a third space between teaching and the student's world of experience and home is being created (Kuhlthau, 2015). The library as a third space becomes a transformable online and physical facility between personal service provision, the student's experience and curriculum-based teaching. Flexible services and different types of learning support solutions create more space for growth in learning. Flexibility makes room for the key focus, which is learning.

Digitalization and advanced technology can challenge libraries to build learning in the third space of a student. New tools need to be taken in use for both learners and tutors. The various contents will be offered during both face-to-face sessions and in distance delivery through virtual meetings and online activities, for example different kinds of recorded tutorials. The cooperation with the teachers integrates the library into the teaching.

The University of Applied Sciences Libraries Consortium in Finland (2018) is developing online pedagogy in a condition of transformation within and across its member institutions. Good practices and sharing expertise are taking root in the daily work through collaborative working methods. The future with more students studying online across several universities of applied sciences (for example eAMK) challenges us to continuous change and transformation. We just have to make sure that students and their learning can bloom.

\section{References}

Kuhlthau, C. C., Maniotes, L. K., \& Caspari, A. K. (2015). Guided inquiry: Learning in the 21st century (2nd ed.). Santa Barbara, CA; Denver, CO: Libraries unlimited.

Ministry of Education and Culture. (2017a). Korkeakoulujen digitaaliset oppimisympäristöt. Retrieved February 14, 2018 from http://minedu.fi/digitaaliset-oppimisymparistot

Ministry of Education and Culture. (2017b). Vision for higher education and research in 2030. Retrieved February 14, 2018 from http://minedu.fi/en/vision-for-higher-education-and-research-in-2030

University of Applied Sciences Libraries Consortium in Finland. (2018). AMKIT Consortium website. Retrieved February 14, 2018 from http://www.amkit.fi/en/

Keywords: University of applied sciences libraries, online guidance, flexible learning, digital collections 


\title{
Making it Together: Information Specialist and Toxicologist Developing Students' Professional Information Skills
}

\author{
Heikki Laitinen, Risto O. Juvonen and Jarmo Saarti \\ University of Eastern Finland, Kuopio, Finland, \{heikki.laitinen, risto.juvonen, jarmo.saarti\}@uef.fi
}

\section{Introduction}

Continuous improvement of the information literacy of toxicology students is vital for active learning and development during their degree studies and professional life. General toxicology is a specialized multi-science discipline dealing with adverse human health effects of chemicals and physical factors. The amount, versatility, continuous updating, and accessibility of toxicological information pose challenges for teaching and study and lifelong learning. We teach toxicological information literacy to our international students in the Degree programme of General Toxicology in the University of Eastern Finland, aiming to tackle these challenges.

\section{Objectives}

Information specialists of the library and toxicologists of the School of Pharmacy provide practical teaching. Our present instruction is organized into two different courses. In the beginning of studies there is a basic information skills course. In this course students learn how scientific and professional information is published. They also familiarize themselves with basic skills in information retrieval. Other important issues include the critical assessment of retrieved information, ethical principles of science, and the principles of copyright. After students have gained more knowledge in toxicology, they take an advanced information skills course. They also learn the structure of scientific review and original papers, including reference management. After the course the students will also be aware of the advantages of open science including open publishing.

\section{Implementation}

The contact teaching takes place in computer classrooms to provide individual training online. Support material is offered via Moodle. To improve learning the students are required to do personal exercises related to databases and homepages introduced during the course. Finally, students' analysis, evaluation and summarizing skills are assessed from their structured essays about information literacy of toxicology.

According to the course feedback and assessment of their exercises and essays, the students have improved their skills in database searching and in utilizing the information content of homepages. However, feedback indicated overlap between the basic and advanced course. Thus, we have decided to combine these two courses into one new course. The other advantages of integrated approach include better integration of information skills with the progression of toxicological knowledge.

The new course will begin with an introduction to basic toxicological concepts and the societal importance of chemical safety (non-toxicity) and will continue the whole term. Students will learn information skills simultaneously coordinated with subject studies.

\section{Conclusions}

It is important for library and toxicology professionals to work mutually with students. Toxicological information and its management is continuously expanding. This emphasizes the need for close collaboration in updating information literacy skills.

Keywords: toxicology, information literacy, information skills, library, collaboration 


\title{
Analysis of Teaching Design and Teaching Effect in Patent Application and Utilization Skills Course
}

\author{
Ling Li and Dongrong Zhang
}

National Science Library, Chinese Academy of Sciences, Beijing, China, \{liling, mailto:zhangdr $\} @$ mail.las.ac.cn

\section{Course Background}

Patent literature is an important aspect, both for technological inventions and for scientific research. Patent application and utilization skills, started in the fall semester of 2017, and is a new course specially designed for the graduate students in the Chinese Academy of Sciences (CAS), with 36 hours and one credit. Including many practice cases, this course provides a new type of information literacy course for graduate students.

\section{Teaching Objectives}

This course can help students master basic knowledge of patents, learn the patent application process, and help them learn how to use the mainstream patent databases and analysis tools to uncover the value of patent literature.

\section{Course Design}

This course consists of five parts:

- Basic knowledge of patents: this chapter focuses on understanding the origin and development of the patent system and helps students grasp relevant concepts.

- Patent application strategy: this chapter focuses on preparation, composition, and submission of patent application documents.

- Patent literature retrieval: the method of patent literature retrieval, and the use of commercial databases (Derwent Innovation \& Derwent Innovations Index).

- Patent information analysis: the method of patent information analysis, and the patent information analysis tool (Derwent Innovation \& Derwent Data Analyzer).

- Group practice and presentation.

\section{Course Assessment}

A questionnaire was used to evaluate the effect of the curriculum implementation, and 125 valid questionnaires were collected. The questionnaire survey showed that:

1. $98.6 \%$ of students thought the course was very helpful to his/her study and research.

2. $73 \%$ of students selected this course because of curiosity and interest, followed by scientific research needs, about $30 \%$.

3. $67 \%$ of students think the course is moderate and acceptable; $30 \%$ think it is difficult.

4. Students found patent retrieval most interesting, followed by patent application strategy, and then patent information analysis.

5. Students found patent information analysis most difficult, followed by patent retrieval, and then patent writing.

6. $63 \%$ of students think the course should be taught and practiced in the computer classroom.

Suggestions include strengthening the problem-based learning aspect, increasing case teaching, using small class teaching, increasing school hours and credits, and offering increased numbers of supporting handouts.

\section{Improvement measures}

To meet more students' elective needs, the course will be offered in two semesters. As the class hours cannot be added, the teaching content and the difficulty will be reduced. To promote students' digestion and absorption of knowledge, we will strengthen the problem-based learning, increase the number of case studies, and the practice time.

Keywords: patent application, patent retrieval, patent analysis, course design, course assessment 


\title{
The Role of International Partnerships in Supporting Library-Based Instruction
}

\author{
Mark Mattson \\ Penn State University, PA, USA, mam1196@psu.edu \\ Mirta Matošić \\ University of Split, Croatia, mirta.matosic@svkst.hr
}

In early 2017, the University of Split Library in Split, Croatia and Penn State University in Pennsylvania, USA began a sister-library partnership for the mutual benefit of the participating libraries. In addition to the national and cultural contexts in which the libraries operate, the two partners are quite different in organizational structure, size, and distribution. Rather than acting as a hindrance to collaboration, these differences have, in many ways, enhanced the partnership's utility in that the partners see library functions through different lenses, which allows for new perspectives and discoveries.

Over the course of this first year, the partnership has developed and expanded at an unexpected and exciting pace with the identification of many common areas of interest. One such area of common interest for the two partners is librarybased instruction within the institution. An ad-hoc group was formed with members from each partner institution to explore possible collaboration in this area, and in early 2018, the group decided to move forward with the idea of a joint workshop focused on library-based instruction. The workshop will be held in early June of 2018 at the University of Split Library with both on-site and virtual Penn State participation.

The proposed poster presentation will outline the workshop's planning, execution, and assessment within the context of collaboration on an international scale.

Keywords: sister-libraries, international partnership, library-based instruction 
A Study of Critical Thinking and Metaliteracy Skills of Students on Facebook. A Case Study in Three Francophone Universities

\section{Florent Michelot}

Université de Montréal, CRIFPE, Montréal, Canada, florent.michelot@umontreal.ca

In political, social, and economic the real and the fake are intertwined even among reputable media. If data are more accessible, availability is not free of risk: information abundance becomes a challenge, so much so that this overload is sometimes described as "infobesity" (Sauvajol-Rialland, 2013). Internet is a reality in the daily lives of learners. The social web, such as websites and software designed and developed to support and encourage social interactions (Porter, 2008), appears as spontaneously mobilized. For example, Wikipedia is used by more than $80 \%$ of students (Head \& Eisenberg, 2010). While this is appreciable, Serres doubts that "technical autonomy [leads] miraculously [to] intellectual autonomy" (Serres, 2007, p. 73). According to him, "identifying, discerning, evaluating the origin, reliability, quality and relevance of information is [becoming] one of the most crucial challenges." We suggest a new empirical perspective on information literacy and critical thinking strategies, particularly considering information evaluation reinforcement in metaliteracy frameworks. According to this concept (Mackey \& Jacobson, 2011), a person within an information culture knows how to evaluate information through critical thinking and analysis. Consequently, this poster aims to present a research project that focuses on learners' critical thinking as a resource that enhances metaliteracy skills. Our conceptual framework is based on the social-cognitive approach that suggests that learning is the product of interdependent personal, environmental, and behavioral factors (Bandura, 1986). Particularly, the behavioral dimension gives the possibility to study critical thinking strategies that can be associated with metacognition (Tempelaar, 2006), as a process "think about thinking", as proposed by Flavell (Flavell, 1979). In practice, we propose a comparative case study between learners from Quebec and France at university entrance. Quantitative data collection will mobilize the first two subscales of the Stupple's et al. (2017) Critical Thinking Toolkit (CriTT), that (measures participants beliefs about their his own critical thinking), Kurbanoglu's and al. (2004) information literacy self-efficacy scale (beliefs about his own information literacy), and and the Halpern Critical Thinking Assessment (HCTA) scale (Halpern, 2010). The HCTA scale is used to assess general constructs that define critical thinking. Qualitative data collection will be based on non-participant observation of learners' socio-digital activities and a small number of semi-structured interviews. These interviews will focus on critical thinking strategies on the social web, according to that proposed by Gagnon's grid (2011).

\section{References}

Bandura, A. (1986). Social foundations of thought and action: A social cognitive theory. Englewood Cliffs, NJ: Prentice-Hall.

Flavell, J. H. (1979). Metacognition and cognitive monitoring: A new area of cognitive-developmental inquiry. American Psychologist, 34(10), 906.

Gagnon, M. (2011). Proposition d'une grille d'analyse des pratiques critiques d'élèves en situation de résolution de problèmes dits complexes. Revue recherches qualitatives, 30(2), 122-147.

Halpern, D. F. (2010). Halpern critical thinking assessment: Moedling, Autriche: Schuhfried. Retrieved May 5, 2018 from https://www.schuhfried.com/test/HCTA

Head, A. J., \& Eisenberg, M. B. (2010). How today's college students use Wikipedia for course-related research. First Monday, 15(3). Retrieved from http://journals.uic.edu/ojs/index.php/fm/article/view/2830

Kurbanoglu, S. S., Akkoyunlu, B., \& Umay, A. (2006). Developing the information literacy self-efficacy scale. J. Doc., 62(6),

$730-743$.

Mackey, T. P., \& Jacobson, T. E. (2011). Reframing information literacy as a metaliteracy. Coll. Res. Libr., 72(1), 62-78.

Porter, J. (2008). Designing for the social web. Berkeley, CA: New Riders.

Sauvajol-Rialland, C. (2013). Infobésité. Paris: Vuibert.

Serres, A. (2007). Questions autour de la culture informationnelle. Can. J. Inf. Libr. Sci., 31(1), 69-85.

Stupple, E. J. N. et al. (2017). Development of the Critical Thinking Toolkit (CriTT): A measure of student attitudes and beliefs about critical thinking. Thinking Skills and Creativity, 23, 91-100.

Tempelaar, D. T. (2006). The role of metacognition in business education. Industry and Higher Education, 20(5), $291-297$.

Keywords: research proposal, critical thinking, social-cognitive theory, evaluation, metaliteracy 


\title{
Digital Literacy Beyond Social Media: Undergraduates' Self-Perceived Competence of Academic Digital Skills
}

\author{
Olivia-Dumitrina Nechita, Yolanda Capdevila Tomàs and Montserrat Casanovas Català \\ Universitat de Lleida, Spain, \{o.nechita, y.capdevila, m.casanovas \} @ didesp.udl.cat
}

The aim of this contribution is to present the findings of research in progress conducted at the University of Lleida (Spain) under the framework of New Literacy Studies and, more specifically, in the field of digital literacy. The focus is to describe, analyse, and compare the self-perceived competence of first and fourth year students regarding the use of digital tools for developing written academic tasks.

While the net generation is surrounded by technology and skilled in the social use of digital tools (Corrin, Lockyer \& Bennet, 2010; Gallardo, Marqués \& Bullen, 2015), they lack the ability to use different computer applications and online tools for a wide range of purposes in different situations (Kaminski, Switzer \& Gloeckner, 2009). Previous research has shown that even though technology has been integrated in the classroom (van Braak, 2004), it is still not used effectively for academic purposes.

Data were collected by means of a questionnaire and semi-structured interviews from undergraduates enrolled in primary and/or pre-primary education degrees at the faculty of Education, Psychology and Social Work. Initial findings show that students' confidence with digital technologies and an affinity with the digital environment does not necessarily entail a proficient use of web 2.0 tools when engaged in academic activities such as information search and selection, writing, and proofreading academic texts. Even though their self-perceived competence average is higher than 3.10 (on a 6-point scale), more than $75 \%$ would like to receive additional training in all the aspects they were inquired about. On the other hand, students are most familiar with the communicative aspect of cyberspace so they are more assertive when asked about their ability of generating digital content such as web pages and presentations.

Data has shown that undergraduates lack specific digital skills necessary to develop tasks for academic purposes. Students affirm that they require additional training in information and communication technology (ICT) skills ancillary to course content. In our view, specific formal training is essential since many aspects of teaching and learning are mediated through ICTs (Barnes, Marateo \& Ferris, 2007).

\section{References}

Barnes, K., Marateo, R. C., \& Ferris, S. P. (2007). Teaching and learning with the net generation. Innovate: Journal of Online Education, 3(4). Retrieved from https://nsuworks.nova.edu/cgi/viewcontent.cgi?referer=https://www.google.hr/\&httpsredir=1\&article=1091\&context=innovate

Corrin, L., Lockyer, L., \& Bennett, S. (2010). Technological diversity: An investigation of students' technology use in everyday life and academic study. Learning, Media and Technology, 35(4), 387-401.

Gallardo Echenique, E., Marqués Molías, L., \& Bullen, M. (2015). Students in higher education: Social and academic uses of digital technology. RUSC. Universities and Knowledge Society Journal, 12(1), 25.

Kaminski, K., Switzer, J., \& Gloeckner, G. (2009). Workforce readiness: A study of university students' fluency with information technology. Computers and Education, 53(2), 228-233.

Van Braak, J. P. (2004). Domains and determinants of university students' self-perceived computer competence. Computers and Education, 43(3), 299-312.

Keywords: ICT training, higher education, self-perceived competence, digital learners 


\title{
Co-creating an Engaging Tool for Source Criticism
}

\author{
Daniel Prasius and Martin Gundtoft \\ Copenhagen School of Design and Technology, Denmark, \{dapr, marg $\} @$ kea.dk
}

This project aspires to activate students as co-creators with the purpose of delivering more relevant and useful information literacy education - specifically within the area of source criticism. Our goal is to create an application oriented digital tool that can help students improve critical awareness about relevancy and validity in relation to judging sources for independent study assignments.

The idea for this project is based on a survey among students and educators, indicating that the students at the Copenhagen School of Design and Technology (KEA) have difficulties evaluating the relevance and validity of different types of sources.

KEA is a very 'hands-on' type of institution, where a considerable percentage of the students are untrained in the academic disciplines. This is particularly evident in their use of sources for projects. Sources are often applied indiscriminately without reflection on whether the information comes from blogs, webpages, Wikipedia links, textbooks or peer reviewed scientific articles.

Since the students do not possess the adequate skill set for determining whether or not a source is relevant and valid in a certain context, we set out to create a tool to assist and train them in this discipline. The format was developed in a collaborative effort with other Danish institutions of higher education who pursue the same common goal of using co-creation as a means to create better and more relevant tools and services. The project is financially supported in part by The Danish Research Library Association. Libraries are often perceived as having more of a support function, with the teachers as gatekeepers for the attention of the students. In this project our goal is to target the students directly and tap into their own perceived needs, study practices and preferences.

We recruited students and facilitated workshops using methods like cognitive maps, scenarios and prototyping of both contents and visuals. We also plan to implement a working digital prototype with the intent to produce further learning objects based on the same template and co-creation philosophy.

The tool itself will be conceptually developed and tested in a framework consisting of a combination of methods from the fields of system service design, user experience and usability. The technical implementation will be developed using in-house resources in a simple $\mathrm{html} / \mathrm{css} / \mathrm{js}$ framework with a preliminary deadline for a running prototype this summer.

We imagine using the tool primarily as a part of face to face teaching modules, where students will be introduced to the tool and guided on how to use it with exercises in concrete sources. As a secondary purpose, the tool should be intuitive enough to use without instruction, and the long-term strategy is to create a landing page with similar tools for different areas of learning related to information literacy.

We are aiming at doing a poster session sharing our findings and thoughts as well as giving a hands-on demonstration of the tool.

Keywords: co-creation, source criticism, digital learning object, education 


\title{
The Teaching of the Discipline User Studies and User Formation in a Brazilian University through the Use of Comics: An Experience Report
}

\author{
Fernando Bittencourt dos Santos and Janaina F. Fialho \\ Universidade Federal de Sergipe, São Cristóvão, Brazil, fernandoubatuba @ hotmail.com \\ Marta Leandro da Mata \\ Universidade Federal do Espírito Santo, Vitória, Brazil, martaleandrodamata@ gmail.com
}

User Studies and User Formation in Brazil is a curricular component based on presenting, from a holistic and integrated perspective, the theoretical and practical applications in the formation and performance of the librarian student, a future librarian. The knowledge about the development and application of these studies, as well as the familiarization with the practices of education of users, in the context of the information units and in other spaces of professional performance are of utmost importance. In general, the syllabus of this disciplinefocuses on topics such as:

- the origin and evolution of user studies;

- theoretical aspects of these studies;

- $\quad$ methods and techniques applied;

- $\quad$ information needs; and,

This discipline can be taught by using different strategies for the development of the syllabus.

The aim of this work is to present an experience report regarding the use of comics as an auxiliary pedagogical resource in the teaching of User Studies and User Formation at a Brazilian university in the undergraduate course of Librarianship and Documentation. The study was based on the content analysis methodology proposed by Bardin (2010) and on a selection of ten comics available on the Bibliocomics digital platform (Medeiros, 2010). The selected comics present some elements related to the universe of the discipline and represent, from a comic and reflective perspective, aspects related to information needs, information search and use, user typologies, reading habits, and education of users. There was a positive acceptance of students regarding the use of comics in the classroom. Use of the comics contributed to the deepening of the presented concepts. They facilitated the appropriation of the theoretical and practical content of the subject. Their use enabled librarians to provide greater training in the development and application of user studies in information units, familiarization with user education practices. As a result, the students involved demonstrated the development of new skills for effective interaction in a physical or digital information environment, access, evaluation, and use of the information more accurately and critically in different sources.

\section{References}

Bardin, L. (2010). Análise de conteúdo. Lisboa: Edições 70.

Medeiros, A. (2010). Bibliocomics. Retrieved February 1, 2018 from http://bibliocomics.blogspot.com.es

Keywords: user studies and user formation, comics, teaching, experience report 


\title{
Characterization of the Academic Research on Informational Behavior in the Field of Meteorology: Conceptual and Methodological Approaches
}

\author{
Fernando Bittencourt dos Santos and Fernanda Martins \\ Universidade do Porto, Portugal, fernandoubatuba@hotmail.com, martinsfernanda80@gmail.com
}

\begin{abstract}
Informational behavior is considered to be a consolidated research topic in the area of information science. Its key objective is to describe human behaviour in relation to information sources and channels by highlighting information search, access, use, and transfer processes. Thus, from a historical and contemporary perspective, the area of information science has focused on developing scientific research that can be applied to professional practice, dealing with problems related to effective communication of knowledge, and documents resulting from that in the context of social, institutional, and/or individual needs and uses of information. It should be emphasized that informational behavior presents specificities, according to each area, and that production and dissemination of knowledge is influenced by the perspective of each field. The objective of this paper is to present and discuss the research work carried out on the subject of information behavior in the field of meteorology and to identify the type of approach in (traditional or alternative) informational studies and the methodology used by various authors in their research work. In order to achieve the proposed objectives, a bibliographic survey was carried out in (1) primary sources of information (books, journals, congress proceedings, theses and electronic documents of the Internet, among other similar documents); (2) secondary sources (textual databases and references such as: Lisa, Scielo, Scopus, Capes Periodicals, Brapci, B-on, Web of Science, among others); and, (3) tertiary sources (bibliographies, indexes, collective catalogs, directories and others) in the areas of librarianship and information science. We searched in the sources with the following subject descriptors: information seeking, information behavior, user studies, information seeking behavior, needs and use of information, Meteorology, Atmospheric Sciences, environmental information and weather information. Only six research works were found - two based on a traditional approach and four based on an alternative approach. The work of Belter \& Kaske (2016) and the work of Hallmark (2003) used the traditional approach by focusing on the use of information systems and sources and presented quantitative approaches. Both studies resorted to bibliometric analyses on the use and citation of information sources within the scope of atmospheric sciences. In contrast, the works by Hallmark (2001), Murgatroyd \& Calvert (2013), Lopatovska \& Smiley (2014), and Schamber (1991) resorted to an alternative approach based on users' behavior in relation to information. These studies focused on qualitative analysis by evidencing the processes of search of, access to, use, and transfer of meteorological information and outlined aspects of informational behavior related to meteorology. Thus, one can notice an evident lack of studies that explain the characteristics of informational behavior in the field of meteorology. Furthermore, it is verified that the majority of the investigations presented are of an alternative approach and with a qualitative methodological approach., This is a tendency that is broadly evident in the context of the history of informational behavior studies that began to appear in the 1980s with the growth of more appropriate research methods aimed at achieving a wider range of possible analyses.
\end{abstract}

\section{References}

Belter, C. W., \& Kaske, N. K. (2016). Using bibliometrics to demonstrate the value of library journal collections. College \& Research Libraries, 4(77), 410-422.

Hallmark, J. (2001). Information-seeking behavior of academic meteorologists and the role of information specialists. Science \& Technology Libraries, 21(1/2), 57-59.

Hallmark, J. (2003). Information-seeking behavior of meteorologists and other atmospheric scientists: Access and retrieval of cited references. Issues in Science and Technology Librarianship, 38, 1-11.

Lopatovska, I., \& Smiley, B. (2014). Proposed model of information behaviour in crisis: The case of Hurricane Sandy. Information Research, 19(1), 1-13.

Murgatroyd, P., \& Calvert, P. (2013). Information-seeking and information-sharing behavior in the climate change community of practice in the pacific. Science \& Technology Libraries, 32(4), 379-401.

Schamber, L. (1991). User' criteria for evaluation in multimedia information seeking and use situations (Thesis). Syracurse Universitity, Syracurse, New York, EUA.

Keywords: informational behavior, meteorology, bibliographic research 


\title{
Information Literacy as a Tool for Lifelong Learning: Case Study about Systematic Co-Operation between School and Public Library
}

\author{
Leena Toivonen, Outi Vaskin, Jorma Riikonen and Minna Edgren \\ Education and Wellbeing Centre, City of Valkeakoski, Finland, \{leena.toivonen, outi.vaskin $\} @$ valkeakoski.fi
}

\section{Objectives and Background}

This poster presents results of a systematic co-operation with public library and school in order improve pupils' competence on information literacy (IL). The librarians' involvement in the learning and research process is highlighted (Vassilakaki 2015). The poster emphasizes a co-operation, and describes the elements of best practices: information literacy education (school curriculum); cooperation agreement (co-operation plan) and experimental learning experiences ( 7 th grade pupils). The teacher questionnaire clarifies view of teachers about IL education and is to determine whether the library's teaching and literary education supports the current national core curriculum. The poster also reports about the evaluation done by the pupils (7th grade) after IL course. The questionnaire clarifies whether the IL teaching experience and the information needs of pupils are similar, also whether the pupils can use databases and e-books after IL education.

Public library and school has established systematic cooperation since 2001. Co-operation is well planned: arranging library visits, teaching, or other activities in the library, which school schedules in the school year. There is systematic plan for each grade that includes common goals of IL education. Currently, the key areas of cooperation are the teaching of IL, the presentation of the material (tailor-made book packages) and author visit for $8^{\text {th }}$ grade pupils. The comprehensive school provides education for over 2000 pupils with 150 teachers. Multiliteracy is included in the new national core curricula (Core, 2014). Multiliteracy means the ability to acquire, combine, modify, produce, present and evaluate information in various forms, in different environments and situations, and through various tools. In information and computer technology (ICT) skills, students are taught to use information and communication technology in information management and in researching and creative work. The purpose of integrating is to make it possible to understand the relationships and the interdependencies between issues. It helps students to combine the knowledge and skills of different disciplines and to structure them into meaningful entities interacting with others.

\section{Methodology}

The ideas described are based on the literature review, for example technology attitudes of $\mathrm{Z}$ generation (Rowlands et al., 2008). Elements of the curriculum, such as multiliteracy (Kalanzis, \& Cope 2016) and library IL plan are described and then applied to IL education. The poster reports both the questionnaires of the teachers and pupils about the IL education and possible next steps if changes are needed.

\section{Outcomes of the Contribution}

Findings of scientific literature has been used to explore IL education in libraries. The topic is worthy of attention because systematic co-operation between school and public library is important in order to support the current curriculum and to offer to pupils tools for lifelong learning. The poster describes an evaluation and findings of two questionnaires (teachers and pupils) about the IL education. This work is unique in that it focuses specifically on the systematic co-operation of a public library and school in IL education in the new multiliteracy curriculum with.

\section{References}

Kalanzis, M., \& Cope, B. (2016). Multiliteracies. In M. Peters (Ed.), Encyclopedia of Educational Philosophy and Theory (pp. 18). Singapore: Springer.

Rowlands, I. et al. (2008). The Google generation: The information behaviour of the researcher of the future. Aslib Proceedings, 60(4), 290-310.

Vassilakaki, E., \& Moniarou-Papaconstantinou, V. (2015). A systematic literature review informing library and information professionals 'emerging roles'. New Library World, 116(1/2), 37-66.

Keywords: public library, information literacy, school curriculum, multiliteracy 


\title{
Mapping Mechanical Engineering Students' Information Literacy Needs
}

\author{
Evanthia Tramantza and Sheila Webber \\ University of Sheffield, UK, \{lip12et, s.webber $\} @$ sheffield.ac.uk \\ Panayiotis Ketikidis \\ South East European Research Centre, Thessaloniki, Greece, pketikidis@ seerc.org
}

\section{Objectives}

This poster aims to present the findings of a comparative case study with action research components of the information literacy provision in engineering programmes with special focus on the information literacy (IL) needs of mechanical engineering students at an English university and at a Greek university. Data were collected from the mechanical engineering departments and included students from the three levels of study, academics, and librarians.

\section{Methodology}

The data collection took place during the 2013-14, and 2014-15 academic years. The data involved semi-structured interviews of 19 students and 5 academics as well as of 2 librarians. Additionally, reflections of the researcher librarian offered professional expertise. Discussion forums and student feedback helped include the student voice. Results of the pilot study of this research and of the Greek data analysis have been previously reported in Tramantza, (2015) and (2016). The data were mapped and presented using the Entwistle model for the quality of learning achieved in higher education. Some limitations included: limited participation of students, absence of corporeal information, and limited access to the Greek context due to the fact that the researcher was external to this university

\section{Findings}

Findings include a variation in IL needs between departments in the two countries, also among the different years of the programmes and among stakeholders' perception of IL needs. Emerging findings are mapped on the Entwistle framework, a conceptual model that includes all aspects that influence the quality of learning achieved in higher education. There were findings strictly related to the Greek case in the section: How teaching learning environment is designed and implemented. This section identified the lack of library provision for students, lack of departmental communication with the library, lack of resources for English language, lack of support services, English language barrier, inadequate library support, digital literacy needs, teaching and learning services needs, and lack of liaison librarian services. There are similar findings shared by both cases, for example, in the section relating to what students are expected to learn and understand. These results found that these students used Google and Wikipedia for research and pointed out the students' need for being critical, for having models of expected work, for note taking, and time management. Evidence of peer learning and independent learning were also identified. There is limited research in mechanical engineering information literacy student needs. This mapping of IL needs, and findings presented may improve the IL provision as well as teaching and learning in these and other mechanical engineering departments. Findings may offer a model for a holistic integration of IL in mechanical engineering education in both countries. (Entwistle, Nisbet \& Bromage, 2004)

\footnotetext{
References

Entwistle, N., Nisbet, J., \& Bromage, A. (2004). Teaching-learning environments and student learning in electronic engineering. $\begin{array}{llll}\text { Retrieved } & \text { February } & 23, & \end{array} 218$ from https://www.academia.edu/3426418/Teachinglearning_environments_and_student_learning_in_electronic_engineering

Tramantza, E. (2015). Electronic engineering student information literacy needs: A pilot study at the University off Surrey. In S. Špiranec et al. (Eds.), The Third European Conference on Information Literacy (ECIL): Abstracts, October 19-22, 2015, Tallinn, Estonia (p. 109). Tallinn: University of Tallinn.

Tramantza, E., Webber, S., \& Ketikidis, P. (2016). Mechanical engineering students' information literacy needs: Findings of a case study in an English university over three levels of undergraduate study. In S. Špiranec et al. (Eds.), The Fourth European Conference on Information Literacy (ECIL): Abstracts, October 10-13, 2016, Prague, Czech Republic. Prague: Association of Libraries of Czech Universities.
}

Keywords: information literacy, higher education, UK, students, needs, mechanical engineering, quality in teaching 


\title{
Information Preferences when Facing a Health Threat - The Role of Subjective Versus Objective Health Information Literacy
}

\author{
Oliver Wedderhoff, Anita Chasiotis and Anne-Kathrin Mayer \\ Leibniz Institute for Psychology Information, Trier, Germany, \{ow, ac, akm $\} @$ leibniz-psychology.org
}

\section{Background}

Health information literacy (HIL), defined as the ability to seek, evaluate, and use health information, is assumed to be a highly relevant predictor for adaptive health information behaviour. However, differential associations of subjective measures (self-reports) and objective measures (performance tests) of HIL with health information behavior have not been systematically researched. Research on scholarly information literacy has demonstrated that subjective and objective measures complement each other in predicting information behaviour (Rosman, Mayer, \& Krampen, 2015). Based on these findings, our aim was to find out if there are similar differences in the predictive value of subjective vs. objective measures of HIL with regard to aspects of health information behavior, specifically a preference for quality and/or quantity of information in health-threatening situations.

\section{Hypotheses}

Subjective HIL essentially captures an individual's self-efficacy beliefs related to health information seeking. Therefore, we assumed based on self-efficacy research (e.g., Zimmerman, 2000) that higher subjective HIL will lead to more effortful and extensive health information searching, and, thus will predict the preference for high information quantity. On the other hand, objective HIL captures actual knowledge and skills related to using high-quality information sources. Thus, we expected objective HIL to predict the preference for high information quality.

\section{Methods and Results}

$\mathrm{N}=283$ university students from different fields were instructed to imagine themselves being in a specific healththreatening situation and to report their situation-specific information preferences with regard to quality of information sources (self-developed scale) and information quantity (Thoroughness scale from the IBQ; Heinström, 2002). Objective HIL was measured by a self-developed HIL-performance test, and subjective HIL by an adapted version of the SES-IB-16 (Behm, 2015). As expected, objective HIL significantly predicted preferred information quality, but not quantity. Subjective HIL, on the other hand, predicted preferred information quantity, but not quality.

\section{Conclusions}

When a health threat is present, subjective and objective HIL differentially predict certain aspects of information preferences, such as focusing on information quantity versus. quality. This should be acknowledged in future studies on HIL and information behavior which might focus on supporting individuals to seek and use an adequate amount and quality of information in the face of health threats.

\section{References}

Behm, T. (2015). Informationskompetenz und Selbstregulation: Zur Relevanz bereichsspezifischer Selbstwirksamkeitsüberzeugungen. In A.-K. Mayer (Ed.), Informationskompetenz im Hochschulkontext: Interdisziplinäre Forschungsperspektiven (pp. 151-162). Lengerich: Pabst Science Publishers.

Heinström, J. (2002). Fast surfers, broad scanners and deep divers: Personality and information-seeking behavior. Abo: Abo Akademi University Press.

Rosman, T., Mayer, A.-K., \& Krampen, G. (2015). Combining self-assessments and achievement tests in information literacy assessment: Empirical results and recommendations for practice. Assessment and Evaluation in Higher Education, 40(5), 740754.

Zimmerman, B. J. (2000). Self-efficacy: An essential motive to learn. Contemporary Educational Psychology, 25, 82-91.

Keywords: health information literacy, information seeking, assessment 


\title{
A Domain-Specific e-Learning Course to Support Teaching of Information Literacy for Psychology Students at the University of Vienna
}

\author{
Michaela Zemanek \\ University Vienna, Austria, michaela.zemanek@univie.ac.at
}

The teaching of information literacy was integrated into the curriculum for undergraduate psychology majors at the University of Vienna in 2010 (Zemanek, 2013). The teaching activities regarding information literacy include lectures by the author, accompanied by homework assignments and exercises. Following the suggestion of the faculty of psychology, the author developed an e-learning course on domain specific information literacy in Moodle, the elearning system of the University of Vienna, to offer an additional opportunity to learn about information literacy, in particular for undergraduates. It's aim is to provide sustainable learning material that psychology students at Vienna University can use at any time and place through the internet. As a result, there exist learning opportunities for information literacy in various formats and mediatypes for psychology students.

The computer center of the University of Vienna provided the psychology library with a course space in the university's learning management system, which was used by the author to create an information literacy learning experience. The Moodle space now contains the actual learning material, a forum for students to ask questions, a collection of FAQs regarding information literacy, a virtual tour of the faculty library, and a space where the students can find course presentations and sign up for these face-to-face training courses on information literacy. Also, students have the opportunity to give feedback on the Moodle course and the learning material.

The e-learning course aims to foster information literacy in a disciplinary context; the learning outcome for the psychology students should be to "demonstrate psychology information literacy" (American Psychological Association, 2012, p. 21).

The author used Moodle's book module to create the learning material in a book-like format. The text consists of userfriendly small learning units and is enriched with illustrations, a set of cartoons as an introduction, and slide presentations. After each chapter there is a quiz. The author chose interactive question types instead of multiple-choice questions as quiz questions. These tasks allow students to test their knowledge in a more realistic setting and are more fun.

The e-learning course was created in 2017. After a test phase and some adaptations to incorporate the feedbacks the Moodle course was activated in winter term 2017; all first semester psychology students were enrolled. Starting with the summer term 2018, the course is available to all psychology students at the University of Vienna. Participation in this course is voluntary; no credit points will be awarded. To link with other courses and to raise usage of the course, further meetings with the directorate of the study programme will be necessary. The course will be further enhanced by adding of multimedia material, which is still in the planning stage at this point in time.

The poster will present the course and the learning material, report experiences and first results from the feedback as well as activity reports for the course and give an outlook on future developments.

\section{References}

American Psychological Association. (2013). APA guidelines for the undergraduate psychology major: Version 2.0. Retrieved May 6, 2018 from http://www.apa.org/ed/precollege/undergrad/index.aspx

Zemanek, M. (2013). Integrating information literacy into a bachelor's curriculum. In S. Kurbanoğlu et al. (Eds.), European Conference on Information Literacy (ECIL): Abstracts, October 22-25, 2013, Istanbul, Turkey (p. 240). Ankara: Hacettepe University, Department of Information Management.

Keywords: information literacy, psychology students, e-learning, Moodle 


\title{
Opportunities and Challenges for Information Literacy Education under the Core Competencies and Values for Chinese Students' Development
}

\author{
Jing Zhang,Naiyi Yang and Yang Zhang \\ Sun Yat-sen University, China, zhangj87@mail.sysu.edu.cn,975431623@qq.com, zhyang2@mail.sysu.edu.cn
}

In the 21st century, the key competency model based on personal development and lifelong learning has gradually replaced the traditional curriculum, a standard system based on subject knowledge structure, driven by technological change, economic and social development, and education reform (Liu \& Wei, 2016). Under globalization, the ranges of key competencies in different countries show certain commonalities and more emphasis on innovation ability, critical thinking, and information literacy (Ananiadou \& Claro, 2015). However, due to the differences in national conditions, there are also differences in terms of definition and cultivation of key competencies. Take China as an example. In September 2016, "the Core Competencies and Values for Chinese Students' Development" was officially released, which aims to cultivate well-rounded persons. This framework document fully reflects the new requirements of China's economic and social development on talent training in the new era, and attaches great importance to the inheritance of excellent Chinese traditional culture. With the basic education entering a new stage, information literacy education in China has also started a new chapter. Information literacy education in the new era should be carried out in an orderly manner under the framework of "Core Competencies and Values for Chinese Students' Development." The key competencies can be divided into three parts: cultural basis, independent development, and social participation. To make core competencies detailed, they encompass 18 basic elements such as information awareness (Lin, 2016). The various competencies are interrelated, and mutually reinforcing, and they complement each other. Due to the release of this framework document, information literacy education in China is facing new development opportunities. Information literacy is an important component of key competencies. The development of cultivating students' information literacy contributes to the development of other competencies. Information literacy education aims to improve the students' survival skills for the digital age so that they can take the initiative to adapt to the development trend of social informatization. The innovation in content and form helps to adopt practical key competencies and promote basic educational reform. At the same time, information literacy education in China also faces four major challenges. Firstly, in terms of the innovation in content, the essential question is how people could integrate the competencies of various disciplines so as to set specific teaching objectives and establish content standards of information literacy education. Secondly, in terms of innovation in education practice, information literacy education should be placed in a social context. The integration of information literacy education on- and offcampus is a major difficulty. Thirdly, in terms of innovation in educational mechanism, it is' difficult to design a scientific and reasonable modern curriculum system. Fourthly, in terms of innovation in the educational system, it is imperative for relevant institutions to establish a supportive system of information literacy education. Moreover, public cultural service oriented toward juveniles should always be the mainstay of such supportive systems. In the process of adopting practical information literacy education, coordination and cooperation from governments, relevant research institutions, and public cultural institutions are needed for their support and services.

\section{References}

Ananiadou, K., \& Claro, M. (2009). 21 st century skills and competences for new millennium learners in OECD countries. Retrieved February $9, \quad 9017$ from http://www.oecd.org/officialdocuments/publicdisplaydocumentpdf/?cote=edu/wkp(2009)20\&doclanguage=en

Lin, C. (2016). The core competencies and values for Chinese students' development. Retrieved February 7, 2017 from http://www.sohu.com/a/114315061_372513

Liu, J., \& Wei, R. (2016). Oriented-future: The global experience of 21 st century skills and competences education. Journal of East China Normal University Educational Sciences, 32, 17-21.

Keywords: information literacy education, key competency, education reform, children and young people 


\section{WORKSHOPS}




\title{
Evaluating and Constructing Tools for the Assessment of Information Literacy
}

\author{
Anita Chasiotis, Oliver Wedderhoff and Anne-Kathrin Mayer \\ ZPID - Leibniz Institute for Psychology Information, Germany, \{ac, ow, akm $\}$ @ leibniz-psychology.org
}

\begin{abstract}
Adequate assessment of information literacy (IL) is crucial to the evaluation of information literacy instruction in research and practice as well as to information literacy research. But what is an 'adequate' assessment tool? Which criteria may be applied to evaluate the quality of a tool and to decide which of several available tools should be used in a specific context? And how may knowledge about principles of test construction be used to develop new measures of information literacy?
\end{abstract}

\section{Objectives}

The major objectives of the workshop are: a) to make participants familiar with essentials of formal test construction and evaluation criteria for assessment tools, thereby b) strengthening participants' understanding of standardized information literacy assessment, and c) fostering their capacities to evaluate existing tools and to develop new ones. Participants will learn about formal criteria of quality for assessment tools (objectivity, reliability, validity, fairness, efficiency) and step-by-step procedures of test construction. They will reflect on the relevance of these criteria and construction steps for: a) the evaluation of existing information literacy measures (e.g., published in scientific papers), and b) practical applications in their individual work context. Finally, they will discuss possibilities of collaborations with researchers from psychology, social sciences, and other disciplines who are familiar with the statistical procedures involved in test construction.

\section{Topics to be Covered}

- Participants' experiences with assessing information literacy in their work context.

- Formal standards and criteria for evaluating the quality of assessment tools and test items (objectivity, reliability, validity, test norms etc.).

- Pros and Cons of different types of assessment tools (e.g., standardized tests, search tasks, portfolios) and test items (e.g., multiple choice, open-ended questions), particularly with reference to the quality criteria discussed.

- $\quad$ "Build your own tool": Construction strategies and steps of designing assessment tools (precise definition of the concept to be measured; designing, probing, and redesigning draft versions of a tool; analyzing the quality of tools by means of empirical testing).

- $\quad$ "Putting assessment into practice": Possibilities and limitations.

\section{Target Audiences}

Librarians or IL researchers who have little or no prior knowledge about formal quality criteria for assessment tools but want to use such tools or contribute to construing them. Statistical knowledge is not required.

\section{Equipment}

Projector; flipchart or blackboard/whiteboard.

Length

120 minutes.

Keywords: information literacy, assessment, test construction, reliability, validity 


\title{
Using Social Media to Teach Students How to Create a Research Query and Find Effective Keywords
}

\author{
Kiersten Cox and Vicki Gregory \\ University of South Florida, USA, cox@usf.edu
}

For at least a decade education pundits have touted the wonders of using social media for educational purposes. But so often the suggested uses seem like busy work or sidebars to instructions. In this workshop participants will learn how to integrate social media into information literacy instruction in a meaningful way.

The instructors for this workshop use this lesson to teach graduate and undergraduate students in a School of Information but these methods can be adapted to many instructional settings and age groups. Participants will need a laptop or tablet and a wifi connection to fully participate in this workshop. It will also be helpful if participants have a Google+ account. Participants will learn a method of teaching students how to formulate a research query by creating a word cloud using an online reference sources such as Wikipedia or a general source related to the subject. They will be taught how to identify keywords and how to turn those keywords into a research query. The use of thesauri will be explored. Then this work will be posted to a blog so that all participants can view and comment on the work. A wiki can also be used to share information. Participants will be taught how to use keywords to tag their blogs. Other social media such as Twitter links can be added to the blog to enhance communication. We will discuss how these activities are scaled for undergraduate and graduate students.

So how does using these tools help educate your students? The hardest part of research as reported by many students is finding an appropriate research topic or query. It has been our experience that teaching students this method of designing a research query and selecting keywords alleviates some of the anxiety students feel and improves their end results. The addition of subject headings increases students understanding of the topic and their ability to locate useful information. Also, being able to share their work with others in the course as well as the instructor allows everyone to benefit from the learning experiences of others and especially in an online class can help foster connections between classmates and with the instructor. As an added bonus student often have a great graphic in the form of a word cloud they can use to enhance their final product.

Keywords: information literacy, instruction, keywords, research query, research question, undergraduates, 


\title{
Assessment and the ACRL Framework
}

\author{
Samantha Godbey \\ University of Nevada, Las Vegas, NV, USA, samantha.godbey@unlv.edu
}

The Association of College and Research Libraries' Framework for Information Literacy for Higher Education (ACRL Framework) consists of six "interconnected core concepts" that emphasize new roles and responsibilities for learners, teaching faculty, and librarians. The introduction to this framework acknowledges that this is "a richer, more complex set of core ideas" than had been in use previously, namely the widely used and widely translated Information Literacy Competency Standards for Higher Education (2000). While the richness of these ideas can be a source of inspiration for new approaches to information literacy instruction, at the same time the complexity of this document and its core ideas has proven to be challenging for many academic librarians. As a result, many librarians struggle with developing practical applications for this theoretical framework. In this workshop, participants will examine and discuss the ACRL Framework with an emphasis on assessing student progress toward its core concepts. Through a combination of lecture, structured reflection, discussion, and hands-on activities, participants will acquire a fundamental understanding of the six frames and identify strategies for assessing student learning with regards to these frames. Participants will learn about different types of assessment and discuss specific examples of assessment data in the context of the ACRL Framework. Strategies for streamlining data collection and analysis will also be discussed, as well as what to do with assessment data once it has been gathered. As a result of this workshop, participants will be better prepared to gather information that can help improve instruction and increase student engagement and learning with regards to aspects of the ACRL Framework. Emphasis will be placed on articulating potential assessments for the six frames in the ACRL Framework. The target audience includes any academic librarian involved in instruction; strategies discussed in this workshop can be integrated into one-shot library instruction sessions or longer, for-credit courses. Additionally, the fundamentals discussed pertaining to planning and implementing assessment can be applied to programmatic assessment. Participants are encouraged to read the six frames in the ACRL Framework document prior to the workshop, if possible. By the end of the workshop, participants will have articulated an action plan for at least one frame, including strategic assessment methods and priorities for the analysis and communication of results.

\section{References}

Association of College and Research Libraries. (2000). Information literacy competency standards for higher education. Retrieved February 15, 2018 from https://alair.ala.org/handle/11213/7668

Association of College and Research Libraries. (2015). Framework for information literacy for higher education. Retrieved February 15, 2018 from http://www.ala.org/acrl/standards/ilframework

Keywords: ACRL Framework, information literacy, instruction, threshold concepts, assessment 


\title{
Problem Setting Information Literacy: Reconsidering Techniques for Instructional Design
}

\author{
Merinda Kaye Hensley \\ University of Illinois, Urbana, IL, USA, mhensle1@illinois.edu
}

\section{Background and Objectives}

The teaching librarian's overarching goal is to create experiences for students that contribute to their learning process and leading to (hopefully) positive change over time. How do we decide what to teach? Sometimes our decisions are based on the curriculum or what a faculty member specifically requests from us; and sometimes our decisions are based on what we have taught in the past. However, our judgment is primarily based on our understanding of the definition of information literacy (IL) and our goals for moving students along the novice-expert continuum. Librarians often bring tacit knowledge of the underpinnings of IL to our teaching that are difficult to translate to the classroom experience that can create 'bottlenecks' or areas of confusion for student learning. We also make inadvertent assumptions regarding students' IL understandings when they enter our classroom.

Instructional design generally focuses on the lesson development process after decisions have been made regarding the content of our teaching. However, before writing learning outcomes and constructing active learning exercises, there is intellectual pre-work to be done, herein lies a paradigm shift defined as problem setting. Schön (1979) outlines problem setting as the precursor to problem solving and solving the problems of what we decide to teach can hinge on how they are set.

Attendees will engage the problem setting process for information literacy based on two primary questions:

- What is the effect of students' prior knowledge on new learning? (Abrose, et al, 2010).

- How do we determine the bottlenecks students face in mastering IL concepts? (Middendorf and Pace, 2004).

\section{Outcomes}

In the first part of the workshop, we will use evidence-based research and our own experiences to paint a picture of the qualities of student knowledge that can hinder or help their learning. We will contrast these collective observations with a re-examination of our assumptions on student learning. In the second half of the workshop, we will discuss how to shift our focus from teaching specific tools/content to defining the intellectual measures students should master in order to break through the bottlenecks of learning complex ideas in IL.

Attendees will:

- consider and apply a wider perspective of the instructional design process to include problem setting,

- $\quad$ explore a variety of techniques for assessing students' prior knowledge and areas of stuck-ness in order to design effective IL instruction that will activate, build on, and address gaps in knowledge.

\section{Resources Needed}

A projector to display slides, and flip charts and markers.

\section{References}

Ambrose, S. A. et al. (2010). How learning works: Seven research-based principles for smart teaching. San Francisco, CA: JosseyBass.

Middendorf, J., \& Pace, D. (2004). Decoding the disciplines: A model for helping students learn disciplinary ways of thinking. New Directions for Teaching and Learning, 2004(98), 1-12.

Schon, D. A. (1979). Generative metaphor: A perspective on problem-solving in social policy. In A. Ortony (Ed.), Metaphor and Thought (pp. 137-163). Cambridge: Cambridge University Press.

Keywords: instructional design, learning theory, problem setting 


\title{
The Power of Primary Sources: Integrating Archives into the Critical Information Literacy Classroom
}

\author{
Julie M. Porterfield and Rebecca K. Miller \\ Penn State University Libraries, PA, USA, \{jmp48, rkm17\}@psu.edu
}

Critical information literacy offers an opportunity for information literacy practitioners to empower learners to consume and create information in meaningful and civically engaged ways. Information literacy practitioners from institutions with archival, rare books, and manuscript collections can utilize these collections to teach critical information literacy with compelling and engaging strategies. This workshop explains the alignment between primary sources and critical information literacy, and demonstrates how to use primary sources, such as photos, diaries, political propaganda, and correspondence, effectively in a lesson by engaging participants in a mock critical information literacy session developed around primary sources. Presenters will guide participants through integrating primary sources, including civil rights pamphlets, American suffragist literature, and peace movement publications, into their own critical information literacy lesson plans. Ultimately, the presenters endeavor to help participants renew and extend a personal or institutional commitment to diversity and social justice through practicing critical information literacy instruction and leveraging primary sources.

Specifically, this workshop centers around the learning outcomes identified below; in other words, after this workshop, participants will be able to:

recognize the pedagogical potential of primary resources in archives and special collections in order to integrate new elements of social justice, diversity, and inclusion into critical information literacy classrooms.

identify critical information literacy concepts relevant to teaching with archives and special collections in order to effectively use primary resources as teaching tools.

design their own critical information literacy lesson plan in order to be able to transfer their new knowledge to their home institution and individual professional practice.

The target audience for this workshop includes information literacy practitioners looking for new and impactful ways to implement elements of critical librarianship into their practice and into their teaching and learning programs, as well as practitioners already interested in integrating critical pedagogy and primary sources, including those elements housed at their own institution and openly available online. This workshop will require an overhead projector, a computer for a PowerPoint slideshow, and an internet connection. We understand that workshop lengths will be negotiated with conference organizers, and we believe that 90 minutes is an appropriate length for ensuring that the workshop actively engages learners and meets our defined learning outcomes.

Keywords: critical pedagogy, critical information literacy, primary source literacy, archival literacy, special collections, archives, transformative learning 


\title{
Brainstorming on Data Literacy: Bringing out the Best Practices by Mind Mapping
}

\author{
Marco Schirone \\ Chalmers University of Technology, Göteborg, Sweden / University of Borås, Borås, Sweden, \\ schirone@chalmers.se \\ Kaisa Hartikainen \\ University of Eastern Finland, Kuopio, Finland, kaisa.hartikainen@uef.fi
}

Research data related issues are incoming trends, and globally there is increasing interest in data management and sharing. Research data literacy involves all dimensions of information literacy that are required for the creation, management, and reuse of research data. Generally, there is an urge to develop and deploy new initiatives, collaboration, services and resources to meet the scholarly needs at various stages of the research process (Koltay 2017).

As an introduction to the workshop, the actions and practices on data literacy and management addressed at the Chalmers University of Technology (Sweden) and at the University of Eastern Finland (UEF) will be presented.

An online survey was sent to all researchers at Chalmers in November 2017 and responses were collected during November and December $2017(\mathrm{~N} \approx 3170)$. The topics covered were data management issues, the extent of researchers' data literacy skills and their attitudes towards sharing research data. A significant finding from the survey-which became a source of inspiration for this workshop-was the respondents' positive stance towards receiving research data training. Findings from the Swedish survey will be both presented and compared with previous studies in other countries (see Chowdhury, Boustany, Kurbanoğlu, Ünal, and Walton, 2017).

UEF Library has actively focused on research data management services during the past two years. The research support team of the library offers training for graduate students, for example, as a part of the Research Information Retrieval and Management course. The study material of the module-built course is openly available for everyone and the research data module is executed online by the flipped classroom method. In addition, UEF metadata repository for research data is under development.

The main goal of this workshop is to share ideas and experiences about data literacy and management conducted in different countries and organisations. This means defining the concept, discussions, revealing the organisational policies and strategies, as well as considering the possibilities, challenges, and potential risks related to it. The interactive teamwork will be conducted using a collaborative mind map tool (e.g. Canva, Padlet). The outputs will be rounded up and shared, and the best practices are hoped to be widely spread. This workshop will be aimed at everyone interested in working with research data.

\section{References}

Chowdhury, G. et al. (2017). Preparedness for research data sharing: A study of university researchers in three European countries. In S. Choemprayong, F. Crestani, \& S. Cunningham (Eds.), Digital Libraries: Data, Information, and Knowledge for Digital Lives, ICADL 2017 (pp. 104-116). Springer: Cham.

Koltay, T. (2017). Data literacy for researchers and data librarians. Journal of Librarianship and Information Science, 49(1), 3-14.

Keywords: research data, data literacy, data management 


\title{
What's My Approach? Deciding on the Approach to Use for Your Research
}

\author{
Sheila Webber \\ University of Sheffield, UK, s.webber@sheffield.ac.uk \\ Bill Johnston \\ University of Strathclyde, Glasgow, Scotland, b.johnston@strath.ac.uk \\ Pamela McKinney \\ University of Sheffield, UK, p.mckinney@ sheffield.ac.uk
}

The research approach used to undertake research has an impact on what type of research questions are posed, what kind of results are obtained, and what you can do with your results to affect policy and practice. This is more than deciding "interview or questionnaire?": it is looking at the whole research exercise from start to finish and deciding how to shape it.

The objectives of the workshop will be:

1. To identify key characteristics of selected qualitative and mixed-methods research approaches, and to show what kinds of research questions and problems each approach is most suited to. The research approaches covered will be: action research; case study; phenomenography; ethnography; and autoethnography.

2. To enable participants to understand the issues, advantages and disadvantages of different approaches, by looking at a practice-based information literacy problem and asking participants to identify the implications of choosing one approach or another.

By the end of the workshop participants should have an extended understanding of the research approaches available, what they should consider when deciding which approach to use, and the implications of their choices.

There will be three portions:

The key characteristics of each approach will be outlined concisely in an introductory presentation (around 40 minutes). The slides and supporting material (for example, links to examples) will be available online for delegates' access.

1. Following on from this, an information literacy problem that would benefit from research investigation will be presented as a scenario, with sufficient detail that participants can engage with it meaningfully in the limited timespan of a workshop. (around 40 minutes)

2. Participants will form groups, each group taking on one of the research approaches. Each group will draft specific research questions or aims and research design that would be best suited to that particular research approach (for example, ways in which the data would be collected, analysed, and presented). They will think about what the results might look like and how they could be used, for example, to change practice. The group will also identify strengths and weaknesses of using that approach. Finally, they will pull together a case for using that approach.

3. The feedback (around 30 minutes) section will consist of each group identifying concisely the research question/aims and likely outcomes and arguing for their approach being the best to choose. This will lead to discussion of the advantages and disadvantages of each approach and highlighting differences in questions, process and outcomes.

The target audience is anyone interested in carrying out information literacy research. The main audience will be those who are not experienced researchers. More experienced researchers may enjoy thinking about a research problem from a new perspective during the activity and can also contribute valuable insights from their own research. Equipment should include flip chart paper and at least one flip chart stand or at least one personal computer per group with sufficient space to work round it and produce a presentation. The workshop leaders are experienced researchers who also have experience of teaching research methods.

Keywords: research methods, ethnography, case study, action research, phenomenography 
AUTHOR INDEX 

Åhlfeldt, Rose-Mharie, 44

Ahmad, Farhan, 8

Akimitsu, Toshio, 71

Alamettälä, Tuulikki, 9

Albrecht, Olga, 99

AlHuraiti, Reham, 164

Aliagas, Cristina, 73

Andreassen, Helene N., 112

Apolinário Teixeira, José, 96

Azizi, Asmaa, 65

Baldwin, Catherine, 113

Banek Zorica, Mihaela, 10

Barker, Jamie, 102

Bastos, Glória, 75

Bath, Peter, 2

Bernuci, Nadia, 11

Biletsky, Volodymyr, 165

Bittencourt dos Santos, Fernando, 176, 177

Boh Podgornik, Bojana, 24

Bolka-Tabary, Laure, 152

Bonilla, José Luis, 57

Boustany, Joumana, 12

Brenko-Puzak, Mojca, 166

Brenner, Mats, 27

Buchanan, Steven, 13, 67

Budd, John M., 14

Bugaje, Maryam, 15

Buschmann, Paul, 147

Buysse, Heidi, 21, 22

Caballero-Mariscal, David, 83

Callejón Mateu, Anna, 114

Capdevila Tomàs, Yolanda, 174

Casanovas Català, Montserrat, 174

Chang, Yun-Ke, 95

Chaparro, Sergio, 16

Charles, Leslin H., 115

Chasiotis, Anita, 180, 184

Cheradi, Natalia, 56

Chowdhury, Gobinda, 15

Clarot, Kaisu, 153

Cobolet, Noémi, 154

Collina, Elena, 116

Cooke, Louise, 162

Costa Seabra, Célia Revilândia, 117

Cox, Andrew, 66

Cox, Kiersten, 185

Crawford, John, 17

Crnković, Lahorka, 166
Cruz-Palacios, Eduardo, 18

Cupar, Drahomira, 19

da Luz Antunes, Maria, 62

Davidsone, Agnese, 20

De Maeseneer, Jan, 21

De Maeyer, Sven, 21

De Meulemeester, Ann, 21, 22

Devlin, Brendan, 23

Diviak, Tomáš, 60

Dolničar, Danica, 24

Dreisiebner, Stefan, 25

Drobikova, Barbora, 46, 60

Dumaual-Sibal, Hannah Trinity, 95

Düren, Petra, 26

Earp, Vanessa J., 118

Edgren, Minna, 178

Encheva, Marina, 27

Enwald, Heidi, 44

Faletar Tanacković, Sanjica, 29

Faure, Gilbert C., 155

Fehrmann, Paul, 77

Feldvari, Kristina, 29

Fernández-Pascual, Rosaura, 83

Fialho, Janaina F., 176

Fisher, Karen, 3

Foo, Schubert, 95

Francke, Helena, 30

Franke, Fabian, 119

Fulton, Crystal, 31, 63

Gallardo-Romagnoli, Maryna, 108

Gárate, Alberto, 57

Gardner Archambault, Susan, 120

Gastinger, Almuth, 32, 33

Gersch, Beate, 64

Ghinkulov, Silvia, 56

Gilles, Sahut, 34

Godbey, Samantha, 35, 156, 186

Goldstein, Stéphane, 26

Goodman, Xan, 35

Govindan, Sumita, 121

Gregory, Vicki, 185

Grigas, Vincas, 36, 85

Grkinić, Andrea, 37

Guerrero-Quesada, David, 83

Gundtoft, Martin, 175

Hartikainen, Kaisa, 168, 189

Heinbach, Chelsea, 157

Heinikoski, Ursula, 153

Heinström, Jannica, 38 
Helminen, Päivi, 158

Hicks, Alison, 40

Hirose, Yoko, 71

Hirvonen, Noora, 41, 43, 44, 51, 76

Hoff, Martha J., 159

Hollister, Christopher, 160

Holopainen, Riitta, 122

Holoubková, Hana, 167

Hossain, Arman, 9

Howard, Katherine, 42, 55

Huang, Viola, 123

Huhta, Anna-Maija, 41, 43, 51, 76

Huotari, Maija-Leena, 41, 43, 51, 76

Huvila, Isto, 44

Hyvärinen, Katja, 168

Ida, Hiroyuki, 109

Ireton, Daniel, 124

Itsumura, Hiroshi, 110

Jacques, Jerry, 45

Janicke Hinchliffe, Lisa, 140

Jarocki, Zoe, 125

Jarolimkova, Adela, 46

Jarolímková, Adéla, 60

Jasiewicz, Justyna, 47

Jetten, Mijke, 112

Johnston, Bill, 48, 190

Jokić, Maja, 37

Jupowicz-Ginalska, Anna, 47

Juric, Mate, 19

Kämäräinen, Juha, 49

Karhapää, Anne, 168

Karjalainen, Riitta-Liisa, 169

Karsten, Helena, 96

Kaye Hensley, Merinda, 187

Kelley, Brittany, 50

Kelt, Marion, 126

Keränen, Teija, 51

Ketikidis, Panayiotis, 179

Kettunen, Taina, 145

Khim Lim, Siew, 121

Kisilowska, Małgorzata, 47

Kiuru, Eerika, 169

Koltay, Tibor, 36

Korkeamäki, Riitta-Liisa, 79

Kovacs, Susan, 52

Kovářová, Pavla, 53, 54

Krasteva, Rositza, 97

Krüger, Nicole, 127

Kumpulainen, Kristiina, 6

Kunnela, Arja, 169
Lacey, P. Thomas, 55

Lach, Karin, 128

Låg, Torstein, 112

Laineenoja, Elina, 169

Landova, Hana, 60

Landøy, Ane, 26, 32, 33, 56

Laporte, Steven, 149

Lau, Jesus, 57, 108

Lauri, Liia, 58

Leandro da Mata, Marta, 176

Lenstra, Noah, 30

Lepik, Krista, 59

Li, Ling, 171

Lipkova, Helena, 60

Liu, Qianxiu, 110

Lockerbie, Hayley, 61

Lopes, Carlos, 62

Lowe, M. Sara, 129, 144

MacGregor, Teresa, 130

Majid, Shaheen, 95

Mäkynen, Mari, 169

Martinmäki, Pertti, 153

Martinová, Olga, 131

Martins, Fernanda, 177

Martzoukou, Konstantina, 61, 63

Marzal García-Quismondo, Miguel Ángel, 18

Mathiesen, Marit, 98

Matošić, Mirta, 172

Matteson, Miriam, 64

Mattson, Mark, 172

Matusiak, Krystyna K., 157

Maury, Yolande, 65

Mayer, Anne-Kathrin, 180, 184

Mäyrä, Frans, 4

McKinney, Pamela, 66, 103, 190

McMenemy, David, 67

Medina Jr, Virgilio G., 68

Micheau, Béatrice, 69

Michelot, Florent, 70, 173

Mierzecka, Anna, 36

Miettinen, Mervi, 92

Mikkonen, Teemu, 38

Miller, Rebecca K., 188

Ming, Wu, 132

Mink, Fenneke, 133

Miwa, Makiko, 71

Mohamed, Shehaamah, 72

Mönkkönen, Ilkka, 49

Mothe, Josiane, 34 
Msomphora, Mbachi Ruth, 134

Murumaa-Mengel, Maria, 59

Mutlu, Tugba, 73

Nagasawa, Tayo, 74

Narayan, Bhuva, 82

Nechita, Olivia-Dumitrina, 174

Neerut, Lilian, 141

Newell, Zachary, 16

Nicholson, James, 42

Nicol, Emma, 13

Nishina, Emi, 71

Novo, Ana, 75

Nowicki Estell, Allison, 28

Nygård, Tuula, 41, 76

Nzomo, Peggy, 77

Ochôa, Paula, 78

Ojaranta, Anu, 79

Olinto, Gilda, 11

Ondrišová, Miriam, 93

Ong, Vincent, 121

Onkovych, Anna, 165

Öström, Magdalena, 135

Paimre, Marianne, 80

Palmgren-Neuvonen, Laura, 41, 76

Pálsdóttir, Ágústa, 81

Patregnani, Rita, 116

Paulova, Kristyna, 136

Peleman, Renaat, 21, 22

Petr Balog, Kornelija, 29

Pingo, Zablon, 82

Pinto, Leonor Gaspar, 78

Pinto, María, 83

Pittaway, Sarah, 137

Poellhuber, Bruno, 70

Pointon, Matt, 102

Porterfield, Julie M., 188

Potkonjak, Sanja, 10

Præsius, Daniel, 175

Prykäri, Essi, 138

Ratnadeep Suri, Venkata, 95

Repanovici, Angela, 26, 56

Riikonen, Jorma, 178

Rimanova, Jana, 136

Roy, Loriene, 84

Rudžionienė, Jurgita, 85, 139

Saarti, Jarmo, 26, 49

Salaz, A. M., 130

Sales, Dora, 83

Salman, Anmar, 86

Sanches, Tatiana, 62, 87
Sanchez Vanderkast, Egbert John, 88

Saunders, Laura, 140

Savolainen, Sanna, 169

Sbaffi, Laura, 66

Schachter, Debbie, 89

Schirone, Marco, 189

Schoutsen, Monique, 112

Schroeder, Robert, 160

Schuster, Kristen, 50, 90

Seiler, Vilve, 141

Sharma, Priyanka, 142

Silkane, Vineta, 20

Simeonova, Boyka, 162

Singh, Rajesh, 91

Sinisalo, Riikka, 138

Sipilä, Miikka, 92

Skare, Roswitha, 30

Sormunen, Eero, 9, 38

Sosic Klindzic, Rajna, 10

Steinerová, Jela, 93

Stewart, Kristine N., 90, 94

Stieglitz, Tara, 143

Stone, Sean, 129, 144

Sugahara, Sonoe, 11

Sunaga, Kazuyuki, 161

Suorsa, Anna, 14

Syvälahti, Katin, 145

Špiranec, Sonja, 37

Takahashi, Hideaki, 71

Tammaro, Anna Maria, 27

Tassanyi, Pavlína, 131

Taylor, Allie, 146

Tevaniemi, Johanna, 92

Thiault, Florence, 152

Tikkinen, Siinamari, 79

Todd, Ross J., 68

Todorova, Tania, 97

Toivonen, Leena, 178

Tomori, Tímea, 36

Torres Gastelú, Carlos Arturo, 108

Tramantza, Evanthia, 179

Tsvetkova, Elisaveta, 97

Turner, Martin, 102

Urton, Ellen, 124

van der Meer, Harrie, 112

Van der Meulen, Anne-Lise, 147

van Helvoort, Jos, 39, 133

Vanden Berghe, Patrick, 148

Vårheim, Andreas, 30

Vaskin, Outi, 178 
Verryckt, Lieselot, 149

Virkus, Sirje, 58, 86, 98, 99, 100

Vrana, Radovan, 101

Wagg, Sharon, 162

Walton, Geoff, 102

Webber, Sheila, 48, 103, 179, 190

Wedderhoff, Oliver, 180, 184

Whitson, Lindsey, 143

Whitworth, Andrew, 104

Widén, Gunilla, 96

Wilkinson, Andy, 102
Wiorogórska, Zuzanna, 105

Yaginuma, Yoshitomo, 71

Yang, Naiyi, 182

Yanyshyn, Olha, 165

Zemanek, Michaela, 181

Zhang, Dongrong, 171

Zhang, Jing, 182

Zhang, Yan, 84

Zhang, Yang, 182

Zlatkova, Plamena, 27 
ISBN 978-952-62-2013-0
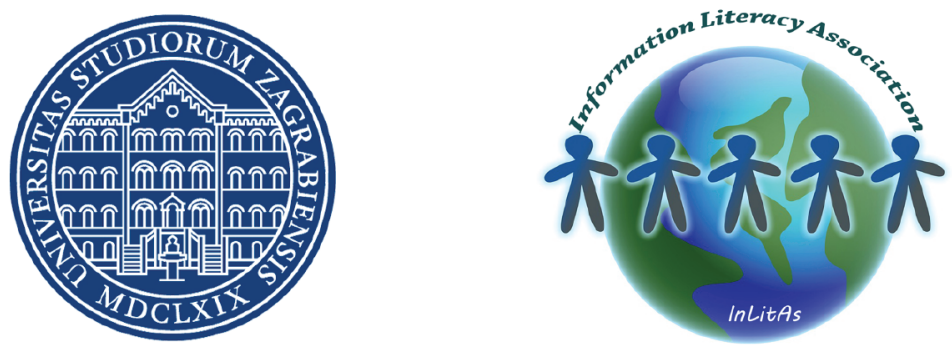